\title{
Comments Received on Proposed \\ Rule on Radiological Criteria \\ for Decommissioning and \\ Related Documents
}

Manuscript Completed: January 1996

Date Published: March 1996

Prepared by

G. Page, J. Caplin, D. Smith, M. Boyd, C. Wiblin

Advanced Systems Technology, Inc.

847-F Quince Orchard Boulevard

Gaithersburg, MD 20878

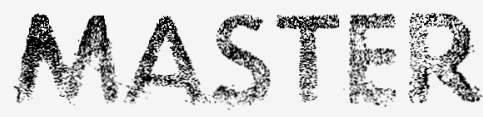

S. Jones, NRC Project Manager

Prepared for

Division of Regulatory Applications

Office of Nuclear Regulatory Research

U.S. Nuclear Regulatory Commission

Washington, DC 20555-0001

NRC Job Code J6039

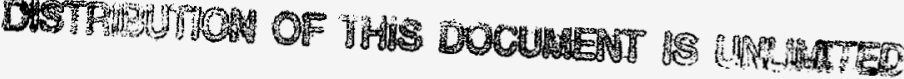





\section{DISCLAMMER}

Portions of this document may be illegible in electronic image products. Images are produced from the best available original document. 


\begin{abstract}
The Nuclear Regulatory Commission (NRC) is conducting an enhanced participatory rulemaking to establish radiological criteria for the decommissioning of NRC-licensed facilities. As a part of this action, the Commission published in the Federal Register (59 FR 43200), on August 22, 1994, a proposed rule on radiological criteria for decommissioning, soliciting comments both on the rule as proposed and on certain specific items as identified in its supplementary statement of considerations. A draft Generic Envirunmental Impact Statement (GEIS) in support of the rule, also published in August 1994 as NUREG-1496, along with its Appendix A (NUREG-1501), were also made available for comment. A staff working draft on regulatory guidance (NUREG-1500) was also made available.
\end{abstract}

This report summarizes the 1,309 comments on the proposed rule and supplementary items and the 311 comments on the GEIS as excerpted from 101 docketed letters received as solicited in the Federal Register notice. Comments from two NRC/Agreement-States meetings are also summarized. 



\section{CONTENTS}

Section

Page

ABSTRACT $\ldots \ldots \ldots \ldots \ldots \ldots \ldots \ldots \ldots \ldots \ldots \ldots \ldots \ldots \ldots \ldots \ldots \ldots \ldots \ldots \ldots$ iii

FOREWORD $\ldots \ldots \ldots \ldots \ldots \ldots \ldots \ldots \ldots \ldots \ldots \ldots \ldots \ldots \ldots \ldots \ldots \ldots \ldots \ldots \ldots$

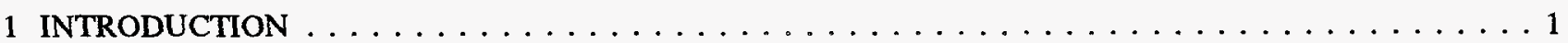

2 COMMENTS ON RADIOLOGICAL CRITERIA FOR DECOMMISSIONING:

PROPOSED RULE PUBLISHED AUGUST $22,1994 \ldots \ldots \ldots \ldots \ldots \ldots \ldots \ldots \ldots \ldots \ldots$

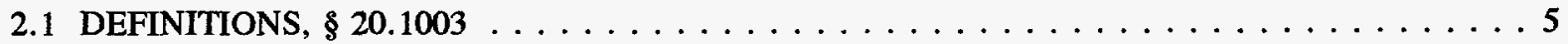

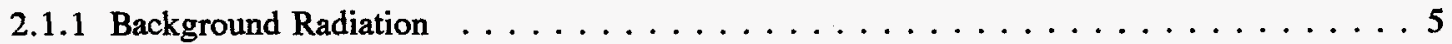

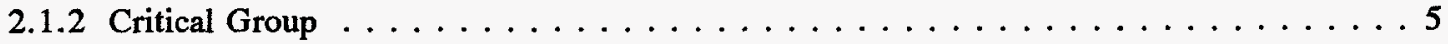

2.1 .3 Decommission . . . . . . . . . . . . . . . . . . . 5

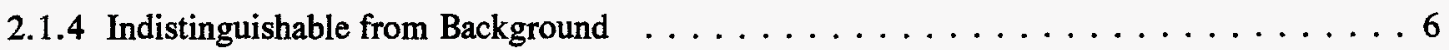

2.1 .5 Readily Removable . . . . . . . . . . . . . . . . . . . 6

2.1.6 Residual Radioactivity . . . . . . . . . . . . . . . . . . 6

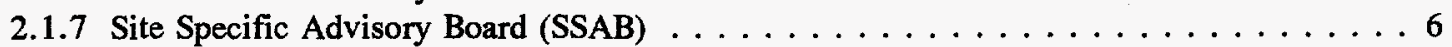

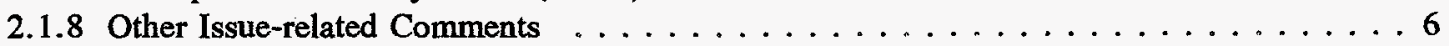

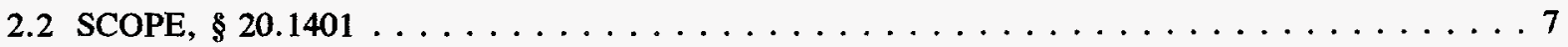

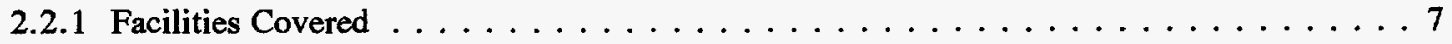

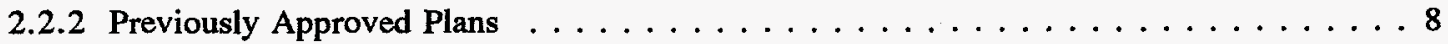

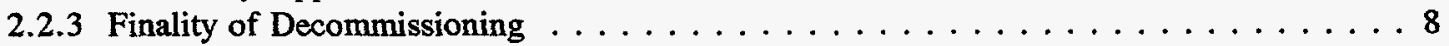

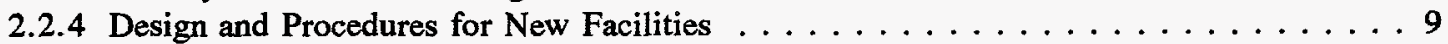

2.2.5 Other Issue-related Comments $\ldots \ldots \ldots \ldots \ldots \ldots \ldots \ldots \ldots$

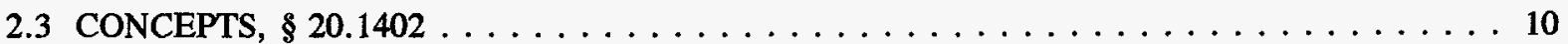

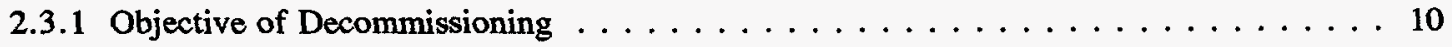

2.3.2 Conditions for Unrestricted Release $\ldots \ldots \ldots \ldots \ldots \ldots \ldots \ldots \ldots \ldots \ldots \ldots$

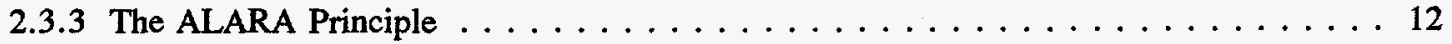

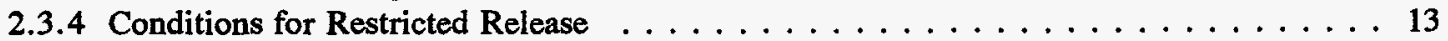

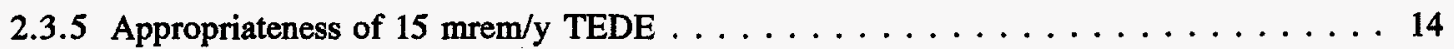

2.3.6 National/International Consensus Standards . . . . . . . . . . . . . 15

2.3.7 Technical Basis for Criteria Vs. Non-Technical/ Political Basis . . . . . . . . 16

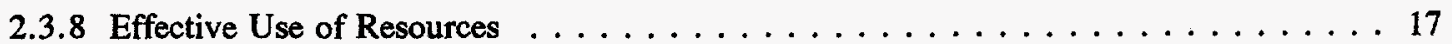

2.3 .9 Other Issue-related Comments $\ldots \ldots \ldots \ldots \ldots \ldots \ldots \ldots \ldots \ldots$

2.4 GENERAL PROVISIONS, $\$ 20.1403 \ldots \ldots \ldots \ldots \ldots \ldots \ldots \ldots \ldots$

2.4.1 Calculations of TEDE to 1000 Years . . . . . . . . . . . . . . . . 19

2.4.2 As Low As Reasonably Achievable (ALARA)
Analysis Determinations $\ldots \ldots \ldots \ldots \ldots \ldots \ldots \ldots \ldots \ldots \ldots \ldots \ldots \ldots \ldots \ldots \ldots$

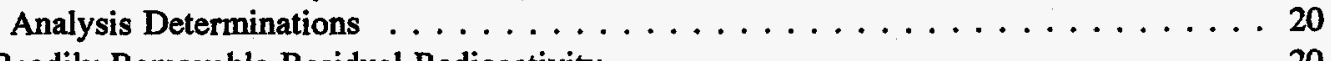

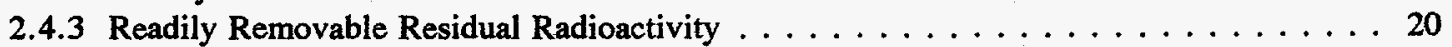

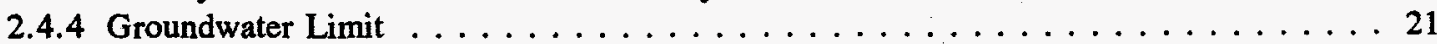

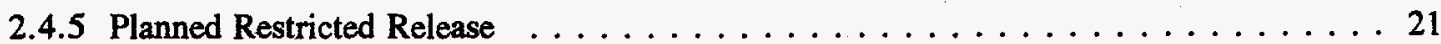

2.5 RADIOLOGICAL CRITERIA FOR UNRESTRICTED USE, $\$ 20.1404 \ldots \ldots \ldots \ldots \ldots \ldots 22$

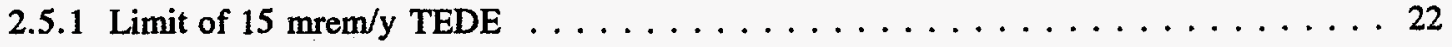

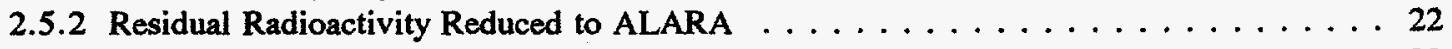

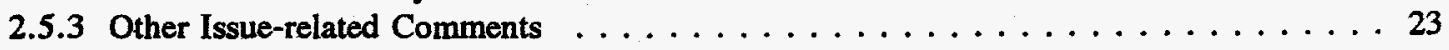


2.6 CRITERIA FOR LICENSE TERMINATION UNDER RESTRICTED

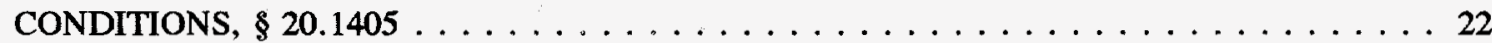

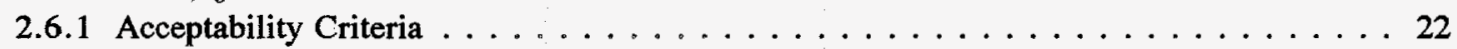

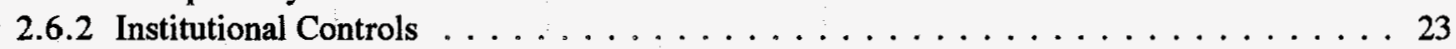

2.6 .3 Financial Assurance . . . . . . . . . . . . . . . . . . . . . 23

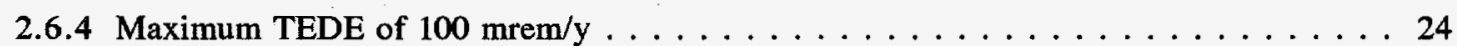

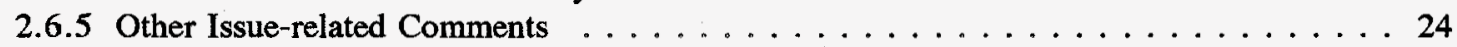

2.7 NOTIFICATION AND PUBLIC PARTICIPATION, $\S 20.1406 \ldots \ldots \ldots \ldots \ldots \ldots \ldots \ldots$

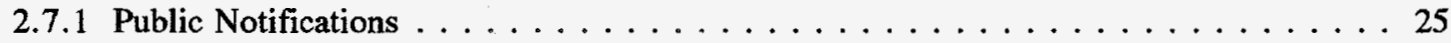

2.7.2 Use of Site Specific Advisory Board . . . . . . . . . . . . . . 25

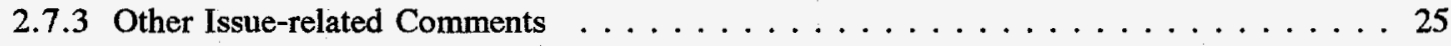

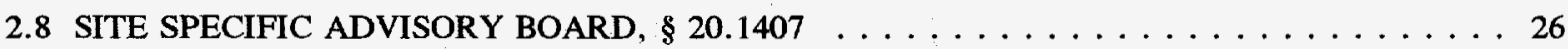

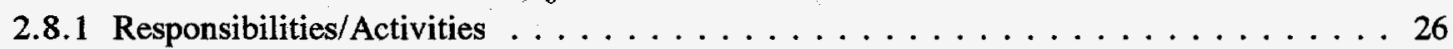

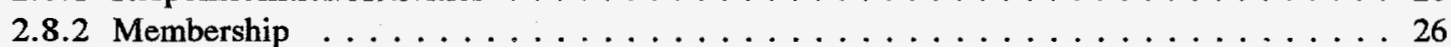

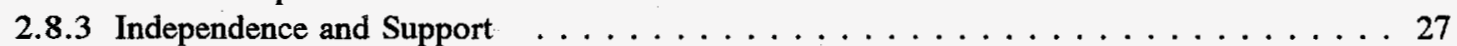

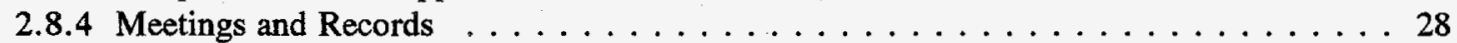

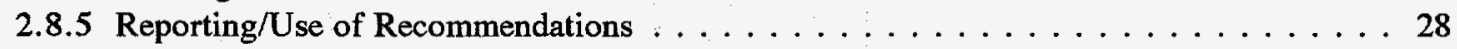

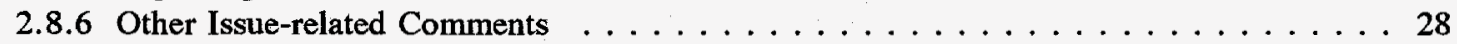

2.9 MINIMIZATION OF CONTAMINATION, $\$ 20.1408 \ldots \ldots \ldots \ldots \ldots \ldots \ldots \ldots$

2.9.1 New Facility Design and Procedures . . . . . . . . . . . . . . . . . 29

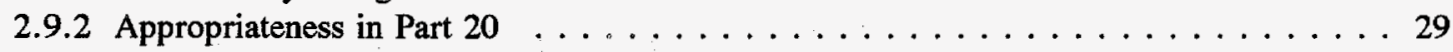

2.9 .3 Other Issue-related Comments . . . . . . . . . . . . . . . . . . . 29

2.10 IMPLEMENTATION . . . . . . . . . . . . . . . . . . . . . . . . . 29

2.10 .1 Regulatory Guidance . . . . . . . . . . . . . . . . . . 29

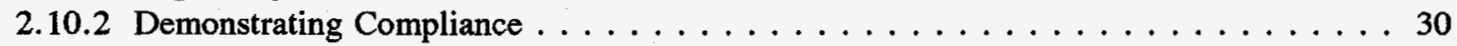

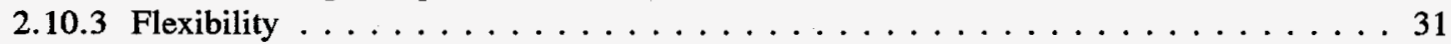

2.10 .4 Waste Disposal . . . . . . . . . . . . . . . . . . . . 31

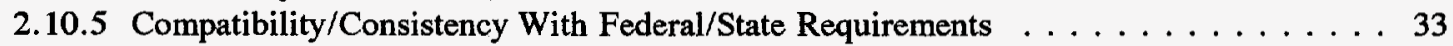

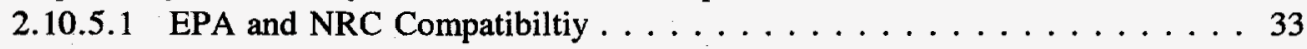

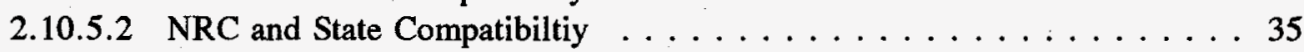

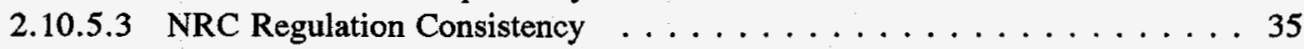

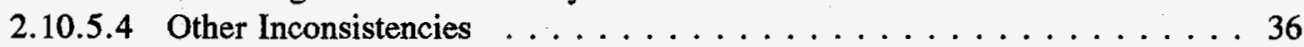

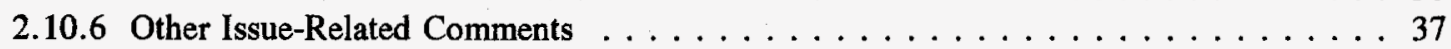

2.11 REGULATORY ANALYSIS $\ldots \ldots \ldots \ldots \ldots \ldots \ldots \ldots \ldots \ldots \ldots \ldots$

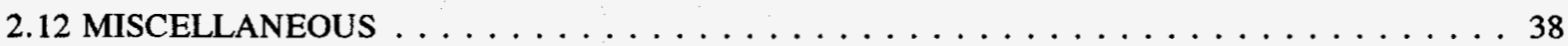

3 SUMMARY OF COMMENTS ON DRAFT GENERIC ENVIRONMENTAL

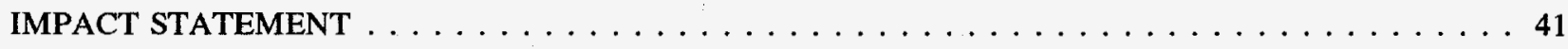

$3.1 \quad$ REGULATORY ALTERNATIVES AND APPROACH $\ldots \ldots \ldots \ldots \ldots \ldots \ldots$

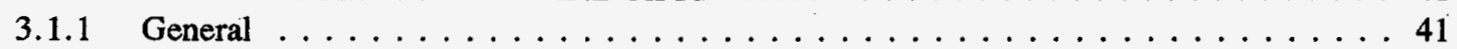

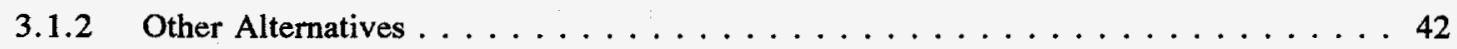

3.2 METHOD OF ANALYSIS OF IMPACTS AND COSTS $\ldots \ldots \ldots \ldots \ldots \ldots$ 
3.2.1 Reference Facilities . . . . . . . . . . . . . . . . . 43

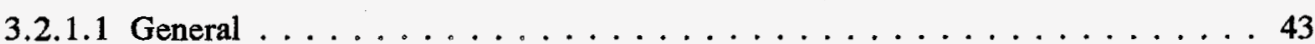

3.2 .1 .2 Reactor . . . . . . . . . . . . . . . . . 43

3.2.1.3 Fuel Fabrication . . . . . . . . . . . . . . . 44

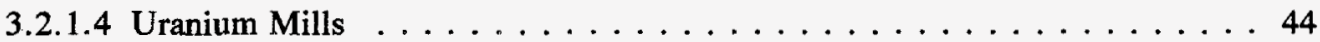

3.2.1.5 Rare Earth Facilities . . . . . . . . . . . . . . . . . . 45

3.2.1.6 Sealed Source Manufacturers . . . . . . . . . . . . . . . . 45

3.2.1.7 Independent Spent Fuel Storage Installation . . . . . . . . . . . . . 45

3.2.2 Human Health Impacts; Dose/Mortality Modeling . . . . . . . . . . . . . . . . 45

3.2.2.1 General Dose Modeling Approach . . . . . . . . . . . . . . 45

3.2.2.2 Use of Linear Non-threshold Hypothesis in Analysis . . . . . . . . . . 46

3.2.2.3 Time Period for Analysis . . . . . . . . . . . . . . . . . . 46

3.2.2.4 Inconsistencies in the Modeling . . . . . . . . . . . . 47

3.2.2.5 Uranium Dose Modeling . . . . . . . . . . . . . . . . 47

3.2.2.6 Transfer of Risk -- Non-radiological Impacts and Waste Disposal Impacts . . . . . . . . . . . . . 47

3.2.2.7 Effects of Chemicals . . . . . . . . . . . . . . . . 48

3.2 .2 .8 Radon . . . . . . . . . . . . . . . . . . . 48

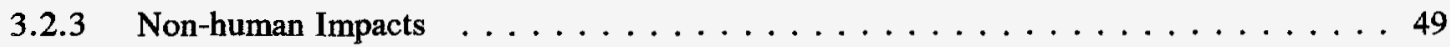

3.2 .4 Impacts on Waste Disposal/Capacity $\ldots \ldots \ldots \ldots \ldots \ldots \ldots \ldots \ldots \ldots \ldots$

3.2.4.1 Limits on Capacity . . . . . . . . . . . . . . . . . . . . . . 49

3.2.4.2 Waste Disposal Regulations . . . . . . . . . . . . . . . 49

3.2.4.3 NORM Waste . . . . . . . . . . . . . . . . . . . . . 49

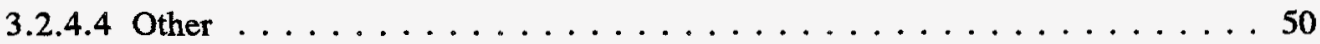

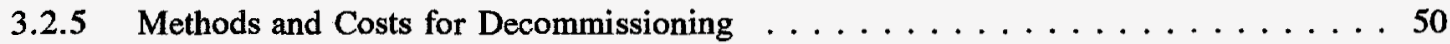

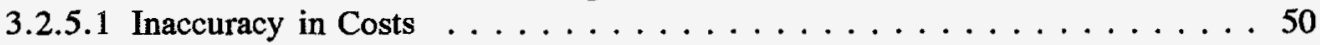

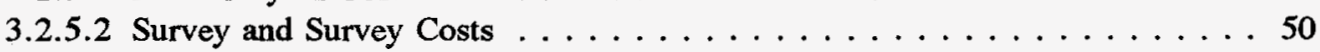

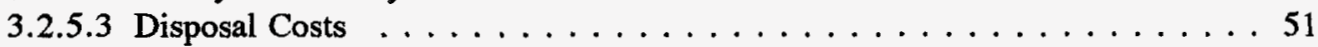

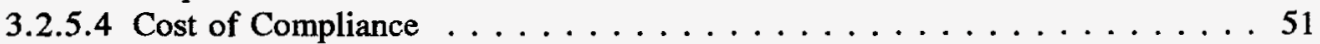

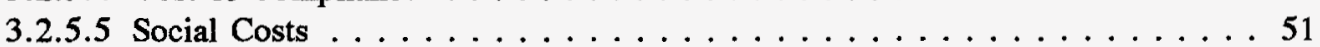

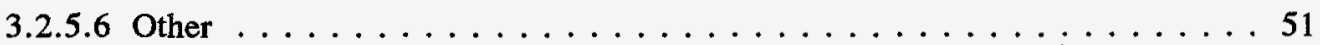

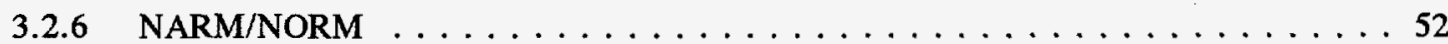

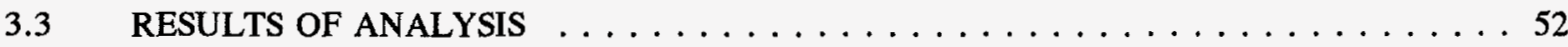

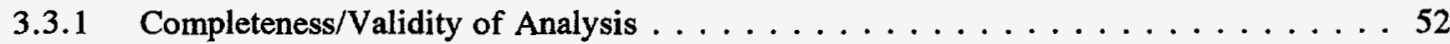

3.3.1.1 Costs Should Not Be A Factor . . . . . . . . . . . . . . 52

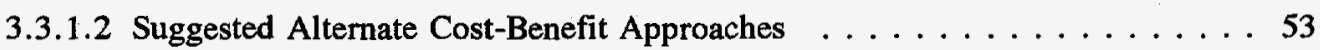

3.3.1.3 Need for Groundwater Analysis . . . . . . . . . . . . . 59

3.3.1.4 Areas Not Considered in the GEIS . . . . . . . . . . . . 54

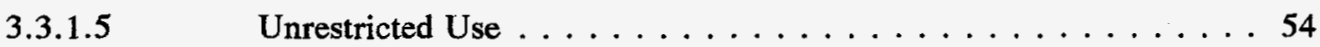

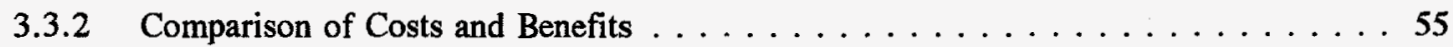

3.3.2.1 Cost-Benefit Analysis Says 15 mrem is Too High . . . . . . . . 55

3.3.2.2 Cost-Benefit Analysis Does Not Support 15 mrem or Lower . . . . . . . 55

4 SUMMARY OF COMMENTS FOR SPECIFIC NRC SOLICITATIONS $\ldots \ldots \ldots \ldots \ldots \ldots \ldots$

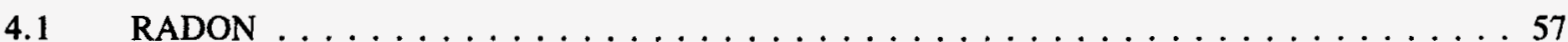

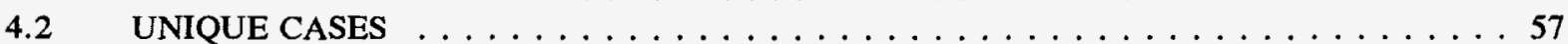

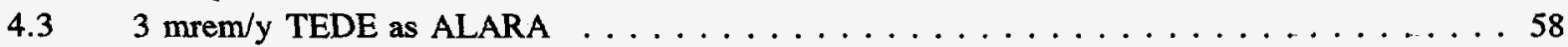

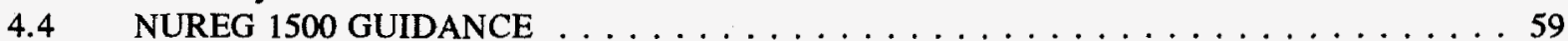

$4.5100 \mathrm{mrem} / \mathrm{y}$ "SAFETY NET" $\ldots \ldots \ldots \ldots \ldots \ldots \ldots \ldots \ldots \ldots \ldots \ldots$

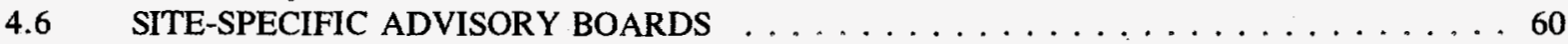


4.7 READILY REMOVABLE RESIDUAL RADIOACTIVITY $\ldots \ldots \ldots \ldots$

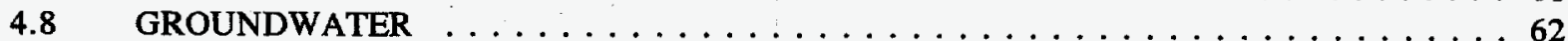

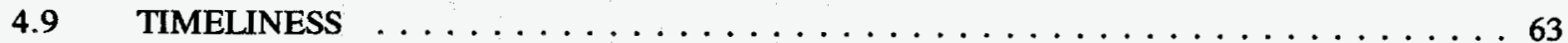

4.10 AGREEMENT STATE COMPATIBILITY $\ldots \ldots \ldots \ldots$

$4.1115 \mathrm{mrem} / \mathrm{y}$ TEDE APPROPRIATENESS $\ldots \ldots \ldots \ldots \ldots$

5 COMMENTS ON RADIOLOGICAL CRITERIA FOR DECOMMISSIONING FROM

TRANSCRIPTS OF NRC/AGREEMENT-STATE MEETINGS

\section{Appendices}

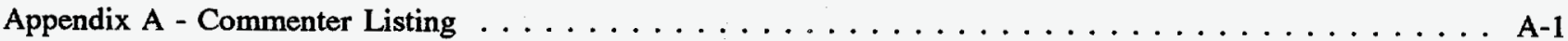

Appendix B - Comment References for the Proposed Rule . . . . . . . . . . . . . . . . . . B-1

Appendix C - Comment References for the GEIS . . . . . . . . . . . . . . . . . . . . . C-1

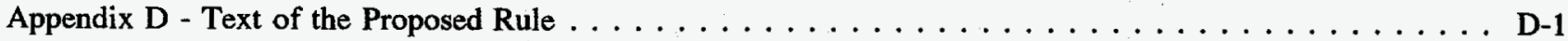




\section{FOREWORD}

The Nuclear Regulatory Commission (NRC) is conducting an enhanced participatory rulemaking to establish radiological criteria for the decommissioning of NRC-licensed facilities. The NRC obtained comments in 1993 on the scope, issues, and approaches for this rulemaking through open-public-meeting workshops held in seven cities on the criteria, and through eight similar meetings held in four cities on the proposed scope of the Generic Environmental Impact Statement (GEIS). A dedicated electronic bulletin board system was also established both for disseminating information and for obtaining comments on the rulemaking in addition to those received in letters responding to notices in the Federal Register.

Copies of the summaries of comments from these workshops and meetings, published as NUREG/CR-6156, and of an NRC "staff draft" proposed rule were distributed to the NRC's Agreement States, to participants in the earlier workshops and meetings, and to other interested parties for comment. A notice of availability of NUREG/CR-6156 and of the staff draft rule was published in the Federal Register, and the documents were placed on the electronic bulletin board. A summary of comments on the staff draft rule was published as NUREG/CR-6250.

After considering the comments received, the Commission published, on August 22, 1994, in the Federal Register (59 FR 43200) a proposed rule on radiological criteria for decommissioning. A draft Generic Environmental Impact Statement in support of the rule, also published in August 1994 as NUREG-1496, along with its Appendix A (NUREG-1501), were also made available for comment. A staff working draft on regulatory guidance (NUREG-1500) was also made available. The Commission also considered comments from two NRC/AgreementStates meetings.

The purpose of this report is to summarize the comments received on the proposed rule and on the related documents made available for comment. The summarized information is being considered by the NRC in developing a final rule on radiological criteria for the decommissioning of NRC-licensed facilities. This report covers letters received between September 23, 1994 and April 16, 1995. Letters received after that date will also be considered, if practical to do so, in preparation of the final rule. The results, approaches, and methods described in this report are provided for information only. Publication of this report does not necessarily constitute NRC approval of, or agreement with, the comments summarized herein.

\footnotetext{
Goth

John

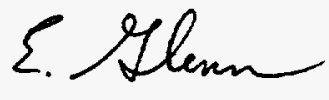

John E. Glenn, Chief

Radiation Protection and

Health Effects Branch

Division of Regulatory Applications

Office of Nuclear Regulatory Research
} 


\section{INTRODUCTION}

\subsection{Background}

The Nuclear Regulatory Commission (NRC) is conducting an enhanced participatory rulemaking to establish radiological criteria for the decommissioning of NRClicensed facilities. The NRC obtained comments in 1993 on the scope, issues, and approaches for this rulemaking through open-public-meeting workshops held in seven cities on the criteria, and through eight similar meetings held in four cities on the proposed scope of the Generic Environmental Impact Statement (GEIS). A dedicated electronic bulletin board system was also established both for disseminating information and for obtaining comments on the rulemaking in addition to those received in letters responding to notices in the Federal Register.

Copies of the summaries of comments from these workshops and meetings, published as NUREG/CR-6156, and of an NRC "staff draft" proposed rule were distributed to the NRC's Agreement States, to participants in the earlier workshops and meetings, and to other interested parties for comment. A notice of availability of NUREG/CR-6156 and of the staff draft rule was published in the Federal Register, and the documents were placed on the electronic bulletin board. A summary of comments on the staff draft rule was published as NUREG/CR- 6250 .

After considering the comments received, the Commission published, on August 22, 1994, in the Federal Register (59 FR 43200) a proposed rule on radiological criteria for decommissioning, soliciting comments both on the rule as proposed and on certain specific items as identified in its supplementary statement of considerations. The actual text of the proposed rule is set out in Appendix D of this report; principal components of the proposed rule are:

\section{- Decommissioning Objective -}

The objective of decommissioning is to reduce residual radioactivity in structures, materials, soils, groundwater, and other media to levels which are indistinguishable from background.
General Provisions -

Estimates of Total Effective Dose Equivalent (TEDE) are to be based on the greatest annual expected TEDE dose within the first 1,000 years after decommissioning.

Residual radioactivity is to be reduced to as low as is reasonably achievable (ALARA), and all significant risks to humans and to the environment are to be considered.

Reasonable steps must be taken to remove all readily removable residual radioactivity.

Demonstration will be provided that there is reasonable expectation that residual radioactivity in any groundwater that is a source of drinking water will not exceed limits specified in 40 CFR 141 by the Environmental Protection Agency.

\section{Radiological Criteria for Unrestricted Termination of License -}

The Total Effective Dose Equivalent to the average member of the critical group does not exceed $15 \mathrm{mrem} / \mathrm{y}$.

Residual radioactivity is as low as is reasonably achievable below the limit.

\section{Criteria for License Termination under Restricted Conditions -}

License terminations under restricted conditions are acceptable if further reductions in residual radioactivity are not technically achievable, would be prohibitively expensive, or would result in net public or environmental harm.

Residual radioactivity at the site must have been reduced, and institutional controls imposed, so that the Total Effective Dose Equivalent to the average member of the critical group will not exceed $15 \mathrm{mrem} / \mathrm{y}$. 
The Total Effective Dose Equivalent to the Critical Group, even if all institutional controls fail, shall be ALARA and shall not exceed 100 mrem/y.

The licensee shall provide sufficient financial assurance to support any necessary control and maintenance activities after license termination.

\section{- Public Participation -}

The Commission will publish a notice and opportunity for comment:

- Upon the receipt of a decommissioning plan from the licensee.

- Upon a proposal by the licensee for restricted release.

- When deemed by the Commission to be in the public interest.

Notice would be published in the Federal Register and in a forum, such as local newspapers, which is readily accessible to individuals in the vicinity of the site.

The licensee shall establish a Site Specific Advisory Board (SSAB) to obtain advice from affected parties on the proposed decommissioning where the licensee does not propose unrestricted release of the facility.

\section{- Site Specific Advisory Board (SSAB) -}

SSAB is to provide advice to licensee on issues associated with restricted release.

SSAB membership is to reflect the full range of interests in the affected community and region and is to consist of approximately 10 members.

Licensees are to be responsible for establishing the SSAB and for administrative support.

SSAB meetings are to be open to the public, with all records generated becoming part of the docket.
Paragraph 20.1406(b) of this proposed rule requires that an SSAB be convened when a licensee proposes to request release of the site to a restricted use after decommissioning. As part of this enhanced participatory rulemaking process, the NRC published in the Federal Register (59 FR 55224) a notice of a workshop on the subject of SSABs which was held on December 6,7, and 8, 1994. A summary of comments received at the workshop was published as NUREG/CR-6307.

A draft Generic Environmental Impact Statement in support of the rule, published in August 1994 as NUREG-1496, along with its Appendix A (NUREG-1501), were also made available for comment. A staff working draft on regulatory guidance (NUREG-1500) was also made available.

The purpose of this report is to summarize the comments received on the proposed rule and on the related documents made available for comment. Comments from two NRC/Agreement-States meetings are also summarized.

\subsection{Overview of Comments}

The enhanced participatory rulemaking process elicited over 10,000 comments regarding radiological criteria for decommissioning as recorded in this report and in NUREG/CR-6156, -6250 , and -6307 . The comments continue to reflect a broad spectrum of viewpoints on many of the issues related to this topic; however, commenters are in general agreement on the following topics:

- There is a need for the rulemaking to proceed.

- The GEIS did not adequately support all of the rule issues.

- There is general support for public participation in decommissioning cases.

Commenters' views were divided on the usefulness of the enhanced participatory rulemaking process. In this report there are twenty-four comments expressing satisfaction with the enhanced rulemaking process undertaken by the NRC for the decommissioning rule. Five of the commenters, who opposed the proposed decommissioning standards for not being sufficiently restrictive, were critical of the rulemaking process and suggested that the NRC had 
ignored their earlier comments. Additional comments on the rulemaking process are in section 2.12 .

For this report there are 1,309 comments on the proposed rule and the specific supplementary items on which the Commission requested comment, and 311 comments on the GEIS, excerpted from 101 docketed letters. A list of commenters is in Appendix A.

The comments are organized into the issues and sub-issues in section 2 for the proposed rule based on the rule sections, in section 3 for the GEIS, and in section 4 for the specific supplementary items. Each of the summaries is followed by its associated comment numbers in parenthesis. It should be noted that some comments are summarized in more than one issue, and some are used more than once in the summaries within a single issue. These comments are identified by commenter, docket (letter) number, and page number in Appendix B for comments on the proposed rule and its specific supplementary items and in Appendix $C$ for comments on the GEIS. No analysis or response is included in this report. 



\section{COMMENTS ON RADIOLOGICAL CRITERIA FOR DECOMMISSIONING: PROPOSED RULE PUBLISHED AUGUST 22, 1994}

This section 2 of this report contains a summary of comments on the proposed rule organized mainly by the sections of the rule on which the comments were submitted. Because some similar requirements are included in more than one section of the proposed rule (e.g., the 15 mrem TEDE annual limit is included in proposed rule sections 20.1402 and 20.1404, and the ALARA provisions are included in proposed rule sections $20.1402,20.1403$, and 20.1404), a single commenter's comment may be referenced in several of the following subsections of this report. This presentation of the comments is intended neither to be redundant nor to give undue weight to some comments; its purpose is rather to assist the reader in determining what comments were made on specific parts of the rule.

This section 2 also includes summaries of comments on certain topics that relate to the development of the proposed rule's criteria but that are not explicit in any particular section of the proposed rule, e.g.,

National/International Consensus Standards, Technical Basis for Criteria vs. Non-Technical/Political Basis, Effective Use of Resources, and Other Issue-Related Comments. These topics are summarized in sections 2.3.6 through 2.3.9 of this section 2 and, as noted above, the presentation may result in the repetition of some comments in the summaries.

\subsection{Definitions, $\$ \mathbf{2 0 . 1 0 0 3}$}

\subsubsection{Background Radiation}

Commenters both favored (195) and opposed (478, 920 , $1241)$ the proposed definition for "background radiation." Some suggested that the definition be modified to exclude radon from the residual radioactivity limit $(199,240,241$, 407,837 ); one commenter proposed to delete the phrase "(except as a decay product of source or special nuclear material)" from the definition (407). Several commenters $(478,479,487,529,849)$ opposed defining "background radiation" in terms of now existing levels, and proposed defining it at the level existing when human beings and other organisms evolved, i.e., man-made sources of radiation should not be considered to be a part of "background radiation." One commenter suggested that the term "naturally occurring radioactive material," which is used in the definition of "background radiation," should also be defined (1055). This commenter also suggested that the word "like," which precedes "Chernobyl," should be replaced with the words "such as" to clearly indicate that an example is being provided.

\subsubsection{Critical Group}

Several commenters opposed the definition of "critical group" and the establishment of a dose limit at decommissioned sites based on the exposure of "an average member of the Critical Group" $(430,437,463$, $473,489,518,524,530,851)$. They recommended that the dose restriction be applied to a maximally exposed individual rather than to an average member of the Critical Group (437, 466, 489, 518, 530, 569, 847) consistent with the EPA's working draft cleanup rule (569). One commenter agreed with the definition of "critical group" and opposed "reasonably maximally exposed (RME) individual" as used by the EPA (389). Another commenter objected to the use of "reasonably expected" in the definition (524).

\subsubsection{Decommission}

Several commenters recommended that license termination not be specified in the definition of decommission $(488,531,993)$. Some stated that license termination is a separate issue from decommissioning $(488,695,993)$ and that licenses should be terminated only when sites are given unrestricted release $(488,531$, 1213). One commenter recommended that all of item (2) of the definition be deleted (531). Item (2) provides for the release of property under restricted conditions.

Another commenter stated that certain decommissioning activities may need to be undertaken before a decision is made to terminate licensed activities, and the rulemaking should not prohibit these from being conducted (993). 


\subsubsection{Indistinguishable from Background}

One commenter stated that the definition should be changed to require that the residual radioactivity not exceed the background level recorded prior to commencement of the operations that are being decontaminated $(480,532)$. Another commenter stated that the objective of "indistinguishable levels above background" is not achievable and should be removed from the rule and associated documents $(887,897)$. Other commenters stated that the NRC needs to be very clear and precise on the guidance it provides licensees on detection, measurement, methodology and scope of measurements, and in determining whether residual radioactivity is "statistically different" from the background radioactivity $(436,532,1056)$.

\subsubsection{Readily Removable}

One commenter stated that the definition shows shallow thinking and trivializes decontamination activities that need to be undertaken; the term should be dropped or redefined to assure that complete cleanup will be accomplished $(490,511,533)$. The commenter stated that the definition as written underscores why the commenter insists on a return to background requirement (533). Other commenters recommended that additional examples of non-destructive techniques, such as vacuuming, wiping, etc., be included in the definition (131) and that the definition be clarified with respect to the amount of excavation and transportation of soil that could be required (828).

\subsubsection{Residual Radioactivity}

Some commenters recommended that the definition be changed to exclude radon and naturally occurring radioactive materials $(241,400,407,408,837)$. One commenter recommended that radon be included in the definition of residual radioactivity $(429,454,476)$. Other commenters recommended the exclusion of materials that were disposed of in accordance with NRC regulations in 10 CFR Part 20, $(245,246,263,829,1200)$. Perhaps wastes, buried prior to 1981 pursuant to 10 CFR 20.304, should be included (829), but not wastes disposed of pursuant to 10 CFR $20.2002,(245,246,829)$. One commenter recommended that the definition include all wastes at a site being decommissioned (535). Another commenter recommended that the rule make clear that any decision made on whether to exhume buried materials should be based on a site-specific analysis of costs and benefits (830). A commenter noted that the NRC appears to have given no consideration to the possibility that decommissioning might occur after an accident (29).

\subsubsection{Site Specific Advisory Board (SSAB)}

One commenter recommended that "Site Specific Advisory Board" be redefined so that it is constituted by and gives advice to regulators rather than to the licensee (491). A commenter urged that the NRC redefine the entity to which an SSAB is to provide its advice; it should be to regulators, local officials, and the public as well as the licensee (534). Another commenter recommended that the definition exclude members who might not be directly affected by the site (273).

\subsubsection{Other Issue-Related Comments}

Several commenters recommended that the rule define the term "significant public risk" as used in proposed paragraph 20.1401(c), (58, 106, 121, 248, 439, 932, $933,1214)$. Commenters also recommended that the following terms used in proposed section 20.1405 be defined: "prohibitively expensive," "technically achievable," "net public or environmental harm," "reasonable assurance," and "sufficient financial assurance." In defining these terms commenters suggested that economic concepts should perhaps be related to the desired level of risk reduction and the cost to achieve that reduction $(295,302,936,1070,1071$, $1214,1247)$. Other commenters recommended that "institutional controls" as used in proposed section 20.1405 also be defined $(574,596)$.

Other commenters stated that the NRC should take care that the term "disposal" is properly defined and appropriately used (181) and should address the definition of "mixed wastes" and the conditions for decommissioning a facility where these exist (919). Another commenter recommended that the NRC make clear what it means by "indefinitely license" a site which cannot be decommissioned for unrestricted or restricted release (646).

One commenter recommended that the rulemaking delete or explain "maximum extent practical" with respect to making measurements and explain appropriate use of 
modeling to demonstrate compliance with the radiological criteria (515).

Another commenter identified characteristics for a definition of "public participation" and recommended that this term be defined in the rule (584).

A commenter suggested that "total effective dose equivalent (TEDE)" be used instead of "radiation dose" in the entire text of the rule (1299).

A commenter recommended that the term "naturally occurring radioactive material" used in the definition of "background radiation" be defined (1055).

\subsection{Scope, $§ 20.1401$}

\subsubsection{Facilities Covered}

Commenters recommended that the rule exempt conventional uranium and thorium mills, in situ leach facilities, and uranium/thorium recovery facilities from the scope of coverage similar to the exemption proposed for uranium mill tailings, since these operations are also covered by the decommissioning criteria in Appendix A of 10 CFR Part 40 and are subject to 40 CFR 192, (52, $99,114,159,226,227,229,230,231,242,264,265$, $378,712,718,793,794,831,1057)$.

A commenter stated that most sites and facilities contaminated with thorium or radium could not meet the stringent $15 \mathrm{mrem} / \mathrm{y}$ dose limit and could not be released for unrestricted use (1276).

Commenters also recommended that the rule not be applied to any facility that possesses large volumes of low-level contaminated wastes and that the NRC provide a specific exemption in the rule for the acknowledged "tens" of existing facilities for which application of the proposed criteria is inappropriate $(270,615,779,791$, $792,793,822,1083$ ). Unless exemptions are specifically provided in the rule or separate criteria for these facilities are specified, licensees will be left with uncertainty as to how decommissioning of these facilities must be accomplished (1083). Other commenters objected to exempting the "tens" of existing facilities from the proposed radiological criteria $(424,430,483,494,521$, $852,853,1100,1101)$. Still other commenters suggested that the continued license approach should be explicitly incorporated into the regulations and appropriate procedures and fees should be specified (148, 577).

One commenter submitted a report of an ALARA analysis for cleanup of a uranium refinery which demonstrates that, for the proposed criteria, the cost per person-rem avoided ranges from $\$ 24,000$ to $\$ 100,000$. The commenter concluded that the site is one of the "tens of sites" that cannot reasonably achieve compliance with the proposed criteria (1304).

Commenters recommended that the NRC tailor the radiological criteria to reflect the range of difficulties associated with the decommissioning of different types of facilities $(793,822,1302)$.

A commenter noted that one spent fuel reprocessing facility would be among the facilities requiring decommissioning (147).

Commenters recommended that large-volume/low-level wastes, including those containing naturally occurring radioactive material (NORM), be covered by a separate decommissioning/waste-management rule, because the radiological criteria proposed in this proposed rulemaking are needlessly restrictive or do not provide an adequate degree of flexibility for such materials $(270,373,375$, $376,377,378,379,391,392,395)$.

Other commenters recommended that an exemption from the rulemaking be specifically provided for licensees that possess and use only sealed sources or limited quantities of radioactive materials $(288,306,321,370)$. A commenter recommended exemption for facilities with respect to disposals pursuant to 10 CFR 20.2002 because for these disposals the ALARA principle is applied on a site-specific basis (246).

One commenter noted that the current guidelines for shallow land burial under 10 CFR Part 61 specify a 75 mrem thyroid and a 25 mrem whole body or any other organ criterion for a residential scenario, which could be more or less stringent than the 15 mrem TEDE criterion of the proposed rulemaking, and questioned why the potential exposure from the buried material should be considered independent of the decommissioning criterion (32). 
Finally, a commenter recommended that the rule not extend to Site Decommissioning Management Plan (SDMP) sites which are in the process of decommissioning $(605,610)$. Another commenter recommended the use of the proposed criteria at SDMP sites if these criteria are more restrictive (535). One commenter recommended the use of the "highest criteria" for consideration of all decommissioning actions and related activities and not just to new decommissionings (182).

\subsubsection{Previously Approved Plans}

Commenters both supported $(89,144,602,665,689$, $795,1017,1087)$ and opposed $(182,332,343,357,459$, $492,535,1098,1099,1101,1102)$ grandfathering sites decommissioned in accordance with the NRC's SDMP. Some who supported the grandfathering also recommended that it be extended to plans in the final stages of review in addition to plans already approved by the NRC $(605,610,617,690,795,832,989,1017$, 1087). Other commenters opposed this extension (332, $343,1101)$.

Some commenters recommended that the grandfathering provision be broadened to cover any NRC-approved decommissioning whether or not conducted pursuant to an approved SDMP decommissioning plan $(42,158,665$, 689 ) or whether conducted on a portion of a site or on the entire site $(710,795,832)$.

An Agreement State Agency recommended that the proposed rule also grandfather those sites covered by an Agreement-State-approved decommissioning plan (1060). Commenters also recommended that the rule specifically address how the criteria will apply to plans currently under review by the NRC (989) and to a plan for the balance of a site or facility after portions have received previous NRC decommissioning approval (603, 710).

\subsubsection{Finality of Decommissioning}

Most commenters stated that decommissioning a nuclear facility and releasing a site should be accomplished as a final regulatory action $(15,176,278,403,602,665,689$, $692,693,1163,1292$ ). A commenter stated that it could not agree that these actions would be final unless all residual activity is reduced to within background radiation levels $(431,439,440,451,535)$.

Many commenters stated that the proposed rule does not provide sufficient assurances for finality of decommissioning actions $(56,58,106,121,212,245$, $247,284,296,297,303,602,692,710,754,796,833$, 872).

Commenters requested that the NRC give consideration to the concepts of statute of limitations, future cleanup action based on risk exceeding that of limits applied to original cleanup, and funds sharing by the government for future cleanup requirements $(208,297,303)$. In addition, commenters suggested that the terms "significant public risk" $(58,106,121,248,439,932,978,1058,1214)$ and "new information" $(754,796,833,1058,1102)$ used in proposed paragraph 20.1401 (c) be appropriately defined. With regard to "significant public risk," commenters recommended that additional remedial activities not be required to be taken at a decommissioned site unless it is definitely shown that a risk to public health exists and that there will be a positive net benefit to the public if further decommissioning takes place $(58,106,121,212,249$, $403,796,833)$. A commenter suggested that the NRC explain whether it believes that any levels in excess of those specified in 10 CFR 20.1402(b) will cause a "significant public risk" (1058). With regard to "new information" which would serve as a basis for additional cleanup, a commenter recommended that it be limited to situations where significant amounts of previously unidentified contamination are discovered or where it becomes known that the licensee failed to comply with the NRC-approved decommissioning plan or that the licensee provided false information to the NRC (833). A commenter indicated that since the NRC is committed to an objective of levels that are indistinguishable from background, there is no assurance that the limits will not be further reduced in the future (872).

A commenter stated that it should be unnecessary to demonstrate the existence of a "significant public risk" before requiring additional site cleanup if there are new scientific findings indicating a need for greater conservatism to protect public health $(440,468,493)$. A commenter indicated a possible need to revisit decommissioning plans approved before January 1, 1995 to determine if additional cleanup activities are feasible (343). 
Other commenters suggested that proposed paragraph 20.1401 (c) should be applied to any site decommissioned in accordance with any NRC-approved decommissioning plan and should not be applied only to sites terminated in accordance with the criteria of the proposed rule $(42,58$, $624,693,694,710)$. A commenter stated that punishment, in the form of great costs for cleanup, should not be imposed on licensees who complied with formerly existing requirements, but who may now encounter different societal norms (208).

A commenter stated that the use of a $15 \mathrm{mrem} / \mathrm{y}$ standard may create inconsistencies with soil cleanup criteria for compliance with 40 CFR Part 192, the Uranium Mill Tailings Radiation Control Act (UMTRCA) standards; these inconsistencies would create problems with continued acceptance of sites already released for unrestricted use under UMTRCA and the Formerly Utilized Sites Remedial Action Program (FUSRAP) (1276).

One commenter stated that if Agreement States are permitted to superimpose more stringent cleanup criteria than the NRC imposes, it would work against achieving finality in the decommissioning of nuclear facilities (1205). Another commenter suggested that if a community or state regulatory agency wants to require more restrictive criteria, these organizations should be required to pay the additional costs for those activities (1163).

\subsubsection{Design and Procedures for New Facilities}

Commenters recommended that the proposed new requirements directed toward minimizing contamination of the facility and the environment be applied both to license renewals and to new licenses $(3,166,179)$. Another commenter recommended that new licensees be required to commit to meet the most technically stringent cleanup limit feasible (567). Another commenter suggested that proposed paragraph $20.1401(\mathrm{~d})$ be deleted or that the phrase "the effective date of the rule" be replaced with the month, day, and year that the rule becomes effective to remove ambiguity in the rule (1059).

\subsubsection{Other Issue-Related Comments}

Commenters stated that the rule suggests three classes of decommissioning sites (1) those that can be released for unrestricted use, (2) those that can be released for restricted use, and (3) those that should be indefinitely licensed; only the first two are specifically addressed in the rule, and more guidance is needed on sites which are to be kept under license $(577,632,644,645,646,647$, $685,737)$. Some commenters recommended that the rule explicitly define which sites qualify for continued licensing and what requirements must be met; and in addition discuss the fees for such licenses (148, 646, 647, $688,764,792,822,823,1083$ ). Commenters also recommended that licensees have the option to terminate their licenses and turn over ownership of the site to the Federal Government or to maintain the site indefinitely under license $(632,664)$. (See discussion also in section 2.3.4 of this report.)

Several commenters requested that the rule provide a categorical exemption from the radiological criteria for sites containing a radioactive burial area established under earlier provisions (10 CFR 20.302 or 20.304) of 10 CFR Part 20 and for sites currently permitted to dispose of radioactive materials on-site $(687,688)$. Commenters recommended that the NRC develop separate standards and criteria for final closure of such sites $(604,609,611$, $613,616,687)$. Other commenters suggested that exemptions be granted on a case-by-case basis under criteria that are explicitly defined in the rule $(823,1083)$. Commenters suggested that the rule explicitly allow a licensee to request an exemption for any of the criteria (647) and that decisions be guided by a site-specific ALARA analysis (830). One commenter recommended against the granting of any waivers or exemptions from the decommissioning requirements (521).

Commenters stated that if the NRC intends to rely on exemption requests, it should include criteria which provide clear guidance on whether a site qualifies for an exemption; the rule must expressly establish the right of a licensee to seek an exemption and must specify the conditions that govern whether an exemption will be granted $(615,823,824)$. Another commenter stated that the NRC must require Agreement States to provide similar opportunity for exemptions (824). Still another commenter recommended that the rule provide specifically for the NRC to accept proposed alternative 
methods for complying with the intent of specific criteria rather than for licensees' needing to apply for exemptions (756).

Commenters stated that the need for licensee exemptions would disappear if the NRC would develop more realistic cleanup standards; i.e., tailor the radiological criteria to reflect the range of difficulties associated with the decommissioning of different types of facilities (791, 793, 822). A commenter requested that decommissioning actions where the contamination remains in place at the site be specifically authorized (preferably encouraged) in instances that are economically viable (1137).

Commenters recommended that the rulemaking address the methodology necessary to decommission a portion of a site in accordance with the Timeliness Rule when only a limited area of a site is decommissioned $(691,710)$. Other commenters recommended that portions of sites that have been decommissioned be grandfathered against a need to revisit these portions when the remainder of the site is decommissioned $(616,691,710,795,832)$.

Several commenters recommended that the rule better address the cleanup of sites with mixed wastes, i.e., wastes containing both non-radioactive and radioactive hazardous material $(328,329,331,340,345,349,356$, $755,919)$. Some recommended that the NRC not regulate any non-radioactive hazardous material beyond what it is authorized to do, such as specified in UMTRCA $(755,995)$. One commenter recommended that the NRC and the EPA agree on definitions and on the characterization and management of mixed wastes (919). Another commenter recommended that the NRC's approval of a licensee's decommissioning activities be dependent on the licensee's fulfilling other regulatory agencies' obligations $(348,349)$. Another commenter disagreed and questioned the NRC's authority to withhold license termination if the licensee has satisfied all of the NRC's regulatory requirements (755).

Commenters recommended that doses from radon and its daughters be categorically excluded from the dose calculations performed to determine compliance with the decommissioning rules; and this exclusion should be specifically stated in section $20.1404,(76,98,113,199$, $753,797)$. One commenter stated that radon doses should be included (454).
A State Public Health Organization commenter cautioned that naturally-occurring and accelerator-produced radioactive material (NARM) is not covered by NRC regulatory authority, and that hazardous amounts of these materials could still be present at a site that could meet the NRC's release criteria (95).

One commenter suggested that the rulemaking explicitly state that it does not apply to off-site property and that the EPA is responsible for specifying criteria for off-site property (30). The DOE stated that under current laws this rule is not applicable to DOE sites, however, the NRC-proposed rule could be determined to be an Applicable or Relevant and Appropriate Requirement (ARAR) under Comprehensive Environmental Response and Compensation Liability Act (CERCLA) for cleanup requirements that the DOE will have to address in its remediation activities (1257). Accordingly, these NRC criteria could significantly impact the DOE's environmental restoration program (1257).

A commenter suggested that the NRC consider the applicability of the proposed criteria to existing NORM sites that have been remediated and released for unrestricted use, many at great cost (1295). This commenter also suggested that the NRC consider establishing limits that would permit disposal of very lowlevel radioactive waste in sanitary landfills rather than require disposal at low-level radioactive waste sites (1293).

One commenter noted that “ ... the NRC appears to have given no consideration to the possibility that decommissioning might occur after an accident" (29). A commenter stated that the draft regulations do not give due consideration to non-cancer risks, especially from non-radioactive hazardous materials (331). A commenter expressed concern that the proposed revision of 10 CFR Part 20 might introduce issues that contribute to an overall risk increase, rather than achieve a desired risk reduction (279).

\subsection{Concepts, $§ 20.1402$}

\subsubsection{Objective of Decommissioning}

Most commenters opposed establishment of the decommissioning objective, as stated in the proposed 
rule, of reducing residual radioactivity to concentrations "indistinguishable from background radiation concentration" $(275,289,301,548,549,550,551,627$, $637,715,721,727,735,742,746,767,784,785,801$, $803,869,872,887,893,894,895,897,1013,1061$, $1138,1152,1246)$ for many reasons, including that it is arbitrary $(550,727)$, is unnecessary for protecting the public health $(556,627,637,721,1013,1246)$, conflicts with the ALARA principle (1013), creates a basis for overturning determinations to release decontaminated sites (894), and is unlikely to be achieved $(289,625,630$, $715,742,744,746,887,895,896,897,1276$ ). Some commenters supported establishing this proposed objective $(126,128,156,358,421,527,850,852,1229$, 1252). Two commenters indicated that the proposed objective should be even more conservative and that there should not be any licensing of dangerous materials ( 47 , 957). The EPA supported the NRC's effort to limit public exposures to no more than $15 \mathrm{mrem} / \mathrm{y}$ above background and to limit radioactivity in groundwater to levels not exceeding the maximum contaminant levels (MCLs) specified in 40 CFR Part 141, (1144). Another commenter agency viewed the need for rulemaking to be rooted in technical considerations involving the relationship between radioactivity and dose to the public (1054), and recommended that the NRC's decommissioning objective should be a known value (1061).

Other commenters stated that they agreed generally with the NRC's approach of permitting both restrictive and unrestrictive releases of sites $(49,94,918)$.

Some commenters stated that the proposed objective does not achieve consistent application across all types of licensees $(743,821)$ and will not eliminate decommissioning delays (745).

\subsubsection{Conditions for Unrestricted Release}

Commenters were divided on whether $15 \mathrm{mrem} / \mathrm{y}$ TEDE should be established as the limiting dose for unrestricted release of decommissioned sites. Many opposed 15 $\mathrm{mrem} / \mathrm{y}$ as being too high and recommended that radioactivity at sites be reduced to background conditions $(8,62,65,66,69,72,91,111,218,220,222,223,421$. $424,434,436,443,444,445,451,460,462,485,497$. $513,537,847,849,850,853,943,951,956,961,967$, $1220,1229,1231,1252,1306$ ). Many opposed 15 $\mathrm{mrem} / \mathrm{y}$ as being too restrictive and recommended that the dose be increased to 25 to $100 \mathrm{mrem} / \mathrm{y}(75,100,103$, $115,118,238,313,373,374,379,380,381,383,384$, $385,390,391,392,399,544,554,713,728,729,730$, $777,785,788,793,801,806,810,815,861,868,929$, 999, 1012, 1019, 1062, 1064, 1065, 1082, 1089, 1133 , $1136,1147,1153,1154,1174,1177,1199)$. Some stated that $15 \mathrm{mrem} / \mathrm{y}$ is believed to be an acceptable limit $(9,88,128,143,167,171,189,195,410,1144)$. Another commenter stated that the NRC's approach of setting $15 \mathrm{mrem} / \mathrm{y}$ with ALARA is viable if realistic use scenarios are employed (1272), but recommended a dose constraint of 25 to $30 \mathrm{mrem} / \mathrm{y}(1273,1274)$. Some recommended that a dose limit below $100 \mathrm{mrem} / \mathrm{y}$ not be specified and that the rule simply require that the cleanup be ALARA below that dose $(365,382)$. Some commenters applauded the NRC for deleting the 3 $\mathrm{mrem} / \mathrm{y}$ goal from the proposed rule $(53,74,100,115$, $987,1278)$. Other commenters recommended that the NRC reinstate the $3 \mathrm{mrem} / \mathrm{y}$ standard $(78,462,1220$, $1229,1250,1255,1307)$. A commenter stated that the NRC's stringent dose standard of $15 \mathrm{mrem} / \mathrm{y}$ will mean that sites contaminated with thorium or radium cannot be released for unrestricted use (1276).

Several commenters questioned or opposed applying the ALARA principle to doses below $15 \mathrm{mrem} / \mathrm{y}(88,785$, $809,810,869,870,999,1263,1266,1283,1286$ ). Others supported the use of ALARA with respect to these doses $(9,171,1217)$. A commenter recommended an upper limit on risk on the basis of dose and the use of a site-specific ALARA review (37).

Some commenters objected to applying the $15 \mathrm{mrem} / \mathrm{y}$ dose limit to "an average member of the Critical Group;" they favored applying the limiting dose limit to the "maximally exposed individual" $(37,463,524,851,923$, $951,1184)$. Other commenters expressed agreement with applying the dose limit to an average member of the Critical Group (194, 389, 1156).

One commenter pointed out the need for consistency between the requirements in $\S 20.1402$ (b) and $\S 20.1404$ (a); presently one specifies that doses shall be "less than 15 mrem" and the other says "not exceed 15 mrem" (1066). Also, $\$ 20.1402$ (b) states that an ALARA analysis is needed at $15 \mathrm{mrem} / \mathrm{y}$, and $\S$ 20.1402(c) states that $15 \mathrm{mrem} / \mathrm{y}$ may be considered ALARA (1215). Another commenter stated that 
Agreement States will want to have authority to set stricter standards than those set by the NRC (70).

A commenter stated that spot monitoring should be performed both on-site and off-site for a number of years after decommissioning and that several years should elapse before the site is released for restricted or unrestricted use (1239).

A commenter stated that it favored setting a single dose criterion covering all pathways rather than having several values for specific media or exposure pathways, e.g., soil, groundwater, and direct radiation (1258).

\subsubsection{The ALARA Principle}

Commenters recommended that the rule provide a mechanism to permit licensees to use a higher dose limit than specified in the rule if an ALARA analysis shows that the risks attributable to removal of the wastes and transportation are larger than the radiological risks from leaving the radioactivity at the site $(103,118,1020$, $1135,1271)$.

Commenters both supported $(180,185,196,278,302$, $406,551,555,626,643,814,830,835,892,896,1013$, $1248,1281)$ and objected $(183,350,445,446,471,501$, $512,517)$ to licensees' basing cleanup actions on ALARA analyses. Some urged the NRC to adopt 100 $\mathrm{mrem} / \mathrm{y}$ as the limiting dose and to require ALARA analyses to determine how much additional cleanup should be performed $(103,118,382,385,392,667,921$, $926,929,1019,1020,1155,1157)$. A commenter stated that the ALARA principle was developed to be used for limiting worker exposures at relatively high exposures and cannot be applied to low dose exposures $(865,867$, 869,870 ). One commenter stated that once projected radiological risks drop to the point where the very real risks of industrial accidents and transportation exceed the speculative risks of low-level radiation, the ALARA process must stop (1219).

Commenters indicated that ALARA analysis should not be required to determine if cleanup should be performed to reduce doses below $15 \mathrm{mrem} / \mathrm{y}(88,128,130,143$, $271,309,314,724,785,809,810,865,869,926,1182$, $1266,1286)$. Other commenters endorsed making ALARA analyses to determine if doses should be reduced below $15 \mathrm{mrem} / \mathrm{y}(171,340,352,570,1247)$.
A commenter supported the requirement to perform an ALARA analysis, but objected to requiring that some nebulous level be attained (1281). This commenter also stated that the ALARA level may sometimes be higher than $15 \mathrm{mrem} / \mathrm{y}(1283)$ and recommended that the NRC consider specifying a higher dose limit in place of 15 mrem/y (1286).

A commenter stated that Executive Order 12866 requires that an agency must design its regulation in the most costeffective manner to achieve the regulatory objective and must consider incentives for innovation, consistency, predictability, the costs of enforcement and compliance (to the government, regulated entities, and the public), flexibility, distributive impacts, and equity (629). The Executive Order also requires the NRC to "assess both the costs and the benefits of the intended regulation and, recognizing that some costs and benefits are difficult to quantify, propose or adopt a regulation only upon reasoned determination that the benefits of the intended regulation justify its costs" (629). The commenter went on to state that the NRC's criteria do not appear to be based upon such an analysis (629). Other commenters also expressed a similar belief $(312,330,627,663,667$, $669,719,720,722,723,726,736,758,774,779,805$, $817,866,871,878,1020,1119,1121,1133,1154$, $1263,1282)$. Commenters indicated that a site-by-site ALARA analysis is the only way to arrive at a conclusion that $15 \mathrm{mrem} / \mathrm{y}$ is not unduly burdensome on licensees $(37,1065)$.

\section{Commenters recommended that the NRC's ALARA} guidance provide for the use of a specific dollar value per unit dose averted for use by licensees in performing cost and benefit analyses $(835,838,1086)$. Also, a commenter recommended that guidance should be provided on the method of comparing dose-based risks from residual radioactivity with non-radiological risks from the decommissioning process (196). A commenter stated that collective dose should be an important consideration in the NRC's criteria $(1260,1281)$. Another commenter stated that the rule should require an evaluation of the risks and benefits of decommissioning in phases and that this evaluation should be included in the decommissioning plans for all facilities (355).

A commenter recommended that $\S 20.1402(b)$ and $\S 20.1402$ (c) be consistently worded. One says that an ALARA analysis is needed to justify acceptance of 15 
$\mathrm{mrem} / \mathrm{y}$, and the other says $15 \mathrm{mrem} / \mathrm{y}$ may be considered ALARA (1215).

\subsubsection{Conditions for Restricted Release}

Commenters both agreed with $(11,103,118,167,203$, $278,405,557,606,608,618,632,648,652,664,680$, $737,738,744,763,764,765,786,1259,1264,1269$, $1279)$ and opposed $(154,223,424,430,437,451,473$, $481,484,500,522,523,537,541,852,853,1091$, $1111,1213,1250)$ the concept of restricted release of decommissioned sites. Those opposing a restricted release of sites indicated that sites should be cleaned up to background conditions $(430,473,523,537,541,852$, $853,1091)$ or continue to be covered by a license $(451$, $473,1213)$. The need for continued licensing of sites with restricted conditions of use was supported by one Agreement State (1213). Some commenters supporting the restricted release of sites indicated that the proposed requirements for restricted release are unreasonably restrictive $(204,210,392,545,606,608,618,680,738$, $744,763,764,765,786)$.

One commenter recommended that the NRC expand and explain the distinction between sites involving on-site disposal that may be released for restricted use and those that will need to be on-site licensed indefinitely (632). Commenters recommended that licensees have the option to close a site with on-site disposal, terminate their license, and turn ownership over to the Federal Government, or to continue to control the site under license indefinitely $(632,648,664)$. One commenter recommended that the NRC ask the Congress to amend the Nuclear Waste Policy Act of 1982 to allow federal ownership of such sites as perhaps the best means of "ensuring long-term protection of the public and the environment" (648). (See section 2.2.5 of this report for other commenters who recommended that licensees have the option to turn over ownership of the site to the Federal Government.) One commenter objected to transferring sites to federal ownership (523).

Some commenters stated that the proposed $100 \mathrm{mrem} / \mathrm{y}$ restriction is unreasonably low when used to assess the worst case scenario $(204,205,210,392,545)$, and other commenters stated that $100 \mathrm{mrem} / \mathrm{y}$ is too high $(223,437$, $461,473,502,541,1254,1306)$. Those wanting a higher limit recommended a $500 \mathrm{mrem} / \mathrm{y}$ backup limit if restrictions fail $(278,385,392)$ or recommended that the rule not stipulate that a licensee must assume that all institutional controls will eventually fail $(210,545)$. Another offered suggestion was to apply a combined dose-and-probability-of-occurrence limit (545). A commenter recommended that a licensee be required to show through modeling for restricted release that the dose to individuals will remain below $100 \mathrm{mrem} / \mathrm{y}$ even if the institutional controls fail and that perhaps the potential dose should be limited to some fraction of $100 \mathrm{mrem} / \mathrm{y}$ such as 50 to $75 \mathrm{mrem} / \mathrm{y}$ (1216). Another commenter recommended the incorporation of graded criteria for onsite disposal options, including on-site burial options similar to those in the NRC Branch Technical Position "Disposal of On-site Storage of Thorium or Uranium from Past Operations" 46 FR 52061, (392).

A commenter objected to the statement of intent in $\S 20.1402$ (d) that the licensee would be expected to make "every reasonable effort" to reduce residual radioactivity to levels that will permit unrestricted use of a site (552). Commenters stated that the option of restricted release of a site should be based on a site-by-site cost/benefit analysis $(11,103,118,552,648,649,1086)$. Another commenter stated that it should be unnecessary, as proposed in $\S 20.1402$ (d)(1), for a licensee to demonstrate that a site cannot be released for unrestricted use before considering the restricted release option (737).

Commenters cautioned that the terms "not technically achievable" $(571,1247)$ and "would be prohibitively expensive" $(1086,1247)$, as used in $\S 20.1402(d)(1)$, could be troublesome and perhaps should be expanded upon or dropped. Another commenter suggested that $\S \S 20.1402$ (d)(3), 20.1405(c), and 20.1407(a)(3) should be changed to permit the organization carrying out the post-closure plan to be either the former licensee or an organization that is not independent of the licensee (706).

One commenter recommended that the NRC clarify whether institutional controls and engineered features could be used to meet the $15 \mathrm{mrem} / \mathrm{y}$ and $100 \mathrm{mrem} / \mathrm{y}$ criteria, and explain why it must be assumed that institutional controls and engineered features will in time fail (738). The DOE stated that some restrictions (such as government control) may not require application of the requirement of proposed

$\S 20.1405(\mathrm{~d}),(1279)$.

Another commenter questioned whether a site could be considered for release if it is unable to meet the proposed 
groundwater criterion (132). A different commenter stated that application of a stringent groundwater standard, which is designed for community water systems, to an aquifer beneath a former nuclear site is not logical and is wasteful of society's resources (798).

A commenter recommended that radioactivity be removed from a site and shipped to another site for disposal only if there is a net decrease in the risk to public health resulting from the transfer (168).

Another commenter recommended that spot monitoring be performed both on-site and off-site for a number of years after decommissioning has occurred and that several years elapse before the site is released for restricted use (1239).

\subsubsection{Appropriateness of $15 \mathrm{mrem} / \mathrm{y}$ TEDE}

Commenters opposed $15 \mathrm{mrem} / \mathrm{y}$ as being too high for several reasons, including a need to reduce radioactivity levels to pre-existing background levels $(62,334,421$, $434,436,443,460,462,537,540,849) ; 15 \mathrm{mrem} / \mathrm{y}$ provides inadequate public protection $(5,19,22,25,152$, $950,1229)$ and is not sufficiently conservative $(433,462$, $499,850) ; 15 \mathrm{mrem} / \mathrm{y}$ represents a large increment of naturally-occurring background radiation (496); the proposed limit exceeds the British limit of $10 \mathrm{mrem} / \mathrm{y}$ and ALARA dose of $2 \mathrm{mrem} / \mathrm{y}$ (334); the dose limit is inconsistent with CERCLA's risk goals of $10^{-4}$ to $10^{-6}$ (564); this would possibly establish a precedent to reintroduce the concept of Below Regulatory Concern (BRC) (847); and the NRC previously rejected a proposed BRC limit of $10 \mathrm{mrem} / \mathrm{y}$ which is less than the level now proposed (950).

Commenters opposed $15 \mathrm{mrem} / \mathrm{y}$ as being too restrictive for several reasons, including that the NRC has not technically justified the need for such a conservative limit $(12,13,54,214,233,236,289,309,318,364,375,376$, $377,379,394,603,627,628,667,668,669,670,671$, $717,728,729,730,731,732,747,753,807,808,864$, $1062,1065,1082,1088,1119,1121,1122,1127,1129$, $1133,1135,1147,1154,1165,1199) ; 15 \mathrm{mrem} / \mathrm{y}$ is far below the dose level where health effects have been observed $(75,289,374,399,410,638,1088,1246) ; 15$ $\mathrm{mrem} / \mathrm{y}$ is politically based and not technically based $(102,117,1082)$; it is inappropriate to set a standard based on EPA's $10^{-4}$ to $10^{-6}$ risk range because this was developed for chemical carcinogens and it is unsound to treat radiation risks and chemical risks identically (411, $413,811,812)$; the limit is so low that demonstration of compliance may be difficult or not be possible $(97,550$, $628,656,668,673,733,789,804,1089,1275,1285)$; $15 \mathrm{mrem} / \mathrm{y}$ could be highly costly $(160,215,375,377$, $379,383,550,669,670,747,817,924,1199,1285)$; this limit is within the natural variations and fluctuations of background radiation levels $(215,375,631,637,638$, $639,668,674,677,708,730,807,813,999,1088$, 1275); this would set a precedent for sites containing naturally-occurring radioactive materials (NORM) and the limit cannot be met or is too low if applied to these materials $(373,375,376,378,379,394,395,1276)$; the limit is below the doses received from tobacco, domestic water supplies, natural gas cooking ranges and heaters, and foods such as Brazil nuts $(376,674) ; 15 \mathrm{mrem} / \mathrm{y}$ is smaller than the dose we receive from our own bodies (638); this represents only a small portion of the 100 $\mathrm{mrem} / \mathrm{y}$ recommended by the NCRP and the ICRP (672, $729,806,808,1122,1154)$; it is unnecessary for the $\mathrm{NRC}$ to use a $15 \mathrm{mrem} / \mathrm{y}$ limit to ensure that doses from multiple sources do not exceed $100 \mathrm{mrem} / \mathrm{y}$ because it would be unusual for an individual to be exposed to multiple sources approaching the limit (1154); $15 \mathrm{mrem} / \mathrm{y}$ is inconsistent with recommendations of the NCRP and the $\operatorname{ICRP}(54,57,100,101,115,116,214,215,234$, $289,290,301,313,364,374,383,384,387,544,554$, $641,662,667,672,728,806,1019,1082,1121,1122$, $1153,1165,1174,1177,1182,1305)$ and also inconsistent with present NRC regulations $(55,57,214$, $289,291,388,667,668,806,814,888,898,925,1174$, $1274,1305)$ as well as inconsistent with EPA regulations in 40 CFR Part 190 and 40 CFR Part 191, $(806,888$, $898,1174,1274) ; 15 \mathrm{mrem} / \mathrm{y}$ will become incompatible with future EPA requirements in 40 CFR Part 141, (404); this limit cannot be achieved, or is virtually unachievable, at many facilities $(668,673,745,771,791,1276)$; it would result in the unnecessary transfer of large amounts of wastes or soil to designated disposal sites $(671,673$, 1147,1148 ); and a $15 \mathrm{mrem} / \mathrm{y}$ limit is unduly restrictive compared with the radiation protection standards for radon $(675,677,708,753)$. Several commenters indicated that they were happy that the NRC had deleted the $3 \mathrm{mrem} / \mathrm{y}$ goal from the proposed rule $(191,232,271$, $905,922,1278)$.

Some commenters stated that a dose limit of $15 \mathrm{mrem} / \mathrm{y}$ is about right $(9,79,88,126,128,143,171,410,411,412$, $1217,1218,1243$ ) but cautioned that they did not believe 
that demonstrable health effects were associated with this dose level $(88,143,410,412)$. The EPA supported establishing the dose limit at $15 \mathrm{mrem} / \mathrm{y}$ coupled with a requirement that residual radioactivity from the site should not cause groundwater to exceed the Maximum Contaminant Levels (MCLs) developed in accordance with the Safe Drinking Water Act and specified in 40 CFR Part 141, (1144). Some commenters who supported $15 \mathrm{mrem} / \mathrm{y}$ stated that they did not believe it necessary to perform ALARA analyses to determine if additional cleanup below $15 \mathrm{mrem} / \mathrm{y}$ might be required $(88,128$, 143).

Those commenters who believed the $15 \mathrm{mrem} / \mathrm{y}$ is too restrictive mostly recommended that the appropriate limit be $100 \mathrm{mrem} / \mathrm{yr}$ or a lower level if supported by a sitespecific ALARA analysis (101, 116, 234, 236, 239, 290, $301,309,313,318,364,374,382,384,387,544,554$, $641,662,667,671,713,728,806,921,925,926,1019$, 1160). Some recommended adoption of $500 \mathrm{mrem} / \mathrm{y}$ as the backup limit in the event institutional controls or engineered features fail $(387,806)$. Other commenters recommended that the $15 \mathrm{mrem} / \mathrm{y}$ limit be increased to a value of from 25 to $50 \mathrm{mrem} / \mathrm{y}(13,97,888,898,928$, $999,1062,1064,1066,1147,1174,1177,1273)$. A commenter suggested a value of 25 or $30 \mathrm{mrem} / \mathrm{y}$ plus the ALARA process (1273).

\subsubsection{National/International Consensus Standards}

Many commenters stated that the decommissioning rule should be consistent with the recommendations of the National Council on Radiation Protection and Measurements (NCRP) and the International Commission on Radiological Protection (ICRP) which state, among other things, that public exposures should not exceed 100 $\mathrm{mrem} / \mathrm{y}$ from multiple radiation sources other than background radiation and medical doses $(36,54,55,57$, $100,101,102,115,116,117,216,234,237,250,282$, $289,290,301,364,374,380,383,387,389,400,544$, $554,629,640,641,662,666,667,677,719,728,729$, $780,802,806,921,1011,1012,1019,1045,1082$, $1120,1121,1122,1153,1155,1162,1165,1174,1177$, $1182,1201)$. Some commenters recommended that the NRC adopt a $100 \mathrm{mrem} / \mathrm{y}$ dose limit coupled with an ALARA provision $(234,921,1019,1155)$. Some recommended that a limit of $500 \mathrm{mrem} / \mathrm{y}$ be established as the backup level for restricted release of sites applicable to conditions of loss of institutional controls or engineered features $(248,374,387,1153,1161)$. Other commenters recommended that the dose limit for unrestricted release be reduced to below $100 \mathrm{mrem} / \mathrm{y}$ to account for possible multiple source exposure, but not to assume exposure from as many as 7 sources, as apparently assumed by the NRC in establishing a 15 mrem/y limit $(384,672,729,1174,1177,1273)$. A commenter suggested that a 25 to $30 \mathrm{mrem} / \mathrm{y}$ limit would be an adequate margin to ensure that the primary 100 $\mathrm{mrem} / \mathrm{y}$ dose limit would be met (1273).

A commenter recommended against the NRC's basing its rule on NCRP and ICRP recommendations, because they believed that recent research indicates that adverse health effects from low doses and chronic low doses are substantially greater than accounted for in existing NCRP and ICRP standards $(425,461,495)$. Another commenter disagreed with a $100 \mathrm{mrem} / \mathrm{y}$ standard, because it would be contrary to NCRP and ICRP guidance (362). Still another commenter stated that notwithstanding what the NCRP and the ICRP recommend, the NRC is not justified in allowing 100 $\mathrm{mrem} / \mathrm{y}$ from a site released for restricted use (461). One commenter stated that the National Academy of Sciences has concluded that there is no safe radiation exposure; and accordingly the commenter recommended that the proper limit for the rule is $3 \mathrm{mrem} / \mathrm{y}$ to the maximally exposed individual (850).

One commenter stated that BEIR-V stated that studies of populations chronically exposed to low-level radiation, such as those residing in regions of elevated natural background radiation, have not shown consistent or conclusive evidence of an associated increase in the risk of cancer (638). This commenter also stated that the International Atomic Energy Agency (IAEA) has indicated that a level of dose which is small in comparison to background can be regarded as trivial (639). Another commenter stated that the concept of ALARA does not justify attempts to reduce detriment to levels so low or trivial as to be inappropriate in relation to reasonable priorities for expenditure of health protection resources (724). Still another commenter stated that there is more evidence showing hormetic effects at low dose than detrimental effects (1165).

Commenters stated that the Health Physics Society has stated that remedial action should do more good than harm, that cleanup standards should be based on the 
principle of balancing society costs and risks, and the net benefit to society should be maximized $(215,216,729$, 1179). One commenter also stated that the Health Physics Society has stated that conditions that produce radiation doses and risks to people within the normal range of background should be regarded as natural (631).

One commenter stated that the EPA's Science Advisory Board has issued a report noting that it is unfortunate and unsound that radiation risks and risks from chemical contaminants are often treated identically, because the application of the standard chemical risk reduction criteria to radionuclides leads to limitations on radiation doses that are small in comparison to natural background radiation (640). The commenter also stated that the report went on to say that it should come as no surprise that some scientists see such limitations on radiation exposure as unworkable and even misguided (640).

Some commenters suggested that the NRC has incorrectly referred to ICRP recommendations which distinguish between "practices" and "intervention" and that ICRP guidance for interventions applies to decommissioning $(216,629,667,1121)$.

One commenter indicated agreement with the proposed $15 \mathrm{mrem} / \mathrm{y}$ limit even though it conflicts with recommendations of the NCRP and the ICRP, because it provides a desired additional margin of safety (1218).

\subsubsection{Technical Basis for Criteria Vs. Non- Technical/Political Basis}

Commenters stated that the proposed limit of $15 \mathrm{mrem} / \mathrm{y}$ is too restrictive and does not conform with the technological guidance provided by national and international groups $(57,102,117,364,368,728,780$, $800,802,868,1063$ ). (See discussion also in section 2.3.6 of this report.) Commenters also stated that the proposed criteria are inconsistent with provisions of the present 10 CFR Part 20, (788, 863, 1246). Some indicated that the proposed limit appears to be nontechnically based and not based on a need to protect the public $(12,75,102,117,233,275,283,318,364,720$, $727,780,805,808,1063,1165,1246)$; the NRC should explain the proposed criteria in terms of scientific and factual findings $(714,727,732,858)$.
One commenter stated that $15 \mathrm{mrem} / \mathrm{y}$ should be reduced to a zero release standard and that failure to do so is "politics and business once again coming first" (1252). Other commenters indicated that the proposed limit appears to come from the NRC's stated objective of decommissioning sites to levels approximating background radiation $(275,627,727,785)$; the NRC has not shown that $15 \mathrm{mrem} / \mathrm{y}$ would reduce any significant risk to the public health or the environment $(75,87,143$, $292,308,309,318,368,410,412,414,417,627,638$, $640,720,723,730,732,802,807,813,863,864,927$, $1088,1131,1132$ ); and the NRC's generic ALARA/netrisk analysis is incomplete and inadequate $(283,308$, $309,364,627,719,728,781,814,860,861,864,865$, $871,873)$.

A commenter stated that the NRC's conceptual approach is very similar to that embodied in the Occupational Safety and Health Administration's (OSHA's) so called "carcinogen policy" that since there is no safe level of exposure to carcinogens (the linear theory), regulatory controls should be made as stringent as feasible (730). The commenter also stated that the Supreme Court rejected OSHA's approach and the NRC should base its regulations instead on reducing "significant risks of harm" (730). Another commenter stated that in a DC Circuit decision in an EPA Vinyl Chloride case the court emphasized that "acceptable risk must represent that level of risk that the public is simply unwilling to exceed" (815).

Some commenters argued against using the same riskbased limits for radionuclides that are used for chemical carcinogens (currently at $10^{-4}$ to $10^{-6}$ risk levels) (411, $413,640,781,782,811,812,814,815,1165$ ). (See discussion also in section 2.3 .6 of this report.) Commenters stated that the NRC should base its standards on the experience it has gained in past decommissionings rather than adopt unreasonable and unrealistic standards advocated by other U.S. agencies (783, 801, 803, 1082).

Several commenters argued against the NRC's basing its radiological criteria on the no-threshold theory model for predicting the effects of low-level radiation $(75,87,143$, $292,308,309,318,368,412,414,417,627,638,640$, $720,723,730,732,807,813,863,927,1088,1131$, $1132,1134,1135)$. Some commenters supported the nothreshold theory or a more restrictive theory $(184,425$, $452,465,485,495,499,504,505,952)$ and stated that 
recent research and a 1990 conclusion of the BEIR V report indicate that adverse health impacts of low doses and chronic low doses are substantially higher than are accounted for in existing radiation protection standards $(425,426,447,452,465,495,496,499,514,516)$. Commenters indicated that they would object to any proposed basis for establishing decommissioning standards unless the resulting standard calls for zerorelease of radiation; if another standard is selected they would want a case-by-case consideration of all environmental and social aspects for each site or facility $(83,222,435,452,455,485,496,504,514)$. A commenter stated that a balancing of risks and costs is unacceptable $(514,517)$. In the latter connection, the commenter stated that risks potentially incurred at an offsite storage or disposal site should not be used to offset or discount the health risks at the site being decommissioned (517).

One commenter stated that, contrary to the view of some people, it is proper for the government to impose acceptable risks on individuals; society accepts the imposition of risk by others in everyday life, e.g., drivers who go five miles per hour faster or slower than the norm on a highway (415).

A commenter expressed agreement with the $\mathrm{NRC}$ that limiting individual doses will ensure that collective dose will be acceptably small (1164).

\subsubsection{Effective Use of Resources}

Commenters indicated that the proposed radiological criteria are too restrictive and recommended that the Commission adopt different standards that offer a better balance between the specified risks and the costs associated with their reduction $(10,13,74,77,87,97$, $143,146,160,161,207,216,235,236,275,292,308$, $312,367,368,375,377,379,381,385,390,397,399$, $401,402,409,417,550,626,663,669,717,719,721$, $722,733,747,779,816,817,897,905,924,1047$, $1089,1135,1137,1138,1147,1165,1199)$.

A commenter expressed hope that the final rule will provide adequate protection of the public without crippling industry or the economic health and competitiveness of the United States (77).
One commenter stated that cost should not be used as an argument for not adopting a stringent decommissioning requirement; primary emphasis should be on minimization of public risk; and cost/benefit analyses should not be used to justify decommissioning actions $(448,460,497,501)$.

Some commenters stated that the NRC had not properly assessed the need for and cost for waste disposal space and removal $(398,721,1147)$ and for verification measurements to determine that the proposed $15 \mathrm{mrem} / \mathrm{y}$ limit has been met $(293,628,820,1089,1199,1285)$. Other commenters stated that it is not in the public interest to spend large amounts of public funds for remediation of calculated public health detriment that is too small to be observed $(216,417,1042)$. Another commenter objected to demonstration of ALARA between $15 \mathrm{mrem} / \mathrm{y}$ and $3 \mathrm{mrem} / \mathrm{y}$ on the belief that this will provide little or no reduction in risks to the public and would be an unwise utilization of resources (271).

A commenter stated that without quantitative decisionmaking tools, such as the $\$ 1,000$ /person-rem used for Appendix I of 10 CFR Part 50, disproportionate and unwarranted resources will be expended to reduce meaningless risks (1248).

A commenter recommended deletion of the requirement that all readily removable residual radioactivity must be removed from a site prior to initiation of decommissioning, because it creates a redundancy in decommissioning that is not cost-effective (266).

Another commenter stated that resources would be wasted if separate characterization plans are prepared for radioactive materials and non-radioactive pollutants, and recommended that a single plan be required (349). Still another commenter stated that if a licensee has prepared a site characterization plan prior to the final rule, it would be a waste of resources to require a new plan to meet the new criteria (1017).

A commenter supported establishment of separate standards for unrestricted and restricted release because the flexibility provided would allow resources to be directed toward innovative cost-effective solutions (175, 203).

Some commenters objected to the phrase "prohibitively expensive," used in $\S 20.1405$ (a), because it could create inequities between licensees and result in an unbalanced economic environment $(295,556,1042)$. Another 
commenter stated that the rule must encourage economic certainty, particularly for utilities who are planning decommissioning into the future (566); and the licensee should be given the expectation that all costs for decommissioning must be borne by that party $(423,567)$.

A commenter indicated that a site should not be reopened unless it can be conclusively shown that a real risk to public health exists and that by re-opening there is a positive net benefit to society (249).

Some commenters stated that the proposed Site Specific Advisory Boards could cause the costs of decommissioning to be increased $(60,108,123,211)$.

One commenter stated that the $15 \mathrm{mrem} / \mathrm{y}$ limit is high enough that unreasonable cleanup costs should be avoided (410).

\subsubsection{Other Issue-Related Comments}

One commenter stated that the concepts in $\S 20.1402$ are inappropriate for inclusion in a regulation and should be moved to regulatory guidance (994); alternatively, the rule should state that the concepts are not themselves enforceable provisions (994).

A commenter agreed with the NRC that the radiological criteria designed to protect public health should also provide adequate environmental protection (1068). The commenter suggested that the language of the proposed rule be carefully reviewed and changed in $\$ \S 20.1402$ (c), 20.1405(a), and 20.1407(a)(1) to remove references to environmental risks or harm (1068). Another commenter stated that the regulation should ensure protection of both the public and the environment (307).

Several commenters recommended that the rule not propose to regulate radon, or expressed concerns about the complications introduced by such regulation and the fact that background radon levels are so high; i.e., the proposed standard of $15 \mathrm{mrem} / \mathrm{y}$ is less than one tenth of the EPA standard for indoor radon $(200 \mathrm{mrem} / \mathrm{y})$ that is recommended for all houses in the United States (241, $393,400,407,650,651,675,676,677,707,708,743$, $744,753,769,770,771,775,776,778,797,837)$. Other commenters recommended that the rule cover radon doses at decommissioned sites $(454,476)$. Some commenters indicated that the rule is not clear on whether doses from radon are included or excluded from consideration $(768,776,797,837)$.

A commenter objected to a statement in the GEIS that a licensee would be required to meet the chemical hazard standards of federal, state, or local agencies before the NRC will terminate its license (755). The commenter stated that it is unclear under what authority the NRC could withhold license termination (755). Another commenter stated that licensees must include all radiological and other adverse health and environmental impacts in their decommissioning plans (854).

A commenter recommended that the NRC ask Congress to amend the Nuclear Waste Policy Act of 1982 to allow federal ownership of extensively contaminated sites as the best means of ensuring long-term protection of the public (648). Another commenter recommended that the NRC ask Congress to provide federal assistance to help defray the cost of decommissioning nuclear sites (209); it would be reasonable for society to provide funding if substantial costs are caused by shifting society norms for the treatment of radioactive materials (209). One commenter stated that all costs of decommissioning must be borne in full by the licensees $(853,856)$. Another commenter stated that a uniform and comprehensive decommissioning rule would have permitted utilities to better estimate the true costs (566).

One commenter stated that it will be virtually impossible for a complex site to meet the time frames for completing the decommissioning process (752). Another commenter stated that site specific schedules should be required in decommissioning plans; these should be submitted to the NRC well in advance of termination of operations and require full NRC approval prior to the start of actual decommissioning actions (521). Other commenters stated that a full-scale site-specific EIS should be required of each decommissioning and decontamination plan (422, 522, 524). Another commenter stated that licensees should not be required to prepare site-by-site environmental analyses (1204).

A commenter objected to the promulgation of radiological criteria by the NRC which commit future generations to risks without their receiving any future benefits (481). The commenter stated that the NRC should bring about an orderly conclusion to the operating life of nuclear facilities, and should not license any new nuclear activities (486). Another commenter stated that a 
cost/benefit analysis would favor solar energy over nuclear energy (429).

A commenter strongly supported the risk-based approach, including risks to radiation workers, risks associated with transportation and waste disposal, and risks of damage to ecosystems and wildlife $(1260,1262,1271,1274,1281)$.

Another commenter expressed the belief that inadequate thought has been given by the NRC to possible risk scenarios during cleanups, specifically with respect to possible releases of radiological material and other toxins during cleanup (1237). The commenter stated that the NRC should always require a structure to be built over the contaminated site if there is material that could be blown about by the wind, and in addition, require strict monitoring to ensure against the spread of contamination (1237). This commenter also recommended that the NRC require the expediting of decontamination and decommissioning tasks so as to limit the possible spread of contamination (1240).

One commenter suggested changing the word "radioisotopes" to "radionuclides" in $\S 20.1402$ (c) and throughout 10 CFR Part 20, (1067).

\subsection{General Provisions, § 20.1403}

\subsubsection{Calculations of TEDE to 1000 years}

Commenters objected to the proposed 1000-year time frame for calculating dose estimates; some recommended that the time be lengthened, and some recommended that it be shortened. Those who wanted it lengthened recommended that reasonable efforts be made to predict the health effects over the hazardous life of each radioisotope $(151,464,503,516,538,572,953,1093$, 1094,1235 ). One commenter noted that the buildup of daughter products might cause the maximum dose from some radionuclides to occur after more than 1000 years $(1093,1094)$. Those who wanted it shortened $(14,834$, 1289) recommended that the time frame be 500 years consistent with 10 CFR Part 61, (14), or 200 years consistent with 10 CFR Part 40, Appendix A, Criterion 6, (834). The DOE recommended that the NRC consider other time frames, as appropriate, depending on the nature of the radioactive materials (1289). One commenter recommended that the wording in
$\S 20.1403$ (a) make clear that licensees must demonstrate that the remediation will protect groundwater sources at the specified EPA limit over the 1000-year period (573). Another said that, in a 1000-year time frame, the cost effectiveness of the application of the EPA drinking-water standard is dubious and should be examined (1047, 1051).

Commenters recommended that the NRC provide guidance for making confirming measurements, which does not call for actual measurements of all surfaces when it can be demonstrated by documentation of data and history of operation of facilities that the level of residual contamination is acceptably low $(14,323)$. Another commenter recommended that the second sentence of $\S$ 20.1403(a) be changed somewhat so as not to imply that measurements must be made throughout the 1000-year period (546).

\subsubsection{As Low as Reasonably Achievable (ALARA) Analysis Determinations}

Commenters recommended that the rule allow ALARA analyses to be used to determine if a dose rate up to 100 $\mathrm{mrem} / \mathrm{y}$ can be applied at a site $(382,1139,1157)$. A commenter recommended that ALARA analyses be applied only to demonstrate if additional cleanup is required below $15 \mathrm{mrem} / \mathrm{y}(570,597)$.

Two commenters disagreed with the determination that 3 mrem/y demonstrates ALARA, because the NRC's analysis is based on unrealistically low waste costs and there is an absence of evidence of health effects at low doses $(309,314)$. Some recommended that the NRC reinstate $3 \mathrm{mrem} / \mathrm{y}$ as the decommissioning objective, and possibly this should be reduced to $2 \mathrm{mrem} / \mathrm{y}(359,433)$. A commenter cautioned against the use of the restricteduse criteria to avoid complete remediation to ALARA levels (597).

A commenter stated that the NRC needs to address clearly the cost impact of reducing doses below the limits, both in dollars and in additional exposures and health risks to workers with no realistic gain in benefits to the health of the public (1263). The supporting documentation needs to consider and balance radiological and non-radiological risks as an integral part of the standard development process and also as part of a sitespecific ALARA process (1263). 
An Agreement State Department of Nuclear Safety stated that the ALARA provision is important to Agreement States in order to take account of local conditions, but it should not be considered as indicating a need for states to be more restrictive than the federal rule requires (39).

A commenter stated that ALARA analyses should consider only the risks associated with decommissioning, and not the costs to licensees; costs should not be used to justify financial tradeoffs and licensee profits $(445,471$, $512,517)$. The commenter stated that the potential risks at the off-site storage or disposal site also should not be used to offset or discount a health risk at the site being decommissioned (517). In addition, the commenter stated that the ALARA analysis should not be based on the possible exposure received by the average member of the critical group because an individual may then receive doses above the limit (463).

Commenters questioned the use of the term "significant risks" as used in proposed $\S 20.1403$ (b), (538, 933). One stated that all risks should be considered and not just significant ones as decided by NRC (538). The other commenter requested that this term be defined and quantified (933).

Commenters recommended that the NRC provide flexibility in the determination of valid modeling and parameter selection $(406,1277)$; allow demonstration of ALARA without the need for complex pathway and dose rate analysis (1157); permit licensees to take into account the costs and benefits of each incremental reduction in radioactivity and to incorporate reasonable exposure assumptions $(551,555)$; and permit licensees to take into account institutional and engineered controls (555). Commenters also recommended that the NRC clarify the differences between ALARA as it has been used in 10 CFR Part 50, Appendix I and in 10 CFR Part 20 contexts to date and how it is to be used in the proposed rule ( 987 , 1125). Another commenter questioned in relation to NUREG -1500 what relevance "hot spots" have in making an ALARA assessment (765).

A licensee commenter submitted a report of an ALARA analysis for a uranium refining site which demonstrates that the volume of soil that would require excavation and removal increases exponentially with reductions in decommissioning criteria, and that both existing and proposed criteria require more decommissioning effort than an ALARA analysis would justify (1303).

\subsubsection{Readily Removable Residual Radioactivity}

A commenter questioned the meaning of "remove all readily removable residual radioactivity" as used in $\S 20.1403$ (c), (192). Another said that the provision is unnecessary and should be deleted (266). One suggested that the NRC provide specifications for the required extent of decontamination and the acceptable levels of radioactivity permitted to remain at a site (192). A commenter suggested that there might be situations where no remediation should be required (764). A commenter suggested that the concept of residual radioactivity be dropped and licensees be required to return a site to its pre-licensing state of natural background $(511,512)$. The subject of "good practices" should be addressed in guidance documents, not in the rule (931).

\subsubsection{Groundwater Limit}

Many commenters objected to the NRC's applying the EPA's drinking water standards in 40 CFR 141 to groundwater $(38,45,105,120,132,198,202,242,404$, $678,679,798,836,888,899,931,988,1001,1011$, $1016,1047,1048,1049,1050,1052,1053,1080,1158$, $1170,1174,1206,1258,1290$ ). The reasons for the objection were that a single dose limit standard should be applied by the NRC to all exposure pathways and a separate limit is not needed for groundwater $(38,132$, $198,202,678,798,836,888,899,931,988,1016$, $1047,1049,1053,1080,1158,1170,1174,1258)$ and that the EPA's drinking water standard is improper to use or its use may not be cost-effective $(45,105,120,404$, $679,836,1001,1011,1016,1047,1048,1049,1050$, $1052,1206)$.

Commenters stated that standards already exist for protecting groundwater from uranium recovery facilities under 40 CFR Part 192, Subpart D and draft regulatory guidance on Alternate Concentration Limits (105, 120). Another commenter stated that regulations for protecting groundwater in uranium in-situ leaching operations are contained in 10 CFR Part 40, Appendix A, (242). Others stated that the proposed new requirement would be duplicative $(105,120,242)$. Reasons given for opposing the application of 40 CFR Part 141 standards included that it was not promulgated to apply to groundwater, but rather was promulgated to appiy to a community water system, which serves 25 year-round residents, and 
regulates the quality of water coming out of the tap (105, $120,202,678,679,836,1016,1050,1170,1268)$; the Maximum Contaminant Levels (MCLs) contained in 40 CFR Part 141 include background contributions and are highly restrictive $(132,202,679,787,798,836,988$, 1048 ); no cost/benefit analyses have been made of the application of 40 CFR Part 141 to groundwater (679, 988, 1016, 1047, 1049, 1050, 1051, 1053); and the EPA's standards in 40 CFR Part 141 are based on obsolete dosimetry and are in need of revision $(45,1052)$.

Other commenters supported the NRC's establishing a separate groundwater standard $(337,344,428,518,573)$ and recommended that the rule should require strict compliance with 40 CFR Part 141 standards for protection of groundwater supplies $(337,344,518,573)$.

The EPA commented that the NRC should establish a groundwater standard set at the levels specified in 40 CFR Part 141, (1144, 1145). Other commenters stated that the EPA does not have legislative authority to promulgate binding groundwater protection regulations; rather their authority is derived from the Safe Drinking Water Act which limits their consideration to water coming out of the tap $(836,988,1001,1016)$.

Commenters stated that the phrase "current or potential source" of drinking water used in proposed $\S 20.1403$ (d) should be explained $(836,1170,1268$, 1290). Guidelines should consider physical characteristics of groundwater quality, potential aquifer yield, and current groundwater uses $(553,679,836$, 1170). A commenter suggested that the NRC explain how one demonstrates "reasonable expectation" that residual radioactivity from the site will not cause unacceptable contamination of groundwater (1290).

Commenters questioned whether the proposed NRC groundwater standard was intended to apply to both restricted and unrestricted release scenarios or only to the unrestricted release scenario $(132,836,1170)$. One commenter stated that licensees should be able to propose site specific alternate concentration limits when compliance with the MCLs cannot be practically achieved (836), or alternatively the NRC should permit acceptance of institutional controls (e.g., prohibitions on well drilling, deed restrictions, etc.) and engineering controls (e.g., plugging existing wells or other containment methods) $(608,618,836)$.

\subsubsection{Planned Restricted Release}

Some commenters objected to any planned restricted release of decommissioned sites and indicated that sites should be returned to pre-existing, naturally-occurring background levels $(424,430,437,451,473,484,494$, $500,502,522,523,539)$. Other commenters supported the proposal to permit a restricted release of decommissioned sites $(608,618,632,664,680)$. One commenter stated that the NRC has placed so many onerous requirements on the restricted land-use option that it has effectively precluded its use for many facilities where that option would be in the public interest (680). (See discussion also in section 2.3.4 of this report.)

With regard to the provisions of proposed $\S \S 20.1403$ (e) and $(f)$, commenters recommended that the last sentence of each paragraph be deleted concerning establishment of and interaction with a Site Specific Advisory Board (934, 1069). One commenter recommended that a decommissioning plan and establishment of an SSAB be required for all decommissioning, including unrestricted release cases as well as restricted release cases (539). Another commenter recommended that an SSAB be required only when a licensee proposes to release a site for restricted use (1159).

Commenters recommended that the NRC permit licensees to defer submitting a decommissioning plan until after nuclear operations are shut down and require licensees at that time to perform a thorough site characterization to determine whether a site can be decommissioned for unrestricted release or will be required to be released for restricted use $(1169,1171)$. Other commenters stated that the NRC should simplify and streamline its site characterization requirements $(655,634,698)$. Commenters stated that unless this is done licensees may initially expect to release the site for unrestricted use, but later find out that unrestricted release cannot be accomplished $(938,1169,1171)$. One commenter stated that the rule should permit a licensee to submit one decommissioning plan to cover an entire licensee site, and the timing should be tied to the expiration of the last operating license for that site (1167). Other commenters stated that a decommissioning plan should be submitted to the NRC before any decommissioning activities are undertaken (1087), and this plan as well as a plan to establish an SSAB should be submitted early on (539). 


\subsection{Radiological Criteria for Unrestricted Use, $§ 20.1404$}

\subsubsection{Limit of $15 \mathrm{mrem} / \mathrm{y}$}

Some commenters stated that the proposed unrestricted release limit of $15 \mathrm{mrem} / \mathrm{y}$ should be made more restrictive $(5,19,22,25,334,462,496,537,540)$. Others indicated that the proposed limit should be increased up to $100 \mathrm{mrem} / \mathrm{y}(57,233,234,236,318$, $364,373,374,375,376,377,379,382,383,384,395$, $399,544,554,631,638,641,668,669,670,671,672$, $673,674,675,677,713,731,732,745,807,864,888$, $898,926,1062,1066,1160$ ). Still others stated that the proposed limit of $15 \mathrm{mrem} / \mathrm{y}$ appeared to be an appropriate value $(9,79,88,126,128,143,171,410$, $1144,1217)$, including the EPA (1144). (See discussion also in section 2.3.5 of this report.) The commenters who opposed $15 \mathrm{mrem} / \mathrm{y}$ as too restrictive a standard also opposed applying ALARA to achieve still lower levels. Also, some who supported establishing $15 \mathrm{mrem} / \mathrm{y}$ as the standard for unrestricted release stated that ALARA should not be applied below this dose value $(88,128$, 143, 1283).

\subsubsection{Residual Radioactivity Reduced to ALARA}

Although some commenters endorsed the promulgation of a decommissioning dose standard of $15 \mathrm{mrem} / \mathrm{y}$ or the achievement of a lower dose level through ALARA efforts $(9,171,333,334,340,352,359,436,570,597)$, several stated that ALARA analyses are not meaningful at such dose levels $(88,128,143,236,309,671,724,809$, $810,865,869,999,1000,1263,1286)$. A commenter stated that guidance should be provided that describes how ALARA should be achieved (1284, 1286). Commenters also objected to establishing $3 \mathrm{mrem} / \mathrm{y}$ as the ALARA objective $(900,902,904,926,1266,1278)$. Commenters who favored $15 \mathrm{mrem} / \mathrm{y}$, with ALARA, requested that the $\mathrm{N} \cdot \mathrm{RC}$ explicitly mandate that technical and economic analyses be performed $(339,436)$.

A number of commenters recommended that the decommissioning dose standard be established at 100 mrem/y with further reductions required ALARA (234, $236,365,368,926$ ). (See section 2.3 .5 for additional discussion of this subject.) A commenter suggested that the NRC adopt a 25 to $30 \mathrm{mrem} / \mathrm{y}$ dose constraint plus the ALARA process $(1273,1281,1283)$.

A commenter stated that the risks and benefits of applying a specific ground-water standard needs to be assessed under the ALARA process and should consider worker risks as well as public and environmental risks (1290).

A licensee commenter submitted a report of an ALARA analysis for a uranium refinery site which demonstrates that the volume of soil that would require excavation and removal increases exponentially with reductions in decommissioning criteria, and that both existing and proposed criteria require more decommissioning effort than an ALARA analysis would justify (1303). The report indicated that, for the proposed criteria, the cost per person-rem avoided ranges from $\$ 24,000$ to $\$ 100,000$ at that site (1304).

\subsubsection{Other Issue-Related Comments}

A commenter requested that proposed $\S 20.1404$ be clarified to indicate its applicability to material or equipment decontaminated as a result of the decontamination and decommissioning process (935). The commenter also recommended that the section include provisions for partial unrestricted releases of structures, material, soil, groundwater, and other media at the site (935). Another commenter requested that proposed $\S 20.1404$ allow for post release decay of residual radioactive materials (1140).

\subsection{Criteria for License Termination Under Restricted Conditions, $§ 20.1405$}

\subsubsection{Acceptability Criteria}

Commenters stated that the provisions of proposed $\S 20.1405$ (a) are structured so narrowly that few sites will qualify for license termination under restricted conditions $(680,681,685,737,786,907,1011,1015,1040,1042$, $1044,1084,1160)$. Commenters indicated that they had concerns with all three terms used in this paragraph "prohibitively expensive" (556, 652, 838, 907, 1015 , $1044,1070,1244,1247)$, "technically achievable" (571, $652,680,838,907,1044,1247)$, and "net public or environmental harm" $(763,936,1015,1044)$. 
Commenters stated that these terms should be explained, deleted, or replaced with a requirement that restricted release be justified by an ALARA analysis $(556,652$, $664,680,838,1040$ ). Other commenters requested that the paragraph permit restricted release under conditions of continued ownership and industrial use of a site (597, $681,907,1015,1044)$. One commenter recommended that sites be kept under restricted conditions of use even if cleaned up to $15 \mathrm{mrem} / \mathrm{y}$ (79). Another commenter suggested that the final rule provide an option to decommission whereby the original holder of the license meets the radiological criteria for restricted conditions of use and is then issued a holding license (907). Still another stated that a licensee should not be required to meet the conditions for restricted release if it continues to control access to a site (647).

\subsubsection{Institutional Controls}

Several commenters opposed or expressed concern about the use of institutional controls to provide needed protection at decommissioned sites $(6,363,473,500$, $523,574,596,598,600,601,739,740,757,953,962$, $968,1107,1186)$, because these cannot be enforced indefinitely into the future $(473,500,739)$; restrictive covenants may be struck down $(523,739)$; easements may be broken $(523,739)$; and companies which generate the waste should remain responsible for any subsequent damage (473). One commenter described the use of institutional controls as " . . a an admirable concept, yet has always proven, in practice, to be ineffective" (1107).

One commenter opposed reliance on institutional controls because of uncertainties about the permanency of restriction at sites under private ownership, and recommended that the Federal Government assume ownership $(739,740,757)$. It was recommended that the NRC, the EPA, and the DOE seek a legislative solution to long term control at complex sites, similar to that set forth in Section 151 of the Nuclear Waste Policy Act of 1982 , $(740,757)$. The DOE stated that some restrictions (such as federal or state control) may not require application of the requirements in proposed $\$ 20.1405$ (d), (1279). Other commenters favored reliance on institutional controls and recommended that the rule provide more flexibility in their use, i.e., do not assume that these will eventually fail $(210,606,608,618,620,621,633,683$, $990,1015,1041,1265)$. Commenters recommended that the NRC establish guidelines or permanence criteria for such controls $(608,1265,1280)$. One commenter suggested that doses resulting from failure of institutional controls would not be a concern if the limit was set at 100 mrem/y TEDE coupled with an ALARA requirement (929).

Commenters recommended that proposed $\S 20.1405$ (b) not exclude engineering controls from qualifying a site for restricted release $(243,244,606,1211)$. Other commenters recommended that the term "reasonable assurance" in this proposed paragraph be explained or deleted $(523,1071)$.

\subsubsection{Financial Assurance}

A commenter stated that the proposed requirements for financial assurance are inadequate; the commenter recommended that licensees be required to provide the community with resources needed to evaluate past licensee performance, to perform continuing environmental monitoring, to disseminate information on the decommissioned facility, and to perform community education (361). Another commenter stated that the rulemaking should require sureties or other financial guarantees against future liability (599).

A commenter stated that the financial assurance provisions should be deleted "in order to provide flexibility to licensees" (990). This commenter and others recommended that the licensee be permitted to carry out responsibilities for necessary control and maintenance of a site rather than being required to use an independent third party as proposed in $\S 20.1405$ (c), $(706,937,990)$.

A commenter questioned the enforceability of the financial assurance provisions in the event companies become insolvent (958). Another commenter stated that the NRC could assure adequate long-term surveillance by requiring the licensee to establish a long-term surveillance and enforcement trust fund sufficient to finance periodic inspection by the state or local government indefinitely (621). Still another suggested that the financial assurance provisions be broadened to include equity value of a facility as an acceptable mechanism (1141). 
One commenter stated that unless solutions are provided for disposal of NORM wastes at reasonable costs, organizations will not have the resources necessary to manage these wastes on-site in perpetuity or to pay for their cleanup and disposal off-site (398).

The EPA stated that it was concerned with the level of detail provided in the rule on financial assurance (1145).

\subsubsection{Maximum TEDE of $100 \mathrm{mrem} / \mathrm{y}$}

Some commenters agreed with establishing a maximum TEDE of $100 \mathrm{mrem} / \mathrm{y}$ in the event institutional controls are no longer in effect $(201,392,545,557,1077,1078$, $1172,1201)$; some believed a lower value should be applied $(6,19,22,25,91,362,363,461,473,502,541$, $564,851,953,956,1185,1228,1250)$; and some believed a higher value on the order of $500 \mathrm{mrem} / \mathrm{y}$ should be used $(392,840,1046,1161)$. Several recommended that $100 \mathrm{mrem} / \mathrm{y}$ be applied, but that credit be given to institutional controls, i.e., the rule should not bar their use in demonstrating compliance with the 100 $\mathrm{mrem} / \mathrm{y}$ limit $(557,558,608,613,618,619,620,622$, $623,642,644,682,997,998,1015,1043,1084,1279)$. Other commenters recommended that the limit be expressed as a product of dose and probability that institutional controls and engineered barriers fail (682, 1046).

Of those commenters who opposed $100 \mathrm{mrem} / \mathrm{y}$ because they believed this limit to be too high, one supported a safety net limit of $15 \mathrm{mrem} / \mathrm{y}(1228,1230)$, one supported a safety net limit of $30 \mathrm{mrem} / \mathrm{y}(1185)$ and one supported a safety net of 50 or $75 \mathrm{mrem} / \mathrm{y}$ (1216). None of the other commenters who responded to the $100 \mathrm{mrem} / \mathrm{y}$ proposed limit supported a lower value; some specifically stated that they did not support going to $75 \mathrm{mrem} / \mathrm{y}(269,502$, $841,1074,1078)$. One commenter noted that EPA's proposed rulemaking for 40 CFR 196 provides a 75 $\mathrm{mrem} / \mathrm{y}$ limit for release of federal facilities and for consistency both the EPA and NRC proposed regulations should be the same (1300).

Commenters, who recommended that the rule not assume that institutional controls fail, recommended that proposed $\S 20.1405$ (d) be deleted or substantially modified to provide flexibility and give credit for their use $(558,606,608,613,618,619,620,622,623,642,644$. $682,738,997,998,1041,1084)$. A commenter stated that no such assumption is required for 10 CFR Part 61 facilities or by Part 40, Appendix A facilities (620). Another commenter recommended that proposed $\S 20.1405$ (d) be revised to apply only to sites where institutional controls capable of enforcement for more than 100 years can not be established (622). A commenter stated that the NRC should establish longevity criteria for institutional controls $(598,608)$.

Several commenters objected to the last sentence of proposed $\S 20.1405$ (d), which states that licensees may not assume any benefits from an earthen cover or other earthen barriers unless specifically authorized by the Commission and recommended that the sentence be deleted $(243,244,619,622,623,642,644,684,738$, $744,839,997,998,1085,1208,1291)$. Some commenters recommended that the NRC specify the extent to which licensees may take credit for the protection afforded by engineered barriers in the event institutional controls fail $(243,619,622,623,684$, 1291). Another commenter recommended that the NRC prepare a separate rule to incorporate graded criteria for on-site disposal options, including the use of covered burial similar to criteria contained in the NRC Branch Technical Position "Disposal or On-site Storage of Thorium or Uranium from Past Operations" (392).

\subsubsection{Other Issue - Related Comments}

Commenters expressed a range of views on how the NRC should address the "tens of sites" which contain large quantities of radioactive materials and which may best be protected by onsite stabilization and disposal $(1,2,430$, $483,484,494,685,687,1043)$. The Commission specifically solicited comments on how these sites should be handled (59 FR 43217 of the proposed rulemaking). A commenter objected to exempting these facilities from the decommissioning standards and stated that the rulemaking should cover all decommissioning cases, including these, and objected to the NRC's allowing onsite stabilization and disposal at these sites $(430,483$, $484,494)$. Other commenters stated that these sites should be specifically addressed in the rulemaking and applicable requirements or exemptions should be explicitly stated $(685,687,1043)$. One commenter commended the NRC for not addressing these sites in the text of the proposed rule (4). (See also sections 2.2.1 and 2.2.5 of this report for additional discussion of this subject.) 
One commenter stated that, in determining that a site meets the prescribed conditions for restricted release, licensees should not be required to use implausible and overconservative intruder scenarios (1045). One commenter suggested that the original holder of the operating license meet the radiological criteria for restricted conditions and then be issued a holding license under NRC or state regulations (908).

\subsection{Notification and Public Participation, § 20.1406}

\subsubsection{Public Notifications}

Several commenters supported the public notification requirements in proposed $\S 20.1406$ (a), $(44,107,122$, $177,256,275,507,542,575,658,799,842,1032$, $1103,1104)$. One commenter stated that the proposed notice and solicitation of comments requirements are more than what is required by the Administrative Procedure Act and that the NRC has not shown a compelling need for these requirements (1030).

Other commenters stated that the NRC should provide notice sufficiently far in advance so that interested persons and organizations can plan to participate fully in these activities (575). One commenter recommended that the proposed new requirements be applied to all decommissionings and that the NRC not require these only in connection with decommissioning plans for restricted release of a site (542). This commenter also stated that publicizing the notice in only one newspaper is not sufficient notice and recommended that the rule require that periodic meetings be held to keep the community updated on changes made in a decommissioning plan (542).

\subsubsection{Use of Site Specific Advisory Board}

Some commenters supported the proposed requirement in $\S 20.1406$ (b) that would require licensees to convene a Site Specific Advisory Board (SSAB) $(16,18,20,74$, $177,442,456,469,507,539,542,590,945,946,970$, $971,1183,1188,1197,1198$ ), while others objected to the use of a SSAB in each case involving a restricted release of a site $(59,61,107,109,122,124,211,253$, $254,257,258,273,299,310,315,319,547,636,658$, $659,699,700,749,751,799,842,843,890,909,914$,
$979,980,981,982,983,985,1002,1004,1005,1006$, $1007,1011,1026,1031,1032,1034,1035,1069,1073$, $1149,1171,1180,1182,1203,1207,1244,1249)$. Some commenters suggested that SSABs be used in special instances $(43,254,299,547,636,658,749$, 1069,1182 ). Some of those supporting the use of SSABs recommended that they be required also for unrestricted release of sites $(469,507,970,945)$. One commenter questioned assignment of technical duties to the SSAB (1297).

Commenters stated that the use of SSABs is inconsistent with the NRC's rule on timeliness of decommissioning $(61,109,124,211,254,704,1081,1203)$. Other commenters stated that if SSABs are required, affected licensees who use them may need to be excluded from the time requirement, or possibly the time devoted to SSAB activities should be excluded (704, 1037, 1081, 1203).

\subsubsection{Other Issue-Related Comments}

Commenters stated that it is important not only for the public to be informed about decommissioning actions but also to be able to participate effectively in site decommissioning activities; in addition to public participation in SSAB activities, a mechanism should be provided to assure public participation by others in all decommissioning cases $(441,472,506,563,565,568$, $579,580,581,584,1103,1104,1106,1236)$. A commenter stated that there should always be a public hearing before a licensee's decommissioning plan is approved (1236).

Commenters suggested that in place of a requirement to convene an SSAB in each restricted release case, an alternative might be to add a requirement for licensees to address this issue in a proposed public participation plan submitted to the NRC for approval $(316,319,322,587$, $590,890,911,913,914)$.

A commenter suggested that the cost of public participation not be borne solely by the licensee (320). Other commenters believed that licensees should bear the full economic burden of implementing the public participation program $(442,593)$.

Commenters recommended that licensees be required to establish a fund, whenever there is demonstrable residual contamination at the time of license termination, to permit 
the community to evaluate past operation, perform continuing environmental monitoring, disseminate information to the community, and perform community education $(336,342,361)$.

One commenter stated that public participation procedures need to be specified not only for decommissioning cases but also for active waste management sites (578). Another commenter stated that it is inappropriate to have requirements on community relations in NRC health and safety regulations (1025).

Other commenters recommended that the NRC require licensees to make public all relevant documents about environmental releases and contamination that occurred during the period of facility operation and the period of decommissioning $(335,341,360,542,562)$.

A commenter requested that the NRC also clarify its role in public outreach for decommissioning cases (1028).

A commenter stated that the requirement in the proposed $\S 20.1406$ for public participation upon receipt of a decommissioning plan should be changed. Exemption from this requirement should be provided to licensees who are providing a decommissioning plan at the time of license application in support of financial surety obligations and for those who have demonstrated the ability to decommission for unrestricted release even if remediation efforts are required (317).

\subsection{Site Specific Advisory Board, $\S \mathbf{2 0 . 1 4 0 7}$}

\subsubsection{Responsibilities/Activities}

Commenters recommended that SSABs be given responsibilities beyond those specified in proposed $\S 20.1407$ (a), $(18,20,24,27,43,472,507,509,559$, $576,947,1193,1224,1227,1236,1251)$. Proposed additional activities included: give advice on and monitor the development of licensees' decommissioning and decontamination plans $(507,1236)$, participate in the review of studies pertinent to the decommissioning (947), check on compliance with decommissioning documents $(18,20,24,27)$, determine the adequacy of the decontamination (472), evaluate the selection and adoption of particular institutional controls (576), evaluate present and potential future land use (559), carry out ongoing surveillance of a site $(509,1224,1227)$, enforce the cleanup of a site (1251), and comment on any other matter relevant to decommissioning that may be suggested by the licensee, the NRC, or the SSAB membership $(43,1193)$.

Other commenters stated that the rule should restrict SSAB activities to a specific mission which is advisory only $(16,559,701,702,748,844,845,1037,1297)$ and non-technical $(1180,1297)$; SSAB activities should not extend to giving advice on the technical aspects of how to decommission a site (702), what is technically achievable (1180), and whether adequate financial assurance has been provided by the licensee (559). A commenter stated that many of the proposed SSAB issues that are listed appear to require specialized expertise that members of the general public might not have (1297). Commenters stated that unless the rule clarifies that the SSAB is advisory only it will appear that there is impermissible delegation of responsibility to a non-government body and an inappropriate infringement into the role of licensee management $(261,748,984,1037)$. Commenters suggested that the role, components, and scope of SSAB activities be clarified $(304,659,759,1297)$.

In addition, commenters requested that the NRC make the following changes to improve clarification of proposed $\S$ 20.1407(a): in $\S 20.1407(a)(1)$ replace "ways" with the phrase "acceptable processes" and define "net public or environmental harm;" and in $\S 20.1407$ (a)(2)(iii) replace "undue" with the phrase "unnecessary or excessive health and safety requirements" $(936,939,940)$.

\subsubsection{Membership}

Commenters recommended that the rule stipulate that membership on the SSAB be balanced; the proposed rule appears to be disproportionately weighted toward special interest representatives $(274,298,1190)$. Commenters stated that the rule should but does not restrict membership to the local community who may be directly affected by the decommissioning activities $(260,703$, $750,912,1039$ ). Another commenter suggested that the term "affected community" in proposed $\S 20.1407$ (b)(1) be defined (273).

Commenters recommended that membership on the SSAB be offered also to a representative of the potential 
waste recipient community $(169,469,760)$, to a member of the local government which has jurisdiction for land use planning (585), and to a representative of people along the waste transport routes (469). One commenter stated that membership should be decided by the boards themselves (43), while another stated that SSABs should not do this (1190).

One commenter recommended that the NRC delete the rule provisions that describe the functions and staffing of an SSAB (910). Another recommended that the size of the SSAB be flexible, e.g., 10 to 15 members (1190). Another recommended that membership be limited and based on specifics at a particular site (1182). One commenter recommended that membership be restricted to duly elected government officials, and perhaps to Native American representatives (1181).

Commenters stated that many of the people who may be designated for membership under the proposed rule will not have technical knowledge of projects of this nature nor will they understand what is involved $(60,108,123$, $253,702,948,1180,1297)$. Other commenters stated that advice to licensees would be most valuable if members possessed technical expertise $(760,846)$. One commenter recommended that membership include one or two technical and scientific experts who are qualified in technical areas relevant to decommissioning (948). A commenter said that SSAB members should participate as individuals not accountable to their constituencies (1194).

One commenter stated that the NRC should be officially represented on the SSAB (193). Other commenters questioned whether an NRC representative could be a member of the SSAB, since the costs and expenses of the SSAB are to be paid by the licensee; 10 CFR Part 0 , Subpart D may restrict the NRC from participating on the basis of a conflict of interest $(60,108,123,259,759)$. One commenter questioned whether other government agencies might similarly be prohibited from participating (259). Commenters recommended that the NRC consider acting as the mediator of the SSAB $(274,930)$, or that the mediator be selected from an NRC-approved list (1189). Another commenter stated that the NRC should appoint an independent convener, preferably in the local community, and in addition approve the structure and membership of the SSAB (588).

\subsubsection{Independence and Support}

Commenters were in agreement that an SSAB should be selected and operated independently of the licensee (18, $20,24,27,442,469,507,508,520,581,582,970$, $1108,1189,1221,1222,1223,1225)$. One commenter stated that the SSAB, as presently proposed, would be unique in that it does not appear to be accountable to the party that hires it (298). One commenter recommended that the licensee not be a member of the SSAB (442). Another commenter stated that SSAB operation should be independently overseen by parties other than the licensee (970). Still another commenter stated that an SSAB should be appointed by state boards of health or environment, with the other agency (either health or environment) making the ground rules (1225).

Commenters recommended that the NRC appoint an independent convener of the SSAB, preferably from the local community (588) and appoint an independent facilitator from an NRC-approved list (1189); also, the NRC should approve the structure and membership of the SSAB (588).

Commenters questioned what constitutes "administrative support" as used in $\S 20.1407$ (e), and what operating costs licensees are expected to pay $(259,320,705)$.

Some suggested that costs which licensees must pay be limited to those associated with notification of the public, conducting meetings, and providing a venue for holding advisory meetings $(320,705)$; other costs, such as hiring an independent consultant, should be considered the responsibility of the public participants if they determine that one is needed $(320,705)$. Another commenter stated that technical consultants to the SSAB are an absolute requirement (592). A commenter indicated that citizens and state or local groups should be given Technical Assistance Grants so they can hire their own independent labs to take measurements $(1224,1227)$ and hire their own experts to evaluate a licensee's proposed decommissioning plan (1236). One commenter stated that members of the SSAB should be reimbursed for expenses and perhaps receive an honorarium (1192).

Some commenters stated that licensees should pay the full cost of SSAB activities $(442,507,593,970,1108,1189$, 1194), while other commenters stated that licensees should not be required to pay these costs $(986,1032$, 1038 ) and questioned if the NRC has statutory authority 
to require licensees to pay the cost of public participation $(986,1038)$. One commenter recommended that licensee funding of SSAB activities be limited to from one-half to one percent of the estimated cost of decommissioning

(16). Another commenter stated that SSABs should be funded by licensees through a neutral government body -- state or municipal (507).

\subsubsection{Meetings and Records}

One commenter recommended that SSAB meetings be limited to no more than two per month and that these be advertised so as to encourage wide scale public participation (16). Another commenter agreed with the requirement that SSABs hold open meetings (1226).

Commenters stated that SSABs should be given access to all licensee official documents, including proprietary or other confidential information $(20,24,27,508,1191$, 1226). Another commenter recommended that SSABs be given access only to documents relating to decommissioning that are already a part of the public docket (983). The commenter stated that the proposed requirement to give an SSAB access to all licensee records is inconsistent with the Freedom of Information Act (983).

\subsubsection{Reporting/Use of Recommendations}

Commenters recommended that the NRC provide further guidance with respect to the actions expected to be taken by the licensee and the NRC on the advice or comments of the $\operatorname{SSAB}(259,576)$; these actions should not be left unspecified and perhaps should consist of basic formats for procedure, information exchange, and communication of majority and minority comments (576). Another commenter stated that the NRC and licensees should be required to respond in writing to $S S A B$ recommendations and explain why any recommendation is rejected (1195). Other commenters stated that a licensee should not be required to reply formally to all SSAB advice (984), but should be given opportunity to respond before SSAB advice is placed in the public record (560).

Commenters recommended that a licensee's analysis of SSAB recommendations be administratively independent of the licensee's decommissioning plan and that an appropriate change be made in proposed
$\S 20.1403(f)$ to reflect that this is not required $(845,934)$. A commenter stated that there should be no requirement that a licensee obtain consensus of the SSAB on any aspect of the decommissioning plan (845). Another commenter stated that licensees might not be able to meet the time restraints for submitting a decommissioning plan if they must reconcile SSAB advice into the plan before it is submitted (1207).

One commenter objected to the concept of licensee "disposition" of SSABs' advice as expressed in the wording of $\S 20.1403(\mathrm{f})$, (1106).

Commenters objected to the concept of SSABs' providing advice on decommissioning matters, because this is an abdication of the NRC's central responsibility to protect public health and safety $(984,1223)$. Another commenter stated that the final rule must provide assurance to licensees that the Commission's final decision on decommissioning will be based on factual information and objective technical criteria in the regulations, and not on subjective criteria that may arise in the course of the SSAB process (560). Another commenter stated that the NRC should make clear in the rule that the NRC retains legal responsibility to be the ultimate decision maker on all decommissioning issues (987).

\subsubsection{Other Issue-Related Comments}

Commenters stated that the NRC must meet the requirement in the Federal Advisory Committee Act (FACA) that "new advisory committees should be established only when they are determined to be essential" (1036), and the NRC has not demonstrated an essential need that requires establishment of SSABs (1003, 1014). Another commenter stated that it may be possible to avoid FACA issues by incorporating the convening and selection of an SSAB within a licensee's public participation plan that is ultimately approved by the NRC (589).

Commenters recommended that the NRC adopt and consider specific criteria in evaluating proposed public participation processes, such as SSABs; perhaps the rule should provide more flexibility in deciding when SSABs must be used and require their use in instances not contemplated in the proposed rule $(583,585,587,590$, $591,1027)$. Other commenters recommended that the 
NRC explain more fully what the nature of SSAB participation would be $(748,844)$ and how the costs would be distributed or contained (748).

Commenters stated that the SSAB concept, as presented in the proposed rule, is inconsistent with the recently promulgated $\mathrm{NRC}$ rule on timeliness in decommissioning $(61,696,1207)$. Another commenter stated that the SSAB bureaucracy proposed in the rule is likely to result in a substantial increase in delays in the decommissioning process (745).

Some commenters recommended that descriptive information on membership, administrative support, and participation capacity be included in a general policy or regulatory guidance rather than in rulemaking (262, 1196).

A commenter stated that tribal governments pose distinct considerations that cannot be swept within the SSAB framework; tribal relations should be addressed in a separate rule or separate section in the decommissioning rule (586).

\subsection{Minimization of Contamination, $\S 20.1408$}

\subsubsection{New Facility Design and Procedures}

Wide-ranging comments were provided on proposed $\S 20.1408$. Commenters stated that a better approach to waste minimization would be source reduction, i.e., the NRC should take actions to halt additional production of radioactive materials and wastes $(112,453,519,536)$. A commenter stated that more substance is needed in the rule on how to meet the proposed requirement (1112, $1113,1117)$. One commenter expressed agreement with provisions of the rule (1183). Another commenter stated that proposed $\S 20.1408$ will not substantially improve public health and safety (991).

Several commenters recommended that the requirements for describing facility design and procedures for waste minimization apply to all license applicants and not only applicants for new licenses, i.e., renewal licensees should also be required to submit this information $(166,179$, $964,972,1112$ ). One commenter recommended that the rule remain as proposed and not apply to renewal licensees (991).

\subsubsection{Appropriateness in Part 20}

One commenter recommended that $\S 20.1408$ be deleted from 10 CFR Part 20 and that the subject be addressed in other parts of Title 10 which govern the licensing of different types of operations $(300,305)$. Other commenters stated that they were satisfied with the requirements placed in 10 CFR Part $20(475,1183)$.

\subsubsection{Other Issue-Related Comments}

Commenters recommended that recycling of materials be addressed in more depth in the final rule $(285,354,457$, $482,1294)$. Several commenters stated that any recycling of contaminated materials that results in increased exposures to members of the public is unacceptable (17, $64,66,67,69,71,72,73,84,92,222,224,457,477$, $543,944,1253,1308)$. Some commenters favored the establishment of de minimis levels of radioactivity on recycled materials $(170,172,173,178,200)$. One commenter recommended that a high priority be given to development of a recycling rule (200).

A commenter stated that the proposed cleanup standard of $15 \mathrm{mrem} / \mathrm{y}$ would not lead to minimization of wastes, but rather can be expected to dramatically increase the volume of radioactive wastes without any discernible reduction in potential health risks (762).

\subsection{Implementation}

\subsubsection{Regulatory Guidance}

Many comments were provided on the NRC guidance documents issued in support of the proposed rule, including those on NUREG-1500 (28, 34, 96, 133, 134, $135,136,137,138,139,311,321,322,324,325,326$, $401,402,673,763,764,765,772,773,775,826,857$, $889,900,901,1076,1094,1209,1212,1298)$, on NUREG-1501 $(33,96,401,402)$, on NUREG-5512 (14, $34,197,826,857,859,875,1094,1212,1285)$ and on NRC guidance documents generally $(50,80,196,217$, $267,386,401,406,416,498,515,525,684,746,770$, $771,810,819,860,889,902,917,987,1079,1176)$. 
Commenters requested that additional regulatory guidance be provided on the following subjects:

- Format and content of decommissioning plans (138),

- Methodologies for demonstrating compliance with the radiological criteria $(36,50,135,192$, $197,498,734,825,889,987,1157,1173$, $1232,1233,1275,1285,1288$ ),

- How to monitor structures and materials to determine if additional decontamination is required $(192,323,1287)$,

- $\quad$ Dose modeling $(406,515,770,819,826,867$, $875,877,1173,1277$ ),

- How to satisfy the ALARA requirement (96, $129,196,406,810,855,869,901,987,1086$, 1284),

- Regulation of sites maintained under license indefinitely $(646,823)$,

- Circumstances supporting NRC authorization to assume effective reduction of exposure from earthen covers or barriers $(619,645,684$, 1085),

- $\quad$ SSAB operations $(576,1173,1196)$,

- Contents of a licensee's public participation plan $(319,583)$,

- Guidelines for selection of institutional controls (1265, 1280),

- Decommissioning portions of sites (710),

- $\quad$ Recycling criteria (1173).

Commenters also requested that the meaning of the following terms be appropriately clarified: "readily removable residual radioactivity" $(96,134,139,192$, 263), "indistinguishable from background" $(133,498)$, "doses from radon" (768, 770, 775, 778), "maximum extent practical" (515), "not technically achievable" (571), "prohibitively expensive" $(556,1086)$, "significant public risk" (248), "decommissioning" (993), "institutional controls" (574), and "most radionuclides of interest" (1093).

With regard to the methodologies for demonstrating compliance with the radiological criteria (see second and fourth bullets above), commenters recommended that the NRC specify prescriptive and conservative screening options for licensees to use when limited quantities of radioactive material are involved or where full modeling is impractical $(40,192,321,931,1173)$.
A commenter suggested that previously prepared guides used by the NRC over the years in the decommissioning of licensed sites should serve as the foundation for any newly prepared guides $(801,805,810)$.

One commenter cautioned that the NRC should include sufficient information in the rulemaking to assure the enforceability of the radiological criteria rather than place this information in regulatory guides, because the content of guides is not mandatory or enforceable $(498,510$, 525). Another commenter recommended that the NRC remove from the rule the entire contents of $\S 20.1402$ Concepts, and place this information in regulatory guidance (994).

A commenter recommended that the NRC complete all guidance on the proposed rule and solicit public comments on these documents after they are prepared (1176).

\subsubsection{Demonstrating Compliance}

Commenters requested that the NRC develop and publish compliance guidance that describes realistic methods for measuring residual radioactive materials at sites and for translating contamination levels on surfaces and in soils into doses of mrem/y $(14,36,50,96,97,128,130,135$, $192,213,217,232,243,293,294,369,401,498,634$, $656,673,734,765,780,804,825,853,889,903,906$, $1051,1157,1173,1199,1232,1233,1258,1277$, 1288). One commenter requested that the NRC supplement some of the information in NUREG-1500, $(311,324,326)$.

Some commenters stated that the NRC-proposed release limit is so low that it might not be possible for a licensee to demonstrate compliance with it $(7,13,97,215,281$, $287,289,369,628,656,673,733,782,784,789,812$, $825,867,904,1089,1178,1275)$. Other commenters expressed concerns over the extent to which models are permitted to be used in demonstrating compliance with the radiological standard $(450,514,515,517,524,790$, $825,826,867,1089,1277)$.

Commenters recommended that the NRC establish prescriptive/conservative screening options for use by licensees with limited quantities of radioactive materials or where full modeling is impractical $(40,192,655$, 
1173). One commenter supported demonstrating compliance through pathway analysis (189).

Two commenters stated that the NRC, Brookhaven Lab, ORAU, or officials of affected communities should make measurements at contaminated sites, and that the NRC should not rely on licensee measurements $(472,1223$, 1224,1238 ); special consideration should be given to alpha contamination (1231); NRC inspectors should be on-site to monitor that decommissioning is done safely $(1238,1239)$.

Commenters recommended that the NRC altogether exclude radon from the radiation measurements made to demonstrate compliance with the adopted standard (41, $240,707,743)$.

\subsubsection{Flexibility}

Commenters expressed agreement with the statement by the NRC in the preamble to the proposed rule that it is important to provide flexibility to licensees to allow the use of site-specific conditions and the ALARA principle in the implementation of the criteria $(206,405,406,607$, $632,643,647,664,756,975,1302$ ). Some commenters recommended that the rule explicitly allow licensees to propose site-specific alternatives or to request an exemption from any of the proposed criteria if warranted by site-specific conditions $(206,647,756)$. A commenter stated that it supports using a risk-based approach in the rulemaking, because it provides flexibility in the remediation process, which is important because of the great variety of contaminated sites and buildings (1271).

Some commenters stated that the proposed rule does not provide sufficient flexibility $(206,319,385,440,444$, $470,607,613,618,632,704,834,890,910,911,912$, $913,1044,1190)$ and recommended that additional flexibility should be provided with respect to:

- $\quad$ Applying the ALARA principle below a dose limit of $100 \mathrm{mrem} / \mathrm{y}$ (385),

- Requiring additional cleanup later on if new scientific findings indicate a possible need for greater conservatism to protect public health (440),

- Requiring more, never less, complete decontamination $(444,470)$,
- Allowing stabilization of radioactive wastes in place and not assuming that institutional controls fail $(613,618,632,647)$,

- Changing proposed $\$ 20.1403$ (a) to " 1000 years, to the extent reasonably achievable, and in any case, for at least 200 years" (834),

- $\quad$ Eliminating from proposed $\S 20.1405$ (a) the restriction that cleanup must be pursued to achieve an unrestricted release unless it is "not technically achievable, would be prohibitively expensive, or would result in net public or environmental harm" (1044),

- Permitting realistic conditions of land use to be considered in determining the most appropriate way to achieve safe release of the site (1044),

- Permitting licensees to submit site-specific schedules taking into account delays brought about by the use of an SSAB as acceptable substitutes for the time limits specified in the NRC's timeliness rule (704),

- Providing relief from the restrictive $15 \mathrm{mrem} / \mathrm{y}$ standard for sites that contain a wide variety of NORM containing materials (376),

- Deleting the proposed groundwater limit (899) and applying a single dose criterion covering all exposure pathways (1258),

- Proposing alternatives to the use of an SSAB, as described in the proposed rule, to achieve necessary community participation in decommissioning activities $(319,890,910,911$, 912, 913, 1190).

An Agreement State Department of Nuclear Safety stated that flexibility in the decommissioning rule is important to allow Agreement States to develop and apply state regulations (35).

\subsubsection{Waste Disposal}

Commenters suggested that past federal policies and practices have provided inadequately for nuclear waste disposal $(81,452,513,1309)$. One commenter indicated that the NRC should consider what impact the EPA's future radioactive waste management regulations will have on the proposed NRC decommissioning criteria (725). Another commenter stated that the NRC needs the guidance of a uniform waste management rule (577). 
Some commenters stated that all waste must be taken into account and cleaned-up if a site is to be decommissioned $(474,513)$; and no waste can be deregulated or considered "Below Regulatory Concern" $(17,21,23,26$, 944).

\section{Commenters stated that highly restrictive} decommissioning standards would result in large volumes of waste that must be removed to a disposal site (103, $104,118,119,721,1147,1275,1293,1301,1302)$.

Commenters stated that there is not now, nor will there be any time soon, sufficient disposal capacity for the volume of low-level wastes generated from these standards (614, $653,741)$, particularly those containing slight NORM contamination (396). A commenter cautioned that the 15 $\mathrm{mrem} / \mathrm{y}$ dose limit is so low in comparison with the variation in natural background that there will be difficulties differentiating residual radioactivity from natural background (1275). This commenter also recommended that the NRC seriously consider establishing limits that would permit disposal of very lowlevel radioactive waste in sanitary land fills (1293).

Commenters suggested that on-site disposal of uranium wastes be exempted from the radiological criteria for decommissioning and be handled the same way as mill tailings pursuant to the Uranium Mill Tailings Radiation Control Act and implementing regulations (159). Other commenters recommended that sites with large quantities of low-level radioactive materials be managed in conformance with remediation efforts similar to the regulatory requirements developed in 10 CFR Part 40 , Appendix A and 10 CFR Part 61, $(270,687)$ or other requirements suitable for application to large volumes of NORM-like wastes $(390,394,395,396,397,398,399$, $649,652,653,687,688,721,741,960)$. Commenters requested that on-site disposal be permitted where access to the site is restricted (633) and the radioactive materials are properly protected by engineering design and institutional controls (997). Another commenter stated that wastes previously buried in accordance with $10 \mathrm{CFR}$ Part 20, sections 20.302 and 20.304 , should be altogether exempted from the decommissioning rule (687).

Commenters stated that the removal and transportation of radioactive wastes from a site poses inherent nonradiological risks to the general public larger than any radiological risks posed by the materials at a site undergoing decommissioning $(103,118)$. Another commenter stated that off-site disposal would be undesirable from the standpoint of overall environmental impacts, costs, and effects upon planned disposal capacity $(687,688)$. One commenter suggested that waste disposal options should be evaluated in site-by-site cost/benefit assessments $(162,164,165,168)$. A commenter noted that in addition to considering waste volumes, the quantities of radioactivity in the waste should be considered (150). Another commenter stated that, while the NRC suggests that a net benefit analysis (ALARA) be done, the thrust of the proposed rule is that radicactive wastes should not be disposed of on-site and that radioactive wastes previously buried on-site must be exhumed and removed; this should not be the presumption $(649,652)$. With respect to previously buried wastes, a commenter asked about the relationship between the provisions of the proposed rule, the Site Decommissioning Management Plan, and the Branch Technical Position (761).

Commenters stated that the NRC analysis of costs and benefits prepared to support the proposed radiological criteria is flawed because waste disposal costs are not properly estimated $(309,394,395,396,397,398,594$, $670,673,721,744,818,819,1021,1022,1296)$ and that the assessment does not integrate fully all risks and costs associated with waste management $(330,346,353$, $355,721,818,878)$.

A licensee commenter submitted a report of an ALARA analysis for a uranium refinery site which demonstrates that the volume of soil that would require excavation and removal increases exponentially with reductions in decommissioning criteria, and that both existing and proposed criteria require more decommissioning effort than an ALARA analysis would justify (1303).

Commenters stated that the restrictive NRC cleanup standard of $15 \mathrm{mrem} / \mathrm{y}$ and the preclusion of on-site stabilization of wastes both work against the NRC goal of waste minimization $(286,762)$. Another commenter stated that waste minimization efforts are also impeded by the costs and time for laboratory measurements that must be made; in situ measurements are not possible and accordingly waste segregation will be impractical (294).

A commenter objected to the NRC statement in the preamble to the rule that waste minimization is achieved by the ALARA requirement and economic incentives for reduction of disposal costs; continuing improvement in 
waste minimization is necessary $(1113,1114,1115$, 1116).

A commenter stated that the proposed decommissioning requirements are at cross purposes with the NRC timeliness of decommissioning requirements, because of the limited capacity for disposal of low-level radioactive wastes and regional difficulties with interstate compacts and approvals $(252,254)$.

Other comments concerning waste disposal included:

- If the EPA drinking water standard is applied to decommissioned sites, it could adversely affect the disposal of radioactive wastes at waste disposal sites (46),

- The rule should better address the disposal of mixed wastes (those containing hazardous nonradioactive wastes together with radioactive wastes) (919),

- The proposed rule does not adequately ensure against the transfer of radioactive wastes to a community landfill (960),

- Throughout the supporting documents the NRC frequently refers to low-level waste burial sites; if the NRC is referring to the planned LLW Compact and non-Compact LLW sites, the designs for these specify above-grade disposal, and, accordingly, these might best be referred to as disposal facilities rather than burial sites (1293).

\subsubsection{Compatibility/Consistency With Federal/State Requirements}

\subsubsection{EPA and NRC Compatibility}

Commenters stated that the NRC should work closely with the EPA in developing its decommissioning regulations to assure that there are no conflicting or duplicated requirements and that the requirements developed by the two agencies are compatible $(35,86$, $110,142,174,190,410,664,943,976,1029,1162$. 1261, 1270). The DOE stated that there should be a uniform federal approach to residual radioactivity and site cleanup (1256); the NRC's proposed rule could significantly impact the DOE's environmental restoration program (1257). A commenter stated, "These regulations are being prepared in collaboration with the
Environmental Protection Agency; they are therefore expected to have an impact far wider than NRC licensees, if they are found acceptable to the EPA" (327).

Some commenters favored that EPA and NRC decommissioning requirements be the same $(86,142$, 976, 1300). One commenter stated that it would be preferable if the NRC held up finalizing its decommissioning regulations until the EPA proposes total radiation-cleanup/radioactive-waste standards (654). Another commenter stated that the NRC has not considered the impact of the EPA's future radioactive waste management regulations on its proposed decommissioning criteria (725). A commenter stated that the EPA/NRC relationship was meant to be one of promulgation of exposure standards by the EPA and implementation of standards by the NRC; the NRC should abide by this relationship $(458,530)$. A commenter stated that the NRC should take the lead role in the development of radiological criteria since the NRC is the expert federal agency on radiation matters (783). Another commenter stated that the EPA should abide by the limits set forth in the NRC's final rule on decommissioning standards and that licensees should be excluded from the EPA's cleanup standards (916). A commenter stated that the NRC's rules should state that the EPA is responsible for specifying criteria for residual material in off-site property (30). EPA comments on the NRC's proposed rulemaking support the use of both the $15 \mathrm{mrem} / \mathrm{y}$ limit and the groundwater standard in $40 \mathrm{CFR}$ Part 141, (1144) and note that "... if EPA determines that the NRC regulatory program achieves a sufficient level of protection of the public health and environment, EPA will propose in the Federal Register that NRC licensees be exempted from the EPA radiation site cleanup regulations" (1145). The EPA stated it had reviewed the proposed rule and the draft generic EIS and had rated this action EC-2 (Environment Concerns - Insufficient information) (1146).

Commenters stated that the NRC's proposed dose standard of $15 \mathrm{mrem} / \mathrm{y}$ is inconsistent with regulations promulgated by the EPA for similar activities, which specify $25 \mathrm{mrem} / \mathrm{y}(289,291,806,888,898,1174,1246$, 1274, 1276). A commenter stated that $15 \mathrm{mrem} / \mathrm{y}$ is in fact consistent with the EPA regulations in 10 CFR Part $191,(1218)$. Still other commenters stated that the proposed standard of $15 \mathrm{mrem} / \mathrm{y}$ is much lower than the EPA protection standards for indoor radon $(675,677$, 708). 


\section{10 Implementation}

The NRC sought comment (59 FR 43215 and 59 FR 43221) on whether the NRC should adopt $75 \mathrm{mrem} / \mathrm{y}$ in place of $100 \mathrm{mrem} / \mathrm{y}$ as the safety net for evaluating sites acceptable for restricted use release. A commenter stated that such a limit, which is obtained by subtracting the 25 $\mathrm{mrem} / \mathrm{y}$ allowed by EPA standards in 40 CFR Part 190 from $100 \mathrm{mrem} / \mathrm{y}$, can not be justified (841).

Commenters recommended that the proposed rulemaking address the methods to be used by the EPA and the NRC in coordinating the decommissioning of facilities with mixed wastes (i.e., wastes containing non-radioactive hazardous wastes combined with radioactive wastes (329, $347,349,351,919)$. A commenter stated that the NRC has a role to efficiently coordinate where state or other federal agency regulations might apply to decommissioning; it is important that the NRC take the lead in elevating these coordinating activities to the proper level necessary to ensure that all regulators are on board and in agreement prior to embarking on decommissioning activities (1029).

With regard to whether there should be consistency between EPA chemical protection standards and radiation protection standards, commenters opposed adoption of the EPA $10^{-4}$ and $10^{-6}$ range of acceptable risk set for chemical carcinogens. They stated that it is unsound to treat radiation risks and chemical risks identically. Setting radiation risks in the $10^{-4}$ to $10^{-6}$ range will result in radioactivity levels at or below detection limits or background concentrations for natural radionuclides (411, $413,418,640,781,782,784,811,812,815)$.

Commenters recommended against the NRC's setting a groundwater standard equal to the EPA drinking water standards in 10 CFR Part 141, which govern water entering the home from community water systems and not the source of drinking water; groundwater may or may not be a source of drinking water $(836,988,1001,1016$, $1049,1050,1170)$. The Commission specifically invited public comment on this question at 59 FR 43224. Commenters also stated that the EPA's drinking water standard is equal to a dose limit of $4 \mathrm{mrem} / \mathrm{y}$ which is substantially more restrictive than the NRC's proposed standard of $15 \mathrm{mrem} / \mathrm{y}$ for other exposure pathways (988, 1001). Additionally, commenters stated that the EPA's drinking water standards include background radioactive materials whereas the NRC's $15 \mathrm{mrem} / \mathrm{y}$ standard does not $(132,679,988,1001)$. A commenter stated that the EPA has proposed to increase the drinking water standard for radium 226 and radium 228 up by a factor of four (4) to ease the financial burden upon municipalities (404). One commenter stated that NRC's proposed rule should require strict compliance with 40 CFR Part 141 to assure protection of groundwater supplies $(337,344)$.

Commenters called attention to several instances of inconsistencies between EPA regulations and practices, and those proposed and described by the NRC with this rulemaking as follows:

- The NRC proposes to require the use of "an independent third party" to carry out the responsibilities for control and maintenance of restricted use sites $(\S \S 20.1402(d)(3)$, $20.1405(\mathrm{c})$, and 20.1407(a)(3)), whereas this use is not required for landfills under EPA or state jurisdiction (706).

- The NRC's proposed restrictions on land use and use of the intruder scenario drive the regulatory decision making, whereas this is not stipulated under EPA cleanup programs, RCRA and Superfund $(686,1085,1280)$.

- The NRC and the EPA do not use mutually consistent modeling to translate soil concentrations of radionuclides to doses $(402$, 826).

- The EPA's proposed cleanup criteria do not impose an additional ALARA requirement on top of the proposed $15 \mathrm{mrem} / \mathrm{y}$ dose limit as would be required in the NRC's proposed rule (810).

- The NRC position on incorporating radon emission in the dose standard is inconsistent with NCRP and EPA guidance (400).

- The EPA defines "waste minimization" as including both source reduction activities or technologies and environmentally sound recycling whereas the NRC defines it only as source reduction (178).

- The NRC permits compliance to be determined based on exposure to an average member of the Critical Group whereas the EPA limits exposure to the "reasonably maximally exposed (RME) individual" $(389,530,569)$.

The EPA discussed in its proposed National Primary Drinking Water Regulations in 40 CFR Parts 141 and 142 the possible disposal of very low-level radioactive waste in sanitary land fills; the NRC has not addressed this proposal (1293). 
One commenter stated that pursuant to the Council on Environmental Quality (CEQ) guidance implementing the National Environmental Policy Act, the GEIS should accompany the decision-making process; and accordingly the proposed rule should not be separated from the GEIS (145). Another commenter stated that the NRC draft regulations ignore a position generally agreed upon by the committee on radiation cleanup standards of the National Advisory Committee on Environmental Policy and Technology of the EPA that risks from waste disposal be considered together with those from residual radioactivity (330).

\subsubsection{NRC and State Compatibility}

The NRC requested comments, in the preamble to the proposed rule (59 FR 43213), on whether, to what extent, and under what circumstances an Agreement State should be authorized to establish more stringent decommissioning requirements than those proposed by the NRC. Some commenters stated that states should have the authority to demand stricter radiation protection standards than the Federal Government $(63,70,72,225$, $432,467,526,963,969,1187)$. Some of the commenters recommended that states not be allowed to set less strict conditions $(432,1187)$. Two commenters stated that even local communities should be permitted to set stricter standards $(963,969)$. One commenter stated that if there is a conflict between federal/state/local standards the most strict standard should be applied (186). An Agreement State Department of Nuclear Safety stated that it objected to the idea that it must be authorized to set stricter standards $(1072,1075)$. This organization also stated that the NRC's ALARA goal should not be looked upon as a need for states to be more restrictive than the federal rule requires (39). Other commenters stated that the radiological criteria for decommissioning should be an area of strict compatibility, and under no circumstances should a state be permitted to impose a more stringent standard than specified in a federal standard $(268,709,827,891,915$, $992,1008,1142,1205$ ). A commenter suggested that if a community or other regulatory agency imposes a more restrictive standard, it should accept or share the cost for the additional cleanup (1163). Another commenter recommended, in order to assure continued compatibility between the NRC and the Agreement States, that the rule expressly establish the right of licensees to seek an exemption from the criteria and specify the conditions governing whether a site would qualify for the exemption (824).

An Agreement State Department of Nuclear Safety recommended that the rule grandfather, in proposed $\S 20.1401$ (b), previous site decommissionings that were approved by an Agreement State to the same extent that sites previously approved by the NRC are grandfathered (1060).

\subsubsection{NRC Regulation Consistency}

At 59 FR 43225, the NRC requested comments on whether the decommissioning criteria in the proposed rule can be met within the time frames that were specified in the final rule on "Timeliness in Decommissioning of Materials Facilities." Commenters stated that it will be virtually impossible for a complex site to meet the time frames specified, because of the large amounts of lowlevel waste that will be involved; uncertainties of where to transfer these wastes; uncertainties associated with decommissioning a site in stages; the time required to characterize residual contamination, review the results with the $\mathrm{NRC}$, and prepare a decommissioning plan; and delays caused by Site Specific Advisory Board (SSAB) involvement $(61,104,109,119,124,211,251,253$, $254,255,259,635,657,696,697,698,704,710,752$, $1081,1167,1203,1207)$. Commenters suggested that sites be permitted to propose a reasonable schedule for decommissioning rather than be tied to an NRC timedictated schedule $(696,697,704,710)$. Another suggestion was made for the NRC to exclude the time devoted to SSAB activities from the specified timing $(1081,1203,1207)$. Some commenters opposed the NRC's incorporating waivers to the timeliness rule, because adequate provision is provided for a licensee to justify a delay or postponement in the Timeliness Rule at $\S 30.36(\mathrm{e}),(521,1096,1097)$.

Commenters stated that applying the radiological criteria for decommissioning to all areas outside the restricted area at in-situ leaching facilities and uranium mill sites is inconsistent with 10 CFR 40.36 and Criterion 6,

Appendix A of 10 CFR Part 40 (158, 228, 242, 247, 265, $270,718)$. Other commenters stated that thorium should be excluded to the same extent as uranium, because both are regulated by 10 CFR Part 40, Appendix A, (794, 831). 
Commenters stated that on-site disposal areas approved pursuant to 10 CFR 20.302 and 20.304, and other sites with large volumes of contaminated wastes similar to uranium mill tailings, may better be evaluated by requirements consistent with those applied pursuant to 10 CFR Part 40, Appendix A; 10 CFR Part 60 ; or 10 CFR Part 61 than by requirements in the proposed decommissioning rule $(612,645,1274)$.

In addition to the foregoing apparent inconsistencies commenters called attention to several other instances as follows:

- The proposed $15 \mathrm{mrem} / \mathrm{y}$ standard is inconsistent with the $100 \mathrm{mrem} / \mathrm{y}$ standard contained in 10 CFR $20.1301(55,57,289,313$, $388,788,806,924,925,1147,1174)$.

- The NRC's proposed approach not to allow licensees to assume that institutional controls will continue to be effective, or to take credit for engineered features, is inconsistent with UMTRCA and NRC regulations in 10 CFR Part 40, Appendix A and 10 CFR Part 61 (620, 682, $1085,1045,1046)$.

- The proposed provision in proposed $\$ 20.1403$ (a) to consider doses over a 1000-year period is inconsistent with 10 CFR Part 40 , Appendix A, (834).

- The adoption of a 1000-year standard for decommissioning might inadvertently constitute regulatory precedent for low-level waste (LLW) sites or even high level waste repositories (572).

- The proposed $15 \mathrm{mrem} / \mathrm{y}$ standard is inconsistent with the $25 \mathrm{mrem} / \mathrm{y}$ standard contained in 10 CFR Part 60, and 10 CFR Part $61,(806,925,1246,1274)$. Another commenter stated that the two requirements are consistent (1218).

- There is substantial support for an "acceptable risk" level from residual radioactivity that is significantly greater than $10^{-4}$ to $10^{-6}$ in prior NRC rulemakings; recommended dose limits for exposure to radionuclides carry with them risks in the general range of $10^{-2}$ to $10^{-3}(814)$.
- The same rationale NRC used in the "Steve Gannis, Denial of Petition for Rulemaking," (60 FR 13385, March 13, 1995) to conclude that there is no reason to lower the 100 millirem exposure limit for operating facilities, should be applicable to decommissioned facilities (1305).

Commenters stated that the proposed decommissioning criteria are incompatible with those appropriate for the regulation of naturally-occurring and acceleratorproduced radioactive material (NARM) $(95,287,376$, $386,390,391,392,394,395,397,401,402,404,719$, 1276).

A commenter stated that the NRC did not, but needs to, prepare an analysis of how the cleanup of sites contaminated with radioactive materials fits into the entire spectrum of radiation control issues, including the importance of the rule in its relationship to NORM and radioactive material waste management (719).

\subsubsection{Other Inconsistencies}

A commenter stated that the Commission has ruled and the Congress has made very clear that the NRC may not require licensees to provide financial assistance to intervenors (1038). This same policy should apply to SSABs and to the use of technical consultants by these boards; SSABs should not be involved in the types of technical issues specified in proposed $\S 20.1407$ (a), (1038).

Other commenters stated that the SSAB proposal is inconsistent with the Federal Advisory Committee Act (FACA) $(982,1014,1036,1038)$, and inconsistent with the Administrative Procedure Act, the Atomic Energy Act, and the Freedom of Information Act $(983,984$, 1030).

Commenters recommended that the NRC ask the Congress to amend the Nuclear Waste Policy Act of 1982 to specifically allow federal ownership of extensively contaminated sites $(645,718)$.

The DOE stated that it currently uses a dose constraint of 25 to $30 \mathrm{mrem} / \mathrm{y}$ plus the ALARA process which is different from the $15 \mathrm{mrem} / \mathrm{y}$ dose limit proposed by the NRC (1273); the NRC-proposed rule could significantly impact the DOE's environmental restoration program $(1257,1276,1279,1281)$. 


\subsubsection{Other Issue - Related Comments}

Commenters recommended that the costs and benefits associated with the proposed decommissioning criteria and the practicality of implementing the rule be subjected to a comprehensive peer review using outside experts who are compensated for their time $(280,366)$. A more practical rule than the one proposed is needed to ensure that compliance can be achieved without placing additional burdens on tax payers (367). If the rule is too stringent and cannot be complied with, it will not accomplish the goal of cleaning up contaminated sites; small companies may disappear and large companies may delay cleanup activities indefinitely (367). Another commenter stated that the proposed rule and supporting documents are not clear and do not provide stable decommissioning criteria (860). One commenter supported the development of cleanup standards, but disagreed with the approach being taken to levy a vaguely supported standard upon the regulated community (276). A commenter volunteered to draft specific language for NRC consideration (1143). Another commenter opposed the proposed rule because it does not require residual radioactivity to be reduced below background levels (65).

Commenters recommended that each site decommissioning should be preceded by both a full Environmental Impact Statement and a completed Site Decommissioning Plan $(162,422,455,456,522,524$, 854). A commenter stated that the NRC should set at least some minimal regulations concerning acceptable methodologies and assure that workers involved in decommissioning activities are appropriately trained and protected (449).

Another commenter stated that the NRC should agree to review and approve (or supply comments on) any licensee decommissioning plan within a specified period after receipt (1168).

\subsection{Regulatory Analysis}

A commenter stated that the NRC has not considered how cleanup of sites contaminated with radioactive materials fits into the entire spectrum of radiation control issues, including how the proposed rule relates to naturally occurring sources of background radiation and to radioactive waste management $(719,722)$. Also, commenters stated that the NRC has not evaluated whether its proposed rule will do more harm or good to the public welfare; a "net risk" analysis is necessary to assure that risks are being controlled and not just being moved around $(719,722,723,878,1263,1281,1283)$. Another commenter stated that the totality of impact over time must be included in the NRC's analysis (429).

Commenters stated that the GEIS (NUREG-1496) and the NRC's Regulatory Analysis are flawed in that they mix up the purpose of safety factors, best estimates, and conservative modeling; grossly underestimate actual costs of the proposed rule; or do not adequately support the proposed decommissioning criteria $(31,402,594,598$, $599,723,747,774,819,857,858,861,862,873,875$, $876,877,878,879,880,881,882,883,884,885,889$, $900,1003,1012,1020,1021,1022,1023,1024,1047$, $1119,1123,1124,1125,1126,1128,1130,1210,1219$, $1267,1285,1296)$. Another commenter indicated that NUREG-1496 should have more clearly identified all assumptions made to support the analysis, along with their uncertainties, and evaluated the impact of costs associated with alternative disposal options (594). The commenter also stated that the format used in Appendix E of NUREG-1496 for enumerating public comments during scoping and earlier participatory processes is wholly unsatisfactory. Appendix E lists the comments generically and then lists (by number code) the commenters whose opinions could be thus summarized. The use of the codes is awkward, and the summarization of individual comments often suffers in the translation. A more complete effort should have been made to include the comments as close to their original context as possible (595).

Commenters stated that the NRC should explain how 15 percent of the $100 \mathrm{mrem} / \mathrm{y}$ limit is consistent with the recommendations of the NCRP and the ICRP $(669,729$, $746,802,1012,1019$ ) and why the $25 \mathrm{mrem} / \mathrm{y}$ limit used in NRC's regulations in 10 CFR Part 60 and 10 CFR Part 61 and in the EPA's regulations in 40 CFR Part 190 did not receive more consideration (1274). A commenter recommended that the NRC analyze the costs (including impacts on workers and on the environment) and the benefits of a range of dose limits including values higher (such as $25 \mathrm{mrem} / \mathrm{y}$ ) and lower than the proposed 15 $\mathrm{mrem} / \mathrm{y}$ dose limit $(1263,1274)$. Commenters also requested that the NRC explain how its past experience has led to the conclusion that NRC's existing decommissioning criteria provide inadequate protection of the public health $(803,1012)$. 
A commenter stated that the NRC's conceptual approach is similar to that embodied in the Occupational Safety and Health Administration's (OSHA) so-called "carcinogen policy" which assumed that, since there is no safe level of exposure to carcinogens (the linear theory), regulatory controls should be made as stringent as possible (730). The Supreme Court in the so-called Benzene decision rejected this approach and stated that the mere possibility that somebody, somewhere may face a cancer risk someday is not a sufficient basis for regulatory action (730).

Another commenter disagreed with the statement made by the NRC that it is not obligated by 10 CFR 50.109 to perform a backfit analysis for the decommissioning rule (1009).

\subsection{Miscellaneous}

Commenters expressed satisfaction with the enhanced rulemaking process undertaken by the NRC for the decommissioning rule $(51,85,125,127,140,141,167$, $187,188,372,661,858,886,942,949,974,1090$, $1105,1109,1110,1118,1151,1182,1183)$. Of those commenters who opposed the proposed decommissioning standards for not being sufficiently restrictive $(68,82,93$, $149,153,155,219,221,338,420,427,527,941,957$, $965,966,973,1095,1252,1254)$, some were critical of the rulemaking process and suggested that the NRC had ignored their earlier participation $(62,65,66,68,71,72$, $82,91,111,149,218,221,941)$. Other commenters expressed dissatisfaction with the proposed standards because they are over-restrictive $(161,371,381,561$, $625,630,660,711,716,726,766,767,779,800,858$, $874,996,1018,1132,1134)$.

A commenter recommended that the technical basis documents for the proposed rule, in particular the GEIS (NUREG-1496), be subjected to an independent review by an independent panel such as the National Academy of Sciences, or the National Research Council $(272,277)$. (Also see section 2.10.6 of this summary concerning a recommendation for independent review of the proposed rule.)

A commenter stated that Executive Order 12866 requires that an agency must design its regulations in the most cost-effective manner to achieve the regulatory objective (629); it must assess both the costs and the benefits of the intended regulation, and propose or adopt a regulation only upon reasoned determination that the benefits of the intended regulation justifies its costs. The commenter concluded the NRC's proposed decommissioning criteria do not appear to be based on such an analysis (629).

A commenter stated that the NRC's supporting documentation needs to consider and balance the radiological and non-radiological risks to workers resulting from increased quantities of materials that might have to be handled as a result of low dose limits (1263). The commenter also recommended that the NRC use an ALARA decision process to assess all significant risks to workers and the public $(1281,1283)$.

Another commenter stated that several unsupported assertions are made in the Statement of Considerations for the proposed rule and that the NRC's reliance on such statements without identifying the basis for them is a violation of a basic tenet of administrative law (1033). Identification of the basis for a proposed action is needed to permit persons to participate meaningfully in agency proceedings (1033). Another commenter noted that the discussion of Groundwater Protection in the Statement of Considerations, at 59 FR 43224, incorrectly refers to $\S$ 20.1404(d). The correct reference is $\S 20.1403$ (d), (1202).

Other commenters suggested that since the NRC accepts a responsibility for declaring a site suitable for restricted or unrestricted release through its termination protocol, the government should share the financial responsibility for future cleanup requirements $(297,303)$. The commenters recommended that the government's share should be a minimum of 50 percent of any financial requirements $(297,303)$. Another commenter disagreed saying that licensees should be liable for paying the full cost of decommissioning (856).

Other miscellaneous comments included:

- The NRC should give additional time for supplying comments on the proposed rule $(419,848)$.

- The goal of a uniform rule is the restoration of public trust in the decommissioning process (565).

- A state which accepts wastes for disposal expressed dissatisfaction with the Commission's Waste Confidence 
Decision and indication that waste disposal capacity is not a limiting condition (163).

- The Council on Environmental Quality's (CEQ) guidance

implementing the National Environmental Policy Act states that the proposed rule should not be separated from the GEIS $(90,145)$.

- Waste minimization can most readily be accomplished if the NRC takes action to halt additional production of radioactive materials and waste (48, $112,528,954)$.

- The NRC should perhaps give more weight to comments on the proposed rule from affected members of the public than to comments submitted by the affected industry $(955,959)$.

- Licensees should be financially liable for all off-site contamination; compensation to neighbors and municipalities should be automatic (1234).

- The request that the NRC consider the public's comments and not use the "public comments" opportunity as a mechanism to allow the public to let off steam (1242).

A commenter stated that there is a tenuous relationship among the contaminated communities, licensees that own the contamination, and government agencies (1092). Nonetheless, there is a relationship and its very existence allows for the possibility of improvement and resolution. However, the commenter believes that it is of the utmost importance that the NRC understand that if a system is designed whereas responsible parties announce they will be leaving soon, not being able to take the problem with them or not providing any compensation for leaving it behind, then the relationship begins to no longer exist. In such a situation, the hope or desire for mutual resolution begins to decrease and the reaction towards vindication increases with disrespect. The commenter recommends that the NRC revise its entire institutional thought process to accept the facts of mutual responsibility and equitable resolution in the supposed "decommissioning" of these several very difficult cases of extensive radioactive contamination (1092).
The DOE stated that it supported the NRC's effort to promulgate the rule, and the joint efforts of the EPA and the NRC to coordinate their respective rulemaking proceedings (1270).

Several commenters submitted specific comments and also endorsed the comments and recommendations of their respective national organizations, e.g., those of the American Mining Congress and the Nuclear Energy Institute $(157,977,1150,1166,1175,1245)$.

A commenter stated, "We have commented previously on NRC's Issues Paper associated with the seven public workshops held from December 1992 to August 1993 (June 28, 1993); on the scoping process for the draft GEIS (September 16, 1993); and on the staff draft of the proposed rule (March 11, 1994). Many of those comments remain relevant to this latest proposal" (1010). 



\section{SUMMARY OF COMMENTS ON DRAFT GENERIC ENVIRONMENTAL IMPACT STATEMENT}

\subsection{Regulatory Alternatives and Approach}

\subsubsection{General}

Some commenters agreed with the general purport of the GEIS: one said that the GEIS sufficiently addressed all environmental, social, and economic impacts of the proposed rulemaking on radiological criteria for decommissioning (10); another said that the GEIS fulfilled NEPA requirements and thus eliminates the need for licensees' environmental reports or for site-specific NRC preliminary environmental reviews for decommissioning to both unrestricted or restricted release (218). One commenter endorsed the inclusion of cost and risk evaluations of alternatives (27).

Many commenters criticized the GEIS as being incomplete or inconsistent as follows:

The NRC's conclusory statements cannot be evaluated because both of a lack of documentation of critical information and of apparent discrepancies in the analysis $(123,141$, 167, 215).

- The NRC has never explained how its past experience led to the conclusion that the existing decommissioning criteria provide inadequate protection of public health, and does not adequately explain how the reductions in public dose limits justify a near background standard (254).

- The GEIS is technically incomplete and inconsistent and the conclusions were derived from flawed bases and analyses $(153,154,164)$.
The supporting documentation is not clear, does not provide "stable" decommissioning criteria, or appears to be a spurious justification of policies or outcomes that were already decided $(118,144,145)$.
- The analysis of radiological criteria for decommissioning is incomplete, complex, and lacks clarity $(142,144)$.

Other commenters deemed the ALARA process as used inappropriately or misapplied as follows:

- The NRC never "closes the loop" on the ALARA/net-risk analysis; determining whether the proposed decommissioning criteria will minimize overall public risk is impossible (117); the approach inappropriately makes 3 mrem/y TEDE a de facto ALARA limit (178); the totality of impact must be reviewed and included in decision-making (82).

The NRC has misapplied the ALARA principle, and in no circumstances should a site-specific ALARA requirement be used further to reduce the dose below the generic ALARA goal (311). One commenter stated that it is not cost effective to spend millions of dollars to reduce a hypothetical risk of $1 \mathrm{mrem} / \mathrm{y}$ (306).

Some commenters questioned the general approach and basis of the GEIS as follows:

- A "tiered" approach to decommissioning (NUREG 1496, p. xvii) is not appropriate because it subjects the process to influences that are neither risk based nor cost effective (176). "Safety" factors are not appropriate for riskbased regulations; the value identified in the risk analysis should be the level chosen $(146,151)$.

- The statutory basis for decommissioning to levels approximating background is not addressed (118); a decommissioning objective of return to indistinguishable from background is not technically achievable, and reference to such an objective should be removed from the rule and associated documents (177). 
- The Nuclear Regulatory Commission has expanded the definition of "decommissioning" for the purpose of releasing private companies and the Commission from liability for the problems they have created; it is recommended that the Commission revise its thought process to accept the facts of mutual responsibility and equitable resolution in the "decommissioning" of very difficult cases of extensive contamination (252).

- Exclusion of Alternative 5a (maintenance of a license) from consideration in the GEIS is based on artificial reasoning and Alternative $5 b$ (restricted release) purports to be different by eliminating continuing liability problems posed by Alternative $5 \mathrm{a}(198,253)$.

- The decommissioning rule is anthropocentric and is based on risks or doses only to humans. There are situations whereby a slightly larger dose/risk of radiation exposure would be an acceptable tradeoff (i.e., major environmental disruption due to restoration efforts, safety risk to cleanup workers) (241).

- The alternative of decommissioning to restricted use with termination of the license should not be allowed (85).

- $\quad$ The NRC should base its regulations on the recommendations of the NCRP (332) and not try to determine acceptable levels of risk (38).

\subsubsection{Other Alternatives}

Several commenters indicated and recommended other regulatory alternatives, approaches, or areas to consider and in particular offered the following comments:

- The NRC should never permit incomplete remediation to a level higher than some specified small increment above natural background radiation (308).

- The NRC's "policy" not to enforce compliance with licensee [sic] conditions is not discussed in the GEIS (5).
- The GEIS does not evaluate environmental impacts of the alternative of on-site stabilization and disposal of decommissioning wastes (45). Waste disposal areas and on-site waste disposal areas previously approved by the NRC differ significantly from other areas that are potentially subject to the decommissioning criteria (104).

The Commission does not adequately explain why its existing regulatory guidance, criteria, and practices do not provide an adequate basis to develop codified criteria (256).

Commenters provided the following suggestions regarding procedural issues:

- The proposed rule should not be separated from the GEIS; it should be presented through the "GEIS review process" so that the rule and alternatives are available for analysis and comments at the same time (11).

- The GEIS and the rule should be presented simultaneously for analysis and comments (11), and all supporting documents finalized before finalizing the rule (185).

The GEIS should be reviewed by an independent panel such as one from the National Academy of Sciences or the National Research Council $(25,26,28)$.

Adoption of the rule is premature as it has not had sufficient review of the impact of the radiological criteria on actual decommissioning activities. Therefore, the proposed rule should be "test driven before purchase" by a peer review analysis of its impact on "actual decommissioning activities" to determine if the rule should be implemented in its present form or with its proposed limits (48).

- Although one commenter supported the GEIS issues, it recommended that each decommissioning must be preceded by both a full Environmental Impact Statement and a completed Site Decommissioning Plan, with full public review and NRC approval, before any decommissioning begins $(67,74)$. The full 
scope of environmental and public health and safety impacts must be included in each licensee's decommissioning plans with major emphasis on radiation effects on health and environment (278).

\subsection{Method of Analysis of Impacts and Costs}

\subsubsection{Reference Facilities}

\subsubsection{General}

Several commenters recommended that real and actual case studies be used or developed as references for the GEIS:

-

The GEIS should include a case study of a

licensed facility that has disposed of material onsite in shallow land burial (3) and should provide specific examples of real facilities where on-site disposal is considered the "most desirable" option $(46,99)$.

The GEIS, should, but does not, refer in detail to actual decommissioning case studies (99).

$\bullet$

The GEIS should include recent decommissioning experience as assumptions used and as validity checks in the calculation of cost estimates (213). Further, the GEIS should identify the factors most likely to influence the availability of disposal sites among the states (99).

Remediation costs should be based upon several factors including soil volumes, costs to excavate the soil, and costs of disposing of the waste offsite (295).

The NRC should conduct a generic ALARAtype analysis to determine the dose levels that can be practically achieved during site decommissioning. Any site-specific analysis should be applied to the 100 mrem limit to ensure that further reductions in dose are justified based on both costs and risk (311).
Commenters provided recommendations and statements for the following specific facilities as identified in the GEIS: reactors, fuel fabrication facilities, uranium mills, rare-earth facilities, sealed source manufacturers, and independent spent fuel storage installations (ISFSI).

These comments are summarized as follows:

\subsubsection{Reactors}

One commenter stated that the GEIS should include "actual decommissioning costs" of the damaged reactor at Three Mile Island as a case study (2).

Many commenters expressed concern about potentially low estimations of waste volumes, contaminated land areas, and disposal costs:

- The GEIS uses simplistic assumptions to estimate impacts as less than they really are as indicated by data from actual cleanups ( 175 , 190, 214)

- The NRC uses an oversimplistic model to examine the impacts of various levels of soil contamination on costs. The model fails to account for several significant mechanisms for the distribution of contamination in soil (190).

- The models used to estimate the amounts or types of waste or the costs and risks of waste handling, removal, and disposal are incorrect $(181,182,183,189,191,216)$.

- A major error in the GEIS's analysis lies in assuming that waste material volumes do not increase as permitted residual contamination levels are reduced $(87,189)$. A commenter's data predict that the volumes of soil needing remediation will increase by an order of magnitude when the residual contamination criterion is halved (190).

- There is a lack of consideration of certain conditions leading to high volumes of waste and associated costs in the GEIS $(189,191)$. The draft GEIS overlooks what could be significant disposal costs for some power reactors that have significant volumes of activated concrete in containment structures $(183,191)$. 
- There are inconsistencies in estimates of contaminated land area for power reactors (251).

- The actual cost impacts are greater than those presented (175).

One commenter stated that effluent releases need further evaluation:

- Although the generic power reactor, as modeled in the GEIS, is appropriate for spill "hot spots," it does not address the potential for contamination contributions from airborne releases; the NRC model ignores the gaseous effluent release pathway $(156,157)$.

- The "expected" contamination levels and models used are arbitrary and are not the same as those developed in support of the NRC's prior decommissioning rule which were based on exposures from residuals from effluent releases made over the life of the plant and affecting the entire site (155).

\subsubsection{Fuel Fabrication Plants}

Commenters stated that the NRC has made inconsistent and misleading use of reference facilities in the GEIS, as in the use of a gaseous diffusion reference facility for soil contamination at a uranium hexafluoride facility (43, 202).

Several commenters stated that the proposed rule incorrectly assumes that for many licensees incrementally more stringent cleanup standards would not result in a significant increase in the volume of soil and in the cost of excavation and disposal:

- The NRC used an oversimplistic model to examine the impact of various levels of soil contamination on cleanup costs (190).

- The models used are too conservative and costs were not fully considered or adequately analyzed (173). The model used to estimate radionuclide distribution in soil is incorrect (172).

- The NRC uses an unrealistic and inappropriate model to estimate volumes of contaminated soil present at radiological sites (136), and, as a result, underestimates the rate at which disposal volumes increase as dose limits decrease (135, $214,237)$.

- The ALARA analysis about soil contamination is insensitive to lower dose limits because of the use of the assumptions that initial soil contamination resides within the top 1 centimeter of soil and that only downward migration of water produces contamination of depth. Under more realistic scenarios, cleanup costs would increase rapidly with decreasing residual dose criteria (128).

- Data that were developed for an actual site indicated that to achieve an annual TEDE of 15 mrem would result in enormously increasing the volume of material to be excavated and would result in very significant expense (238). For many types of facilities circumstances are different from those assumed by the NRC (135, $171,237,238,239,240)$.

\subsubsection{Uranium Mills}

Commenters indicated that the reference mill used for analysis in the GEIS is inappropriate for the purpose:

- The NRC should evaluate a facility representative of its licensees $(21,313)$.

- With regard to uranium mills, the GEIS is confusing about the intended scope of the proposal, and the NRC's analysis is muddled; there is no logical reason to include uranium mills and uranium recovery facilities within the scope of the proposed rule (111).

- The GEIS's analysis should, but does not, include consideration of a reference facility for depleted uranium sites (199).

One commenter stated that a $15 \mathrm{mrem} / \mathrm{y}$ limit would cause an unnecessary fourfold increase in decommissioning costs (22). 


\subsubsection{Rare Earth Facilities}

One commenter stated that most of the scenarios used for analysis in the GEIS are inappropriate and that soil removal costs in the GEIS are underestimated (283).

\subsubsection{Sealed Source Manufacturers}

One commenter stated that the reference facilities considered do not include typical examples of radiopharmaceutical and radiochemical manufacturing as part of the impact analysis, although the decommissioning impacts for these facilities would be significant (36).

\subsubsection{Independent Spent Fuel Storage Installation}

One commenter stated that the discussion on ISFSI does not address neutron activation caused by the spent fuel in storage (223).

\subsubsection{Human Health Impacts; Dose/Mortality Modeling}

\subsubsection{General Dose Modeling Approach}

Several commenters had specific comments on the calculational method for estimating doses. These included:

- The GEIS was in some respects incomplete or inconsistent, or the conclusions were derived from flawed bases or analysis (275), e.g., it employed models that give grossly conservative estimates of dose for given concentrations (149, $150,163)$; it didn't take into account dose reduction by simple techniques such as tearing down buildings (165); it lacked supporting data for comparison of individual vs. collective dose $(169,225)$; it was inconsistent in its use of default assumptions $(170,228)$.

- The problem with the supporting analyses is that they completely mix up the purposes of safety factors, best estimates, and conservative modeling in ways that are incorrect and completely inappropriate $(146,322)$.

- The residential scenario is too conservative and should be revised to provide a higher level of realism to the dose estimates $(129,246,263$, $264,268,269,276$ ).

The NRC virtually excludes alpha radiation in its analysis of radiation hazards (336).

- The agricultural pathway (home gardening, etc.) appears to misrepresent current agricultural practices in the United States and may help overestimate the dose by a factor of 100 or more (265).

In its supporting analysis for validating release limits, the NRC is using a dose-conversion computer code that has not yet been released for public review (143).

- $\quad$ The GEIS should clearly delineate the three stages of modeling radiological pathways and consequent dose to people (257).

There were some comments on the general approach for calculating impacts, including:

- $\quad$ The parametric study (NUREG-1496, Table 51, Estimated Mortality for Power Reactors) was flawed in that it omits an evaluation above 100 $\mathrm{mrem} / \mathrm{y}$ and omits an evaluation of the 25 $\mathrm{mrem} / \mathrm{y}$ level used for waste disposal (160).

- Incomplete consideration was given to both nonradiation and radiation hazards, and additional review and consideration is warranted of the NRC's position that collective dose is not an important factor in the development of sitespecific criteria (225).

- The NRC should provide examples of real facilities where it considers on-site waste disposal the best option, and it should provide a comprehensive analysis including estimates of dose to the critical group from residual contamination and on-site waste (46).

Some commenters had suggestions about the level of risk that should be allowed, including:

- General population health risks are related, in part, to the volume of soil to be disposed of offsite (286). The cost per hypothetical cancer 
averted for a risk level of $10^{-6}$ for soil cleanup is extremely high compared to other costs for death averted for other federal regulations (288).

- The proposed $15 \mathrm{mrem} / \mathrm{y}$ TEDE criterion should be changed to a $3 \mathrm{mrem} / \mathrm{y}$ TEDE to any member of the public (81).

- The limits recommended by the NCRP and ICRP of an average annual dose of $100 \mathrm{mrem} / \mathrm{y}$ TEDE for members of the general public should be permitted, with occasional excursions to 500 $\mathrm{mrem} / \mathrm{y}(332)$.

- Nowhere in the proposed rule or background documents does the NRC explain how the reduction in the recommended public dose limit justifies a background standard (131). The justifications to support the decommissioning rule are not consistent with scientific evidence or actual experience for implementation. (29).

\subsubsection{Use of the Linear Non-threshold Hypothesis in Analysis}

Several commenters stated that the use of the linear nonthreshold hypothesis was not appropriate in the GEIS analysis. Reasons given included:

- The linear non-threshold model for health effects of radiation exposure is too conservative, of uncertain validity, or scientifically indefensible as a basis for radiation protection standards $(30$, $37,66,113,119,243,262,270,271,272,273$, $274,337)$.

- Risks at radiation dose rates comparable to background cannot be determined and may be zero $(34,37)$; no harmful effects have been documented below acute exposures of about 20,000 mrem (147).

- Even if the linear non-threshold model were correct it would not justify making regulatory controls as stringent as possible, and the Supreme Court's so-called Benzene Decision notes "...[s]afe is not the equivalent to risk free . .." (119).
Other commenters noted that there is no safe threshold of exposure to ionizing radiation $(261,275)$.

\subsubsection{Time Period for Analysis}

Several commenters were concerned that the time period for analysis in the GEIS was not adequate. Specific comments included:

The NRC should consider whether a fixed 1,000-year cutoff will provide it with sufficient flexibility to handle all types of decommissioning actions, and should consider several time intervals, as appropriate to the nature of the radioactive materials, so that the effect of the evaluation time can be seen on the result of the analysis, thus ensuring that important dose contributions from radioactive decay-product in-growth are not omitted (234).

The NRC should explain in simple terms the cases in which the buildup of radioactive daughter products will cause the peak doses to occur more than 1,000 years after decommissioning (200).

- To ensure the safety and health of the general population and environment the NRC must consider the impact for the next hundred thousand years, at least (280). A 1,000-year time frame is inadequate for sites that may have residual contaminants with hazardous lives several orders of magnitude larger $(75,83,96$, 279).

- The NRC's analysis must consider the "[t]otality of the impact over time" (68). Reasonable efforts should be made to predict health effects resulting from the entire hazardous life of each isotope (277). The GEIS should provide a better explanation of ingrowth of daughter products from long-lived radionuclides (201).

- The GEIS must include all radiological and other adverse health or environmental impacts for the full period of the hazard but the major emphasis must remain on radiation effects on health and environment (278). 
Power reactor sites are so dangerous that the NRC must keep people from getting exposed to them for 1,000 years (279). Further, a 1,000year time frame is inadequate for sites that may have residual contamination with half-lives several orders of magnitude larger (280).

Other commenters questioned the 70 -year time period as excessive:

- The NRC's use of a 70-year period when evaluating exposures of individuals living onsite exaggerates the real-world risks. The commenter also notes that the EPA uses a 30year exposure period in its parallel radiation site cleanup standards (138).

- The $15 \mathrm{mrem} / \mathrm{y}$ TEDE is overconservative and does not allow for radioactive decay. There is no justification for the NRC's assuming a 70year exposure period because it is highly unlikely that any person would, in fact, spend 70 years working or living on-site after a facility is decommissioned (281).

\subsubsection{Inconsistencies in the Modeling}

Commenters noted inconsistencies in various aspects of the dose modeling used and suggested that the model be reexamined and revised to provide a higher level of realism to the dose estimates $(165,260,267)$.

\subsubsection{Uranium Dose Modeling}

The following comments were offered regarding uranium dose modeling:

- The GEIS is inconsistent both in estimating doses to the bone and to the lung and in summing organ doses (7).

- The NRC's limited pathway assessment for natural uranium considers soluble uranium and does not take into account that, for many sourcematerial wastes, the uranium is insoluble (63).

- The scenario used assumed 1:1 concentration ratios for residual uranium and its long-lived decay products. This was a very conservative assumption since fuel cycle facilities downstream of uranium mines and mills process refined uranium (separated from its progeny) (258).

- The model should take into account the general safety and health of future generations past the first 1,000 years (280). A 1,000-year time frame is not sufficient for sites that may have residual contaminants with half-lives several orders of magnitude larger (280).

- The NRC should provide a better explanation of ingrowth of daughter products from long-lived radionuclides (201).

\subsubsection{Transfer of Risk -- Non-radiological Impacts and Waste Disposal Impacts}

Some commenters questioned the use of collective dose and stated that the GEIS incorrectly uses collective versus individual dose; overall activity risk comes from collective dose, not individual dose (169). The Commission should further consider its position on collective dose as a factor in the development of site specific criteria $(114,115,225)$.

Several commenters questioned whether the net risk from decommissioning adequately considers all risks involved. Specific comments include:

- The models used to estimate the amounts or types of waste or the costs and risks of waste handling, removal, and disposal are not adequate $(49,114,162,166)$.

There is no net benefit to transfer risk without minimizing total risk $(84,152)$. The risks potentially incurred at off-site disposal sites cannot be used to offset risks at the site being decommissioned (84); a risk does not disappear when moved (163).

- A 30-year remediation period would be needed to remediate a site to a $10^{-6}$ risk level, and the level of worker and general population fatalities attributable to cleanup activities would be nearly twice the level of hypothetical cancers attributable to radiation (285). 
- A risk-based approach should be used that, in addition to radiological impacts, considers other impacts, such as risks to remediation workers, risks from transportation and waste disposal, and risks of damage to ecosystems and wildlife $(229,231,233)$.

- The supporting documentation needs to consider and balance the radiological and nonradiological risks resulting from workers' having to handle increased quantities of materials because of low dose limits (226).

- Further analysis would reveal on-site disposal, instead of transfer to another site, to be an option for adequate long-term protection of the public $(108,109,133)$. If waste transferred to a disposal site results in similar off-site impacts, then there is no net reduction in dose, and the transfer cannot be justified (39).

- $\quad$ Trucking accidents are something quite different from the health damage resulting from radiation exposures $(70)$.

- Waste materials must be transported to a suitable disposal site. The removal and transport of these materials pose inherent nonradiological risks to the general public from such events as motor vehicle accidents (282, 284). The risks of both volume reduction and non-volume reduction scenarios for wastes should be considered (287).

- There is no mechanism for the Commission to allow release for unrestricted use with a higher dose to the general public if the transportation risk exceeds the potential risk caused by higher doses to the general public $(282,284)$.

\subsubsection{Effect of Chemicals}

The GEIS fails to consider non-radioactive hazardous pollutants and the adequacy of funding to deal with them (41).

Two commenters noted a failure to consider synergistic effects of non-radiation hazards and radiation hazards (18, 19), while one said that although chemical hazards are outside the scope of the GEIS, the NRC states that it would require compliance with other applicable standards for these hazards before it would terminate any license (126).

A commenter stated that the NRC should not disregard injuries and illnesses from exposures to chemicals and from conventional industrial hazards that might present the greatest risks to workers' health and safety (231).

\subsubsection{Radon}

The inconsistency between the GEIS's analysis of doses from radon and its daughters and the language of the proposed rule with respect to such doses must be resolved $(130,302,303,310,321)$.

Some commenters questioned the approach of the GEIS in its analysis of radon and its precursors, including the following specific comments:

- $\quad$ Radon will only be addressed through its precursors and such an approach will lead to "inconsistent application across all types of licensees" (302).

- It appears that radon will be addressed only through its precursors or will be excluded, thereby essentially ignoring the most significant theoretical radiation risk in developing the decommissioning criteria $(302,303)$.

- Relying on radon precursors as the NRC proposes would drive permissible concentrations of the precursors so low that they could never be achieved $(124,292,301,302)$.

Some commenters suggested how to consider radon in establishing a standard:

- $\quad$ Radon should be treated as a special case and not as part of satisfying the TEDE criteria ( 290 , 291, 310, 322).

It is entirely appropriate to exclude all forms of radon (i.e., radon-220 and radon-222) from the site release criteria $(291,310)$. Exposure due to radon should be excluded from the $15 \mathrm{mrem} / \mathrm{y}$ TEDE and the EPA's total indoor radon limit of $4 \mathrm{pCi} / \mathrm{L}$ should be used to control radon exposures $(289,310)$. 
- The EPA's radon action level of $4 \mathrm{pCi} / \mathrm{L}$ may impose additional constraints on site decommissioning $(250,259)$.

- In order to achieve the $15 \mathrm{mrem} / \mathrm{y}$ TEDE, models must be established to predict doses that people would receive through the relevant exposure pathways (259).

\subsubsection{Non-human Impacts}

Some commenters noted that non-human impacts should be included as follows:

- All environmental impacts need to be incorporated into decisions (82).

- Because of the paucity of understanding of ecosystems, the NRC should provide for a full case-by-case consideration of all environmental and social "aspects" for each site or facility (73).

- The NRC has not adequately considered the issue of environmental effects and costs of management of contaminated materials and of waste disposal (44).

- Detailed radiometric and pathway (bioindicator) surveillance criteria are needed for evaluating contamination of soil, sediments, and "biological contamination" before, during, and after decommissioning (8).

- Sometimes slightly higher doses or risks to humans would be an acceptable tradeoff to major environmental disruption from restoration efforts (13).

\subsubsection{Impacts on Waste Disposal/Capacity}

\subsubsection{Limits on Capacity}

Commenters noted the following with regard to waste disposal capacity:

- It is not clear if the full scope of impacts of the cleanup criteria has been considered if the wastes from the Site Decommissioning Management Plan (SDMP) facilities are excluded from the GEIS (324). The SDMP waste volumes could be a major fraction of the planned disposal capacity and should be considered in assessing the impacts of the established limits and included in the final GEIS (324).

- There is no discussion of the current, and potential future, lack of accessibility to disposal sites (39).

- The GEIS should identify those factors most likely to influence the availability of disposal options among the states for the waste produced by decommissioning activities (242).

- The analysis of matters such as costs, uncertainties, and delays associated with limited available radioactive waste disposal capacity is inadequate $(110,122,323)$, as is the analysis of conditions leading to high volumes of waste and associated costs $(53,122,236)$.

-

There is a large degree of uncertainty about the cost of a national cleanup of wastes since there are limited data available regarding both the quantities of NORM and their radionuclide content, and the availability of off-site disposal capacity (294).

- The decommissioning requirements should not be relaxed even though the NRC might not have previously considered the associated non-linear increase in waste volumes at low concentrations (77).

- The proposed $15 \mathrm{mrem} / \mathrm{y}$ limit is likely to result in large amounts of material that must be removed from facilities (316).

\subsubsection{Waste Disposal Regulations}

A commenter noted that the NRC has not fully considered the impact of the EPA's future radioactive-waste management regulations (116).

\subsubsection{NORM Waste}

The analysis fails to address the impact of NORM wastes generated because of EPA or state and local governmental requirements $(58)$. 
The GEIS cost estimates do not address the impact of high volume NORM wastes, including impacts on available waste disposal capacity (56).

The technical and economic impacts of regulating sites with NORM have not been adequately addressed even though the NRC recognizes potential difficulties with these sites (54).

One commenter indicated concern about the NRC's analysis of conditions caused by high volumes of waste requiring disposal which would necessitate the permitting and construction of numerous new disposal facilities (57).

\subsubsection{Other}

The analysis for wastes could be misleading and appears to be volume-based without any activity analysis (14).

\subsubsection{Methods and Costs for Decommissioning}

\subsubsection{Inaccuracy in Costs}

Commenters provided several comments about the cost models including:

- The models used to estimate the costs and risks of waste handling, removal, and disposal are inadequate $(189,304)$, including failure to address costs for high-volume NORM wastes $(58,294)$.

- Decommissioning requirements should be justifiable by the reduction of risk, not by a company's ability to pay. The NRC's analysis underestimates the economic impact of decommissioning activities (307).

- The NRC fails to take into account all the costs associated with decommissioning activities (299).

- Instead of estimating decommissioning costs as in the GEIS, a rule-of-thumb basis of ten times construction costs should be used (6).

- The GEIS should include "actual decommissioning costs" of the damaged reactor at Three Mile Island as a case study (2), and comprehensive analyses based on risk levels (293).

- The assumptions used for the conclusion in the draft regulatory analysis that a 3 millirem per year limit is the most effective dose limit were questioned (216).

- Costs as a function of decreasing dose limits are underestimated, or the cost analysis is flawed or requires correction (88).

The GEIS does not account for the costs of additional soil washing and labor at lower dose limits (50). Soil washing is not an appropriate technology for use at uranium mills and should not have been included in the cost analysis for them (23).

\subsubsection{Survey and Survey Costs}

Commenters provided several comments on survey costs as follows:

- For the various reference facilities the NRC should thoroughly reexamine the analysis of the costs of demonstrating compliance at cleanup levels marginally above background radiation $(227,232)$.

- The GEIS uses very simplistic and unrealistic assumptions regarding the feasibility and costs of performing surveys to demonstrate compliance to successively lower limits of residual contamination $(189,244,245,247$, 248).

- The GEIS should consider other costs not included in the NRC's cost analysis, e.g., costs of regulatory oversight of site closings (125).

- The impact of the costs of laboratory analyses, surveys, sampling, and measurements during decommissioning is not adequately considered in the GEIS $(31,32,137,184,192,216,219$, $224,232,244,245)$.

The implication that less sophisticated measurement techniques or less substantial costs 
would have to be applied for "greater than 3 mrem/y" surveys was questioned (180).

- The cost-benefit analysis shows that the survey costs would be reduced by a factor of 4 by setting a $30 \mathrm{mrem} / \mathrm{y}$ decommissioning limit (221).

- The units to be used, the basis of the analysis, and the costs for certain surveys at the level of accuracy specified in the GEIS was questioned $(220,222)$.

\subsubsection{Disposal Costs}

Several commenters offered the following comments on disposal costs:

- Estimates of waste disposal costs are unrealistically low $(36,40,217)$.

- There is a need for better evaluation of costs and recognition of uncertainty associated with various radioactive waste disposal options (32, $99,125,294,295)$.

- The NRC needs to reexamine and include costs that will be incurred from delays due to limited disposal capacity and increased regulatory requirements (24).

- The $15 \mathrm{mrem} / \mathrm{y}$ criterion will generate unnecessarily large volumes of wastes and increase costs without any additional health and safety benefits (316).

- Adopting a $15 \mathrm{mrem} / \mathrm{y}$ "precedent" will result in negligible radiological risk reduction compared to background levels at costs that have not been adequately analyzed. Municipalities which use incineration to reduce volumes of either trash or water treatment sludges will have higher radiation levels in the ash than the $15 \mathrm{mrem} / \mathrm{y}$ proposal (60).

\subsubsection{Cost of Compliance}

Several commenters indicated that the NRC needs to reexamine and consider other costs not included in the cost analysis, e.g., costs owing to limited available disposal capacity, increased NRC and state and local regulatory costs, SSAB costs, costs of extensive public comment and hearing procedures $(24,125,296,300,326,328,330)$.

One commenter stated that the cost of compliance with regulations with unjustified added "margins of safety" is excessive (35).

Other commenters noted that cost estimates for decommissioning are subject to uncertainties and DOE sources have publicly stated that current cost estimates show a range of costs of $\$ 400-800$ billion $(294,295)$.

\subsubsection{Social Costs}

One commenter stated that the full social cost of radiological exposure was not considered; costs of decommissioning are emphasized but not costs of morbidity or mortality (16).

Others stated that the NRC must take into account all costs over the full period of toxicity of residual radioactivity to both present and future members of the public $(297,298,317,319)$.

\subsubsection{Other}

Several other comments were received on costs as follows:

- Contemplated amendments to the EPA's Superfund regulation would result in excessive costs with little or no health benefit at the $10^{-6}$ cleanup standard, and it is not technically feasible $(52,64)$. One commenter provided multiple data and tables in support of an estimate of a cost to the Federal Government in excess of $\$ 1$ trillion with little or no health benefit (64).

- How can costs be estimated if the licensee cannot take credit for soil covers in meeting the criteria for restricted use if there is to be on-site disposal (127)?

- The GEIS's analysis of impacts and costs appears to be the beginning of a rational consideration of waste minimization (203). There is a past and continuing need for a proper evaluation of cost of decommissioning (94). 
- The Commission should carefully consider the benefits and costs of public comment and hearing procedures for decommissioning (330).

- Some of the analyses appear to be inconsistent and underestimate the economic impact for compliance and implementation of alternative residual dose requirements $(232,307)$.

- The SSAB costs are not included in the NRC's cost analysis (335).

$\bullet$

The SSAB involvement would add significantly to the overall decommissioning costs and slow the overall decommissioning process (326, 328).

- Once the risks and costs are identified, the public should be consulted to determine how much they are willing to spend to reduce risks. The SSABs or public groups should make this decision (305).

\subsubsection{NARM/NORM}

[See also $§ 3.2 .4 .3$ of this report.]

Comments received on the effect of NARM/NORM on the rule included:

- The GEIS's cost estimates do not address the impact of high-volume NORM wastes, including impacts on available waste disposal capacity $(56,58)$.

- The NRC has not done a risk/cost-benefit analysis for NORM contaminated sites ( 51 , 112).

- The technical and economic impacts of regulating sites with NORM have not been adequately addressed even though the NRC recognizes potential difficulties with these sites $(52,54,235)$.

- The analytical methods and measurement difficulties and excessive costs associated with NORM are not adequately addressed $(62,174)$.
- The GEIS should fully assess the impact on small business of the application of the proposed criteria in view of the many consumer products and building materials that contain low levels of NORM (58).

\subsection{Results of Analysis}

\subsubsection{Completeness/Validity of Analysis}

\subsubsection{Costs Should Not Be A Factor}

Several commenters indicated that costs should not be a factor in setting dose criteria. Comments included the following:

- The NRC should never permit incomplete remediation to levels higher than some specified small increment above natural background radiation levels (308).

- The completeness of decontamination or cleanup should be decided by some criterion that does not include any consideration of the costs to achieve them $(76,79,80)$.

- Licensees should be responsible for decontaminating even very severely contaminated sites without regard to decommissioning costs. The NRC and State regulators must not allow license termination or site release unless full decontamination has been completed, and independently reconfirmed and approved by the regulators and by the affected community (309).

- Public radiation standards that promulgate [sic] any cancer rate above zero for any decommissioning activity are unacceptable (327).

- The health, public welfare and environment must be the NRC's priority without regard to costs associated with decommissioning (320).

- Any analysis that claims to show that the expected health benefits of radiological decontamination would not be justified by the cost must be viewed with skepticism (15). 


\subsubsection{Suggested Alternate Cost-Benefit Approaches}

Three specific aspects of the cost-benefit approach used in the GEIS that raised comments included the \$/personrem value, the "knee-in-curve" approach, and the lumping of different areas in the analysis as follows:

- $\quad$ A value of $\$ 250 /$ man-rem should be used in decision-making cost-benefit analyses (208); alternatively a value of $\$ 200$ /person-rem should be used for ". . a residential farm scenario" (249).

- The NRC staff ostensibly uses a cost-benefit analysis to help derive a residual dose criterion, but the cost analysis is flawed and requires correction. The staff inappropriately uses a knee in a cost-benefit curve (205).

- It is appropriate to use graphical plots of cost vs. dose, but the focus should be on the slope of the curve rather than on the break point (207). All environmental impacts must be reviewed and included in decision-making (82).

- The GEIS incorrectly tabulates and presents lumped costs as a function of dose equivalent by mistakenly focusing on a preconceived set of dose levels, instead of considering costbeneficiality [sic] separately for different decommissioning activities in different facility areas and to various dose levels $(209,210,211$, 212). A commenter noted that, in the NRC's rulemaking for Appendix I to 10 CFR Part 50, the issue of component-part benefit analysis was considered, and the Commissioners agreed that the cost-benefit calculations required by Appendix I should include assessment of the worth of each augment by this procedure (210).

- The method of estimating costs in the GEIS fails by lumping costs of decommissioning and of dose reduction rather than by performing separate analyses for individual areas (buildings and land) and operations $(204,206)$.

Commenters also indicated general concerns regarding the cost-benefit analysis in the GEIS, including:
- The NRC has allowed systematically flawed cost and benefit estimates, and the ALARA analysis is invalid $(206,207)$, although the GEIS's thorough documentation and analyses provide a basis for a valid ALARA analysis (212).

- The NRC's decommissioning criteria do not appear to be based on an analysis such as is required by Executive Order 12886 to ensure that the regulation is designed in the most costeffective manner to achieve the regulatory objective (107).

- The analysis should compare the costs (including impacts on workers and on the environment) and the benefits of a range of dose limits including values higher (such as 25 mrem) and lower than the proposed 15 mrem dose limit [sic] (230).

The use of conservative analyses violates the purpose of a cost-benefit analysis and the purpose of an EIS, i.e., to compare the costs and benefits of a proposed action (148).

- The supporting documentation needs to consider and balance the radiological and nonradiological risks that result from workers' having to handle increased quantities of materials because of low dose rate limits (226).

- All environmental impacts must be reviewed and included in decision making (82).

Comments related to the effort in the GEIS to perform a generic analysis included:

- Industry recommends that the NRC perform optimizations of costs and benefits on a sitespecific basis below an upper limit of maximum acceptable dose to an individual; this approach is more likely to lead to valid results than the approach in the draft GEIS where the NRC attempts to arrive at a generic point of optimization that would apply across all industries and all sites (188).

- It is inappropriate to impose both a generic ALARA goal and a site-specific ALARA requirement (311). A commenter urges that the 
NRC adopt a realistic and ALARA-sound limit of $100 \mathrm{mrem} / \mathrm{y}$ for licensees having large volumes of contaminated soil (173). Sites with radiation, and particularly NORM, should not be regulated to levels that are indistinguishable from the variations in background (51).

\subsubsection{Need for Groundwater Analysis}

Comments were received on the need for the GEIS to provide a groundwater analysis as follows:

- The GEIS does not adequately analyze the technical basis or costs of applying the EPA drinking-water standard as proposed (4).

- The GEIS should provide for public comment, a cost-benefit analysis of imposing the EPA's drinking-water standard as proposed $(194,197)$.

The NRC has not provided a proper justification of the manner of applying the EPA's drinking-water standard to the NRC's decommissioning requirements $(187,194$, 195).

Costs and benefits of complying with the EPA's drinkingwater standard for the groundwater pathway should be examined in the context that one-third of the nation's community drinking-water supplies are already candidates for treating water to remove naturally occurring radionuclides (196).

\subsubsection{Areas Not Considered in the GEIS}

Other comments were received as follows:

- The GEIS fails to consider non-radioactive hazardous pollutants and the adequacy of funding to deal with them (41).

- The GEIS does not consider impacts of on-site disposal of decommissioning wastes $(45,122)$.

- The GEIS fails to consider waste disposal options fully (42).

- The scenarios and models for the NRC's analysis are apparently arbitrary and are not the same as those it has used before, e.g. $25 \mathrm{mrem} / \mathrm{y}$ for waste disposal, and there is no evaluation for above $100 \mathrm{mrem} / \mathrm{y}(160)$.

Effects such as cost, public acceptance, time to accomplish, and the ability to dispose of the wastes should be included in the analysis (48).

The NRC has not considered the possibility of decommissioning after an accident (1).

\subsubsection{Restricted Use}

A number of comments were received on the GEIS's analysis of restricted use including the following:

- The working definition and concepts for institutional controls "leave much to be desired"; the GEIS's discussion does not support the conclusions $(97,105)$.

- The NRC and the EPA should consider, in concert with local government representatives, the development of model zoning ordinances addressing contaminated sites not otherwise released for unrestricted use (103).

It would be arbitrary for the NRC to dismiss the option of governmental ownership of restricteduse sites without thorough analysis and adequate support in the record (121).

- The GEIS does not clearly estimate either how many licensees will be subject to the restricted use criteria or the ultimate impact of such criteria on the cost estimates in the GEIS (101).

- Both Volume I and Appendix F of the GEIS lack sufficient guidance as to what the NRC envisions as acceptable land use controls to protect the public and ensure that "critical group" members (a flexible population) will only be exposed to 15 mrem TEDE per year (100).

The implicit intent in Appendix $F$ of the GEIS that deed restrictions should be combined with local ordinances, development agreements, or other mechanisms enforceable by local government is proper (102). 
- Licensees who cannot meet the criteria for restricted use will continue under license without the guidance of a uniform waste management rule. Without a uniform waste management rule the GEIS lacks a firm basis for comparison of various remediation outcomes, e.g., to restricted vs. unrestricted release (98).

- The NRC should provide better guidance and flexibility in calculating realistic doses to the average member of the critical group, without requiring deed restrictions due to dose contributions from pathways that do not exist (266).

- The cost analysis should take into account institutional and engineering controls that can be maintained to ensure that the costs of incremental reductions in residual radioactivity are truly proportional to the benefits achieved (333).

- The NRC must not adopt the concept of a vague dose limit for a hypothetical average member of a critical group with an allowable dose limit of $100 \mathrm{mrem} / \mathrm{y}$ for a site that is to be released for restricted use (334).

\subsubsection{Comparison of Costs and Benefits}

\subsubsection{Cost-Benefit Analysis Says 15 mrem is Too High}

Commenters stated that the NRC's reason for using a 15 $\mathrm{mrem} / \mathrm{y}$ TEDE criterion rather than a lesser annual dose rate criterion is not clear $(17,317)$.

Others stated that the proposed $15 \mathrm{mrem} / \mathrm{y}$ TEDE criterion is ". . . insupportable and should be changed ... " to a $3 \mathrm{mrem} / \mathrm{y}$ TEDE $(78,81,318)$.

\subsubsection{Cost-Benefit Analysis Does Not Support 15 mrem or Lower}

Several comments were received on the GEIS costbenefit analysis as follows:

- Society cannot afford to spend resources for controversial theories of radiation risk to public health achieved by regulating to levels that are indistinguishable from variations in normal background levels (51).

The analysis used for deriving the proposed limits is not supportable scientifically or by experience $(20,28,34,36,47,51,106,134$, $186,312,325)$. Only a limit consistent with NCRP and ICRP recommendations for public exposures can be scientifically supported ( 47 , 186).

- The NRC has not demonstrated that a limit of 15 $\mathrm{mrem} / \mathrm{y}$ TEDE or a goal of $3 \mathrm{mrem} / \mathrm{y}$ TEDE is reasonably achievable $(120,150,175,179,189$, $193,225,306,314$ ).

The $15 \mathrm{mrem} / \mathrm{y}$ TEDE will result in increased waste volumes, unnecessary and unavoidable environmental damage, and substantial increase in decommissioning costs without any significant discernible benefit to the public safety and health $(315,316,329)$. 



\section{SUMMARY OF COMMENTS FOR SPECIFIC NRC SOLICITATIONS}

In the Federal Register containing the proposed rule, the NRC solicited comments on the following topics (these are summarized per the order in the Federal Register that they were published):

$\begin{array}{ll}\text { - } & \text { Radon } \\ \text { - } & \text { Unique Cases } \\ \text { - } & 3 \text { mrem/y TEDE as ALARA } \\ \text { - } & \text { NUREG } 1500 \text { Guidance } \\ \text { - } & 100 \mathrm{mrem} / \mathrm{y} \text { "Safety Net" } \\ \text { - } & \text { Site-Specific Advisory Board } \\ \text { - } & \text { Readily Removable Residual Radioactivity } \\ \text { - } & \text { Troundwater } \\ \text { - } & \text { Agreement State Compatibility } \\ & 15 \text { mrem/y TEDE Appropriateness }\end{array}$

\subsection{Radon}

At 59 FR 43216 the NRC requested comments on the problem of determining compliance with the NRC's radiological criteria at sites contaminated with processed radon-bearing-or-producing materials. Some commenters advocated that the NRC exclude radon from the radiation measurements made to demonstrate compliance with the adopted standard $(41,240,707$, 743). In addition, some commenters suggested that radon be excluded from the residual radioactivity limit (199, $240,241,407,837)$. One commenter stated that existing regulations generally exclude radon and thoron and their progeny from all the applications of dose-based standards. The radon and thoron from facility sources pose special problems which must be carefully considered and which are amenable only to special standards and requirements (837). Some commenters recommended that radon be excluded from the definition of residual radioactivity and that a total indoor radon limit of $4 \mathrm{pCi} / \mathrm{L}$, consistent with EPA guidance, be used to control radon exposure (400, $407,837)$. One commenter strongly disagreed with the NRC's proposal to control radon by requiring the reduction of residual concentrations of radon precursors like uranium, thorium, and radium because this proposal would require the reduction of these parameters to meaningless levels that may be well below the average natural levels of natural uranium and radium in soils (241). Further, another commenter stated that the NRC must require the compilation and reporting of background radon levels at all affected sites in anticipation of the problem of determining compliance at the time of decommissioning. Several commenters suggested that radon be included in the residual radioactivity limit (429, 454,476 ). In addition, commenters recommended that doses from radon and its daughters be categorically excluded from the dose calculations performed to determine compliance with the decommissioning rule. This exclusion should be specifically stated in $\S$ 20.1402(b) $(76,98,13,199,753,797)$. Several commenters suggested that the rule not propose to regulate radon, or communicated concerns about the complications introduced by such regulation and the fact that background radon levels are so high. For example, the proposed standard of $15 \mathrm{mrem} / \mathrm{y}$ is less than one tenth of the EPA standard for indoor radon $(200 \mathrm{mrem} / \mathrm{y})(241$, $393,400,407,650,651,675,676,677,707,708,743$, $744,753,769,770,771,775,776,778,797,837)$. One commenter indicated that the NRC's position on incorporating radon emissions in the dose standard is inconsistent with NCRP and EPA guidance (400). Other commenters recommended that the rule include radon doses at decommissioned sites, since the purpose of the rule is to protect the health of present and future populations by minimizing radiation doses received from the environment $(454,476)$. Several commenters indicated that the rule is not clear on whether doses from radon are included or excluded from consideration (768, 776, 797, 837).

\subsection{Unique Cases}

At 59 FR 43217 the NRC discussed certain existing licensed sites (no more than a few tens) containing large quantities of materials contaminated with low level radioactivity where health and environment may best be protected by on-site stabilization and disposal. The NRC solicited comments on an approach to the handling of these unique cases, including proposals for alternative strategies which could be used to assure adequate protection of public health and environment.

Commenters expressed a range of views on how the NRC should address the "tens of sites" which contain large quantities of low level radioactive materials. 
Some commenters recommended that the rule not be applied to any facility that possessed large volumes of low-level contaminated wastes and that the NRC provide a specific exemption in the rule for the acknowledged "tens" of existing facilities for which application of the proposed criteria is inappropriate $(270,615,779,791$, $792,793,822,1083)$. Unless exemptions are specifically provided in the rule or separate criteria for these facilities are specified, licensees will be left with uncertainty as to how decommissioning of these facilities must be accomplished (1083). Other commenters objected to exempting the "tens" of existing facilities from the proposed radiological criteria $(424,430,483,494,521$, $852,853,1100,1101)$. Still other commenters suggested that the continued license approach should be explicitly incorporated into the regulations and that appropriate procedures and fees should be specified $(148,577)$.

Some commenters recommended that licensees have the option to terminate their licenses and turn over ownership of the site to the Federal Government or to maintain the site indefinitely under license $(632,664)$. One commenter recommended that the NRC ask the Congress to amend the Nuclear Waste Policy Act of 1982 to allow federal ownership of such sites as perhaps the best means of "ensuring long-term protection of the public and the environment" (648).

A commenter suggested that the rule explicitly allow a licensee to request an exemption from any of the criteria (647) and another suggested that decisions be guided by site-specific ALARA analysis (830). One commenter recommended against the granting of any waivers or exemptions from the decommissioning requirements (521).

Some commenters stated that if the NRC intends to rely on exemption requests, it should include criteria which provide clear guidance on whether a site qualifies for an exemption; it must expressly establish the right of a licensee to seek an exemption and must specify the conditions that govern whether an exemption will be granted $(615,823,824)$. Also, the NRC must require Agreement States to provide similar opportunity for exemptions (824). Another commenter recommended that the rule specifically provide for the NRC to accept proposed alternative methods for complying with the intent of specific criteria rather than for licensees' needing to apply for exemptions (756).
Commenters stated that the need for licensee exemptions would disappear if the NRC would develop more realistic cleanup standards; i.e, tailor the radiological criteria to reflect the range of difficulties associated with the decommissioning of different types of facilities (791, 793, 822).

A commenter recommended that large-volume/low-level wastes, including those containing naturally occurring radioactive materials (NORM), be covered by a separate decommissioning/waste-management rule, because the radiological criteria proposed in this proposed rulemaking are needlessly restrictive or do not provide an adequate degree of flexibility for such materials $(270,373,375$, $376,377,378,379,391,392,395)$.

\section{$4.33 \mathrm{mrem} / \mathrm{y}$ TEDE as ALARA}

At 59 FR 43220 the NRC requested comments on the appropriateness of the $3 \mathrm{mrem} / \mathrm{y}$ above background criterion as sufficient for demonstrating compliance with the ALARA requirement. Some commenters recommended that the NRC reinstate the $3 \mathrm{mrem} / \mathrm{y}$ standard $(78,462,1220,1229,1250,1255,1307)$. Some commenters recommended that the NRC reinstate 3 $\mathrm{mrem} / \mathrm{y}$ as the decommissioning objective, and should possibly reduce it to $2 \mathrm{mrem} / \mathrm{y}(359,433)$. One commenter stated that $3 \mathrm{mrem} / \mathrm{y}$ should not be incorporated into any requirements within this rulemaking because it provides no additional reductions in risk to public health or the environment, nor is it a wise utilization of resources (271). Further, two commenters disagreed with the NRC's determination that $3 \mathrm{mrem} / \mathrm{y}$ demonstrates ALARA, because the NRC's analysis is based on unrealistically low estimates of waste disposal costs, and there is no epidemiological evidence of health effects at these low doses $(309,314)$. Several commenters also objected to establishing $3 \mathrm{mrem} / \mathrm{y}$ as sufficient for demonstrating compliance with ALARA $(900,902,904,926,1266,1278)$. Further, one commenter stated that the ALARA cut-off level of 3 $\mathrm{mrem} / \mathrm{y}$ is unrealistically low when compared to the temporal variability of dose from natural background radiation (1182). One commenter stated that the NRC has not demonstrated that $3 \mathrm{mrem} / \mathrm{y}$ is achievable for complex sites, particularly those sites with NORM, nor has the NRC shown that the $3 \mathrm{mrem} / \mathrm{y}$ goal makes sense given natural background levels (736). 


\subsection{NUREG 1500 Guidance}

At 59 FR 43220 the Commission requested comments on the appropriateness of the approach and the methodology described in NUREG-1500, "Working Draft Regulatory Guide on Release Criteria for Decommissioning; Staff Draft for Comment." NUREG-1500 provides guidance on acceptable methods which can be used by licensees for estimating annual TEDE to the average member of the Critical Group.

Many comments were provided on the NRC guidance documents issued in support of the proposed rule, including those on NUREG-1500 $(28,34,96,133,134$, $135,136,137,138,139,311,321,322,324,325,326$, $401,402,673,763,764,765,772,773,775,826,857$, $889,900,901,1076,1094,1209,1212,1298)$, on NUREG-1501 (33, 96, 401, 402), on NUREG-5512 (14, $34,197,826,857,859,875,1094,1212,1285)$ and on NRC guidance documents generally $(50,80,196,217$, $267,386,401,406,416,498,515,525,684,746,770$, $771,810,819,860,889,902,917,987,1079,1176)$. One commenter stated that the draft NUREG-1500 is not particularly useful in that, for most details, the reader is referred to another NUREG or NUREG/CR (1298).

Commenters requested that additional regulatory guidance be provided on the following subjects:

- Format and content of decommissioning plans (138),

- Methodologies for demonstrating compliance with the radiological criteria $(36,50,135,192$, $197,498,734,825,889,987,1157,1173$, $1232,1233,1275,1285,1288)$,

- How to monitor structures and materials to determine if additional decontamination is required $(192,323,1287)$,

- $\quad$ Dose modeling $(406,515,770,819,826,867$, $875,877,1173,1277)$,

- How to satisfy the ALARA requirement (96, $129,196,406,810,855,869,901,987,1086$, 1284),

- Regulation of sites maintained under license indefinitely $(646,823)$,

Circumstances supporting NRC authorization to assume effective reduction of exposure from earthen covers or barriers $(619,645,684$, 1085),
- $\quad$ SSAB operations $(576,1173,1196)$,

- Contents of a licensee's public participation plan $(319,583)$,

- Guidelines for selection of institutional controls $(1265,1280)$,

- Decommissioning portions of sites (710),

- $\quad$ Recycling criteria (1173)

With regard to the methodologies for demonstrating compliance with the radiological criteria (see second and fourth bullets above), commenters recommended that the NRC specify prescriptive and conservative screening options for licensees to use when limited quantities of radioactive material are involved or where full modeling is impractical $(40,192,321,931,1173)$.

A commenter suggested that previously prepared guides used by the NRC over the years in the decommissioning of licensed sites should serve as the foundation for any newly prepared guides $(801,805,810)$.

A commenter recommended that the NRC complete all guidance on the proposed rule and solicit public comments on these documents after they are prepared (1176).

\section{$4.5100 \mathrm{mrem} / \mathrm{y}$ "Safety Net"}

At 59 FR 43221 the NRC solicited comments on the adequacy of the $100 \mathrm{mrem}(1 \mathrm{mSv})$ per year value as the "safety net" to prevent exposures in excess of the public dose limits in the event that all site restrictions fail, and also solicited suggestions for alternatives to the proposed safety net, including the use of some fraction of the 100 $\mathrm{mrem} / \mathrm{y}$ (e.g., $75 \mathrm{mrem} / \mathrm{y}$ ) as the safety net, particularly the relative merits of selecting a fraction of the routine public dose limit in light of the required conservatism in the calculation of the dose, and the rationale for selecting some particular fraction. The NRC also solicited comments on the relative benefits and impacts of the NRC's proposed safety net and proposed options, including comments on the number of facilities that could be impacted by selection of alternative values.

Commenters expressed divergent views on the proposed 100 mrem ( $1 \mathrm{mSv}$ ) per year "safety net." Some commenters said that the proposed value is not restrictive enough $(362,363,461,473,502,1185,1228,1230$, $1250,1306)$. Other commenters said that $100 \mathrm{mrem} / \mathrm{y}$ is 
either unnecessarily stringent $(642,840)$ or is sufficient and a lesser alternative value is not necessary $(269,1074$, $1077,1078,1172,1201)$. Others suggested that lesser alternative values are needed $(502,1185,1216,1230$, 1250).

One commenter said that the "safety net" approach is "...another bad idea that should be dropped," and that neither the proposed $100 \mathrm{mrem} / \mathrm{y}$ nor the suggested alternative $75 \mathrm{mrem} / \mathrm{y}$ values are acceptable (502).

Others said that the maximum "safety net" limit should be $15 \mathrm{mrem} / \mathrm{y}$ above background $(1228,1230)$, or that it should be $30 \mathrm{mrem} / \mathrm{y}$ (1185). One commenter recommended setting a limit of $3 \mathrm{mrem} / \mathrm{y}$ "of residual radiation" (1250).

A commenter recommended an alternative value of perhaps $50 \mathrm{mrem} / \mathrm{y}$ or $75 \mathrm{mrem} / \mathrm{y}$ (1216), while another commenter recommended that no lesser alternative values be considered and agreed with the NRC's rationale for the $100 \mathrm{mrem} / \mathrm{y}$ value as adequate to prevent exposures in excess of public dose limits even if all site restrictions fail $(1074,1077,1078)$.

One commenter said that the $100 \mathrm{mrem} / \mathrm{y}$ "safety net" is too high as it takes credit for the maintenance of institutional controls over a 1,000-year time frame and because it is contrary to NCRP and ICRP guidance (362). Another said that if the EPA has a $25 \mathrm{mrem} / \mathrm{y}$ fuel cycle standard, the NRC is not justified in using $100 \mathrm{mrem} / \mathrm{y}$, "...no matter what NCRP and ICRP recommend" (461).

Commenters suggested that, for restricted-use sites, the NRC set a $100 \mathrm{mrem} / \mathrm{y}$ as a limit rather than as a safety net and require the application of the ALARA principle $(764,929,623)$, or that the NRC set a lesser maximum limit on the basis of "...the most exposed individual" (851).

Commenters said that there is no rationale or analysis for allowing the use of the $100 \mathrm{mrem} / \mathrm{y}$ "safety net" only when the conditions for unrestricted or restricted use cannot be met and that it would be arbitrary for the NRC to abandon the use of engineering controls to achieve either the $15 \mathrm{mrem} / \mathrm{y}$ or the $100 \mathrm{mrem} / \mathrm{y}$ standards $(642$, 738).

One commenter said that the NRC should establish a "safety net" of long-term community control and monitoring of sites (363).
None of the other commenters who responded to the 100 mrem/y proposed limit supported a lower value; some specifically did not support setting a $75 \mathrm{mrem} / \mathrm{y}$ value $(269,502,841,1074,1078)$. One commenter noted that the EPA's proposed rulemaking for 40 CFR Part 196 provides a $75 \mathrm{mrem} / \mathrm{y}$ limit for the release of federal facilities, and for consistency both the EPA's and the NRC's proposed regulations should be the same (1300).

\subsection{Site-Specific Advisory Boards}

At $59 \mathrm{FR} 43223$ the NRC requested comments on whether there are situations where the establishment of an SSAB would be inconsistent with other government regulations and statutes, or whether there are circumstances in which local government officials may not be allowed to participate in privately funded advisory groups.

One commenter stated that local government representatives have expressed concerns regarding the legitimacy of the SSAB's advice on issues that traditionally fall under the authority of elected local officials (1026). Another commenter stated that the NRC should be officially represented on the SSAB (193). Other commenters questioned whether an NRC representative could be a member of the SSAB, since the costs and expenses of the SSAB are to be paid by the licensees; 10 CFR Part 0, Subpart D may restrict the NRC from participating on a basis of conflict of interest $(60,108,123,259,759)$. One commenter questioned whether other government agencies might similarly be prohibited from participating (259).

Commenters stated that the SSAB proposal is inconsistent with the Federal Advisory Committee Act (FACA), $(982,1014,1036,1038)$ and inconsistent with the Administrative Procedure Act, Atomic Energy Act, and Freedom of Information Act $(983,984,1030)$. Commenters recommended that the NRC consider acting as the mediator of the SSAB $(274,930)$, or that the mediator be selected from an NRC-approved list (1189). Another commenter stated that the NRC should appoint an independent facilitator, preferably in the local community (558). Several commenters stated that, in addition to public participation in SSAB activities, a mechanism should be provided to assure public participation by others in the decommissioning cases $(441,472,506,563,565,568,579,580,581,584$, $1103,1104,1106,1236)$. 
One commenter stated that tribal governments pose distinct considerations that cannot be swept within the SSAB framework; tribal relations should be addressed in a separate rule or separate sections in the decommissioning rule (586). Some commenters suggested that SSABs should be used in special instances $(43,254,299,547,636,658,749,1069,1182)$.

Commenters suggested that in place of a requirement to convene an SSAB in each restricted release case, an alternative might be to add a requirement for licensees to address this issue in a proposed public participation plan submitted to the NRC for approval $(316,319,322,587$, $590,890,911,913,914)$.

Commenters recommended that the rule stipulate that membership on the SSAB should be balanced among the industry, the workers involved, and other members of the community because the proposed rule appears to be inappropriately weighted toward special interest representatives $(274,298,1190)$. Commenters also recommended that membership on the SSAB be offered to a representative of the potential waste disposal community $(169,469,760)$, to a member of the local government which has jurisdiction for the land use planning (585), and to a representative of people along the waste transport routes (469). One commenter stated that the membership of the SSAB should be limited and based on the specifics at a particular site (1182). Another commenter recommended that membership be restricted to duly elected government officials, and perhaps to Native American representatives (1181). Still another commenter stated that an SSAB should be appointed by state boards of health or environment, with another agency (either health or environment) making the ground rules of the committee (1225). One commenter stated that the size of the SSAB should be flexible, e.g., 10 to 15 members (1190). Some commenters stated that the proposed rule does not provide sufficient flexibility for proposing alternatives to the use of an SSAB to achieve necessary community participation in decommissioning activities $(319,704,890,910,911,912,913,1190)$. One commenter stated that the NRC should approve the structure and membership of the SSAB (588). One commenter recommended that the NRC delete the rule provisions that describe the functions and staffing of an SSAB (910).

Commenters questioned what constitutes "administrative support" as used in $\$ 20.1407(\mathrm{e}),(259,320,705)$.
Commenters recommended that the NRC provide further guidance on the actions expected to be taken by the licensee and the NRC on the advice or comments of the SSAB $(259,576)$. These actions should not be left unspecified and perhaps should consist of basic formats for procedure, information exchange, and communication of majority and minority comments (576).

Some commenters recommended that descriptive information on membership, administrative support, and participation capacity should be published as regulatory guidance or general policy rather than as part of the regulations $(262,1196)$.

\subsection{Readily Removable Residual Radioactivity}

At 59 FR 43223 the NRC solicited comments on how best to define the activities that should be included under the "Readily Removable Residual Radioactivity" provision. Several commenters stated that the definition of readily removable demonstrates shallow thinking and trivializes decontamination activities that need to be undertaken $(490,511,533)$. Another commenter stated that proposed $\S 20.1403$ (c) would require that the licensee as part of the decommissioning activities take reasonable steps to remove all "readily removable" residual radioactivity from the site. Therefore, the section should be revised to clarify that the term "readily removable" does not refer to situations in which residual activity could be removed by excavation and transportation of soil. Some commenters recommended that the definition of residual radioactivity be changed to exclude radon and naturally occurring radioactive materials (241, 400, 407, 408, 837). One commenter stated that radon should be included in the definition of residual activity $(429,454,476)$. Several commenters suggested that the NRC's definition of "residual activity" should exclude radioactive materials that were disposed of in accordance with the provisions of 10 CFR Part 20 $(245,246,263,829,1200)$. One commenter stated that it is appropriate to include wastes buried prior to 1981 pursuant to 10 CFR 20.304, but not wastes disposed of pursuant to 10 CFR $20.2002,(245,246,829)$. One commenter stated that the definition of residual radioactivity should include all waste at a site to be decommissioned (535). Another commenter recommended that the rule clarify that any decision made 
on whether to exhume buried materials would be based on a site-specific analysis of costs and benefits (830). This commenter also indicated that the exhumation of buried waste could result in large volumes of slightly contaminated soils and that off-site disposal costs would substantially increase costs and risks (830).

One commenter questioned the NRC's interpretation of "remove all readily removable residual activity" as specified in $\S 20.1403$ (c), (192). Another commenter stated that the provision of $\S 20.1403$ (c) is unnecessary and should be deleted (266). One commenter suggested that the NRC's concept of residual radioactivity should be dropped and licensees should be required to return a site to its pre-licensing state of natural background ( 511 , 512). One commenter stated that past NRC practice of allowing "easily or readily removable" was and is wrong (511).

\subsection{Groundwater}

At 59 FR 43224 the Nuclear Regulatory Commission (NRC) solicited comments on the proposed groundwater requirement. The NRC specifically solicited comments on whether a separate standard is needed for groundwater when the overall radiological criterion of $15 \mathrm{mrem} / \mathrm{y}$ total effective dose equivalent (TEDE) is applied to all pathways and on the appropriateness of applying the drinking-water standard ("at the tap") to groundwater.

Commenters stated that there is no need for a separate standard for groundwater because a single dose limit standard should be applied to all exposure pathways (38, $132,198,202,678,798.836,888,899,931,988,1016$, $1047,1053,1080,1158,1170,1174,1254)$.

Commenters stated that standards already exist for the protection of groundwater from uranium recovery facilities under 40 CFR Part 192, Subpart D and regulatory guidance on Alternative Concentration Limits $(105,120)$. Another commenter stated that regulations for protecting groundwater in uranium in-situ leaching operations are contained in 10 CFR Part 40, Appendix A, (242). A commenter stated that it favored setting a single dose criterion covering all pathways rather than having several values for specific media or exposure pathways, e.g., soil, groundwater, and direct radiation (1258). A commenter indicated that the limits in the decommissioning rule should be expressed as TEDE and thus combine doses from all pathways into one term (38):
Other commenters supported the NRC's establishing a separate groundwater standard $(337,344,428,518,573)$ and recommended that the rule require strict compliance with 40 CFR Part 141 standards for protection of groundwater supplies $(337,344,518,573)$. The U.S. Environmental Protection Agency (EPA) commented that a groundwater standard should be established at the levels specified in 40 CFR Part 141, (1144, 1145).

Commenters stated that it is inappropriate for the NRC to apply the EPA's drinking-water standards in 40 CFR Part 141 to groundwater $(38,45,105,120,132,198,202$, $242,404,678,679,798,836,888,899,1001,1011$, $1016,1047,1048,1049,1050,1052,1053,1080,1158$, $1170,1174,1206,1258,1290$ ). Further, commenters stated that the proposed new requirement would be duplicative $(105,120,242)$. Others stated that $40 \mathrm{CFR}$ Part 141 was not promulgated to apply to groundwater, but rather was promulgated to apply to a community water system, which serves at least 25 persons daily for at least 60 days per year, and regulates water as it comes out of the tap $(105,120,202,678,679,798,836,1016$, $1049,1050,1170,1268)$; no cost/benefit analysis has been performed for the application of 40 CFR Part 141 to groundwater $(679,988,1016,1047,1049,1050,1051$, 1053); the EPA's standards in 40 CFR Part 141 are based on obsolete dosimetry and are in need of revision (45, 102); and the Maximum Contaminant Levels (MCLs) contained in 40 CFR Part 141 include background contributions and are highly restrictive $(132,202,679$, $787,798,836,988,1048)$. Commenters recommended against the NRC's setting a groundwater standard equal to the EPA's drinking-water standards in 10 CFR Part 141, which governs water entering the home from community water systems and not the source of drinking water $(836,988,1001,1016,1049,1050,1170,1268$, 1290). One commenter stated that applying the EPA's drinking-water standard to decommissioned sites could adversely affect the disposal of radioactive wastes at waste disposal sites. Commenters also stated that the EPA's drinking-water standard is equal to a dose limit of $4 \mathrm{mrem} / \mathrm{y}$ which is substantially more restrictive than the NRC's proposed standard of $15 \mathrm{mrem} / \mathrm{y}$ for other exposure pathways $(988,1001)$. One commenter indicated that the NRC's proposed rule should require strict compliance with 40 CFR Part 141 to assure the protection of groundwater supplies (344). 


\subsection{Timeliness}

At 59 FR 43225 the NRC requested comments on whether the criteria contained in this proposed rule can be met within the time frames that were specified in the final rule on "Timeliness in Decommissioning of Materials Facilities." The Commission specifically requested comments on "whether licensees that anticipate having to establish an SSAB should be exempted from the generic timeliness requirements."

Several commenters stated that the use of SSABs is inconsistent with the NRC's rule on timeliness of decommissioning $(61,109,124,211,254,704,1081$, 1203). Commenters stated that licensees with an SSAB should be exempted from the timeliness requirements $(211,254,696,704,745,752,1037,1081,1203,1207)$. Numerous commenters stated that there will be a substantial increase in delays caused by the SSAB involvement $(61,104,109,119,124,211,251,253$, $254,255,259,635,657,696,697,698,704,710,752$, $1081,1167,1203,1207)$. In addition, several commenters suggested that the NRC exclude time devoted to SSAB involvement from the specified timing $(1081,1203,1207)$. One commenter stated that the NRC has adequately provided for a request to justify a delay or postponement in the Timeliness Rule at $\S 30.36(\mathrm{e})$, (1096). The same commenter indicated that any SSAB involvement that may affect the timeliness could be included in the provisions of $\S 30.36(\mathrm{e})$, (1097). One commenter stated that no waivers or exemptions from decommissioning requirements should be allowed because the issue of "timeliness" is subject to manipulation (521).

Further, the NRC requested comments on alternative provisions that could be made to assure timely decommissioning of the site. One commenter suggested that the sites be permitted to propose a reasonable schedule for decommissioning rather than be tied to an NRC mandated time schedule $(696,697,704,710)$. One commenter stated that an SSAB should be established only in special instances on a site by site basis, not as a general rule (254). Another commenter stated that licensees should be required to provide a reasonable schedule for the necessary steps to develop a decommissioning plan and a reasonable schedule for decommissioning should be specified in this plan (696). One commenter indicated that the NRC needs to coordinate the requirements under the existing and proposed rules so that licensees will not readily seek extensions of deadlines (211). A commenter believed this mechanism puts the "cart before the horse" and indicated that, if such schedules are required prior to completion of the decommissioning plan, the schedule would not incorporate changes typically required in the review and approval process (255).

Additionally, several commenters stated that site-specific decommissioning schedules should be submitted to the NRC well in advance of termination of operations (521, $696,704,1167)$.

\subsection{Agreement State Compatibility}

At 59 FR 43226 the NRC solicited comments as to what extent and under what circumstances an Agreement State should be authorized to establish more stringent requirements than those set forth in NRC criteria for decommissioning. One commenter stated that it is important to Agreement States that the NRC and EPA rules be compatible and allow flexibility for the Agreement States to develop and apply state regulations (35). Some commenters stated that the states should have the authority to demand stricter radiation protection standards than those imposed by the Federal Government $(63,70,72,225,432,467,526,963,969,1187)$.

Further, two commenters stated that the states must possess the authority to set more (but not less) restrictive criteria and regulations to provide adequate health and safety protection for their populations $(432,1187)$. Additionally, two commenters stated that the NRC should make provisions for local communities to set stricter standards so that they can protect themselves even if the NRC does not choose to protect them fully $(963,969)$. An Agreement State Department of Nuclear Safety indicated its objections to the idea that it would have to be "authorized to establish more stringent requirements" $(1072,1075)$. Other commenters indicated that the radiological criteria for decommissioning should be an area of absolute compatibility and under no circumstances should a state be permitted to impose a more stringent standard than specified in a federal standard $(268,709$, $891,915,992,1008,1142,1205)$. One commenter implied that if a community or other regulatory organization imposes a more restrictive standard it should accept or share the cost for the additional cleanup (1163). Another commenter recommended, in order to guarantee 


\section{$4.1115 \mathrm{mrem} / \mathrm{y}$ TEDE Appropriateness}

continued compatibility between the NRC and the Agreement States, that the rule must expressly establish the right of the licensees to seek exemption from the criteria and must specify the conditions that would govern whether a site would qualify for the exemption. Moreover, the NRC must require that the Agreement States provide similar opportunity for Agreement State licensees to seek exemption from the parallel Agreement State criteria, and any NRC criteria for exemptions must be followed in decision-making in respect to the decommissioning of nuclear sites under Agreement State authority (824).

\section{$4.1115 \mathrm{mrem} / \mathrm{y}$ TEDE Appropriateness}

At 59 FR 63733 the NRC requested comments on the appropriateness of the $15 \mathrm{mrem} / \mathrm{y}$ TEDE. The DOE stated that the use of a $15 \mathrm{mrem} / \mathrm{y}$ standard might create inconsistencies with soil cleanup criteria for compliance with 40 CFR Part 192, the Uranium Mill Tailings Radiation Control Act (UMTRCA) standards, and these inconsistencies would create problems with acceptance of sites already released for unrestricted use under UMTRCA and the Formerly Utilized Site Remedial Action Programs (FUSRAP)(1276). Many commenters opposed $15 \mathrm{mrem} / \mathrm{y}$ as too high for numerous reasons, including the need to reduce radioactivity concentration levels to background levels $(62,334,421,434,436$, $443,460,462,537,540,849,1306) ; 15 \mathrm{mrem} / \mathrm{y}$ represents a large increment of naturally-occurring background radiation (496); the proposed $15 \mathrm{mrem} / \mathrm{y}$ limit exceeds the corresponding British limits of 10 mrem/y and ALARA dose of $2 \mathrm{mrem} / \mathrm{y}$; the dose limit is inconsistent with the Comprehensive Environmental Response and Compensation Liability Act (CERCLA) risk goals of $10^{-4}$ to $10^{-6},(564) ; 15 \mathrm{inrem} / \mathrm{y}$ provides inadequate public protection $(5,19,22,25,152,950$, $1229)$ and is not sufficiently conservative $(433,462,499$, $850)$; this would possibly establish a precedent to reintroduce the concept Below Regulatory Concern (BRC)(847); and the NRC previously rejected a proposed BRC limit of $10 \mathrm{mrem} / \mathrm{y}$ which is less than the current level proposed (950).

Many commenters opposed the $15 \mathrm{mrem} / \mathrm{y}$ TEDE as too restrictive for several reasons, including that the $\mathrm{NRC}$ has not explained or provided technical justification for the need of such a conservative limit $(12,13,54,214,233$,
$236,289,309,318,364,375,376,377,379,394,603$, $627,628,667,668,669,670,671,717,728,729,730$, $731,732,747,753,807,808,864,1062,1065,1082$, $1085,1119,1121,1122,1127,1129,1133,1135,1147$, $1154,1165,1199)$. In addition, some commenters stated that the $15 \mathrm{mrem} / \mathrm{y}$ limit is well below the dose threshold where biological effects have been observed $(75,289$, $374,399,410,638,1088,1088)$. Some commenters also stated that the $15 \mathrm{mrem} / \mathrm{y}$ limit is politically based and does not conform with technological guidance from national and international radiation standards groups $(102,117,1082)$. Some commenters stated that the 15 $\mathrm{mrem} / \mathrm{y}$ limit is so low that demonstration of compliance might be difficult or virtually impossible to achieve (97, $550,628,656,668,673,733,789,804,1089,1275$, 1285). Other commenters stated that the $15 \mathrm{mrem} / \mathrm{y}$ limit would lead to extraordinary costs, difficulties, and delays in decommissioning $(160,215,375,377,379,383,550$, $669,670,747,817,924,1199,1285)$. Others have indicated that the $15 \mathrm{mrem} / \mathrm{y}$ is within the natural variations and fluctuations of background radiation levels $(215,375,631,637,638,639,668,674,677,708,730$, $807,813,999,1088,1275)$. Other commenters stated that the $15 \mathrm{mrem} / \mathrm{y}$ limit would set a precedent for sites containing naturally-occurring radioactive materials (NORM) and that the limit cannot be met or is too low if applied to these materials $(373,375,376,378,379,394$, $395,1276)$. One commenter indicated that the 15 $\mathrm{mrem} / \mathrm{y}$ limit is less than the internal radiations that people, in effect, give themselves (638). One commenter stated that it is unnecessary for the NRC to use a 15 $\mathrm{mrem} / \mathrm{y}$ limit to ensure that doses from multiple sources do not exceed $100 \mathrm{mrem} / \mathrm{y}$ because it would be unusual for an individual to be exposed from multiple sources approaching the limit especially when current practice and ALARA requirements cause most of these licensees to operate far below regulatory limits (1154).

Additionally, commenters stated that the $15 \mathrm{mrem} / \mathrm{y}$ limit is inconsistent with the recommendations of the National Council on Radiation Protection and Measurements (NCRP) and the International Commission on Radiological Protection (ICRP) $(54,57,100,101,115$, $116,214,215,234,289,290,301,313,364,374,383$, $384,387,544,554,641,662,667,672,728,806,1019$, $1082,1121,1122,1153,1165,1174,1177,1182)$ and also inconsistent with present NRC regulations $(55,57$, $214,289,291,388,667,668,806,814,888,898,925$, $1174,1274,1305)$ as well as inconsistent with EPA regulations in 40 CFR Part 190 and 40 CFR Part 191 $(806,888,898,1174,1274)$. A commenter indicated 
that the $15 \mathrm{mrem} / \mathrm{y}$ limit will become incompatible with future EPA requirements in 40 CFR Part 141, (404). Several commenters stated that the $15 \mathrm{mrem} / \mathrm{y}$ limit cannot be achieved at many facilities $(668,673,745,771$, $791,1276)$. The $15 \mathrm{mrem} / \mathrm{y}$ limit is unduly restrictive when compared with radiation protection standards for radon $(675,677,708,753)$. One commenter stated that the proposed cleanup standard of $15 \mathrm{mrem} / \mathrm{y}$ would not lead to minimization of waste, but would drastically increase the volume of radioactive wastes without any discernible reduction in potential health risks (762); others said that it would result in the transfer of large amounts of wastes or soil to designated disposal sites $(671,673,1147,1148)$.

Some commenters stated that a dose limit of $15 \mathrm{mrem} / \mathrm{y}$ is adequate $(9,79,88,126,128,143,171,410,412,1217$, 1218,1243 ) but cautioned that they do not believe that there are any measurable health effects associated with doses at this level $(88,143,410,412)$. Further, some commenters who favored the $15 \mathrm{mrem} / \mathrm{y}$ limit stated that they did not believe it necessary to perform ALARA analyses to determine if additional cleanups below 15 $\mathrm{mrem} / \mathrm{y}$ are required $(88,128,143)$. 



\section{COMMENTS ON RADIOLOGICAL CRITERIA FOR}

\section{DECOMMISSIONING FROM TRANSCRIPTS OF NRC/AGREEMENT- STATE MEETINGS}

The transcripts of the "Organization of Agreement State Managers' Workshop and Public Meeting on Rulemakings" of July 12-14, 1994, and of the "1994 All Agreement States Meeting" of October 24, 1994, meetings between the Agreement States and the Nuclear Regulatory Commission, were reviewed for comments on radiological criteria for decommissioning. There were relatively few comments on radiological criteria for decommissioning, and almost all of these comments were peripheral to subjects of more immediate interest at the meetings.

NRC staff members presented much of the discussion on radiological criteria in briefing the Agreement State attendees, or in responding to their questions, on the status of decommissioning-related rulemaking ( $\mathrm{Tr}$. $7 / 12 / 94$, p. 211 ; Tr. $10 / 24 / 94$, pp. 300,302 ). They also noted the establishment of an electronic bulletin board for the decommissioning rulemaking (Tr. 10/24/94, p. 143), and discussed recordkeeping in connection with decommissioning (Tr. 10/24/94, p. 294).

An Agreement State representative asked whether the decommissioning rulemaking would proceed and become effective simultaneously with rulemakings on financial assurance and on timeliness ( $\mathrm{Tr} .7 / 12 / 94$, p. 213).

A commenter asked for the rationale for a decommissioning radiological criterion of $15 \mathrm{mrem} / \mathrm{y}$ in light of the $100 \mathrm{mrem} / \mathrm{y}$ criterion for licensed operations in unrestricted areas, and asked how the $15 \mathrm{mrem} / \mathrm{y}$ criterion "comports" with EPA protective action guides (Tr. 7/12/94, p. 216). This commenter also said that the criteria should be the same for decommissioning as for operations (Tr. 7/12/94, p. 219). Another commenter asked if the NRC's decommissioning rule were being coordinated with the EPA (Tr. 7/12/94, p. 224).

One commenter suggested that licensees could "make sure" to have an accident in order to be subject to cleanup criteria less stringent than those proposed for decommissioning (Tr. 7/12/94, p. 219).

One commenter said that guidance is needed on whether the $4 \mathrm{mrem} / \mathrm{y}$ drinking-water limit is included in or is in addition to the $15 \mathrm{mrem} / \mathrm{y}$ proposed decommissioning criterion (Tr. 7/12/94, p. 220).
One commenter asked for a definition of "critical group" (Tr. 7/12/94, p. 221).

A commenter asked why it is necessary to have "...a decommissioning objective that establishes yet another limit" (Tr. 7/12/94, p.222). The same commenter noted that the public would view an indistinguishable-frombackground objective as "...the legitimate goal of decommissioning," and would have "...a problem accepting 15 mrem [sic] above that," and also noted that there is no similar statement in the low-level waste rule (Tr. 1/12/94, p. 223).

A commenter noted problems with allowing decommissioning with restricted termination of a license (Tr. 7/12/94, p.223).

One commenter said that the cooperative NRC/Agreement State programs for establishing criteria and for monitoring around nuclear plants will assist states in "...establishing a clean-up criterion standard" ( $\mathrm{Tr}$. 10/24/94, p. 42).

One commenter suggested that the proposed $15 \mathrm{mrem} / \mathrm{y}$ decommissioning criterion would necessitate a longneeded major revision of 10 CFR Part 40 concerning general licenses for source material (Tr. 10/24/94, p.299).

One commenter said that Agreement States would "...really have to be able to get in on, or know that the NRC is going to get in to look at [sites with radioactivewaste disposal problems] before they're decommissioned" (Tr. 10/24/94, p. 342).

A commenter said that it would be convenient for Agreement States to have data available from the NRC on radioactive materials and licenses at [military] bases scheduled for closure ( $\mathrm{Tr}, 10 / 24 / 94$, p. 346). 

APPENDIX A

COMMENTER LISTING 
Appendix $A$ Commenter Listing

\section{COMMENTER LISTING}

\section{DOCKET COMMENTER \\ NUMBER}

1

2

9

10

11

12

13

14

Bret Leslie

Bret Leslie

Frazier L. Bronson

Bronson, Frazier L.

Barkley, Richard S.

Bugbee, Barbara

Thorpe, Mignon

Edwards, Sarah J.

David I. Chanin

G. Wayne Kerr

Matthew W. Kozak

Lewis, Marvin I.
Institute for Energy and Environmental Research

Institute for Energy and Environmental Research

Committee to Bridge the Gap

Cinquemani, Drs. D. K. \& F. L.

Technadyne Engineering Consultants, Inc.

Illinois Department of Nuclear Safety

Sandia National Laboratories

Allied Signal Chemicals

M.D. Kosmider

\section{ORGANIZATION OR GROUP*}

1

1

1

11

11

11

11

11

11

2

7

9

11

10

\footnotetext{
* For information, organization groups are grouped as follows: 1) Citizen/Environmental Organizations, 2) Cleanup/Consultants, 3) Local Government, 4) Medical Community and Non-Fuel-Cycle Licensees, 5) Nuclear Utilities, 6) Professional Society/Standard-Setting Organizations, 7) State Government, 8) Tribal Organizations, 9) Federal Agencies, 10) Fuel Cycle Industry, 11) Individuals.
} 
Appendix $A$

DOCKET COMMENTER

NUMBER

Power Resources, Inc.

Paul R. Hildenbrand

Sierra Club, New Jersey Chapter

1

Sidney J. Goodman

Lewis, Marvin I.

Debolt, Bob

Traum, Samuel B.

Geary, Barbara

Stewart, James

1

Anthony, Robert L.

Ygdrasil Institute

1

Mary Byrd Davis

Gehrke, Robert J.

Gaims, Augustine \& Horace

Center for Biological Monitoring

H.G. Brack

Meddick \& Remington, Sherry L. \& Stuart A.

New York State

Department of Environmental Conservation

Norman H. Nosenchuck

Mid-Island Radiation Alert

Miriam Goodman

Michigan Department of Public Health

George W. Bruchmann 
Wyoming Mining Association Marion Loomis

Envirocare of Utah, Inc.

Charles A. Judd

ORISE 2

Eric W. Abelquist

New York State Energy Office

Atlantic Richfield Company

R. S. Ziegler

Peter Loysen Associates

Peter Loysen

Molten Metal Technology, Inc.

Randall Jones

Carey, Corinne

Chem-Nuclear Systems, Inc.

William House

46 Lewis, Marvin I. 
Rio Algom Mining Corporation

Bill Ferdinand

American Nuclear Society

6

Alan Walter

51

CORAR

4

Mark Doruff

52

IEER

1

53

Dam, A. Scott

11

54

Dupont White Pigment and Mineral Products

4

Pearson, Charles E.

Environmental Coalition on Nuclear Power (ECNP) Judith Johnsrud

Consumers Power

Robert Fenech

Woodward-Clyde Consultants

Rudolph Torrini

Western States Legal Foundation Michael Veiluva

60 B\&W Nuclear Environmental Services, Inc. D.W. Zeff

Urte H. Barker 
David G. Culberson

64

American Mining Congress

James E. Gilchrist

65

Kerr-McGee Corporation

George B. Rice

META

Barry C. Mingst

Commonwealth Edison

Michael J. Wallace

69 Westinghouse Electric Corporation

Stephen A. Green

Nuclear Information and Resource Service

Michael Mariotte

Yankee Atomic Electric Company

Jane M. Grant

Nuclear Energy Institute

John F. Schmitt, CHP

74 State of Illinois

Thomas W. Ortciger, Director

Michael Kay

Weizenbaum, Ruth 
79 Winston \& Strawn

Joseph B. Knotts, Jr.

80 Sequoyah Fuels

John Ellis, President

Lance Hughes

J. A. Ransohoff, President

U.S. Environmental Protection Agency

Richard E. Sanderson

Director, Office of Federal Activities

M.L. Bowling, Manager Leonard R. Smith, CHP

Southern California Edison Company

Arizona Public Service Company

L. C. Kelly, Director 
Appendix $A$

DOCKET COMMENTER

Commenter Listing

NUMBER

92

Texas Department of Health

Richard A. Ratliff, P.E.

93

94

95

96

97

98

99

100

101
Ohio Department of Health

Robert E. Owen, Chief

Citizens Research \&

Environmental Watch (CREW)

Boston Edison

E. T. Boulette

City of Sylvania

Margaret Rauch

Cope, Terry

Natale, Elizabeth

Department of Energy

Berube, Raymond P.

NUCORE Consulting Services, Inc.

Patel, Gopal J.

Mauner, Jeffrey $R$.

\section{GROUP}

7

7

1

5

3

11

11

9

2

11 


\section{APPENDIX B}

COMMENT REFERENCES FOR THE PROPOSED RULE 


\section{APPENDIX 13 - COMMENT REFERENCES FOR THE PROPOSED RULE}

This appendix can be used to determine the origin of ench comment and where each comment is used in the summary of comments on the proposed rule. The listed information includes a comment number, the particular summary sections (issues) to which it contributes, the name or abbreviated name of the commenter, the docket number of the letter containing the comment, and the page of the letter on which the conment begins.

About half of the comments are used in more than one summary section, but the comment number is unique and remains with the comment in each summary section where it is used. The last name of the commenter is listed or, if an organization, the full or abbreviated name. For example:

\begin{tabular}{|c|c|c|c|}
\hline $\begin{array}{l}\text { Comment } \\
\text { Number }\end{array}$ & $\begin{array}{l}\text { Report } \\
\text { Section }\end{array}$ & Name & $\begin{array}{l}\text { Docket } \\
\text { Number }\end{array}$ \\
\hline 29 & $\begin{array}{l}2.3 .4 \\
2.5 .2\end{array}$ & E.I. DU PONT DE NEMOURS \& CO. & 6 \\
\hline
\end{tabular}

In this (fictitious) example, comment number 29 is used in sections 2.3.4 and 2.5.2 of this report. The name of the commenter is isted; the letter is docketed as number 6 , and the comment begins on page 2 of the first appendix to that letter. If no alphabet character is used, the number refers to the page of the basic letter; A, B, C, etc. refer to the successive appendices of a letter.

Thus, every comment is assigned a single number, retains that same number in each issue where it is summarized, and can be traced to a page in its docketed source letter.

The following pages contain a column listing of these data per comment number. 


\begin{tabular}{|c|c|c|c|c|}
\hline \multicolumn{5}{|c|}{$\begin{array}{l}\text { Comment Reference Listing } \\
\text { (For Section } 2 \text { of This Report) }\end{array}$} \\
\hline $\begin{array}{l}\text { Comment } \\
\text { Numbers }\end{array}$ & $\begin{array}{l}\text { Issue } \\
\text { Numbers }\end{array}$ & Commenter & $\begin{array}{l}\text { Docket } \\
\text { Letter }\end{array}$ & $\begin{array}{l}\text { Page } \\
\text { Number }\end{array}$ \\
\hline 1 & 2.6 .5 & INSTITUTE FOR ENERGY AND ENVIRONMENTAL RESEARCH & 1 & 1 \\
\hline 2 & 2.6 .5 & INSTITUTE FOR ENERGY AND ENVIRONMENTAL RESEARCH & 1 & 1 \\
\hline 3 & 2.2 .4 & INSTITUTE FOR ENERGY AND ENVIRONMENTAL RESEARCH & 1 & 2 \\
\hline 4 & 2.6 .5 & INSTITUTE FOR ENERGY AND ENVIRONMENTAL RESEARCH & 2 & 1 \\
\hline 5 & 2.3 .5 & COMMITTEE TO BRIDGE THE GAP & 3 & 1 \\
\hline 5 & 2.5 .1 & COMMITTEE TO BRIDGE THE GAP & 3 & 1 \\
\hline 6 & 2.6 .2 & COMMITTEE TO BRIDGE THE GAP & 3 & 1 \\
\hline 6 & 2.6 .4 & COMMITTEE TO BRIDGE THE GAP & 3 & 1 \\
\hline 7 & 2.10 .2 & COMMITTEE TO BRIDGE THE GAP & 3 & 2 \\
\hline 8 & 2.3 .2 & COMMITTEE TO BRIDGE THE GAP & 3 & 2 \\
\hline 9 & 2.3 .2 & BRONSON, FRAZIER L. & 4 & 2 \\
\hline 9 & 2.3 .5 & BRONSON, FRAZIER L. & 4 & 2 \\
\hline 9 & 2.5 .1 & BRONSON, FRAZIER L. & 4 & 2 \\
\hline 9 & 2.5 .2 & BRONSON, FRAZIER L. & 4 & 2 \\
\hline 10 & 2.3 .8 & BARKLEY, RICHARD S. & 5 & 2 \\
\hline 11 & 2.3 .4 & BARKLEY, RICHARD S. & 5 & 3 \\
\hline 12 & 2.3 .5 & BARKLEY, RICHARD S. & 5 & 3 \\
\hline 12 & 2.3 .7 & BARKLEY, RICHARD S. & 5 & 3 \\
\hline 13 & 2.3 .5 & BARKLEY, RICHARD S. & 5 & 3 \\
\hline 13 & 2.3 .8 & BARKLEY, RICHARD S. & 5 & 3 \\
\hline 13 & 2.10 .2 & BARKLEY, RICHARD S. & 5 & 3 \\
\hline 14 & 2.4 .1 & BARKIEY, RICHARD S. & 5 & 4 \\
\hline 14 & 2.10 .1 & BARKLEY, RICHARD S. & 5 & 4 \\
\hline 14 & 2.10 .2 & BARKLEY, RICHARD S. & 5 & 4 \\
\hline 15 & 2.2 .3 & BARKLEY, RICHARD S. & 5 & 5 \\
\hline 16 & 2.7 .2 & BARKLEY, RICHARD $S$. & 5 & 6 \\
\hline 16 & 2.8 .1 & BARKLEY, RICHARD S. & 5 & 6 \\
\hline 16 & 2.8 .3 & BARKLEY, RICHARD S. & 5 & 6 \\
\hline 16 & 2.8 .4 & BARKLEY, RICHARD S. & 5 & 6 \\
\hline 17 & 2.9 .3 & BUGBEE, BARBARA & 6 & 1 \\
\hline 17 & 2.10 .4 & BUGBEE, BARBARA & 6 & 1 \\
\hline 18 & 2.7 .2 & BUGBEE, BARBARA & 6 & 1 \\
\hline 18 & 2.8 .1 & BUGBEE, BARBARA & 6 & 1 \\
\hline 18 & 2.8 .3 & BUGBEE, BARBARA & 6 & 1 \\
\hline 19 & 2.3 .5 & CINQUEMANI, Dr. D.K. \& F.L. & 7 & 1 \\
\hline 19 & 2.5 .1 & CINQUEMANI, Dr. D.K. F.L. & 7 & 1 \\
\hline 19 & 2.6 .4 & CINQUEMANI, Dr. D.K. \& & 7 & 1 \\
\hline 20 & 2.7 .2 & CINQUEMANI, Dr. D.K. \& F.L. & 7 & 1 \\
\hline
\end{tabular}




\begin{tabular}{|c|c|c|c|c|c|}
\hline $\begin{array}{l}\text { Comment } \\
\text { Numbers } \\
\end{array}$ & $\begin{array}{l}\text { Issue } \\
\text { Numbers }\end{array}$ & Commenter & & $\begin{array}{l}\text { Docket } \\
\text { Letter }\end{array}$ & $\begin{array}{l}\text { Page } \\
\text { Number }\end{array}$ \\
\hline 20 & 2.8 .1 & CINQUEMANI, Dr. D.K. \& & F.L. & 7 & 1 \\
\hline 20 & 2.8 .3 & CINQUEMANI， Dr. D.K. \& & F.I. & 7 & 1 \\
\hline 20 & 2.8 .4 & CINQUEMANI， Dr. D.K. \& & F.L. & 7 & 1 \\
\hline 21 & 2.10 .4 & CINQUEMANI， Dr. D.K. \& & F.L. & 7 & 1 \\
\hline 22 & 2.3 .5 & THORPE, MIGNON & & 8 & 1 \\
\hline 22 & 2.5 .1 & THORPE, MIGNON & & 8 & 1 \\
\hline 22 & 2.6 .4 & THORPE, MIGNON & & 8 & 1 \\
\hline 23 & 2.10 .4 & THORPE, MIGNON & & 8 & 1 \\
\hline 24 & 2.8 .1 & THORPE, MIGNON & & 8 & 1 \\
\hline 24 & 2.8 .3 & THORPE, MIGNON & & 8 & 1 \\
\hline 24 & 2.8 .4 & THORPE, MIGNON & & 8 & 1 \\
\hline 25 & 2.3 .5 & EDWARDS， SARAH J. & & 9 & 1 \\
\hline 25 & 2.5 .1 & EDWARDS, SARAH J. & & 9 & 1 \\
\hline 25 & 2.6 .4 & EDWARDS, SARAH J. & & 9 & 1 \\
\hline 26 & 2.10 .4 & EDWARDS, SARAH J. & & 9 & 1 \\
\hline 27 & 2.8 .1 & EDWARDS, SARAH J. & & 9 & 1 \\
\hline 27 & 2.8 .3 & EDWARDS, SARAH J. & & 9 & 1 \\
\hline 27 & 2.8 .4 & EDWARDS， SARAH J. & & 9 & 1 \\
\hline 28 & 2.10 .1 & TECHNADYNE ENGINEERING & CONSULTANTS, INC. & 10 & 1 \\
\hline 29 & 2.1 .6 & TECHNADYNE ENGINEERING & CONSULTANTS, INC. & 10 & 1 \\
\hline 29 & 2.2 .5 & TECHNADYNE ENGINEERING & CONSULTANTS, INC. & 10 & 1 \\
\hline 30 & 2.2 .5 & TECHNADYNE ENGINEERING & CONSULTANTS, INC. & 10 & 1 \\
\hline 30 & 2.10 .5 .1 & TECHNADYNE ENGINEERING & CONSULTANTS, INC. & 10 & 1 \\
\hline 31 & 2.11 .0 & TECHNADYNE ENGINEERING & CONSULTANTS, INC. & 10 & 2 \\
\hline 32 & 2.2 .1 & TECHNADYNE ENGINEERING & CONSULTANTS, INC. & 10 & 2 \\
\hline 33 & 2.10 .1 & TECHNADYNE ENGINEERING & CONSULTANTS, INC. & 10 & 2 \\
\hline 34 & 2.10 .1 & TECHNADYNE ENGINEERING & CONSULTANTS, INC. & 10 & 2 \\
\hline 35 & 2.10 .3 & ILLINOIS: G. WAYNE KER & & 11 & 4 \\
\hline 35 & 2.10 .5 .1 & ILLINOIS: G. WAYNE KER & & 11 & 4 \\
\hline 36 & 2.3 .6 & ILLINOIS: G. WAYNE KER & & 11 & 5 \\
\hline 36 & 2.10 .1 & ILLINOIS: G. WAYNE KER & & 11 & 5 \\
\hline 36 & 2.10 .2 & ILLINOIS: G. WAYNE KER & & 11 & 5 \\
\hline 37 & 2.3 .2 & ILLINOIS: G. WAYNE KER & & 11 & 5 \\
\hline 37 & 2.3 .3 & ILLINOIS: G. WAYNE KER & & 11 & 5 \\
\hline 38 & 2.4 .4 & ILLINOIS: G. WAYNE KER & & 11 & 5 \\
\hline 39 & 2.4 .2 & ILLINOIS: G. WAYNE KER & & 11 & 6 \\
\hline 39 & 2.10 .5 .2 & ILLINOIS: G. WAYNE KER & & 11 & 6 \\
\hline 40 & 2.10 .1 & ILLINOIS: G. WAYNE KER & & 11 & 6 \\
\hline 40 & 2.10 .2 & ILLINOIS: G. WAYNE KER & & 11 & 6 \\
\hline 41 & 2.10 .2 & ILLINOIS: G. WAYNE KER & & 11 & 6 \\
\hline 42 & 2.2 .2 & ILIINOIS: G. WAYNE KER & & 11 & 7 \\
\hline
\end{tabular}




\begin{tabular}{|c|c|c|c|}
\hline 42 & 2.2 .3 & ILLINOIS: G. WAYNE KERR & 11 \\
\hline 43 & 2.7 .2 & ILLINOIS: G. WAYNE KERR & 11 \\
\hline 43 & 2.8 .1 & ILLINOIS: G. WAYNE KERR & 11 \\
\hline 43 & 2.8 .2 & ILIINOIS: G. WAYNE KERR & 11 \\
\hline 44 & 2.7 .1 & ILLINOIS: G. WAYNE KERR & 11 \\
\hline 45 & 2.4 .4 & SANDIA NATIONAI LABORATORIES & 12 \\
\hline 46 & 2.10 .4 & SANDIA NATIONAL LABORATORIES & 12 \\
\hline 47 & 2.3 .1 & LEWIS, MARVIN I. & 13 \\
\hline 48 & 2.12 .0 & LEWIS, MARVIN I. & 13 \\
\hline 49 & 2.3 .1 & ALLIED SIGNAL CHEMICALS & 14 \\
\hline 50 & 2.10 .1 & ALLIED SIGNAL CHEMICALS & 14 \\
\hline 50 & 2.10 .2 & ALLIED SIGNAL CHEMICALS & 14 \\
\hline 51 & 2.12 .0 & POWER RESOURCES, INC. & 15 \\
\hline 52 & 2.2 .1 & POWER RESOURCES, INC. & 15 \\
\hline 53 & 2.3 .2 & POWER RESOURCES, INC. & 15 \\
\hline 54 & 2.3 .5 & POWER RESOURCES, INC. & 15 \\
\hline 54 & 2.3 .6 & POWER RESOURCES, INC. & 15 \\
\hline 55 & 2.3 .5 & POWER RESOURCES, INC. & 15 \\
\hline 55 & 2.3 .6 & POWER RESOURCES, INC. & 15 \\
\hline 55 & 2.10 .5 .3 & POWER RESOURCES, INC. & 15 \\
\hline 56 & 2.2 .3 & POWER RESOURCES, INC. & 15 \\
\hline 57 & 2.3 .5 & POWER RESOURCES, INC. & 15 \\
\hline 57 & 2.3 .6 & POWER RESOURCES, INC. & 15 \\
\hline 57 & 2.3 .7 & POWER RESOURCES, INC. & 15 \\
\hline 57 & 2.5 .1 & POWER RESOURCES, INC. & 15 \\
\hline 57 & 2.10 .5 .3 & POWER RESOURCES, INC. & 15 \\
\hline 58 & 2.1 .8 & POWER RESOURCES, INC. & 15 \\
\hline 58 & 2.2 .3 & POWER RESOURCES, INC. & 15 \\
\hline 59 & 2.7 .2 & POWER RESOURCES, INC. & 15 \\
\hline 60 & 2.3 .8 & POWER RESOURCES, INC. & 15 \\
\hline 60 & 2.8 .2 & POWER RESOURCES, INC. & 15 \\
\hline 61 & 2.7 .2 & POWER RESOURCES, INC. & 15 \\
\hline 61 & 2.8 .6 & POWER RESOURCES, INC. & 15 \\
\hline 61 & 2.10 .5 .3 & POWER RESOURCES, INC. & 15 \\
\hline 62 & 2.3 .2 & SIERRA CLUB, NEW JERSEY CHAPTER & 16 \\
\hline 62 & 2.3 .5 & SIERRA CLUB, NEW JERSEY CHAPTER & 16 \\
\hline 62 & 2.12 .0 & SIERRA CLUB, NEW JERSEY CHAPTER & 16 \\
\hline 63 & 2.10 .5 .2 & SIERRA CLUB, NEW JERSEY CHAPTER & 16 \\
\hline 64 & 2.9 .3 & SIERRA CLUB, NEW JERSEY CHAPTER & 16 \\
\hline 65 & 2.3 .2 & LEWIS, MARVIN I. & 17 \\
\hline 65 & 2.10 .6 & LEWIS, MARVIN I. & 17 \\
\hline
\end{tabular}




\begin{tabular}{|c|c|c|c|}
\hline 65 & 2.12 .0 & LEWIS, MARVIN I. & 17 \\
\hline 66 & 2.3 .2 & DEBOLT, BOB & 18 \\
\hline 66 & 2.9 .3 & DEBOLT, BOB & 18 \\
\hline 66 & 2.12 .0 & DEBOLT, $B O B$ & 18 \\
\hline 67 & 2.9 .3 & TRAUM, SAMUEL B. & 19 \\
\hline 68 & 2.12 .0 & GEARY， BARBARA & 20 \\
\hline 69 & 2.3 .2 & GEARY, BARBARA & 20 \\
\hline 69 & 2.9 .3 & GEARY， BARBARA & 20 \\
\hline 70 & 2.3 .2 & GEARY, BARBARA & 20 \\
\hline 70 & 2.10 .5 .2 & GEARY, BARBARA & 20 \\
\hline 71 & 2.9 .3 & STEWART, JAMES A & 21 \\
\hline 71 & 2.12 .0 & STEWART, JAMES A & 21 \\
\hline 72 & 2.3 .2 & ANTHONY, ROBERT L. & 22 \\
\hline 72 & 2.9 .3 & ANTHONY, ROBERT I. & 22 \\
\hline 72 & 2.10 .5 .2 & ANTHONY, ROBERT I. & 22 \\
\hline 72 & 2.12 .0 & ANTHONY, ROBERT I. & 22 \\
\hline 73 & 2.9 .3 & YGDRASIL INSTITUTE & 23 \\
\hline 74 & 2.3 .2 & GEHRKE, ROBERT J. & 24 \\
\hline 74 & 2.3 .8 & GEHRKE, ROBERT J. & 24 \\
\hline 74 & 2.7 .2 & GEHRKE, ROBERT J. & 24 \\
\hline 75 & 2.3 .2 & GEHRKE, ROBERT J. & 24 \\
\hline 75 & 2.3 .5 & GEHRKE, ROBERT J. & 24 \\
\hline 75 & 2.3 .7 & GEHRKE, ROBERT J. & 24 \\
\hline 76 & 2.2 .5 & GEHRKE, ROBERT J. & 24 \\
\hline 77 & 2.3 .8 & GEHRKE, ROBERT J. & 24 \\
\hline 78 & 2.3 .2 & GAIMS, AUGUSTINE \& HORACE & 25 \\
\hline 79 & 2.3 .5 & CENTER FOR BIOLOGICAL MONITORING & 26 \\
\hline 79 & 2.5 .1 & CENTER FOR BIOLOGICAL MONITORING & 26 \\
\hline 79 & 2.6 .1 & CENTER FOR BIOLOGICAL MONITORING & 26 \\
\hline 80 & 2.10 .1 & CENTER FOR BIOLOGICAL MONITORING & 26 \\
\hline 81 & 2.10 .4 & CENTER FOR BIOLOGICAL MONITORING & 26 \\
\hline 82 & 2.12 .0 & MEDDICK \& REMINGTON, SHERRY L. \& STUART A. & 27 \\
\hline 83 & 2.3 .7 & MEDDICK \& REMINGTON, SHERRY L. \& STUART A. & 27 \\
\hline 84 & 2.9 .3 & MEDDICK \& REMINGTON, SHERRY L. \& STUART A. & 27 \\
\hline 85 & 2.12 .0 & $\begin{array}{l}\text { NEW YORK STATE DEPARTMENT OF ENVIRONMENTAL } \\
\text { CONSERVATION }\end{array}$ & 28 \\
\hline 86 & 2.10 .5 .1 & $\begin{array}{l}\text { NEW YORK STATE DEPARTMENT OF ENVIRONMENTAL } \\
\text { CONSERVATION }\end{array}$ & 28 \\
\hline 87 & 2.3 .7 & NEW YORK STATE DEPARTMENT OF ENVIRONMENTAL & 28 \\
\hline
\end{tabular}




\begin{tabular}{|c|c|c|c|c|}
\hline $\begin{array}{l}\text { Comment } \\
\text { Numbers }\end{array}$ & $\begin{array}{l}\text { Issue } \\
\text { Numbers }\end{array}$ & Commenter & $\begin{array}{l}\text { Docket } \\
\text { Letter }\end{array}$ & $\begin{array}{l}\text { Page } \\
\text { Number }\end{array}$ \\
\hline 87 & 2.3 .8 & $\begin{array}{l}\text { NEW YORK STATE DEPARTMENT OF ENVIRONMENTAL } \\
\text { CONSERVATION }\end{array}$ & 28 & 1 \\
\hline 88 & 2.3 .2 & $\begin{array}{l}\text { NEW YORK STATE DEPARTMENT OF ENVIRONMENTAL } \\
\text { CONSERVATION }\end{array}$ & 28 & 2 \\
\hline 88 & 2.3 .3 & $\begin{array}{l}\text { NEW YORK STATE DEPARTMENT OF ENVIRONMENTAL } \\
\text { CONSERVATION }\end{array}$ & 28 & 2 \\
\hline 88 & 2.3 .5 & $\begin{array}{l}\text { NEW YORK STATE DEPARTMENT OF ENVIRONMENTAL } \\
\text { CONSERVATION }\end{array}$ & 28 & 2 \\
\hline 88 & 2.5 .1 & $\begin{array}{l}\text { NEW YORK STATE DEPARTMENT OF ENVIRONMENTAL } \\
\text { CONSERVATION }\end{array}$ & 28 & 2 \\
\hline 88 & 2.5 .2 & $\begin{array}{l}\text { NEW YORK STATE DEPARTMENT OF ENVIRONMENTAL } \\
\text { CONSERVATION }\end{array}$ & 28 & 2 \\
\hline 89 & 2.2 .2 & $\begin{array}{l}\text { NEW YORK STATE DEPARTMENT OF ENVIRONMENTAL } \\
\text { CONSERVATION }\end{array}$ & 28 & 2 \\
\hline 90 & 2.12 .0 & $\begin{array}{l}\text { NEW YORK STATE DEPARTMENT OF ENVIRONMENTAL } \\
\text { CONSERVATION }\end{array}$ & 28 & 2 \\
\hline 91 & 2.3 .2 & MID-ISLAND RADIATION ALERT & 29 & 1 \\
\hline 91 & 2.6 .4 & MID-ISLAND RADIATION ALERT & 29 & 1 \\
\hline 91 & 2.12 .0 & MID-ISLAND RADIATION ALERT & 29 & 1 \\
\hline 92 & 2.9 .3 & MID-ISLAND RADIATION ALERT & 29 & 1 \\
\hline 93 & 2.12 .0 & MID-ISLAND RADIATION ALERT & 29 & 1 \\
\hline 94 & 2.3 .1 & MICHIGAN DEPARTMENT OF PUBLIC HEALTH & 30 & 1 \\
\hline 95 & 2.2 .5 & MICHIGAN DEPARTMENT OF PUBLIC HEALTH & 30 & 1 \\
\hline 95 & 2.10 .5 .3 & MICHIGAN DEPARTMENT OF PUBLIC HEALTH & 30 & 1 \\
\hline 96 & 2.10 .1 & MICHIGAN DEPARTMENT OF PUBLIC HEALTH & 30 & 1 \\
\hline 96 & 2.10 .2 & MICHIGAN DEPARTMENT OF PUBLIC HEALTH & 30 & 1 \\
\hline 97 & 2.3 .5 & MICHIGAN DEPARTMENT OF PUBLIC HEALTH & 30 & 2 \\
\hline 97 & 2.3 .8 & MICHIGAN DEPARTMENT OF PUBLIC HEALTH & 30 & 2 \\
\hline 97 & 2.10 .2 & MICHIGAN DEPARTMENT OF PUBLIC HEALTH & 30 & 2 \\
\hline 98 & 2.2 .5 & KENNECOTT ENERGY & 31 & 1 \\
\hline 99 & 2.2 .1 & KENNECOTT ENERGY & 31 & 2 \\
\hline 100 & 2.3 .2 & KENNECOTT ENERGY & 31 & 2 \\
\hline 100 & 2.3 .5 & KENNECOTT ENERGY & 31 & 2 \\
\hline 100 & 2.3 .6 & KENNECOTT ENERGY & 31 & 2 \\
\hline 101 & 2.3 .5 & KENNECOTT ENERGY & 31 & 3 \\
\hline 101 & 2.3 .6 & KENNECOTT ENERGY & 31 & 3 \\
\hline 102 & 2.3 .5 & KENNECOTT ENERGY & 31 & 3 \\
\hline 102 & 2.3 .6 & KENNECOTT ENERGY & 31 & 3 \\
\hline 102 & 2.3 .7 & KENNECOTT ENERGY & 31 & 3 \\
\hline 103 & 2.3 .2 & KENNECOTT ENERGY & 31 & 3 \\
\hline 103 & 2.3 .3 & KENNECOTT ENERGY & 31 & 3 \\
\hline
\end{tabular}




\begin{tabular}{|c|c|c|c|}
\hline 103 & 2.3 .4 & KENNECOTT ENERGY & 31 \\
\hline 103 & 2.10 .4 & KENNECOTT ENERGY & 31 \\
\hline 104 & 2.10 .4 & KENNECOTT ENERGY & 31 \\
\hline 104 & 2.10 .5 .3 & KENNECOTT ENERGY & 31 \\
\hline 105 & 2.4 .4 & KENNECOT'T ENERGY & 31 \\
\hline 106 & 2.1 .8 & KENNECOTT ENERGY & 31 \\
\hline 106 & 2.2 .3 & KENNECOTT ENERGY & 31 \\
\hline 107 & 2.7 .1 & KENNECOTT ENERGY & 31 \\
\hline 107 & 2.7 .2 & KENNECOTT ENERGY & 31 \\
\hline 108 & 2.3 .8 & KENNECOTT ENERGY & 31 \\
\hline 108 & 2.8 .2 & KENNECOTT ENERGY & 31 \\
\hline 109 & 2.7 .2 & KENNECOTT ENERGY & 31 \\
\hline 109 & 2.10 .5 .3 & KENNECOTT ENERGY & 31 \\
\hline 110 & 2.10 .5 .1 & LUM, ALLEN H. & 32 \\
\hline 111 & 2.3 .2 & LUM, ALLEN H. & 32 \\
\hline 111 & 2.12 .0 & LUM, ALLEN H. & 32 \\
\hline 112 & 2.9 .1 & LUM, ALLEN H. & 32 \\
\hline 112 & 2.12 .0 & LUM, ALLEN $H$ & 32 \\
\hline 113 & 2.2 .5 & WYOMING MINING ASSOCIATION & 33 \\
\hline 114 & 2.2 .1 & WYOMING MINING ASSOCIATION & 33 \\
\hline 115 & 2.3 .2 & WYOMING MINING ASSOCIATION & 33 \\
\hline 115 & 2.3 .5 & WYOMING MINING ASSOCIATION & 33 \\
\hline 115 & 2.3 .6 & WYOMING MINING ASSOCIATION & 33 \\
\hline 116 & 2.3 .5 & WYOMING MINING ASSOCIATION & 33 \\
\hline 116 & 2.3 .6 & WYOMING MINING ASSOCIATION & 33 \\
\hline 117 & 2.3 .5 & WYOMING MINING ASSOCIATION & 33 \\
\hline 117 & 2.3 .6 & WYOMING MINING ASSOCIATION & 33 \\
\hline 117 & 2.3 .7 & WYOMING MINING ASSOCIATION & 33 \\
\hline 118 & 2.3 .2 & WYOMING MINING ASSOCIATION & 33 \\
\hline 118 & 2.3 .3 & WYOMING MINING ASSOCIATION & 33 \\
\hline 118 & 2.3 .4 & WYOMING MINING ASSOCIATION & 33 \\
\hline 118 & 2.10 .4 & WYOMING MINING ASSOCIATION & 33 \\
\hline 119 & 2.10 .4 & WYOMING MINING ASSOCIATION & 33 \\
\hline 119 & 2.10 .5 .3 & WYOMING MINING ASSOCIATION & 33 \\
\hline 120 & 2.4 .4 & WYOMING MINING ASSOCIATION & 33 \\
\hline 121 & 2.1 .8 & WYOMING MINING ASSOCIATION & 33 \\
\hline 121 & 2.2 .3 & WYOMING MINING ASSOCIATION & 33 \\
\hline 122 & 2.7 .1 & WYOMING MINING ASSOCIATION & 33 \\
\hline 122 & 2.7 .2 & WYOMING MINING ASSOCIATION & 33 \\
\hline 123 & 2.3 .8 & WYOMING MINING ASSOCIATION & 33 \\
\hline 123 & 2.8 .2 & WYOMING MINING ASSOCIATION & 33 \\
\hline
\end{tabular}




\begin{tabular}{|c|c|c|c|c|}
\hline $\begin{array}{l}\text { Comment } \\
\text { Numbers }\end{array}$ & $\begin{array}{l}\text { Issue } \\
\text { Numbers }\end{array}$ & Commentex & $\begin{array}{l}\text { Docket } \\
\text { Letter }\end{array}$ & $\begin{array}{l}\text { Page } \\
\text { Number }\end{array}$ \\
\hline 124 & 2.7 .2 & WYOMING MINING ASSOCIATION & 33 & 6 \\
\hline 124 & $2 \cdot 10 \cdot 5 \cdot 3$ & WYOMING MINING ASSOCIATION & 33 & 6 \\
\hline 125 & 2.12 .0 & ENVIROCARE OF UTAH, INC. & 34 & 1 \\
\hline 126 & $2 \cdot 3.1$ & ENVIROCARE OF UTAH, INC. & 34 & 1 \\
\hline 126 & 2.3 .5 & ENVIROCARE OF UTAH, INC. & 34 & 1 \\
\hline 126 & 2.5 .1 & ENVIROCARE OF UTAH, INC. & 34 & 1 \\
\hline 127 & 2.12 .0 & ORISE & 35 & 1 \\
\hline 128 & 2.3 .1 & ORISE & 35 & $A-1$ \\
\hline 128 & 2.3 .2 & ORISE & 35 & $A-1$ \\
\hline 128 & 2.3 .3 & ORISE & 35 & $A-1$ \\
\hline 128 & 2.3 .5 & ORISE & 35 & $A-1$ \\
\hline 128 & 2.5 .1 & ORISE & 35 & $A-1$ \\
\hline 128 & 2.5 .2 & ORISE & 35 & $A-1$ \\
\hline 128 & 2.10 .2 & ORISE & 35 & $A-1$ \\
\hline 129 & 2.10 .1 & ORISE & 35 & $A-1$ \\
\hline 130 & 2.3 .3 & ORISE & 35 & $A-1$ \\
\hline 130 & 2.10 .2 & ORISE & 35 & $A-1$ \\
\hline 131 & 2.1 .5 & ORISE & 35 & $A-2$ \\
\hline 132 & 2.3 .4 & ORISE & 35 & $\mathrm{~A}-2$ \\
\hline 132 & 2.4 .4 & ORISE & 35 & $A-2$ \\
\hline 132 & 2.10 .5 .1 & ORISE & 35 & $A-2$ \\
\hline 133 & 2.10 .1 & ORISE & 35 & $A-2$ \\
\hline 134 & 2.10 .1 & ORISE & 35 & $A-2$ \\
\hline 135 & 2.10 .1 & ORISE & 35 & $A-3$ \\
\hline 135 & 2.10 .2 & ORISE & 35 & $A-3$ \\
\hline 136 & 2.10 .1 & ORISE & 35 & $A-3$ \\
\hline 137 & 2.10 .1 & ORISE & 35 & $A-3$ \\
\hline 138 & 2.10 .1 & ORISE & 35 & $A-3$ \\
\hline 139 & 2.10 .1 & ORISE & 35 & $A-3$ \\
\hline 140 & 2.12 .0 & NEW YORK STATE ENERGY OFFICE & 36 & 1 \\
\hline 141 & 2.12 .0 & NEW YORK STATE ENERGY OFFICE & 36 & $A-1$ \\
\hline 142 & 2.10 .5 .1 & NEW YORK STATE ENERGY OFFICE & 36 & $A-1$ \\
\hline 143 & 2.3 .2 & NEW YORK STATE ENERGY OFFICE & 36 & $A-1$ \\
\hline 143 & $2 \cdot 3 \cdot 3$ & NEW YORK STATE ENERGY OFFICE & 36 & $A-1$ \\
\hline 143 & 2.3 .5 & NEW YORK STATE ENERGY OFEICE & 36 & $A-1$ \\
\hline 143 & 2.3 .7 & NEW YORK STATE ENERGY OFFICE & 36 & $A-1$ \\
\hline 143 & 2.3 .8 & NEW YORK STATE ENERGY OFFICE & 36 & $A-1$ \\
\hline 143 & 2.5 .1 & NEW YORK STATE ENERGY OFFICE & 36 & $A-1$ \\
\hline 143 & 2.5 .2 & NEW YORK STATE ENERGY OFFICE & 36 & $A-1$ \\
\hline 144 & 2.2 .2 & NEW YORK STATE ENERGY OFFICE & 36 & $A-2$ \\
\hline 145 & 2.10 .5 .1 & NEW YORK STATE ENERGY OFFICE & 36 & $A-2$ \\
\hline
\end{tabular}




\begin{tabular}{|c|c|c|c|c|}
\hline $\begin{array}{l}\text { Comment } \\
\text { Numbers }\end{array}$ & $\begin{array}{l}\text { Issue } \\
\text { Numbers }\end{array}$ & Commenter & $\begin{array}{l}\text { Docket } \\
\text { Letter }\end{array}$ & $\begin{array}{l}\text { Page } \\
\text { Number }\end{array}$ \\
\hline 145 & 2.12 .0 & NEW YORK STATE ENERGY OFFICE & 36 & $A-2$ \\
\hline 146 & 2.3 .8 & NEW YORK STATE ENERGY OFFICE & 36 & $A-2$ \\
\hline 147 & 2.2 .1 & NEW YORK STATE ENERGY OEFICE & 36 & $\mathrm{~B}-1$ \\
\hline 148 & 2.2 .1 & NEW YORK STATE ENERGY OFFICE & 36 & $\mathrm{~B}-1$ \\
\hline 148 & 2.2 .5 & NEW YORK STATE ENERGY OFFICE & 36 & $\mathrm{~B}-1$ \\
\hline 149 & 2.12 .0 & CLEAN WATER FUND OF NORTH CAROLINA & 37 & 1 \\
\hline 150 & 2.10 .4 & CLEAN WATER FUND OF NORTH CAROLINA & 37 & 1 \\
\hline 151 & 2.4 .1 & CLEAN WATER FUND OF NORTH CAROIINA & 37 & 2 \\
\hline 152 & 2.3 .5 & CLEAN WATER FUND OF NORTH CAROLINA & 37 & 2 \\
\hline 153 & 2.12 .0 & CLEAN WATER FUND OF NORTH CAROLINA & 37 & 3 \\
\hline 154 & 2.3 .4 & CLEAN WATER FUND OF NORTH CAROLINA & 37 & 4 \\
\hline 155 & 2.12 .0 & CLEAN WATER FUND OF NORTH CAROLINA & 37 & 4 \\
\hline 156 & 2.3 .1 & CLEAN WATER EUND OF NORTH CAROLINA & 37 & 4 \\
\hline 157 & 2.12 .0 & ATLANTIC RICHFIELD COMPANY & 38 & 1 \\
\hline 158 & 2.2 .2 & ATLANTIC RICHFIELD COMPANY & 38 & 1 \\
\hline 158 & $2.10 \cdot 5.3$ & ATLANTIC RICHFIELD COMPANY & 38 & 1 \\
\hline 159 & 2.1 & ATLANTIC RICHFIELD COMPANY & 38 & 2 \\
\hline 159 & 2.10 .4 & ATLANTIC RICHFIELD COMPANY & 38 & 2 \\
\hline 160 & 2.3 .5 & PETER LOYSEN ASSOCIATES & 39 & 1 \\
\hline 160 & 2.3 .8 & PETER LOYSEN ASSOCIATES & 39 & 1 \\
\hline 161 & 2.3 .8 & PETER LOYSEN ASSOCIATES & 39 & 1 \\
\hline 161 & 2.12 .0 & PETER LOYSEN ASSOCIATES & 39 & 1 \\
\hline 162 & 2.10 .4 & STATE OF NEVADA & 40 & 1 \\
\hline 162 & 2.10 .6 & STATE OF NEVADA & 4.0 & 1 \\
\hline 163 & 2.12 .0 & STATE OF NEVADA & 40 & 7 \\
\hline 164 & 2.10 .4 & STATE OF NEVADA & 40 & 7 \\
\hline 165 & 2.10 .4 & STATE OF NEVADA & 40 & 8 \\
\hline 166 & 2.2 .4 & STATE OF NEVADA & 40 & 8 \\
\hline 166 & 2.9 .1 & STATE OF NEVADA & 40 & 8 \\
\hline 167 & 2.3 .2 & STATE OF NEVADA & 40 & 9 \\
\hline 167 & 2.3 .4 & STATE OF NEVADA & 40 & 9 \\
\hline 167 & 2.12 .0 & STATE OF NEVADA & 40 & 9 \\
\hline 168 & 2.3 .4 & STATE OF NEVADA & 40 & 9 \\
\hline 168 & 2.10 .4 & STATE OF NEVADA & 40 & 9 \\
\hline 169 & 2.8 .2 & STATE OF NEVADA & 40 & 10 \\
\hline 170 & $2 \cdot 9 \cdot 3$ & MOLTEN METAL TECHNOLOGY, INC. & 41 & 1 \\
\hline 171 & 2.3 .2 & MOLTEN METAL TECHNOLOGY, INC. & 41 & 1 \\
\hline 171 & $2 \cdot 3 \cdot 3$ & MOLTEN METAL TECHNOLOGY, INC. & 41 & 1 \\
\hline 171 & 2.3 .5 & MOLTEN METAL TECHNOLOGY, INC. & 41 & 1 \\
\hline 171 & 2.5 .1 & MOLTEN METAL TECHNOLOGY, INC. & 41 & 1 \\
\hline 171 & 2.5 .2 & MOLTEN METAL TECHNOLOGY, INC. & 41 & 1 \\
\hline
\end{tabular}




\begin{tabular}{|c|c|c|c|c|}
\hline $\begin{array}{l}\text { Comment } \\
\text { Numbers } \\
\end{array}$ & $\begin{array}{l}\text { Issue } \\
\text { Numbers }\end{array}$ & Commenter & $\begin{array}{l}\text { Docket } \\
\text { Letter }\end{array}$ & $\begin{array}{l}\text { Page } \\
\text { Numb }\end{array}$ \\
\hline 172 & 2.9 .3 & MOLTEN METAL TECHNOLOGY, INC. & 41 & 2 \\
\hline 173 & $2 \cdot 9 \cdot 3$ & MOLTEN METAL TECHNOLOGY, INC. & 41 & 2 \\
\hline 174 & 2.10 .5 .1 & MOLTEN METAL TECHNOLOGY, INC. & 41 & 3 \\
\hline 175 & 2.3 .8 & MOLTEN METAL TECHNOLOGY, INC. & 41 & 3 \\
\hline 176 & $2 \cdot 2 \cdot 3$ & MOLTEN METAL TECHNOLOGY, INC. & 41 & 4 \\
\hline 177 & 2.7 .1 & MOLTEN METAL TECHNOLOGY, INC. & 41 & 4 \\
\hline 177 & 2.7 .2 & MOLTEN METAL TECHNOLOGY, INC. & 41 & 4 \\
\hline 178 & $2 \cdot 9 \cdot 3$ & MOLTEN METAL TECHNOLOGY, INC. & 41 & 4 \\
\hline 178 & 2.10 .5 .1 & MOLTEN METAL TECHNOLOGY, INC. & 41 & 4 \\
\hline 179 & 2.2 .4 & MOLTEN METAL TECHNOLOGY, INC. & 41 & 5 \\
\hline 179 & 2.9 .1 & MOLTEN METAL TECHNOLOGY, INC. & 41 & 5 \\
\hline 180 & 2.3 .3 & MOLTEN METAL TECHNOLOGY, INC. & 41 & 6 \\
\hline 181 & 2.1 .8 & CAREY, CORINNE & 42 & 1 \\
\hline 182 & 2.2 .1 & CAREY, CORINNE & 42 & 2 \\
\hline 182 & 2.2 .2 & CAREY, CORINNE & 42 & 2 \\
\hline 183 & 2.3 .3 & CAREY, CORINNE. & 42 & 2 \\
\hline 184 & 2.3 .7 & CAREY, CORINNE & 42 & 2 \\
\hline 185 & $2 \cdot 3 \cdot 3$ & CAREY, CORINNE & 42 & 3 \\
\hline 186 & 2.10 .5 .2 & CAREY, CORINNE & 42 & 3 \\
\hline 187 & 2.12 .0 & CAREY, CORINNE & 42 & 4 \\
\hline 188 & 2.12 .0 & CHEM-NUCLEAR SYSTEMS, INC. & 43 & 1 \\
\hline 189 & 2.3 .2 & CHEM-NUCLEAR SYSTEMS, INC. & 43 & 1 \\
\hline 189 & 2.2 .10 .2 & CHEM-NUCLEAR SYSTEMS, INC. & 43 & 1 \\
\hline 190 & 2.10 .5 .1 & CHEM-NUCLEAR SYSTEMS, INC. & 43 & 1 \\
\hline 191 & 2.3 .5 & CHEM-NUCLEAR SYSTEMS, INC. & 43 & 1 \\
\hline 192 & 2.4 .3 & CHEM-NUCLEAR SYSTEMS, INC. & 43 & 1 \\
\hline 192 & 2.10 .1 & CHEM-NUCLEAR SYSTEMS, INC. & 43 & 1 \\
\hline 192 & 2.10 .2 & CHEM-NUCLEAR SYSTEMS, INC. & 43 & 1 \\
\hline 193 & 2.8 .2 & CHEM-NUCLEAR SYSTEMS, INC. & 43 & 1 \\
\hline 194 & 2.3 .2 & CHEM-NUCLEAR SYSTEMS, INC. & 43 & 1 \\
\hline 195 & 2.1 .1 & CHEM-NUCLEAR SYSTEMS, INC. & 43 & 2 \\
\hline 195 & 2.3 .2 & CHEM-NUCLEAR SYSTEMS, INC. & 43 & 2 \\
\hline 196 & 2.3 .3 & CHEM-NUCLEAR SYSTEMS, INC. & 43 & 2 \\
\hline 196 & 2.10 .1 & CHEM-NUCLEAR SYSTEMS, INC. & 43 & 2 \\
\hline 197 & 2.10 .1 & CHEM-NUCLEAR SYSTEMS, INC. & 43 & 2 \\
\hline 198 & 2.4 .4 & CHEM-NUCLEAR SYSTEMS, INC. & 43 & 2 \\
\hline 199 & 2.1 .1 & CHEM-NUCLEAR SYSTEMS, INC. & 43 & 2 \\
\hline 199 & 2.2 .5 & CHEM-NUCLEAR SYSTEMS, INC. & 43 & 2 \\
\hline 200 & 2.9 .3 & CHEM-NUCLEAR SYSTEMS, INC. & 43 & 2 \\
\hline 201 & 2.6 .4 & CHEM-NUCLEAR SYSTEMS, INC. & 43 & 3 \\
\hline 202 & $2 \cdot 4 \cdot 4$ & CHEM-NUCLEAR SYSTEMS, INC. & 43 & 3 \\
\hline
\end{tabular}




\begin{tabular}{|c|c|c|c|c|}
\hline $\begin{array}{l}\text { Comment } \\
\text { Numbers }\end{array}$ & $\begin{array}{l}\text { Issue } \\
\text { Numbers }\end{array}$ & Commenter & $\begin{array}{l}\text { Docket } \\
\text { Letter } \\
\end{array}$ & $\begin{array}{l}\text { Page } \\
\text { Numbe }\end{array}$ \\
\hline 203 & $2 \cdot 3 \cdot 4$ & WHITTAKER CORPORATION & 44 & 1 \\
\hline 203 & 2.3 .8 & WHITTAKER CORPORATION & 44 & 1 \\
\hline 204 & 2.3 .4 & WHITTAKER CORPORATION & 44 & 2 \\
\hline 205 & 2.3 .4 & WHITTAKER CORPORATION & 44 & 2 \\
\hline 206 & 2.10 .3 & WHITTAKER CORPORATION & 44 & 2 \\
\hline 207 & 2.3 .8 & WHITTAKER CORPORATION & 44 & 3 \\
\hline 208 & 2.2 .3 & WHITTAKER CORPORATION & 44 & 4 \\
\hline 209 & 2.3 .9 & WHITTAKER CORPORATION & 44 & 4 \\
\hline 210 & $2 \cdot 3 \cdot 4$ & WHITTAKER CORPORATION & 44 & 4 \\
\hline 210 & 2.6 .2 & WHITTAKER CORPORATION & 44 & 4 \\
\hline 211 & 2.3 .8 & WHITTAKER CORPORATION & 44 & 5 \\
\hline 211 & 2.7 .2 & WHITTAKER CORPORATION & 44 & 5 \\
\hline 211 & $2 \cdot 10 \cdot 5 \cdot 3$ & WHITTAKER CORPORATION & 44 & 5 \\
\hline 212 & 2.2 .3 & WHITTAKER CORPORATION & 44 & 5 \\
\hline 213 & 2.10 .2 & WHITTAKER CORPORATION & 44 & 5 \\
\hline 214 & 2.3 .5 & WHITTAKER CORPORATION & 44 & 5 \\
\hline 215 & $2 \cdot 3 \cdot 5$ & WHITTAKER CORPORATION & 44 & 6 \\
\hline 215 & 2.3 .6 & WHITTAKER CORPORATION & 44 & 6 \\
\hline 215 & 2.10 .2 & WHITTAKER CORPORATION & 44 & 6 \\
\hline 216 & 2.3 .6 & WHITTAKER CORPORATION & 44 & 6 \\
\hline 216 & 2.3 .8 & WHITTAKER CORPORATION & 44 & 6 \\
\hline 217 & 2.10 .1 & WHITTAKER CORPORATION & 44 & 7 \\
\hline 217 & 2.10 .2 & WHITTAKER CORPORATION & 44 & 7 \\
\hline 218 & 2.3 .2 & JOAN O. KING & 45 & 1 \\
\hline 218 & 2.12 .0 & JOAN O. KING & 45 & 1 \\
\hline 219 & 2.12 .0 & LEWIS, MARVIN I. & 46 & 1 \\
\hline 220 & 2.3 .2 & LEWIS, MARVIN I. & 46 & 2 \\
\hline $221^{\circ}$ & 2.12 .0 & HUMANS AGAINST NUCLEAR-WASTE DUMPS & 47 & 1 \\
\hline 222 & 2.3 .2 & HUMANS AGAINST NUCLEAR-WASTE DUMPS & 47 & 1 \\
\hline 222 & 2.3 .7 & HUMANS AGAINST NUCLEAR-WASTE DUMPS & 47 & 1 \\
\hline 222 & 2.9 .3 & HUMANS AGAINST NUCLEAR-WASTE DUMPS & 47 & 1 \\
\hline 223 & 2.3 .2 & FLORSHEIM, NANCY P. & 48 & 1 \\
\hline 223 & 2.3 .4 & FLORSHEIM, NANCY P. & 48 & 1 \\
\hline 224 & 2.9 .3 & FLORSHEIM, NANCY P. & 48 & 1 \\
\hline 225 & 2.10 .5 .2 & FLORSHEIM, NANCY P. & 48 & 1 \\
\hline 226 & 2.2 .1 & RIO ALGOM MINING CORPORATION & 49 & 1 \\
\hline 227 & 2.2 .1 & RIO ALGOM MINING CORPORATION & 49 & 2 \\
\hline 228 & $2 \cdot 10 \cdot 5 \cdot 3$ & RIO ALGOM MINING CORPORATION & 49 & 4 \\
\hline 229 & 2.2 .1 & RIO ALGOM MINING CORPORATION & 49 & 4 \\
\hline 230 & 2.2 .1 & RIO ALGOM MINING CORPORATION & 49 & 4 \\
\hline 231 & 2.2 .1 & RIO ALGOM MINING CORPORATION & 49 & 5 \\
\hline
\end{tabular}

Page: B - 11 


\begin{tabular}{|c|c|c|c|c|}
\hline $\begin{array}{l}\text { Comment } \\
\text { Numbers } \\
\end{array}$ & $\begin{array}{l}\text { Issue } \\
\text { Numbers }\end{array}$ & Commenter & $\begin{array}{l}\text { Docket } \\
\text { Letter }\end{array}$ & $\begin{array}{l}\text { Page } \\
\text { Number }\end{array}$ \\
\hline 232 & 2.3 .5 & RIO ALGOM. MINING CORPORATION & 49 & 6 \\
\hline 232 & 2.10 .2 & RIO ALGOM MINING CORPORATION & 49 & 6 \\
\hline 233 & 2.3 .5 & RIO ALGOM MINING CORPORATION & 49 & 6 \\
\hline 233 & 2.3 .7 & RIO ALGOM MINING CORPORATION & 49 & 6 \\
\hline 233 & 2.5 .1 & RIO ALGOM MINING CORPORATION & 49 & 6 \\
\hline 234 & 2.3 .5 & RIO ALGOM MINING CORPORATION & 49 & 6 \\
\hline 234 & 2.3 .6 & RIO ALGOM MINING CORPORATION & 49 & 6 \\
\hline 234 & 2.5 .1 & RIO ALGOM MINING CORPORATION & 49 & 6 \\
\hline 234 & 2.5 .2 & RIO ALGOM MINING CORPORATION & 49 & 6 \\
\hline 235 & 2.3 .8 & RIO ALGOM MINING CORPORATION & 49 & 7 \\
\hline 236 & 2.3 .5 & RIO ALGOM MINING CORPORATION & 49 & 7 \\
\hline 236 & 2.3 .8 & RIO ALGOM MINING CORPORATION & 49 & 7 \\
\hline 236 & 2.5 .1 & RIO ALGOM MINING CORPORATION & 49 & 7 \\
\hline 236 & 2.5 .2 & RIO ALGOM MINING CORPORATION & 49 & 7 \\
\hline 237 & 2.3 .6 & RIO ALGOM MINING CORPORATION & 49 & 8 \\
\hline 238 & 2.3 .2 & RIO ALGOM MINING CORPORATION & 49 & 8 \\
\hline 239 & 2.3 .5 & RIO ALGOM MINING CORPORATION & 49 & 9 \\
\hline 240 & 2.1 .1 & RIO ALGOM MINING CORPORATION & 49 & 9 \\
\hline 240 & 2.10 .2 & RIO ALGOM MINING CORPORATION & 49 & 9 \\
\hline 241 & 2.1 .1 & RIO ALGOM MINING CORPORATION & 49 & 9 \\
\hline 241 & 2.1 .6 & RIO ALGOM MINING CORPORATION & 49 & 9 \\
\hline 241 & 2.3 .9 & RIO ALGOM MINING CORPORATION & 49 & 9 \\
\hline 242 & 2.2 .1 & RIO ALGOM MINING CORPORATION & 49 & 11 \\
\hline 242 & 2.4 .4 & RIO ALGOM MINING CORPORATION & 49 & 11 \\
\hline 242 & 2.10 .5 .3 & RIO ALGOM MINING CORPORATION & 49 & 11 \\
\hline 243 & 2.6 .2 & RIO ALGOM MINING CORPORATION & 49 & 12 \\
\hline 243 & 2.6 .4 & RIO ALGOM MINING CORPORATION & 49 & 12 \\
\hline 243 & 2.10 .2 & RIO ALGOM MINING CORPORATION & 49 & 12 \\
\hline 244 & 2.6 .2 & RIO ALGOM MINING CORPORATION & 49 & 12 \\
\hline 244 & 2.6 .4 & RIO ALGOM MINING CORPORATION & 49 & 12 \\
\hline 245 & 2.1 .6 & RIO ALGOM MINING CORPORATION & 49 & 13 \\
\hline 245 & 2.2 .3 & RIO ALGOM MINING CORPORATION & 49 & 13 \\
\hline 246 & 2.1 .6 & RIO ALGOM MINING CORPORATION & 49 & 13 \\
\hline 246 & 2.2 .1 & RIO ALGOM MINING CORPORATION & 49 & 13 \\
\hline 247 & 2.2 .3 & RIO ALGOM MINING CORPORATION & 49 & 14 \\
\hline 247 & 2.10 .5 .3 & RIO ALGOM MINING CORPORATION & 49 & 14 \\
\hline 248 & 2.1 .8 & RIO ALGOM MINING CORPORATION & 49 & 15 \\
\hline 248 & 2.2 .3 & RIO ALGOM MINING CORPORATION & 49 & 15 \\
\hline 248 & 2.3 .6 & RIO ALGOM MINING CORPORATION & 49 & 15 \\
\hline 248 & 2.10 .1 & RIO AIGOM MINING CORPORATION & 49 & 15 \\
\hline 249 & 2.2 .3 & RIO ALGOM MINING CORPORATION & 49 & 15 \\
\hline
\end{tabular}




\begin{tabular}{|c|c|c|c|c|}
\hline $\begin{array}{l}\text { Comment } \\
\text { Numbers }\end{array}$ & $\begin{array}{l}\text { Issue } \\
\text { Numbers }\end{array}$ & Commenter & $\begin{array}{l}\text { Docket } \\
\text { Letter }\end{array}$ & $\begin{array}{l}\text { Page } \\
\text { Number }\end{array}$ \\
\hline 249 & 2.3 .8 & RIO ALGOM MINING CORPORATION & 49 & 15 \\
\hline 250 & 2.3 .6 & RIO ALGOM MINING CORPORATION & 49 & 15 \\
\hline 251 & 2.10 .5 .3 & RIO ALGOM MINING CORPORATION & 49 & 16 \\
\hline 252 & 2.10 .4 & RIO ALGOM MINING CORPORATION & 49 & 16 \\
\hline 253 & 2.7 .2 & RIO ALGOM MINING CORPORATION & 49 & 17 \\
\hline 253 & 2.8 .2 & RIO ALGOM MINING CORPORATION & 49 & 17 \\
\hline 253 & $2 \cdot 10 \cdot 5 \cdot 3$ & RIO ALGOM MINING CORPORATION & 49 & 17 \\
\hline 254 & 2.7 .2 & RIO ALGOM MINING CORPORATION & 49 & 18 \\
\hline 254 & 2.10 .4 & RIO ALGOM MINING CORPORATION & 49 & 18 \\
\hline 254 & 2.10 .5 .3 & RIO ALGOM MINING CORPORATION & 49 & 18 \\
\hline 255 & $2.10 \cdot 5 \cdot 3$ & KIO ALGOM MINING CORPORATION & 49 & 18 \\
\hline 256 & 2.7 .1 & RIO ALGOM MINING CORPORATION & 49 & 18 \\
\hline 257 & 2.7 .2 & RIO ALGOM MINING CORPORATION & 49 & 18 \\
\hline 258 & 2.7 .2 & RIO ALGOM MINING CORPORATION & 49 & 19 \\
\hline 259 & $2.8 \cdot 3$ & RIO ALGOM MINING CORPORATION & 49 & 19 \\
\hline 259 & 2.8 .5 & RIO ALGOM MINING CORPORATION & 49 & 19 \\
\hline 259 & 2.10 .5 .3 & RIO ALGOM MINING CORPORATION & 49 & 19 \\
\hline 260 & 2.8 .2 & RIO ALGOM MINING CORPORATION & 49 & 19 \\
\hline 261 & 2.8 .1 & RIO AEGOM MINING CORPORATION & 49 & 20 \\
\hline 262 & 2.8 .6 & RIO ALGOM MINING CORPORATION & 49 & 20 \\
\hline 263 & 2.1 .6 & RIO ALGOM MINING CORPORATION & 49 & 22 \\
\hline 263 & 2.10 .1 & RIO ALGOM MINING CORPORATION & 49 & 22 \\
\hline 264 & 2.2 .1 & RIO ALGOM MINING CORPORATION & 49 & 23 \\
\hline 265 & 2.2 .1 & RIO ALGOM MINING CORPORATION & 49 & 23 \\
\hline 265 & $2.10 \cdot 5.3$ & RIO ALGOM MINING CORPORATION & 49 & 23 \\
\hline 266 & 2.3 .8 & RIO ALGOM MINING CORPORATION & 49 & 24 \\
\hline 266 & 2.4 .3 & RIO ALGOM MINING CORPORATION & 49 & 24 \\
\hline 267 & 2.10 .1 & RIO ALGOM MINING CORPORATION & 49 & 25 \\
\hline 268 & 2.10 .5 .2 & RIO ALGOM MINING CORPORATION & 49 & 25 \\
\hline 269 & 2.6 .4 & RIO ALGOM MINING CORPORATION & 49 & 25 \\
\hline 270 & 2.2 .1 & RIO ALGOM MINING CORPORATION & 49 & 26 \\
\hline 270 & 2.10 .4 & RIO ALGOM MINING CORPORATION & 49 & 26 \\
\hline 270 & 2.10 .5 .3 & RIO ALGOM MINING CORPORATION & 49 & 26 \\
\hline 271 & 2.3 .3 & RIO ALGOM MINING CORPORATION & 49 & 27 \\
\hline 271 & 2.3 .5 & RIO ALGOM MINING CORPORATION & 49 & 27 \\
\hline 271 & 2.3 .8 & RIO ALGOM MINING CORPORATION & 49 & 27 \\
\hline 272 & 2.12 .0 & AMERICAN NUCLEAR SOCIETY & 50 & 1 \\
\hline 273 & 2.1 .7 & AMERICAN NUCLEAR SOCIETY & 50 & 1 \\
\hline 273 & 2.7 .2 & AMERICAN NUCLEAR SOCIETY & 50 & 1 \\
\hline 273 & 2.8 .2 & AMERICAN NUCLEAR SOCIETY & 50 & 1 \\
\hline 274 & 2.8 .2 & AMERICAN NUCLEAR SOCIETY & 50 & 2 \\
\hline
\end{tabular}




\begin{tabular}{|c|c|c|c|c|c|}
\hline $\begin{array}{l}\text { Comment } \\
\text { Numbers } \\
\end{array}$ & $\begin{array}{l}\text { Issue } \\
\text { Numbers }\end{array}$ & & Commenter & $\begin{array}{l}\text { Docket } \\
\text { Letter }\end{array}$ & $\begin{array}{l}\text { Page } \\
\text { Number }\end{array}$ \\
\hline 275 & 2.3 .1 & AMERICAN & NUCLEAR SOCIETY & 50 & 2 \\
\hline 275 & 2.3 .7 & AMERICAN & NUCLEAR SOCIETY & 50 & 2 \\
\hline 275 & 2.3 .8 & AMERICAN & NUCLEAR SOCIETY & 50 & 2 \\
\hline 275 & 2.7 .1 & AMERICAN & NUCLEAR SOCIETY & 50 & 2 \\
\hline 276 & 2.10 .6 & AMERICAN & NUCLEAR SOCIETY & 50 & 2 \\
\hline 277 & 2.12 .0 & AMERICAN & NUCLEAR SOCIETY & 50 & 2 \\
\hline 278 & 2.2 .3 & AMERICAN & NUCLEAR SOCIETY & 50 & $A-1$ \\
\hline 278 & 2.3 .3 & AMERICAN & NUCLEAR SOCIETY & 50 & $A-1$ \\
\hline 278 & 2.3 .4 & AMERICAN & NUCLEAR SOCIETY & 50 & $A-1$ \\
\hline 279 & 2.2 .5 & AMERICAN & NUCLEAR SOCIETY & 50 & $A-1$ \\
\hline 280 & 2.10 .6 & AMERICAN & NUCLEAR SOCIETY & 50 & $A-1$ \\
\hline 281 & 2.10 .2 & AMERICAN & NUCLEAR SOCIETY & 50 & $A-1$ \\
\hline 282 & 2.3 .6 & AMERICAN & NUCLEAR SOCIETY & 50 & $A-1$ \\
\hline 283 & 2.3 .7 & AMERICAN & NUCLEAR SOCIETY & 50 & $A-1$ \\
\hline 284 & 2.2 .3 & AMERICAN & NUCLEAR SOCIETY & 50 & $A-1$ \\
\hline 285 & 2.9 .3 & AMERICAN & NUCLEAR SOCIETY & 50 & $A-2$ \\
\hline 286 & 2.10 .4 & AMERICAN & NUCLEAR SOCIETY & 50 & $A-2$ \\
\hline 287 & 2.10 .2 & AMERICAN & NUCLEAR SOCIETY & 50 & $A-2$ \\
\hline 287 & 2.10 .5 .3 & AMERICAN & NUCLEAR SOCIETY & 50 & $A-2$ \\
\hline 288 & 2.2 .2 .1 & AMERICAN & NUCLEAR SOCIETY & 50 & $A-2$ \\
\hline 289 & 2.3 .1 & AMERICAN & NUCLEAR SOCIETY & 50 & $A-2$ \\
\hline 289 & 2.3 .5 & AMERICAN & NUCLEAR SOCIETY & 50 & $A-2$ \\
\hline 289 & 2.3 .6 & AMERICAN & NUCLEAR SOCIETY & 50 & $A-2$ \\
\hline 289 & 2.10 .2 & AMERICAN & NUCLEAR SOCIETY & 50 & $A-2$ \\
\hline 289 & 2.10 .5 .1 & AMERICAN & NUCLEAR SOCIETY & 50 & $A-2$ \\
\hline 289 & 2.10 .5 .3 & AMERICAN & NUCLEAR SOCIETY & 50 & $A-2$ \\
\hline 290 & 2.3 .5 & AMERICAN & NUCLEAR SOCIETY & 50 & $A-2$ \\
\hline 290 & 2.3 .6 & AMERICAN & NUCLEAR SOCIETY & 50 & $A-2$ \\
\hline 291 & 2.3 .5 & AMERICAN & NUCLEAR SOCIETY & 50 & $A-3$ \\
\hline 291 & 2.10 .5 .1 & AMERICAN & NUCLEAR SOCIETY & 50 & $A-3$ \\
\hline 292 & 3.7 & AMERICAN & NUCLEAR SOCIETY & 50 & $A-3$ \\
\hline 292 & 2.2 .3 .8 & AMERICAN & NUCLEAR SOCIETY & 50 & $A-3$ \\
\hline 293 & 2.3 .8 & AMERICAN & NUCLEAR SOCIETY & 50 & $A-3$ \\
\hline 293 & 2.10 .2 & AMERICAN & NUCLEAR SOCIETY & 50 & $A-3$ \\
\hline 294 & 2.10 .2 & AMERICAN & NUCLEAR SOCIETY & 50 & $A-4$ \\
\hline 294 & 2.10 .4 & AMERICAN & NUCLEAR SOCIETY & 50 & A- 4 \\
\hline 295 & 2.1 .8 & AMERICAN & NUCLEAR SOCIETY & 50 & $A-4$ \\
\hline 295 & 2.3 .8 & AMERICAN & NUCLEAR SOCIETY & 50 & $A-4$ \\
\hline 296 & 2.2 .3 & AMERICAN & NUCLEAR SOCIETY & 50 & $A-4$ \\
\hline 297 & 2.2 .3 & AMERICAN & NUCLEAR SOCIETY & 50 & $A-5$ \\
\hline 297 & 2.12 .0 & AMERICAN & NUCLEAR SOCIETY & 50 & $A-5$ \\
\hline
\end{tabular}




\begin{tabular}{|c|c|c|c|c|}
\hline $\begin{array}{l}\text { Comment } \\
\text { Numbers } \\
\end{array}$ & $\begin{array}{l}\text { Issue } \\
\text { Numbers } \\
\end{array}$ & Commenter & $\begin{array}{l}\text { Docket } \\
\text { Letter }\end{array}$ & $\begin{array}{l}\text { Page } \\
\text { Number }\end{array}$ \\
\hline 298 & 2.8 .2 & AMERICAN NUCLEAR SOCIETY & 50 & $A-5$ \\
\hline 298 & 2.8 .3 & AMERICAN NUCLEAR SOCIETY & 50 & $A-5$ \\
\hline 299 & 2.7 .2 & AMERICAN NUCLEAR SOCIETY & 50 & $A-5$ \\
\hline 300 & 9.2 & AMERICAN NUCLEAR SOCIETY & 50 & $A-6$ \\
\hline 301 & 2.3 .1 & AMERICAN NUCLEAR SOCIETY & 50 & $A-6$ \\
\hline 301 & 2.3 .5 & AMERICAN NUCLEAR SOCIETY & 50 & $A-6$ \\
\hline 301 & 2.3 .6 & AMERICAN NUCLEAR SOCIETY & 50 & $A-6$ \\
\hline 302 & 2.1 .8 & AMERICAN NUCLEAR SOCIETY & 50 & $A-6$ \\
\hline 302 & 2.3 .3 & AMERICAN NUCLEAR SOCIETY & 50 & $A-6$ \\
\hline 303 & 2.2 .3 & AMERICAN NUCLEAR SOCIETY & 50 & $A-6$ \\
\hline 303 & 2.12 .0 & AMERICAN NUCLEAR SOCIETY & 50 & $A-6$ \\
\hline 304 & 2.8 .1 & AMERICAN NUCLEAR SOCIETY & 50 & $A-6$ \\
\hline 305 & 2.9 .2 & AMERICAN NUCLEAR SOCIETY & 50 & $A-6$ \\
\hline 306 & 2.2 .1 & AMERICAN NUCLEAR SOCIETY & 50 & $A-6$ \\
\hline 307 & 2.3 .9 & CORAR & 51 & 1 \\
\hline 308 & 2.3 .7 & CORAR & 51 & 2 \\
\hline 308 & 2.3 .8 & CORAR & 51 & 2 \\
\hline 309 & $2 \cdot 3 \cdot 3$ & CORAR & 51 & 2 \\
\hline 309 & 2.3 .5 & CORAR & 51 & 2 \\
\hline 309 & 2.3 .7 & CORAR & 51 & 2 \\
\hline 309 & 2.4 .2 & CORAR & 51 & 2 \\
\hline 309 & 2.5 .2 & CORAR & 51 & 2 \\
\hline 309 & 2.10 .4 & CORAR & 51 & 2 \\
\hline 310 & 2.7 .2 & CORAR & 51 & 2 \\
\hline 311 & 2.10 .1 & CORAR & 51 & 2 \\
\hline 311 & 2.10 .2 & CORAR & 51 & 2 \\
\hline 312 & 2.3 .3 & CORAR & 51 & 2 \\
\hline 312 & 2.3 .8 & CORAR & 51 & 2 \\
\hline 313 & 2.3 .2 & CORAR & 51 & 3 \\
\hline 313 & 2.3 .5 & CORAR & 51 & 3 \\
\hline 313 & 2.10 .5 .3 & CORAR & 51 & 3 \\
\hline 314 & $2 \cdot 3 \cdot 3$ & CORAR & 51 & 3 \\
\hline 314 & 2.4 .2 & CORAR & 51 & 3 \\
\hline 315 & 2.7 .2 & CORAR & 51 & 3 \\
\hline 316 & 2.7 .3 & CORAR & 51 & 4 \\
\hline 317 & 2.7 .3 & CORAR & 51 & 4 \\
\hline 318 & 2.3 .5 & CORAR & 51 & 3 \\
\hline 318 & 2.3 .7 & CORAR & 51 & 3 \\
\hline 318 & 2.5 .1 & CORAR & 51 & 3 \\
\hline 319 & 2.7 .2 & CORAR & 51 & 4 \\
\hline 319 & 2.7 .3 & CORAR & 51 & 4 \\
\hline
\end{tabular}




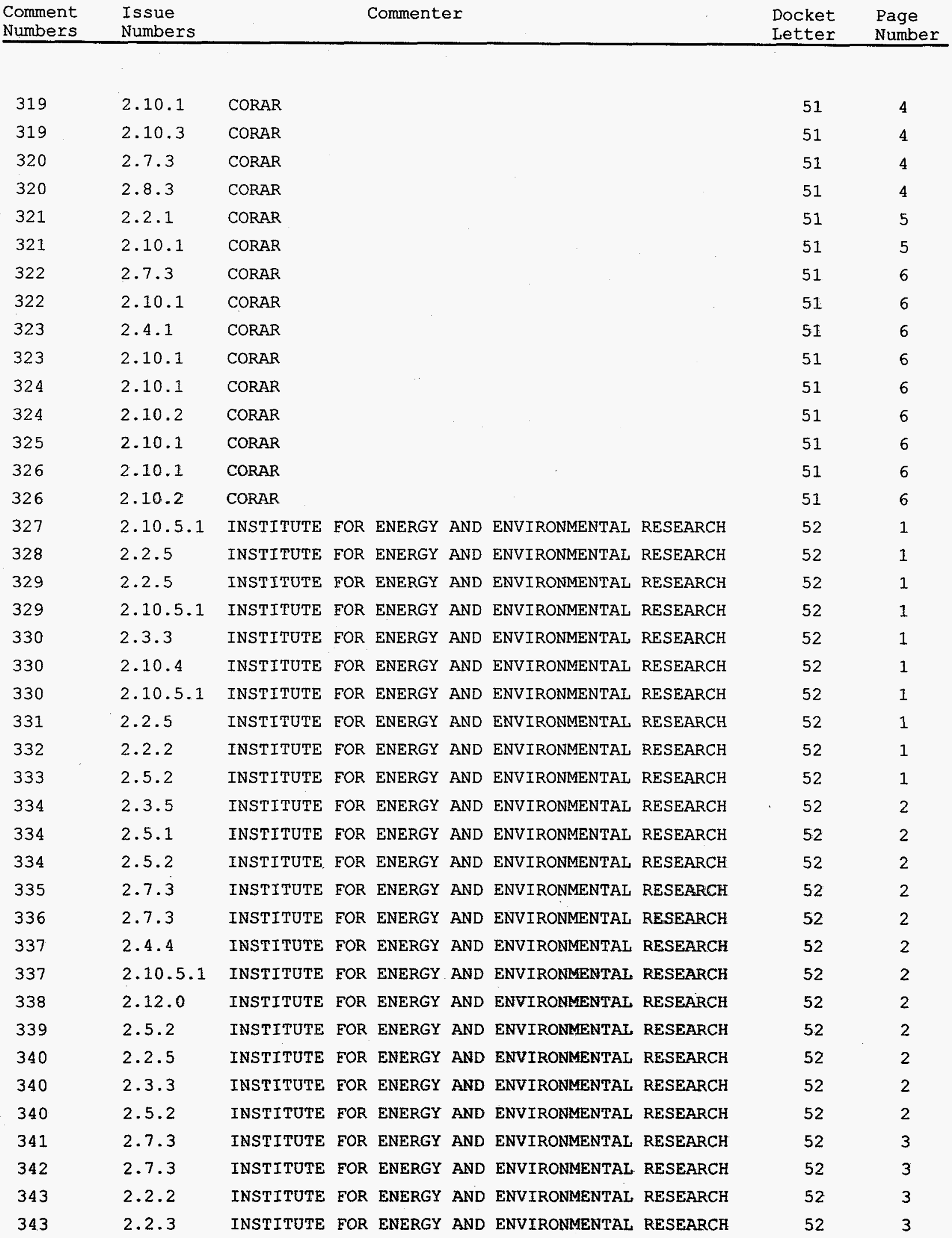




\begin{tabular}{|c|c|c|c|c|c|c|c|}
\hline 344 & $2 \cdot 4 \cdot 4$ & INSTITUTE & FOR & ENERGY & AND & ENVIRONMENTAL & RESEARCH \\
\hline 344 & 2.10 .5 .1 & INSTITUTE & FOR & ENERGY & AND & ENVIRONMENTAL & RESEARCH \\
\hline 345 & 2.2 .5 & INSTITUTE & FOR & ENERGY & AND & ENVIRONMENTAL & RESEARCH \\
\hline 346 & 2.10 .4 & INSTITUTE & FOR & ENERGY & AND & ENVIRONMENTAL & RESEARCH \\
\hline 347 & 2.10 .5 .1 & INSTITUTE & FOR & ENERGY & AND & ENVIRONMENTAI & RESEARCH \\
\hline 348 & 2.2 .5 & INSTITUTE & EOR & ENERGY & AND & ENVIRONMENTAL, & RESEARCH \\
\hline 349 & 2.2 .5 & INSTITUTE & EOR & ENERGY & AND & ENVIRONMENTAL & RESEARCH \\
\hline 349 & 2.3 .8 & INSTITUTE & FOR & ENERGY & AND & ENVIRONMENTAL & RESEARCH \\
\hline 349 & 2.10 .5 .1 & INSTITUTE & FOR & ENERGY & AND & ENVIRONMENTAL & RESEARCH \\
\hline 350 & 2.3 .3 & INSTITUTE & FOR & ENERGY & AND & ENVIRONMENTAL & RESEARCH \\
\hline 351 & 2.10 .5 .1 & INSTITUTE & FOR & ENERGY & AND & ENVIRONMENTAL & RESEARCH \\
\hline 352 & 2.3 .3 & INSTITUTE & FOR & ENERGY & AND & ENVIRONMENTAL & RESEARCH \\
\hline 352 & 2.5 .2 & INSTITUTE & FOR & ENERGY & AND & ENVIRONMENTAL & RESEARCH \\
\hline 353 & 2.10 .4 & INSTITUTE & FOR & ENERGY & AND & ENVIRONMENTAI & RESEARCH \\
\hline 354 & $2 \cdot 9 \cdot 3$ & INSTITUTE & FOR & ENERGY & AND & ENVIRONMENTAL & RESEARCH \\
\hline 355 & 2.3 .3 & INSTITUTE & EOR & ENERGY & AND & ENVIRONMENTAL & RESEARCH \\
\hline 355 & 2.10 .4 & INSTITUTE & FOR & ENERGY & AND & ENVIRONMENTAL & RESEARCH \\
\hline 356 & 2.2 .5 & INSTITUTE & FOR & ENERGY & AND & ENVIRONMENTAL & RESEARCH \\
\hline 57 & 2.2 .2 & INSTITUTE & FOR & ENERGY & AND & ENVIRONMENTAL & RESEARCH \\
\hline 358 & 2.3 .1 & INSTITUTE & FOR & ENERGY & AND & ENVIRONMENTAL & RESEARCH \\
\hline 359 & 2.4 .2 & INSTITUTE & FOR & ENERGY & AND & ENVIRONMENTAL & RESEARCH \\
\hline 359 & 2.5 .2 & INSTITUTE & FOR & ENERGY & AND & ENVIRONMENTAL & RESEARCH \\
\hline 360 & 2.7 .3 & INSTITUTE & EOR & ENERGY & AND & ENVIRONMENTAL & RESEARCH \\
\hline 361 & 2.6 .3 & INSTITUTE & FOR & ENERGY & AND & ENVIRONMENTAL & RESEARCH \\
\hline 361 & 2.7 .3 & INSTITUTE & FOR & ENERGY & AND & ENVIRONMENTAL & RESEARCH \\
\hline 362 & 2.3 .6 & INSTITUTE & EOR & ENERGY & AND & ENVIRONMENTAL & RESEARCH \\
\hline 362 & 2.6 .4 & INSTITUTE & FOR & ENERGY & AND & ENVIRONMENTAL & RESEARCH \\
\hline 363 & 2.6 .2 & INSTITUTE & FOR & ENERGY & AND & ENVIRONMENTAL & RESEARCH \\
\hline 363 & 2.6 .4 & INSTITUTE & FOR & ENERGY & AND & ENVIRONMENTAL & RESEARCH \\
\hline 364 & 2.3 .5 & DAM, SCOTT & $\Gamma A$. & & & & \\
\hline 364 & 2.3 .6 & DAM, SCOTT & A. & & & & \\
\hline 364 & 2.3 .7 & DAM, SCOTT & $\Gamma A$. & & & & \\
\hline 364 & 2.5 .1 & DAM, SCOTT & I A. & & & & \\
\hline 365 & 2.3 .2 & DAM, SCOTT & A. & & & & \\
\hline 365 & 2.5 .2 & DAM, SCOTT & T A. & & & & \\
\hline 366 & 2.10 .6 & DAM, SCOTT & I A. & & & & \\
\hline 367 & 2.3 .8 & DAM, SCOTT & I A. & & & & \\
\hline 367 & 2.10 .6 & DAM, SCOTT & $\mathrm{I} \mathrm{A}$. & & & & \\
\hline 368 & 2.3 .7 & DAM, SCOTT & I A. & & & & \\
\hline 68 & 2.3 .8 & DAM, SCOTT & I A. & & & & \\
\hline & 2.5 .2 & DAM, SCO & A. & & & & \\
\hline
\end{tabular}

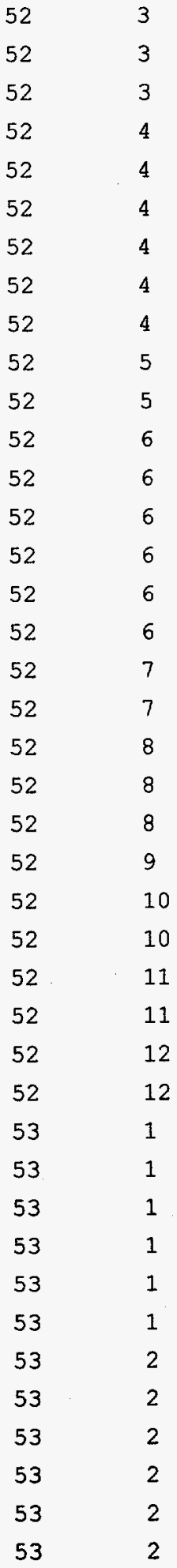




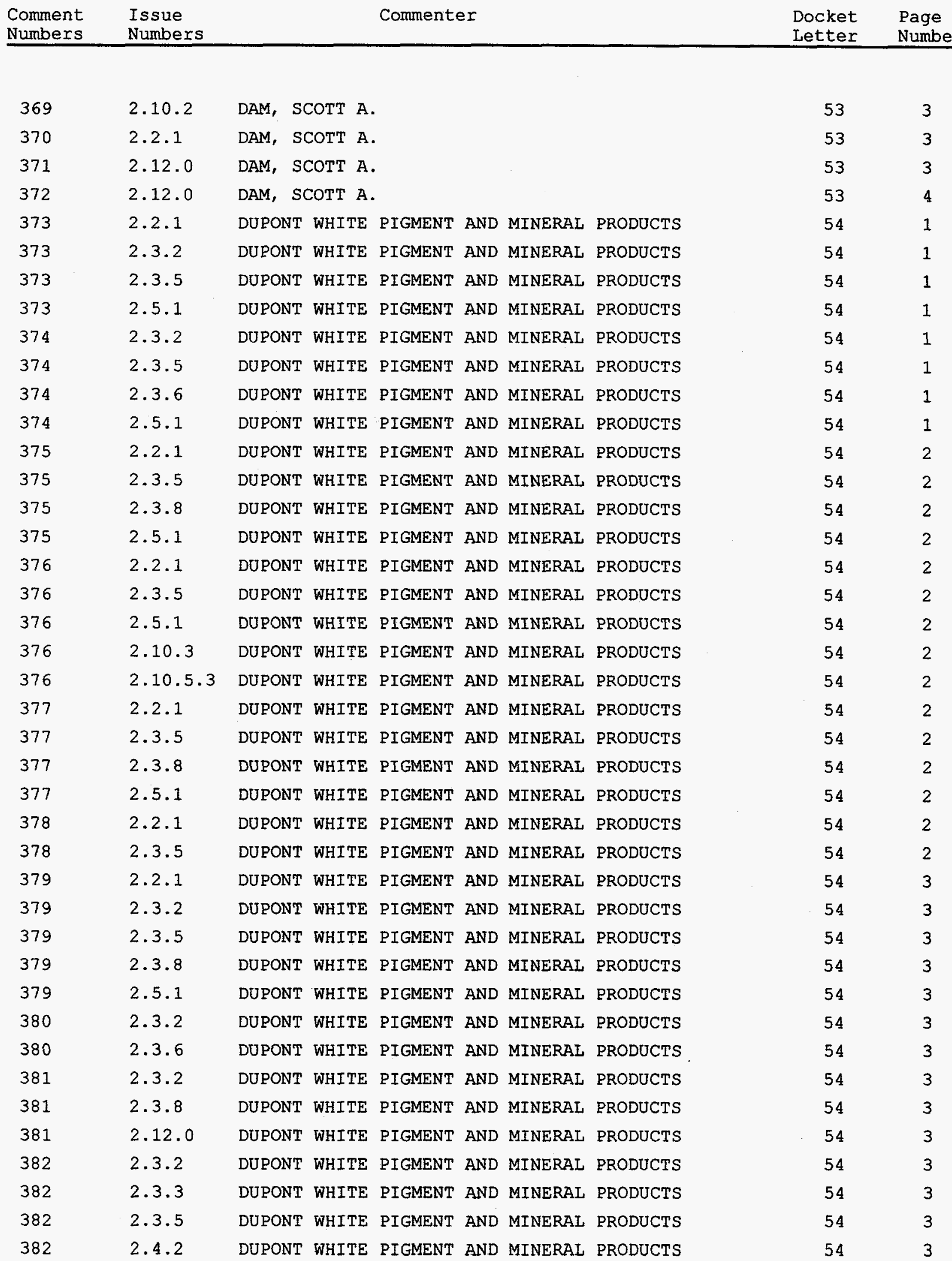




\begin{tabular}{|c|c|c|c|c|c|c|c|c|}
\hline 382 & 2.5 .1 & DUPONT & WHITE & PIGMENT & AND & MINERAL & PRODUCTS & 54 \\
\hline 383 & 2.3 .2 & DUPONT & WHITE & PIGMENT & AND & MINERAL & PRODUCTS & 54 \\
\hline 383 & 2.3 .5 & DUPONT & WHITE & PIGMENT & AND & MINERAL & PRODUCTS & 54 \\
\hline 383 & 2.3 .6 & DUPONT & WHITE & PIGMENT & AND & MINERAL & PRODUCTS & 54 \\
\hline 383 & 2.5 .1 & DUPONT & WHITE & PIGMENT & AND & MINERAL & PRODUCTS & 54 \\
\hline 384 & 2.3 .2 & DUPONT & WHITE & PIGMENT & AND & MINERAL & PRODUCTS & 54 \\
\hline 384 & 2.3 .5 & DUPONT & WHITE & PIGMENT & AND & MINERAL & PRODUCTS & 54 \\
\hline 384 & 2.3 .6 & DUPONT & WHITE & PIGMENT & AND & MINERAL & , PRODUCTS & 54 \\
\hline 384 & 2.5 .1 & DUPONT & WHITE & PIGMENT & AND & MINERAI & PRODUCTS & 54 \\
\hline 385 & 2.3 .2 & DUPONT & WHITE & PIGMENT & AND & MINERAL & - PRODUCTS & 54 \\
\hline 385 & $2 \cdot 3 \cdot 3$ & DUPONT & WHITE & PIGMENT & AND & MINERAL & PRODUCTS & 54 \\
\hline 385 & 2.3 .4 & DUPONT & WHITE & PIGMENT & AND & MINERAL & - PRODUCTS & 54 \\
\hline 385 & 2.3 .8 & DUPONT & WHITE & PIGMENT & AND & MINERAL & PRODUCTS & 54 \\
\hline 385 & 2.10 .3 & DUPONT & WHITE & PIGMENT & AND & MINERAL & PRODUCTS & 54 \\
\hline 386 & 2.10 .1 & DUPONT & WHITE & PIGMENT & AND & MINERAL & PRODUCTS & 54 \\
\hline 386 & 2.10 .5 .3 & DUPONT & WHITE & PIGMENT & AND & MINERAL & PRODUCTS & 54 \\
\hline 387 & 2.3 .5 & DUPONT & WHITE & PIGMENT & AND & MINERAL & PRODUCTS & 54 \\
\hline 387 & 2.3 .6 & DUPONT & WHITE & PIGMENT & AND & MINERAL & PRODUCTS & 54 \\
\hline 388 & 2.3 .5 & DUPONT & WHITE & PIGMENT & AND & MINERAL & PRODUCTS & 54 \\
\hline 388 & 2.10 .5 .3 & DUPONT & WHITE & PIGMENT & AND & MINERAL & PRODUCTS & 54 \\
\hline 389 & 2.1 .2 & DUPONT & WHITE & PIGMENT & AND & MINERAL & PRODUCTS & 54 \\
\hline 389 & 2.3 .2 & DUPONT & WHITE & PIGMENT & AND & MINERAL & PRODUCTS & 54 \\
\hline 389 & 2.3 .6 & DUPONT & WHITE & PIGMENT & AND & MINERAL & PRODUCTS & 54 \\
\hline 389 & 2.10 .5 .1 & DUPONT & WHITE & PIGMENT & AND & MINERAL & PRODUCTS & 54 \\
\hline 390 & 2.3 .2 & DUPONT & WHITE & PIGMENT & AND & MINERAL & PRODUCTS & 54 \\
\hline 390 & 2.3 .8 & DUPONT & WHITE & PIGMENT & AND & MINERAL & PRODUCTS & 54 \\
\hline 390 & 2.10 .4 & DUPONT & WHITE & PIGMENT & AND & MINERAL & PRODUCTS & 54 \\
\hline 390 & 2.10 .5 .3 & DUPONT & WHITE & PIGMENT & AND & MINERAL & PRODUCTS & 54 \\
\hline 391 & 2.2 .1 & DUPONT & WHITE & PIGMENT & AND & MINERAL & PRODUCTS & 54 \\
\hline 391 & 2.3 .2 & DUPONT & WHITE & PIGMENT & AND & MINERAL & PRODUCTS & 54 \\
\hline 391 & 2.10 .5 .3 & DUPONT & WHITE & PIGMENT & AND & MINERAL & PRODUCTS & 54 \\
\hline 392 & 2.2 .1 & DUPONT & WHITE & PIGMENT & AND & MINERAL & PRODUCTS & 54 \\
\hline 392 & 2.3 .2 & DUPONT & WHITE & PIGMENT & AND & MINERAL & PRODUCTS & 54 \\
\hline 392 & $2 \cdot 3 \cdot 3$ & DUPONT & WHITE & PIGMENT & AND & MINERAL & PRODUCTS & 54 \\
\hline 392 & 2.3 .4 & DUPONT & WHITE & PIGMENT & AND & MINERAL & PRODUCTS & 54 \\
\hline 392 & 2.6 .4 & DUPONT & WHITE & PIGMENT & AND & MINERAL & PRODUCTS & 54 \\
\hline 392 & 2.10 .5 .3 & DUPONT & WHITE & PIGMENT & AND & MINERAL & PRODUCTS & 54 \\
\hline 393 & 2.3 .9 & DUPONT & WHITE & PIGMENT & AND & MINERAL & PRODUCTS & 54 \\
\hline 394 & 2.3 .5 & DUPONT & WHITE & PIGMENT & AND & MINERAL & PRODUCTS & 54 \\
\hline 394 & 2.10 .4 & DUPONT & WHITE & PIGMENT & AND & MINERAL & PRODUCTS & 54 \\
\hline 394 & 2.10 .5 .3 & DUPONT & WHITE & PIGMENT & AND & MINERAL & PRODUCTS & 54 \\
\hline
\end{tabular}




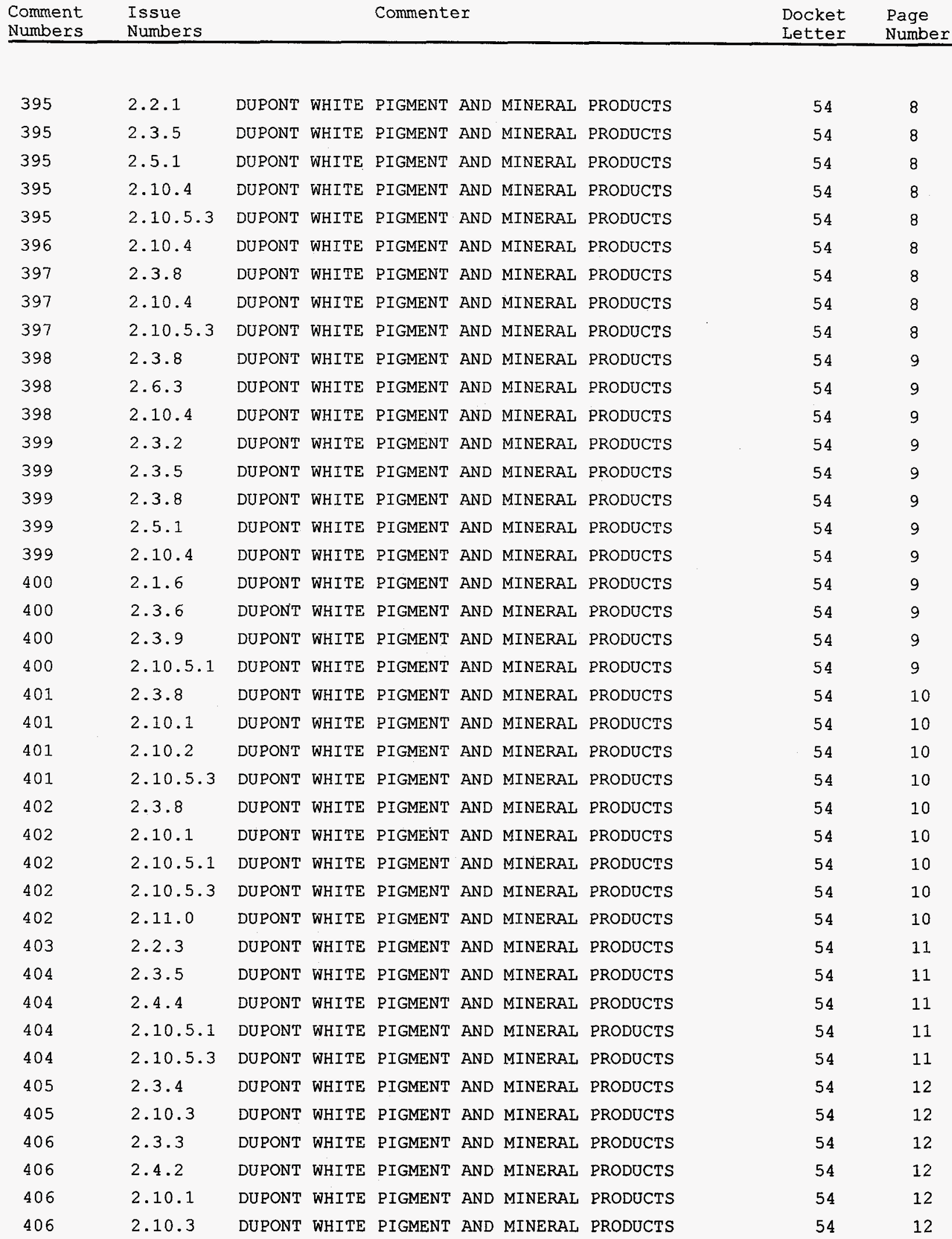




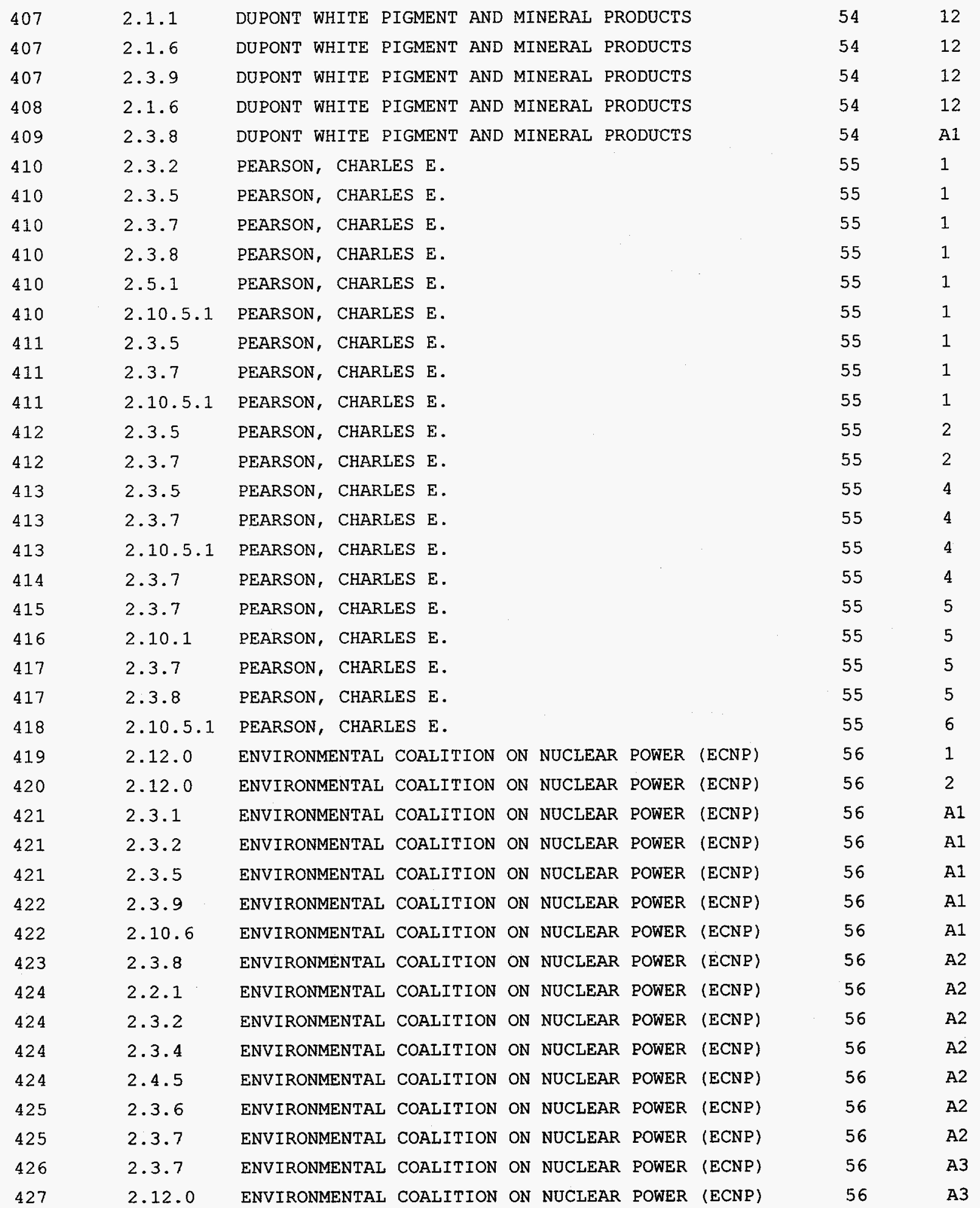




\begin{tabular}{|c|c|c|c|c|}
\hline $\begin{array}{l}\text { Comment } \\
\text { Numbers }\end{array}$ & $\begin{array}{l}\text { Issue } \\
\text { Numbers }\end{array}$ & Commenter & $\begin{array}{l}\text { Docket } \\
\text { Letter }\end{array}$ & $\begin{array}{l}\text { Page } \\
\text { Number }\end{array}$ \\
\hline
\end{tabular}

\begin{tabular}{|c|c|c|c|c|c|c|c|c|c|}
\hline 428 & 2.4 .4 & ENVIRONMENTAL & COALITION & ON & NUCLEAR & POWER & (ECNP) & 56 & A3 \\
\hline 429 & 2.1 .6 & ENVIRONMENTAL & COALITION & ON & NUCLEAR & POWER & (ECNP) & 56 & A4 \\
\hline 429 & 2.3 .9 & ENVIRONMENTAL & COALITION & ON & NUCLEAR & POWER & (ECNP) & 56 & A4 \\
\hline 429 & 2.11 .0 & ENVIRONMENTAL & COALITION & ON & NUCLEAR & POWER & (ECNP) & 56 & A4 \\
\hline 430 & 2.1 .2 & ENVIRONMENTAL & COALITION & ON & NUCLEAR & POWER & (ECNP) & 56 & A4 \\
\hline 430 & 2.2 .1 & ENVIRONMENTAL & COALITION & ON & NUCLEAR & POWER & (ECNP) & 56 & A4 \\
\hline 430 & 2.3 .4 & ENVIRONMENTAL & COALITION & ON & NUCLEAR & POWER & (ECNP) & 56 & A4 \\
\hline 430 & 2.4 .5 & ENVIRONMENTAL & COALITION & ON & NUCLEAR & POWER & (ECNP) & 56 & A4 \\
\hline 430 & 2.6 .5 & ENVIRONMENTAL & COALITION & ON & NUCLEAR & POWER & (ECNP) & 56 & A4 \\
\hline 431 & 2.2 .3 & ENVIRONMENTAL & COALITION & ON & NUCLEAR & POWER & (ECNP) & 56 & A5 \\
\hline 432 & 2.10 .5 .2 & ENVIRONMENTAL & COALITION & ON & NUCLEAR & POWER & (ECNP) & 56 & A5 \\
\hline 433 & 2.3 .5 & ENVIRONMENTAL & COALITION & ON & NUCLEAR & POWER & (ECNP) & 56 & A6 \\
\hline 433 & 2.4 .2 & ENVIRONMENTAL & COALITION & ON & NUCLEAR & POWER & (ECNP) & 56 & A6 \\
\hline 434 & 2.3 .2 & ENVIRONMENTAL & COALITION & ON & NUCLEAR & POWER & (ECNP) & 56 & A6 6 \\
\hline 434 & 2.3 .5 & ENVIRONMENTAL & COALITION & ON & NUCLEAR & POWER & (ECNP) & 56 & A6 \\
\hline 435 & 2.3 .7 & ENVIRONMENTAL & COALITION & ON & NUCLEAR & POWER & (ECNP) & 56 & A6 \\
\hline 436 & 2.1 .4 & ENVIRONMENTAI & COALITION & ON & NUCLEAR & POWER & (ECNP) & 56 & A6 \\
\hline 436 & 2.3 .2 & ENVIRONMENTAL & COALITION & ON & NUCLEAR & POWER & (ECNP) & 56 & A6 \\
\hline 436 & 2.3 .5 & ENVIRONMENTAI & COALITION & ON & NUCLEAR & POWER & (ECNP) & 56 & A6 \\
\hline 436 & 2.5 .2 & ENVIRONMENTAL & COALITION & ON & NUCLEAR & POWER & (ECNP) & 56 & A6 \\
\hline 437 & 2.1 .2 & ENVIRONMENTAL & COALITION & ON & NUCLEAR & POWER & (ECNP) & 56 & A6 \\
\hline 437 & $2 \cdot 3 \cdot 4$ & ENVIRONMENTAL & COALITION & ON & NUCLEAR & POWER & (ECNP) & 56 & A6 \\
\hline 437 & 2.4 .5 & ENVIRONMENTAL & COALITION & ON & NUCLEAR & POWER & (ECNP) & 56 & A6 \\
\hline 439 & 2.1 .8 & ENVIRONMENTAL & COALITION & ON & NUCLEAR & POWER & (ECNP) & 56 & A7 \\
\hline 439 & 2.2 .3 & ENVIRONMENTAL & COALITION & ON & NUCLEAR & POWER & (ECNP) & 56 & A7 \\
\hline 440 & 2.2 .3 & ENVIRONMENTAL & COALITION & ON & NUCLEAR & POWER & (ECNP) & 56 & A7 \\
\hline 440 & 2.10 .3 & ENVIRONMENTAL & COALITION & ON & NUCLEAR & POWER & (ECNP) & 56 & A7 \\
\hline 441 & 2.7 .3 & ENVIRONMENTAL & COALITION & ON & NUCLEAR & POWER & (ECNP) & 56 & A7 \\
\hline 442 & 2.7 .2 & ENVIRONMENTAL & COALITION & ON & NUCLEAR & POWER & (ECNP) & 56 & AB \\
\hline 442 & 2.7 .3 & ENVIRONMENTAL & COALITION & ON & NUCLEAR & POWER & (ECNP) & 56 & A8 \\
\hline 442 & 2.8 .3 & ENVIRONMENTAL & COALITION & ON & NUCLEAR & POWER & (ECNP) & 56 & A8 \\
\hline 443 & 2.3 .2 & ENVIRONMENTAL & COALITION & ON & NUCLEAR & POWER & $(\mathrm{ECNP})$ & 56 & A8 \\
\hline 443 & 2.3 .5 & ENVIRONMENTAL & COALITION & ON & NUCLEAR & POWER & (ECNP) & 56 & A8 \\
\hline 444 & 2.3 .2 & ENVIRONMENTAL & COALITION & ON & NUCLEAR & POWER & (ECNP) & 56 & A8 \\
\hline 444 & 2.10 .3 & ENVIRONMENTAL & COALITION & ON & NUCLEAR & POWER & (ECNP) & 56 & A8 \\
\hline 445 & 2.3 .2 & ENVIRONMENTAL, & COALITION & ON & NUCLEAR & POWER & $(\mathrm{ECNP})$ & 56 & A8 \\
\hline 445 & 2.3 .3 & ENVIRONMENTAL & COALITION & ON & NUCLEAR & POWER & (ECNP) & 56 & A8 \\
\hline 445 & 2.4 .2 & ENVIRONMENTAL & COALITION & ON & NUCLEAR & POWER & (ECNP) & 56 & $A 8$ \\
\hline 446 & $2 \cdot 3 \cdot 3$ & ENVIRONMENTAL & COALITION & ON & NUCLEAR & POWER & (ECNP) & 56 & A9 \\
\hline 447 & 2.3 .7 & ENVIRONMENTAL & COALITION & ON & NUCLEAR & POWER & $(\mathrm{ECNP})$ & 56 & A9 \\
\hline 448 & 2.3 .8 & ENVIRONMENTAL & COALITION & ON & NUCLEAR & POWER & (ECNP) & 56 & A9 \\
\hline
\end{tabular}




\begin{tabular}{|c|c|c|c|c|c|c|c|}
\hline $\begin{array}{l}\text { Comment } \\
\text { Numbers } \\
\end{array}$ & $\begin{array}{l}\text { Issue } \\
\text { Numbers }\end{array}$ & Commenter & & & & $\begin{array}{l}\text { Docket } \\
\text { Letter }\end{array}$ & $\begin{array}{l}\text { Page } \\
\text { Number }\end{array}$ \\
\hline 449 & 2.10 .6 & ENVIRONMENTAL COALITION & ON NUCLEAR & POWER & (ECNP) & 56 & A9 \\
\hline 450 & 2.10 .2 & ENVIRONMENTAL COALITION & ON NUCLEAR & POWER & (ECNP) & 56 & A9 \\
\hline 451 & 2.2 .3 & ENVIRONMENTAL COALITION & ON NUCLEAR & POWER & (ECNP) & 56 & A10 \\
\hline 451 & 2.3 .2 & ENVIRONMENTAL COALITION & ON NUCLEAR & POWER & (ECNP) & 56 & A10 \\
\hline 451 & 2.3 .4 & ENVIRONMENTAL COALITION & ON NUCLEAR & POWER & (ECNP) & 56 & A10 \\
\hline 451 & 2.4 .5 & ENVIRONMENTAL COALITION & ON NUCLEAR & POWER & (ECNP) & 56 & A10 \\
\hline 452 & 2.3 .7 & ENVIRONMENTAL COALITION & ON NUCLEAR & POWER & (ECNP) & 56 & A10 \\
\hline 452 & 2.10 .4 & ENVIRONMENTAL COALITION & ON NUCLEAR & POWER & (ECNP) & 56 & A10 \\
\hline 453 & 2.9 .1 & ENVIRONMENTAI COALITION & ON NUCLEAR & POWER & (ECNP) & 56 & A10 \\
\hline 454 & 2.1 .6 & ENVIRONMENTAL COALITION & ON NUCLEAR & POWER & (ECNP) & 56 & A11 \\
\hline 454 & 2.2 .5 & ENVIRONMENTAL COALITION & ON NUCLEAR & POWER & (ECNP) & 56 & A 11 \\
\hline 454 & 2.3 .9 & ENVIRONMENTAL COALITION & ON NUCLEAR & POWER & (ECNP) & 56 & A11 \\
\hline 455 & 2.3 .7 & ENVIRONMENTAL COALITION & ON NUCLEAR & POWER & (ECNP) & 56 & A11 \\
\hline 455 & 2.10 .6 & ENVIRONMENTAL COALITION & ON NUCLEAR & POWER & (ECNP) & 56 & A11 \\
\hline 456 & 2.7 .2 & ENVIRONMENTAL COALITION & ON NUCLEAR & POWER & (ECNP) & 56 & A11 \\
\hline 456 & 2.10 .6 & ENVIRONMENTAL COALITION & ON NUCLEAR & POWER & (ECNP) & 56 & A11 \\
\hline 457 & 2.9 .3 & ENVIRONMENTAL COALITION & ON NUCLEAR & POWER & (ECNP) & 56 & A11 \\
\hline 458 & 2.10 .5 .1 & ENVIRONMENTAL COALITION & ON NUCLEAR & POWER & (ECNP) & 56 & $\mathrm{~A} 12$ \\
\hline 459 & 2.2 .2 & ENVIRONMENTAL COALITION & ON NUCLEAR & POWER & (ECNP) & 56 & A12 \\
\hline 460 & 2.3 .2 & ENVIRONMENTAL COALITION & ON NUCLEAR & POWER & (ECNP) & 56 & A12 \\
\hline 460 & 2.3 .5 & ENVIRONMENTAL COALITION & ON NUCLEAR & POWER & $(E C N P)$ & 56 & A12 \\
\hline 460 & 2.3 .8 & ENVIRONMENTAL COALITION & ON NUCLEAR & POWER & $(E C N P)$ & 56 & A12 \\
\hline 461 & 2.3 .4 & ENVIRONMENTAI COALITION & ON NUCLEAR & POWER & (ECNP) & 56 & A 12 \\
\hline 461 & 2.3 .6 & ENVIRONMENTAI COALITION & ON NUCLEAR & POWER & (ECNP) & 56 & A12 \\
\hline 461 & 2.6 .4 & ENVIRONMENTAL COALITION & ON NUCLEAR & POWER & (ECNP) & 56 & A12 \\
\hline 462 & 2.3 .2 & ENVIRONMENTAL COALITION & ON NUCLEAR & POWER & (ECNP) & 56 & A13 \\
\hline 462 & 2.3 .5 & ENVIRONMENTAL COALITION & ON NUCLEAR & POWER & $(\mathrm{ECNP})$ & 56 & A13 \\
\hline 462 & 2.5 .1 & ENVIRONMENTAL COALITION & ON NUCLEAR & POWER & $(\mathrm{ECNP})$ & 56 & A13 \\
\hline 463 & 2.1 .2 & ENVIRONMENTAL COALITION & ON NUCLEAR & POWER & (ECNP) & 56 & A13 \\
\hline 463 & 2.3 .2 & ENVIRONMENTAL COALITION & ON NUCLEAR & POWER & (ECNP) & 56 & A13 \\
\hline 463 & 2.4 .2 & ENVIRONMENTAL COALITION & ON NUCLEAR & POWER & (ECNP) & 56 & A13 \\
\hline 464 & 2.4 .1 & ENVIRONMENTAL COALITION & ON NUCLEAR & POWER & (ECNP) & 56 & A13 \\
\hline 465 & 2.3 .7 & ENVIRONMENTAL COALITION & ON NUCLEAR & POWER & (ECNP) & 56 & A13 \\
\hline 466 & 2.1 .2 & ENVIRONMENTAL COALITION & ON NUCLEAR & POWER & $(\mathrm{ECNP})$ & 56 & A13 \\
\hline 467 & 2.10 .5 .2 & ENVIRONMENTAL COALITION & ON NUCLEAR & POWER & $(\mathrm{ECNP})$ & 56 & A13 \\
\hline 468 & 2.2 .3 & ENVIRONMENTAI COALITION & ON NUCLEAR & POWER & (ECNP) & 56 & A14 \\
\hline 469 & 2.7 .2 & ENVIRONMENTAL COALITION & ON NUCLEAR & POWER & (ECNP) & 56 & A14 \\
\hline 469 & 2.8 .2 & ENVIRONMENTAL COALITION & ON NUCLEAR & POWER & (ECNP) & 56 & A14 \\
\hline 469 & 2.8 .3 & ENVIRONMENTAL COALITION & ON NUCLEAR & POWER & (ECNP) & 56 & A14 \\
\hline 470 & 2.10 .3 & ENVIRONMENTAL COALITION & ON NUCLEAR & POWER & (ECNP) & 56 & A14 \\
\hline 471 & 2.3 .3 & ENVIRONMENTAL COALITION & ON NUCLEAR & POWER & (ECNP) & 56 & A14 \\
\hline
\end{tabular}




\begin{tabular}{|c|c|c|c|c|c|c|c|}
\hline $\begin{array}{l}\text { Comment } \\
\text { Numbers }\end{array}$ & $\begin{array}{l}\text { Issue } \\
\text { Numbers }\end{array}$ & Commenter & & & & $\begin{array}{l}\text { Docket } \\
\text { Letter }\end{array}$ & $\begin{array}{l}\text { Page } \\
\text { Number }\end{array}$ \\
\hline 471 & 2.4 .2 & ENVIRONMENTAL COALITION & ON NUCLEAR & POWER & $(\mathrm{ECNP})$ & 56 & A14 \\
\hline 472 & 2.7 .3 & ENVIRONMENTAL COALITION & ON NUCLEAR & POWER & (ECNP) & 56 & A14 \\
\hline 472 & 2.8 .1 & ENVIRONMENTAL COALITION & ON NUCLEAR & POWER & (ECNP) & 56 & A14 \\
\hline 472 & 2.10 .2 & ENVIRONMENTAL COALITION & ON NUCLEAR & POWER & (ECNP) & 56 & A14 \\
\hline 473 & 2.1 .2 & ENVIRONMENTAI COALITION & ON NUCLEAR & POWER & (ECNP) & 56 & A15 \\
\hline 473 & 2.3 .4 & ENVIRONMENTAL COALITION & ON NUCLEAR & POWER & (ECNP) & 56 & A15 \\
\hline 473 & 2.4 .5 & ENVIRONMENTAL COALITION & ON NUCLEAR & POWER & (ECNP) & 56 & A15 \\
\hline 473 & 2.6 .2 & ENVIRONMENTAL COALITION & ON NUCLEAR & POWER & (ECNP) & 56 & A15 \\
\hline 473 & 2.6 .4 & ENVIRONMENTAL COALITION & ON NUCLEAR & POWER & (ECNP) & 56 & A15 \\
\hline 474 & 2.10 .4 & ENVIRONMENTAL COALITION & ON NUCLEAR & POWER & (ECNP) & 56 & A15 \\
\hline 475 & 2.9 .2 & ENVIRONMENTAL COAIITION & ON NUCLEAR & POWER & (ECNP) & 56 & A15 \\
\hline 476 & 2.1 .6 & ENVIRONMENTAL COALITION & ON NUCLEAR & POWER & (ECNP) & 56 & A15 \\
\hline 476 & 2.3 .9 & ENVIRONMENTAL COALITION & ON NUCLEAR & POWER & (ECNP) & 56 & A15 \\
\hline 477 & 2.9 .3 & ENVIRONMENTAL COALITION & ON NUCLEAR & POWER & (ECNP) & 56 & A15 \\
\hline 478 & 2.1 .1 & ENVIRONMENTAL COALITION & ON NUCLEAR & POWER & (ECNP) & 56 & A15 \\
\hline 479 & 2.1 .1 & ENVIRONMENTAL COALITION & ON NUCLEAR & POWER & (ECNP) & 56 & A16 \\
\hline 480 & 2.1 .4 & ENVIRONMENTAL COALITION & ON NUCLEAR & POWER & (ECNP) & 56 & A16 \\
\hline 481 & 2.3 .4 & ENVIRONMENTAL COALITION & ON NUCLEAR & POWER & (ECNP) & 56 & A16. \\
\hline 481 & 2.3 .9 & ENVIRONMENTAL COALITION & ON NUCLEAR & POWER & (ECNP) & 56 & A16 \\
\hline 482 & 2.9 .3 & ENVIRONMENTAL COALITION & ON NUCLEAR & POWER & (ECNP) & 56 & A17 \\
\hline 483 & 2.2 .1 & ENVIRONMENTAL COALITION & ON NUCLEAR & POWER & (ECNP) & 56 & $A 17$ \\
\hline 483 & 2.6 .5 & ENVIRONMENTAL COALITION & ON NUCLEAR & POWER & (ECNP) & 56 & A17 \\
\hline 484 & 2.3 .4 & ENVIRONMENTAL COALITION & ON NUCLEAR & POWER & (ECNP) & 56 & A 17 \\
\hline 484 & 2.4 .5 & ENVIRONMENTAL COALITION & ON NUCLEAR & POWER & (ECNP) & 56 & A17 \\
\hline 484 & 2.6 .5 & ENVIRONMENTAL COALITION & ON NUCLEAR & POWER & (ECNP) & 56 & A17 \\
\hline 485 & 2.3 .2 & ENVIRONMENTAL COALITION & ON NUCLEAR & POWER & (ECNP) & 56 & A17 \\
\hline 485 & 2.3 .7 & ENVIRONMENTAI COALITION & ON NUCLEAR & POWER & (ECNP) & 56 & A17 \\
\hline 486 & 2.3 .9 & ENVIRONMENTAL COALITION & ON NUCLEAR & POWER & (ECNP) & 56 & A18 \\
\hline 487 & 2.1 .1 & ENVIRONMENTAI COALITION & ON NUCLEAR & POWER & (ECNP) & 56 & A18 \\
\hline 488 & 2.1 .3 & ENVIRONMENTAL COALITION & ON NUCLEAR & POWER & (ECNP) & 56 & A18 \\
\hline 489 & 2.1 .2 & ENVIRONMENTAL COALITION & ON NUCLEAR & POWER & (ECNP) & 56 & A18 \\
\hline 490 & 2.1 .5 & ENVIRONMENTAL COALITION & ON NUCLEAR & POWER & (ECNP) & 56 & A19 \\
\hline 491 & 2.1 .7 & ENVIRONMENTAL COALITION & ON NUCLEAR & POWER & (ECNP) & 56 & A19 \\
\hline 492 & 2.2 .2 & ENVIRONMENTAL COALITION & ON NUCLEAR & POWER & (ECNP) & 56 & A19 \\
\hline 493 & 2.2 .3 & ENVIRONMENTAL COALITION & ON NUCLEAR & POWER & (ECNP) & 56 & A19 \\
\hline 494 & 2.2 .1 & ENVIRONMENTAI COALITION & ON NUCLEAR & POWER & (ECNP) & 56 & A19 \\
\hline 494 & 2.4 .5 & ENVIRONMENTAL COALITION & ON NUCLEAR & POWER & (ECNP) & 56 & A19 \\
\hline 494 & 2.6 .5 & ENVIRONMENTAL COALITION & ON NUCLEAR & POWER & (ECNP) & 56 & A19 \\
\hline 495 & 2.3 .6 & ENVIRONMENTAL COALITION & ON NUCLEAR & POWER & (ECNP) & 56 & A19 \\
\hline 495 & 2.3 .7 & ENVIRONMENTAL COALITION & ON NUCLEAR & POWER & (ECNP) & 56 & A19 \\
\hline 496 & 2.3 .5 & ENVIRONMENTAL COALITION & ON NUCLEAR & POWER & (ECNP) & 56 & $\mathrm{~A} 20$ \\
\hline
\end{tabular}




\begin{tabular}{|c|c|c|c|c|c|c|c|c|c|}
\hline 496 & 2.3 .7 & ENVIRONMENTAL & COALITION & ON & NUCLEAR & POWER & (ECNP) & 56 & A20 \\
\hline 496 & 2.5 .1 & ENVIRONMENTAL & COALITION & ON & NUCLEAR & POWER & (ECNP) & 56 & $\mathrm{~A} 20$ \\
\hline 497 & 2.3 .2 & ENVIRONMENTAL & COALITION & ON & NUCLEAR & POWER & (ECNP) & 56 & A20 \\
\hline 497 & 2.3 .8 & ENVIRONMENTAL & COALITION & ON & NUCLEAR & POWER & (ECNP) & 56 & A20 \\
\hline 498 & 2.10 .1 & ENVIRONMENTAL & COALITION & ON & NUCLEAR & POWER & (ECNP) & 56 & $\mathrm{~A} 20$ \\
\hline 498 & 2.10 .2 & ENVIRONMENTAL & COALITION & ON & NUCLEAR & POWER & (ECNP) & 56 & $\mathrm{~A} 20$ \\
\hline 499 & 2.3 .5 & ENVIRONMENTAL & COALITION & ON & NUCLEAR & POWER & (ECNP) & 56 & A21 \\
\hline 499 & 2.3 .7 & ENVIRONMENTAL & COALITION & ON & NUCLEAR & POWER & (ECNP) & 56 & A21 \\
\hline 500 & 2.3 .4 & ENVIRONMENTAL & COALITION & ON & NUCLEAR & POWER & (ECNP) & 56 & A21 \\
\hline 500 & 2.4 .5 & ENVIRONMENTAL & COALITION & ON & NUCLEAR & POWER & (ECNP) & 56 & A21 \\
\hline 500 & 2.6 .2 & ENVIRONMENTAL & COALITION & ON & NUCLEAR & POWER & (ECNP) & 56 & A21 \\
\hline 501 & 2.3 .3 & ENVIRONMENTAL & COALITION & ON & NUCLEAR & POWER & (ECNP) & 56 & A21 \\
\hline 501 & 2.3 .8 & ENVIRONMENTAL & COALITION & ON & NUCLEAR & POWER & (ECNP) & 56 & A21 \\
\hline 502 & 2.3 .4 & ENVIRONMENTAL & COALITION & ON & NUCLEAR & POWER & (ECNP) & 56 & A22 2 \\
\hline 502 & 2.4 .5 & ENVIRONMENTAL & COALITION & ON & NUCLEAR & POWER & (ECNP) & 56 & A22 \\
\hline 502 & 2.6 .4 & ENVIRONMENTAL & COALITION & ON & NUCLEAR & POWER & (ECNP) & 56 & A22 \\
\hline 503 & 2.4 .1 & ENVIRONMENTAL & COALITION & ON & NUCLEAR & POWER & (ECNP) & 56 & A22 \\
\hline 504 & 2.3 .7 & ENVIRONMENTAI & COALITION & ON & NUCLEAR & POWER & (ECNP) & 56 & $\mathrm{~A} 22$ \\
\hline 505 & 2.3 .7 & ENVIRONMENTAL & COALITION & ON & NUCLEAR & POWER & (ECNP) & 56 & A22 \\
\hline 506 & 2.7 .3 & ENVIRONMENTAL & COALITION & ON & NUCLEAR & POWER & (ECNP) & 56 & A23 \\
\hline 507 & 2.7 .1 & ENVIRONMENTAI & COALITION & ON & NUCLEAR & POWER & (ECNP) & 56 & A23 \\
\hline 507 & 2.7 .2 & ENVIRONMENTAL & COALITION & ON & NUCLEAR & POWER & (ECNP) & 56 & A23 \\
\hline 507 & 2.8 .1 & ENVIRONMENTAL & COALITION & ON & NUCLEAR & POWER & (ECNP) & 56 & A23 \\
\hline 507 & 2.8 .3 & ENVIRONMENTAI & COALITION & ON & NUCLEAR & POWER & (ECNP) & 56 & A23 \\
\hline 508 & 2.8 .3 & ENVIRONMENTAI & COALITION & ON & NUCLEAR & POWER & $(\mathrm{ECNP})$ & 56 & A23 \\
\hline 508 & 2.8 .4 & ENVIRONMENTAI & COALITION & ON & NUCLEAR & POWER & (ECNP) & 56 & A23 \\
\hline 509 & 2.8 .1 & ENVIRONMENTAL & COALITION & ON & NUCLEAR & POWER & (ECNP) & 56 & A23 \\
\hline 510 & 2.10 .1 & ENVIRONMENTAL & COALITION & ON & NUCLEAR & POWER & (ECNP) & 56 & A23 \\
\hline 511 & 2.1 .5 & ENVIRONMENTAL & COALITION & ON & NUCLEAR & POWER & (ECNP) & 56 & A2 4 \\
\hline 512 & 2.3 .3 & ENVIRONMENTAI & COALITION & ON & NUCLEAR & POWER & (ECNP) & 56 & A2 4 \\
\hline 512 & 2.4 .2 & ENVIRONMENTAL & COALITION & ON & NUCLEAR & POWER & (ECNP) & 56 & A24 \\
\hline 512 & 2.4 .3 & ENVIRONMENTAL & COALITION & ON & NUCLEAR & POWER & (ECNP) & 56 & A2 4 \\
\hline 512 & 2.4 .3 & ENVIRONMENTAL & COALITION & ON & NUCLEAR & POWER & (ECNP) & 56 & A24 \\
\hline 513 & 2.3 .2 & ENVIRONMENTAL & COALITION & ON & NUCLEAR & POWER & (ECNP) & 56 & A24 \\
\hline 513 & 2.10 .4 & ENVIRONMENTAL & COALITION & ON & NUCLEAR & POWER & (ECNP) & 56 & A2 4 \\
\hline 514 & 2.3 .7 & ENVIRONMENTAL & COALITION & ON & NUCLEAR & POWER & (ECNP) & 56 & A24 \\
\hline 514 & 2.10 .2 & ENVIRONMENTAL & COALITION & ON & NUCLEAR & POWER & (ECNP) & 56 & A2 4 \\
\hline 515 & 2.1 .8 & ENVIRONMENTAI & COALITION & ON & NUCLEAR & POWER & (ECNP) & 56 & A2 4 \\
\hline 515 & 2.10 .1 & ENVIRONMENTAL & COALITION & ON & NUCLEAR & POWER & (ECNP) & 56 & A2 4 \\
\hline 515 & 2.10 .2 & ENVIRONMENTAI & COALITION & ON & NUCLEAR & POWER & (ECNP) & 56 & A24 \\
\hline 516 & 2.3 .7 & ENVIRONMENTAI & COAIITION & ON & NUCLEAR & POWER & (ECNP) & 56 & A25 \\
\hline
\end{tabular}




\begin{tabular}{|c|c|c|c|c|c|c|}
\hline $\begin{array}{l}\text { Comment } \\
\text { Numbers } \\
\end{array}$ & $\begin{array}{l}\text { Issue } \\
\text { Numbers }\end{array}$ & Commenter & & & $\begin{array}{l}\text { Docket } \\
\text { Letter }\end{array}$ & $\begin{array}{l}\text { Page } \\
\text { Number }\end{array}$ \\
\hline 516 & 2.4 .1 & ENVIRONMENTAL COALITION & ON NUCLEAR & POWER (ECNP) & 56 & A25 \\
\hline 517 & 2.3 .3 & ENVIRONMENTAL COALITION & ON NUCLEAR & POWER (ECNP) & 56 & A25 \\
\hline 517 & 2.3 .7 & ENVIRONMENTAL COALITION & ON NUCLEAR & POWER (ECNP) & 56 & A25 \\
\hline 517 & 2.4 .2 & ENVIRONMENTAL COALITION & ON NUCLEAR & POWER (ECNP) & 56 & A25 \\
\hline 517 & 2.10 .2 & ENVIRONMENTAL COALITION & ON NUCLEAR & POWER (ECNP) & 56 & A25 \\
\hline 518 & 2.1 .2 & ENVIRONMENTAL COALITION & ON NUCLEAR & POWER (ECNP) & 56 & A2 6 \\
\hline 518 & 2.4 .4 & ENVIRONMENTAL COALITION & ON NUCLEAR & POWER (ECNP) & 56 & A2 6 \\
\hline 519 & 2.9 .1 & ENVIRONMENTAL COALITION & ON NUCLEAR & POWER (ECNP) & 56 & A26 \\
\hline 520 & 2.8 .3 & ENVIRONMENTAL COALITION. & ON NUCLEAR & POWER (ECNP) & 56 & A2 6 \\
\hline 521 & 2.2 .1 & ENVIRONMENTAL COALITION & ON NUCLEAR & POWER (ECNP) & 56 & A26 \\
\hline 521 & 2.2 .5 & ENVIRONMENTAL COALITION & ON NUCLEAR & POWER (ECNP) & 56 & A2 6 \\
\hline 521 & 2.3 .9 & ENVIRONMENTAL COALITION & ON NUCLEAR & POWER (ECNP) & 56 & A26 \\
\hline 521 & 2.10 .5 .3 & ENVIRONMENTAL COALITION & ON NUCLEAR & POWER (ECNP) & 56 & A26 \\
\hline 522 & 2.3 .4 & ENVIRONMENTAL COALITION & ON NUCLEAR & POWER (ECNP) & 56 & A 27 \\
\hline 522 & 2.3 .9 & ENVIRONMENTAL COALITION & ON NUCLEAR & POWER (ECNP) & 56 & $A 27$ \\
\hline 522 & 2.4 .5 & ENVIRONMENTAL COALITION & ON NUCLEAR & POWER (ECNP) & 56 & A27 \\
\hline 522 & 2.10 .6 & ENVIRONMENTAL COALITION & ON NUCLEAR & POWER (ECNP) & 56 & A27 \\
\hline 523 & $2 \cdot 3 \cdot 4$ & ENVIRONMENTAL COALITION & ON NUCLEAR & POWER (ECNP) & 56 & A27 \\
\hline 523 & 2.4 .5 & ENVIRONMENTAL COALITION & ON NUCLEAR & POWER (ECNP) & 56 & A27 \\
\hline 523 & 2.6 .2 & ENVIRONMENTAL COALITION & ON NUCLEAR & POWER (ECNP) & 56 & A27 \\
\hline 524 & 2.1 .2 & ENVIRONMENTAL COALITION & ON NUCLEAR & POWER (ECNP) & 56 & A28 \\
\hline 524 & 2.3 .2 & ENVIRONMENTAL COALITION & ON NUCLEAR & POWER (ECNP) & 56 & A28 \\
\hline 524 & 2.3 .9 & ENVIRONMENTAL COALITION & ON NUCLEAR & POWER (ECNP) & 56 & A28 \\
\hline 524 & 2.10 .2 & ENVIRONMENTAL COALITION & ON NUCLEAR & POWER (ECNP) & 56 & A28 \\
\hline 524 & 2.10 .6 & ENVIRONMENTAL COALITION & ON NUCLEAR & POWER (ECNP) & 56 & A28 \\
\hline 525 & 2.10 .1 & ENVIRONMENTAL COALITION & ON NUCLEAR & POWER (ECNP) & 56 & A28 \\
\hline 526 & 2.10 .5 .2 & ENVIRONMENTAL COALITION & ON NUCLEAR & POWER (ECNP) & 56 & A28 \\
\hline 527 & 2.3 .1 & ENVIRONMENTAL COAIITION & ON NUCLEAR & POWER (ECNP) & 56 & A29 \\
\hline 527 & 2.12 .0 & ENVIRONMENTAL COALITION & ON NUCLEAR & POWER (ECNP) & 56 & A29 \\
\hline 528 & 2.12 .0 & ENVIRONMENTAL COALITION & ON NUCLEAR & POWER (ECNP) & 56 & A29 \\
\hline 529 & 2.1 .1 & ENVIRONMENTAL COALITION & ON NUCLEAR & POWER (ECNP) & 56 & A30 \\
\hline 530 & 2.1 .2 & ENVIRONMENTAL COALITION & ON NUCLEAR & POWER (ECNP) & 56 & A30 \\
\hline 530 & 2.10 .5 .1 & ENVIRONMENTAL COALITION & ON NUCLEAR & POWER (ECNP) & 56 & A30 \\
\hline 531 & 2.1 .3 & ENVIRONMENTAL COALITION & ON NUCLEAR & POWER (ECNP) & 56 & A31 \\
\hline 532 & 2.1 .4 & ENVIRONMENTAL COALITION & ON NUCLEAR & POWER (ECNP) & 56 & A31 \\
\hline 533 & 2.1 .5 & ENVIRONMENTAL COALITION & ON NUCLEAR & POWER (ECNP) & 56 & A32 \\
\hline 534 & 2.1 .7 & ENVIRONMENTAL COALITION & ON NUCLEAR & POWER (ECNP) & 56 & A32 \\
\hline 535 & 2.1 .6 & ENVIRONMENTAL COALITION & ON NUCLEAR & POWER (ECNP) & 56 & A32 \\
\hline 535 & 2.2 .1 & ENVIRONMENTAL COALITION & ON NUCLEAR & POWER (ECNP) & 56 & A32 \\
\hline 535 & 2.2 .2 & ENVIRONMENTAL COALITION & ON NUCLEAR & POWER (ECNP) & 56 & A32 \\
\hline 535 & 2.2 .3 & ENVIRONMENTAL COALITION & ON NUCLEAR & POWER (ECNP) & 56 & A32 \\
\hline
\end{tabular}




\begin{tabular}{|c|c|c|c|c|c|}
\hline $\begin{array}{l}\text { Comment } \\
\text { Numbers }\end{array}$ & $\begin{array}{l}\text { Issue } \\
\text { Numbers }\end{array}$ & Commenter & & $\begin{array}{l}\text { Docket } \\
\text { Letter }\end{array}$ & $\begin{array}{l}\text { Page } \\
\text { Number }\end{array}$ \\
\hline 536 & 2.9 .1 & ENVIRONMENTAL COALITION ON & NUCLEAR POWER (ECNP) & 56 & A33 \\
\hline 537 & 2.3 .2 & ENVIRONMENTAL COALITION ON & NUCLEAR POWER (ECNP) & 56 & A33 \\
\hline 537 & 2.3 .4 & ENVIRONMENTAL COALITION ON & NUCLEAR POWER (ECNP) & 56 & A33 \\
\hline 537 & 2.3 .5 & ENVIRONMENTAL COALITION ON & NUCLEAR POWER (ECNP) & 56 & A33 \\
\hline 537 & 2.5 .1 & ENVIRONMENTAL COALITION ON & NUCLEAR POWER (ECNP) & 56 & A33 \\
\hline 538 & 2.4 .1 & ENVIRONMENTAL COALITION ON & NUCLEAR POWER (ECNP) & 56 & A33 \\
\hline 538 & 2.4 .2 & ENVIRONMENTAL COALITION ON & NUCLEAR POWER (ECNP) & 56 & A33 \\
\hline 539 & 2.4 .5 & ENVIRONMENTAL COALITION ON & NUCLEAR POWER (ECNP) & 56 & A33 \\
\hline 539 & 2.7 .2 & ENVIRONMENTAL COALITION ON & NUCLEAR POWER (ECNP) & 56 & A33 \\
\hline 540 & 2.3 .5 & ENVIRONMENTAL COALITION ON & NUCLEAR POWER (ECNP) & 56 & A33 \\
\hline 540 & 2.5 .1 & ENVIRONMENTAL COALITION ON & NUCLEAR POWER (ECNP) & 56 & A33 \\
\hline 541 & 2.3 .4 & ENVIRONMENTAL COALITION ON & NUCLEAR POWER (ECNP) & 56 & A34 \\
\hline 541 & 2.6 .4 & ENVIRONMENTAL COALITION ON & NUCLEAR POWER (ECNP) & 56 & A34 \\
\hline 542 & 2.7 .1 & ENVIRONMENTAL COALITION ON & NUCLEAR POWER (ECNP) & 56 & A34 \\
\hline 542 & 2.7 .2 & ENVIRONMENTAL COALITION ON & NUCLEAR POWER (ECNP) & 56 & A34 \\
\hline 542 & 2.7 .3 & ENVIRONMENTAL COALITION ON & NUCLEAR POWER (ECNP) & 56 & A34 \\
\hline 543 & 2.9 .3 & ENVIRONMENTAI COALITION ON & NUCLEAR POWER (ECNP) & 56 & A34 \\
\hline 544 & 2.3 .2 & CONSUMERS POWER & & 57 & 1 \\
\hline 544 & $2 \cdot 3 \cdot 5$ & CONSUMERS POWER & & 57 & 1 \\
\hline 544 & 2.3 .6 & CONSUMERS POWER & & 57 & 1 \\
\hline 544 & 2.5 .1 & CONSUMERS POWER & & 57 & 1 \\
\hline 545 & 2.3 .4 & CONSUMERS POWER & & 57 & 1 \\
\hline 545 & 2.6 .4 & CONSUMERS POWER & & 57 & 1 \\
\hline 546 & 2.4 .1 & CONSUMERS POWER & & 57 & 2 \\
\hline 547 & 2.7 .2 & CONSUMERS POWER & & 57 & 2 \\
\hline 548 & $2.3 \cdot 1$ & WOODWARD-CLYDE CONSULTANTS & & 58 & 1 \\
\hline 549 & 2.3 .1 & WOODWARD-CLYDE CONSULTANTS & & 58 & 1 \\
\hline 550 & 2.3 .1 & WOODWARD-CLYDE CONSULTANTS & & 58 & 1 \\
\hline 550 & 2.3 .5 & WOODWARD-CLYDE CONSULTANTS & & 58 & 1 \\
\hline 550 & 2.3 .8 & WOODWARD-CLYDE CONSULTANTS & & 58 & 1 \\
\hline 551 & 2.3 .1 & WOODWARD-CLYDE CONSULTANTS & & 58 & 2 \\
\hline 551 & 2.3 .3 & WOODWARD-CLYDE CONSULTANTS & & 58 & 2 \\
\hline 551 & 2.4 .2 & WOODWARD-CLYDE CONSULTANTS & & 58 & 2 \\
\hline 552 & 2.3 .4 & WOODWARD-CLYDE CONSULTANTS & & 58 & 2 \\
\hline 553 & 2.4 .4 & WOODWARD-CLYDE CONSULTANTS & & 58 & 3 \\
\hline 554 & 2.3 .2 & WOODWARD-CLYDE CONSULTANTS & & 58 & 4 \\
\hline 554 & 2.3 .5 & WOODWARD-CLYDE CONSULTANTS & & 58 & 4 \\
\hline 554 & 2.3 .6 & WOODWARD-CLYDE CONSULTANTS & & 58 & 4 \\
\hline 554 & 2.5 .1 & WOODWARD-CLYDE CONSULTANTS & & 58 & 4 \\
\hline 555 & 2.3 .3 & WOODWARD-CLYDE CONSULTANTS & & 58 & 4 \\
\hline 555 & 2.4 .2 & WOODWARD-CLYDE CONSULTANTS & & 58 & 4 \\
\hline
\end{tabular}




\begin{tabular}{|c|c|c|c|c|}
\hline 556 & 2.3 .1 & WOODWARD-CLYDE & CONSULTANTS & 58 \\
\hline 556 & 2.3 .8 & WOODWARD-CLYDE & CONSULTANTS & 58 \\
\hline 556 & 2.6 .1 & WOODWARD-CLYDE & CONSULTANTS & 58 \\
\hline 556 & 2.10 .1 & WOODWARD-CLYDE & CONSULTANTS & 58 \\
\hline 557 & 2.3 .4 & WOODWARD-CLYDE & CONSULTANTS & 58 \\
\hline 557 & 2.6 .4 & WOODWARD-CLYDE & CONSULTANTS & 58 \\
\hline 558 & 2.6 .4 & WOODWARD-CIYDE & CONSULTANTS & 58 \\
\hline 559 & 2.8 .1 & WOODWARD-CLYDE & CONSULTANTS & 58 \\
\hline 560 & 2.8 .5 & WOODWARD-CLYDE & CONSULTANTS & 58 \\
\hline 561 & 2.12 .0 & WOODWARD-CLYDE & CONSULTANTS & 58 \\
\hline 562 & 2.7 .3 & WESTERN STATES & LEGAL FOUNDATION & 59 \\
\hline 563 & 2.7 .3 & WESTERN STATES & LEGAI FOUNDATION & 59 \\
\hline 564 & 2.3 .5 & WESTERN STATES & LEGAL FOUNDATION & 59 \\
\hline 564 & 2.6 .4 & WESTERN STATES & LEGAL FOUNDATION & 59 \\
\hline 565 & 2.7 .3 & WESTERN STATES & LEGAL FOUNDATION & 59 \\
\hline 565 & 2.12 .0 & WESTERN STATES & LEGAL FOUNDATION & 59 \\
\hline 566 & 2.3 .8 & WESTERN STATES & LEGAL FOUNDATION & 59 \\
\hline 566 & 2.3 .9 & WESTERN STATES & LEGAL FOUNDATION & 59 \\
\hline 567 & 2.2 .4 & WESTERN STATES & LEGAI FOUNDATION & 59 \\
\hline 567 & 2.3 .8 & WESTERN STATES & LEGAL FOUNDATION & 59 \\
\hline 568 & 2.7 .3 & WESTERN STATES & LEGAL FOUNDATION & 59 \\
\hline 569 & 2.1 .2 & WESTERN STATES & LEGAI FOUNDATION & 59 \\
\hline 569 & 2.10 .5 .1 & WESTERN STATES & LEGAI FOUNDATION & 59 \\
\hline 570 & 2.3 .3 & WESTERN STATES & LEGAL FOUNDATION & 59 \\
\hline 570 & 2.4 .2 & WESTERN STATES & LEGAL FOUNDATION & 59 \\
\hline 570 & 2.5 .2 & WESTERN STATES & LEGAL FOUNDATION & 59 \\
\hline 571 & 2.3 .4 & WESTERN STATES & LEGAL FOUNDATION & 59 \\
\hline 571 & 2.6 .1 & WESTERN STATES & LEGAL FOUNDATION & 59 \\
\hline 571 & 2.10 .1 & WESTERN STATES & LEGAI FOUNDATION & 59 \\
\hline 572 & 2.4 .1 & WESTERN STATES & LEGAL FOUNDATION & 59 \\
\hline 572 & 2.10 .5 .3 & WESTERN STATES & LEGAL FOUNDATION & 59 \\
\hline 573 & 2.4 .1 & WESTERN STATES & LEGAL FOUNDATION & 59 \\
\hline 573 & 2.4 .4 & WESTERN STATES & LEGAL FOUNDATION & 59 \\
\hline 574 & 2.1 .8 & WESTERN STATES & LEGAL FOUNDATION & 59 \\
\hline 574. & 2.6 .2 & WESTERN STATES & LEGAL FOUNDATION & 59 \\
\hline 574 & 2.10 .1 & WESTERN STATES & LEGAL FOUNDATION & 59 \\
\hline 575 & 2.7 .1 & WESTERN STATES & LEGAI FOUNDATION & 59 \\
\hline 576 & 2.8 .1 & WESTERN STATES & LEGAL FOUNDATION & 59 \\
\hline 576 & 2.8 .5 & WESTERN STATES & LEGAI FOUNDATION & 59 \\
\hline 576 & 2.10 .1 & WESTERN STATES & LEGAL FOUNDATION & 59 \\
\hline 577 & 2.2 .1 & WESTERN STATES & LEGAI FOUNDATION & 59 \\
\hline
\end{tabular}




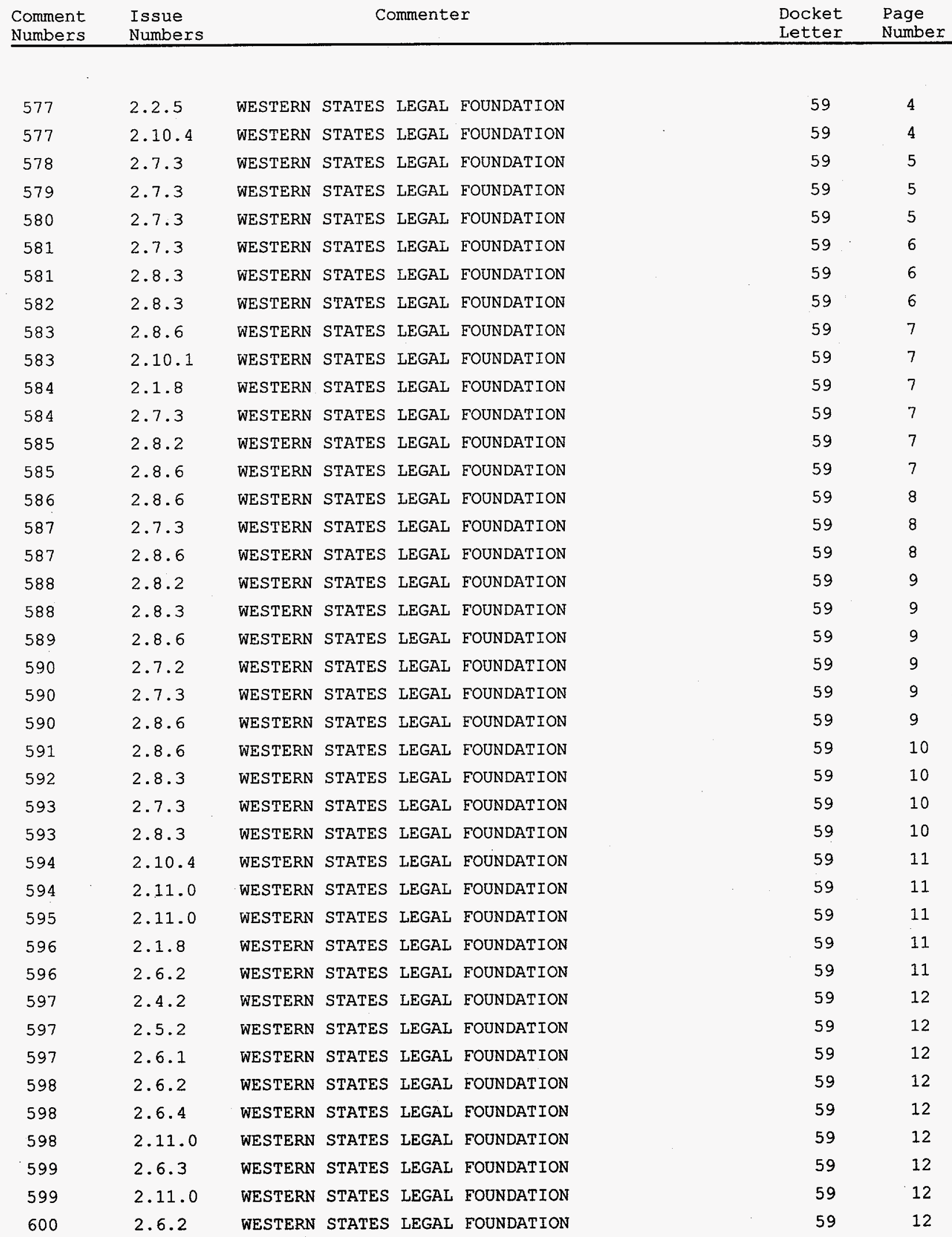




\begin{tabular}{|c|c|c|c|c|}
\hline $\begin{array}{l}\text { Comment } \\
\text { Numbers } \\
\end{array}$ & $\begin{array}{l}\text { Issue } \\
\text { Numbers }\end{array}$ & Commenter & $\begin{array}{l}\text { Docket } \\
\text { Letter }\end{array}$ & $\begin{array}{l}\text { Page } \\
\text { Number }\end{array}$ \\
\hline 601 & 2.6 .2 & WESTERN STATES LEGAL FOUNDATION & 59 & 12 \\
\hline 602 & 2.2 .2 & B\&W NUCLEAR ENVIRONMENTAL SERVICES, INC. & 60 & 1 \\
\hline 602 & 2.2 .3 & B\&W NUCLEAR ENVIRONMENTAL SERVICES, INC. & 60 & 1 \\
\hline 603 & 2.2 .2 & B\&W NUCLEAR ENVIRONMENTAL SERVICES, INC. & 60 & 2 \\
\hline 603 & 2.3 .5 & B\&W NUCLEAR ENVIRONMENTAL SERVICES, INC. & 60 & 2 \\
\hline 604 & 2.2 .5 & $\mathrm{ARCO}$ & 61 & A1 \\
\hline 605 & 2.2 .1 & ARCO & 61 & $\mathrm{~A} 1$ \\
\hline 605 & 2.2 .2 & ARCO & 61 & A1 \\
\hline 606 & 2.3 .4 & $\mathrm{ARCO}$ & 61 & A1 \\
\hline 606 & 2.6 .2 & ARCO & 61 & A1 \\
\hline 606 & 2.6 .4 & ARCO & 61 & A1 \\
\hline 607 & 2.10 .3 & $A R C O$ & 61 & $\mathrm{~A} 2$ \\
\hline 608 & 2.3 .4 & ARCO & 61 & $\mathrm{~A} 2$ \\
\hline 608 & 2.4 .4 & ARCO & 61 & A2 \\
\hline 608 & 2.4 .5 & ARCO & 61 & $\mathrm{~A} 2$ \\
\hline 608 & 2.6 .2 & $\mathrm{ARCO}$ & 61 & $\mathrm{~A} 2$ \\
\hline 608 & 2.6 .4 & ARCO & 61 & $\mathrm{~A} 2$ \\
\hline 609 & 2.2 .5 & ARCO & 61 & $\mathrm{~A} 2$ \\
\hline 610 & 2.2 .1 & ARCO & 61 & $\mathrm{~A} 2$ \\
\hline 610 & 2.2 .2 & ARCO & 61 & A2 \\
\hline 611 & 2.2 .5 & ARCO & 61 & A3 \\
\hline 612 & 2.10 .5 .3 & ARCO & 61 & A3 \\
\hline 613 & 2.2 .5 & ARCO & 61 & A3 \\
\hline 613 & 2.6 .4 & ARCO & 61 & A3 \\
\hline 613 & 2.10 .3 & ARCO & 61 & A3 \\
\hline 614 & 2.10 .4 & ARCO & 61 & A4 \\
\hline 615 & 2.2 .1 & ARCO & 61 & A5 \\
\hline 615 & 2.2 .5 & ARCO & 61 & A5 \\
\hline 616 & 2.2 .5 & ARCO & 61 & A5 \\
\hline 617 & 2.2 .2 & ARCO & 61 & A5 \\
\hline 618 & 2.3 .4 & ARCO & 61 & A6 \\
\hline 618 & 2.4 .4 & ARCO & 61 & A 6 \\
\hline 618 & 2.4 .5 & ARCO & 61 & A6 \\
\hline 618 & 2.6 .2 & ARCO & 61 & A 6 \\
\hline 618 & 2.6 .4 & ARCO & 61 & A6 \\
\hline 618 & 2.10 .3 & ARCO & 61 & A6 \\
\hline 619 & 2.6 .4 & ARCO & 61 & A6 \\
\hline 619 & 2.10 .1 & ARCO & 61 & A6 6 \\
\hline 620 & 2.6 .2 & ARCO & 61 & A.7 \\
\hline 620 & 2.6 .4 & ARCO & 61 & A7 \\
\hline 620 & 2.10 .5 .3 & ARCO & 61 & A7 \\
\hline
\end{tabular}




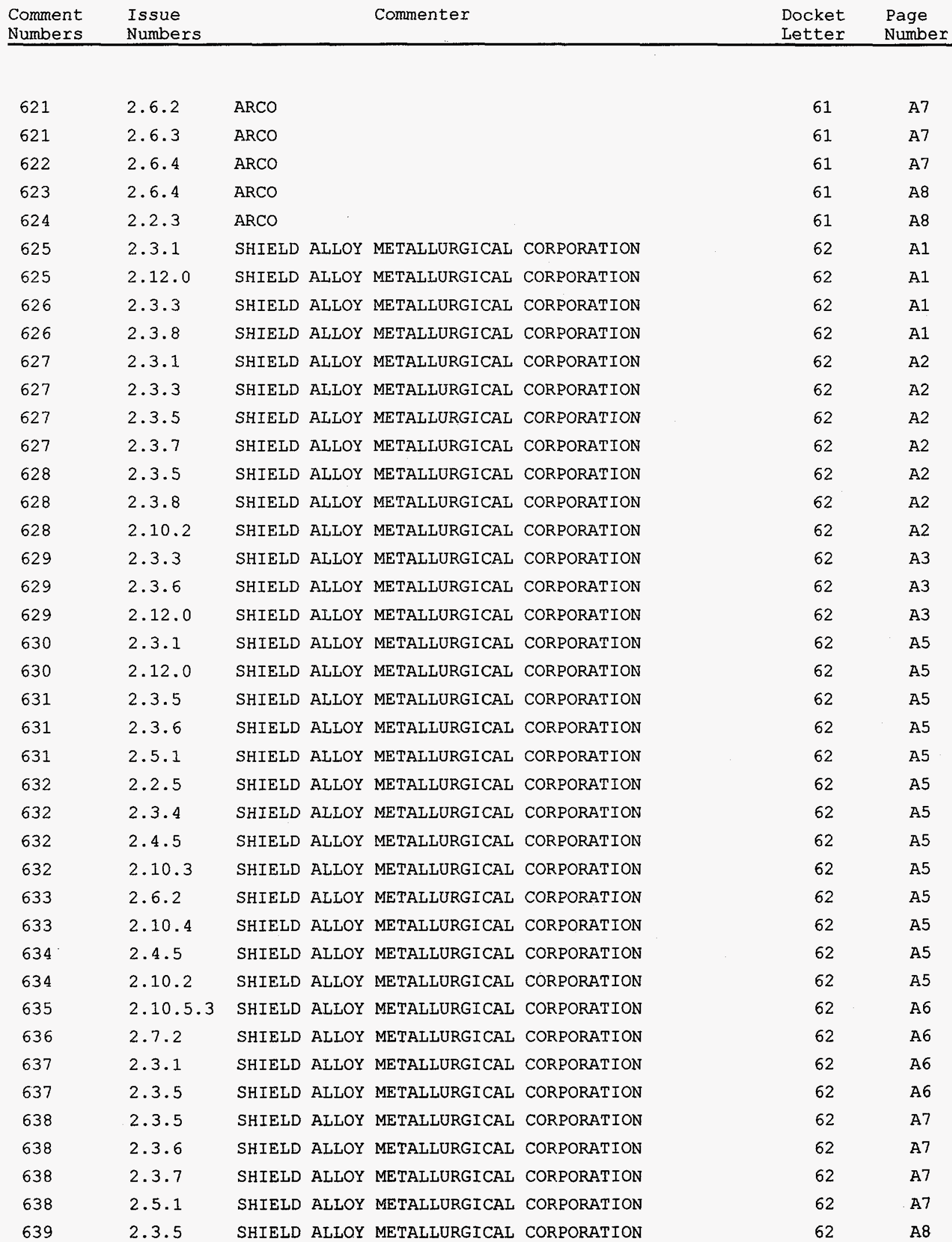




\begin{tabular}{|c|c|c|c|c|c|c|c|}
\hline 639 & 2.3 .6 & SHIELD & ALLOY & METALLURGICAI & CORPORATION & 62 & A8 \\
\hline 640 & 2.3 .6 & SHIELD & ALLOY & METALLURGICAL & CORPORATION & 62 & A 8 \\
\hline 640 & 2.3 .7 & SHIELD & ALLOY & METALLURGICAL & CORPORATION & 62 & A8 \\
\hline 640 & 2.10 .5 .1 & SHIELD & ALLOY & METALLURGICAL & CORPORATION & 62 & A8 \\
\hline 641 & 2.3 .5 & SHIELD & ALLOY & METALLURGICAI & CORPORATION & 62 & A10 \\
\hline 641 & 2.3 .6 & SHIELD & ALLOY & METALLURGICAL & CORPORATION & 62 & $\mathrm{~A} 10$ \\
\hline 641 & 2.5 .1 & SHIELD & ALLOY & METALLURGICAL & CORPORATION & 62 & A10 \\
\hline 642 & 2.6 .4 & SHIELD & ALLOY & METALLURGICAI & CORPORATION & 62 & A12 \\
\hline 643 & 2.3 .3 & SHIELD & ALLOY & METALLURGICAL & CORPORATION & 62 & A12 \\
\hline 643 & 2.10 .3 & SHIELD & ALLOY & METALLURGICAL & CORPORATION & 62 & A12 \\
\hline 644 & 2.2 .5 & SHIELD & ALLOY & METALLURGICAL & CORPORATION & 62 & A13 \\
\hline 644 & 2.6 .4 & SHIELD & ALLOY & METALLURGICAL & CORPORATION & 62 & A13 \\
\hline 645 & 2.2 .5 & SHIEID & ALLOY & METALLURGICAL & CORPORATION & 62 & A14 \\
\hline 645 & 2.10 .1 & SHIELD & ALLOY & METALLURGICAI & CORPORATION & 62 & A14 \\
\hline 645 & 2.10 .5 .3 & SHIELD & ALLOY & METALLURGICAL & CORPORATION & 62 & A14 \\
\hline 645 & 2.10 .5 .4 & SHIELD & ALLOY & METALLURGICAL & CORPORATION & 62 & A14 \\
\hline 646 & 2.1 .8 & SHIELD & ALLOY & METALLURGICAL & CORPORATION & 62 & A15 \\
\hline 646 & 2.2 .5 & SHIELD & ALLOY & METALLURGICAL & CORPORATION & 62 & A15 \\
\hline 646 & 2.10 .1 & SHIELD & ALLOY & METALLURGICAI & CORPORATION & 62 & A15 \\
\hline 647 & 2.2 .5 & SHIELD & ALLOY & METALLURGICAL & CORPORATION & 62 & A16 \\
\hline 647 & 2.6 .1 & SHIELD & ALLOY & METALLURGICAL & CORPORATION & 62 & A16 \\
\hline 647 & 2.10 .3 & SHIELD & ALLOY & METALLURGICAL & CORPORATION & 62 & A16 \\
\hline 648 & 2.3 .4 & SHIELD & ALIOY & METALLURGICAL & CORPORATION & 62 & A17 \\
\hline 648 & 2.3 .9 & SHIELD & ALLOY & METALLURGICAL & CORPORATION & 62 & A17 \\
\hline 649 & 2.3 .4 & SHIELD & ALLOY & METALLURGICAL & CORPORATION & 62 & A17 \\
\hline 649 & 2.10 .4 & SHIELD & ALLOY & METAILURGICAI & CORPORATION & 62 & A17 \\
\hline 650 & 2.3 .9 & SHIELD & ALLOY & METAILURGICAL & CORPORATION & 62 & A19 \\
\hline 651 & 2.3 .9 & SHIELD & ALLOY & METALLURGICAL & CORPORATION & 62 & $\mathrm{~A} 20$ \\
\hline 652 & 2.3 .4 & SHIELD & ALLOY & METALLURGICAL & CORPORATION & 62 & $\mathrm{~A} 20$ \\
\hline 652 & 2.6 .1 & SHIELD & ALLOY & METALLURGICAL & CORPORATION & 62 & $\mathrm{~A} 20$ \\
\hline 652 & 2.10 .4 & SHIELD & ALLOY & METALLURGICAL & CORPORATION & 62 & $\mathrm{~A} 20$ \\
\hline 653 & 2.10 .4 & SHIELD & ALLOY & METALLURGICAL & CORPORATION & 62 & A20 \\
\hline 654 & 2.10 .5 .1 & SHIELD & ALLOY & METAJLURGICAI & CORPORATION & 62 & A21 \\
\hline 655 & 2.4 .5 & SHIELD & ALLOY & METALLURGICAL & CORPORATION & 62 & A.22 \\
\hline 655 & 2.10 .2 & SHIELD & ALLOY & METALLURGICAL & CORPORATION & 62 & $\mathrm{~A} 22$ \\
\hline 656 & 2.3 .5 & SHIELD & ALLOY & METALLURGICAL & CORPORATION & 62 & A22 \\
\hline 656 & 2.10 .2 & SHIELD & ALLOY & METALLURGICAL & CORPORATION & 62 & $\mathrm{~A} 22$ \\
\hline 657 & 2.10 .5 .3 & SHIELD & ALLOY & METALLURGICAL & CORPORATION & 62 & A23 \\
\hline 658 & 2.7 .1 & SHIELD & AILOY & METALLURGICAL & CORPORATION & 62 & A24 \\
\hline 658 & 2.7 .2 & SHIELD & ALLOY & METALLURGICAL & CORPORATION & 62 & A24 \\
\hline 659 & 2.7 .2 & SHIELD & ALLOY & METALIURGICAI & CORPORATION & 62 & A25 \\
\hline
\end{tabular}




\begin{tabular}{|c|c|c|c|c|}
\hline 659 & 2.8 .1 & SHIELD ALLOY METALLURGICAL CORPORATION & 62 & A25 \\
\hline 660 & 2.12 .0 & SHIELD ALLOY METALLURGICAL CORPORATION & 62 & A25 \\
\hline 661 & 2.12 .0 & EUEL CYCLE FACILITIES FORUM & 63 & $A-1$ \\
\hline 662 & 2.3 .5 & FUEL CYCLE FACILITIES FORUM & 63 & $A-2$ \\
\hline 662 & 2.3 .6 & FUEL CYCLE FACILITIES FORUM & 63 & $A-2$ \\
\hline 663 & 2.3 .3 & FUEL CYCLE FACILITIES FORUM & 63 & $A-2$ \\
\hline 663 & 2.3 .8 & FUEL CYCLE FACILITIES FORUM & 63 & $A-2$ \\
\hline 664 & 2.2 .5 & FUEL CYCLE FACILITIES FORUM & 63 & $A-2$ \\
\hline 664 & 2.3 .4 & FUEL CYCLE FACILITIES FORUM & 63 & $A-2$ \\
\hline 664 & 2.4 .5 & FUEL CYCLE FACILITIES FORUM & 63 & $A-2$ \\
\hline 664 & 2.6 .1 & FUEI CYCLE FACILITIES FORUM & 63 & $A-2$ \\
\hline 664 & 2.10 .3 & FUEL CYCLE FACILITIES FORUM & 63 & $A-2$ \\
\hline 664 & 2.10 .5 .1 & FUEL CYCLE FACILITIES FORUM & 63 & $A-2$ \\
\hline 665 & 2.2 .2 & FUEL CYCLE FACILITIES FORUM & 63 & $A-3$ \\
\hline 665 & 2.2 .3 & FUEL CYCLE FACILITIES FORUM & 63 & $A-3$ \\
\hline 666 & 2.3 .6 & FUEL CYCLE FACILITIES FORUM & 63 & $A-4$ \\
\hline 667 & 2.3 .3 & FUEL CYCLE FACILITIES FORUM & 63 & $A-4$ \\
\hline 667 & 2.3 .5 & FUEL CYCLE FACILITIES FORUM & 63 & $A-4$ \\
\hline 667 & 2.3 .6 & FUEL CYCLE FACILITIES FORUM & 63 & $A-4$ \\
\hline 668 & 2.3 .5 & FUEL CYCLE FACILITIES FORUM & 63 & $A-4$ \\
\hline 668 & 2.5 .1 & FUEL CYCLE FACILITIES FORUM & 63 & $A-4$ \\
\hline 669 & 2.3 .3 & FUEL CYCLE FACILITIES FORUM & 63 & $A-5$ \\
\hline 669 & 2.3 .5 & FUEL CYCLE FACILITIES FORUM & 63 & A-5 \\
\hline 669 & 2.3 .8 & FUEL CYCLE FACILITIES FORUM & 63 & $A-5$ \\
\hline 669 & 2.5 .1 & FUEL CYCLE FACILITIES FORUM & 63 & $A-5$ \\
\hline 669 & 2.11 .0 & FUEL CYCLE FACILITIES FORUM & 63 & $A-5$ \\
\hline 670 & 2.3 .5 & FUEL CYCLE FACILITIES FORUM & 63 & $A-5$ \\
\hline 670 & 2.5 .1 & FUEL CYCLE FACIIITIES FORUM. & 63 & $A-5$ \\
\hline 670 & 2.10 .4 & FUEL CYCLE FACILITIES FORUM & 63 & $A-5$ \\
\hline 671 & 2.3 .5 & FUEL CYCLE FACILITIES FORUM & 63 & $A-6$ \\
\hline 671 & 2.5 .1 & FUEL CYCLE FACILITIES FORUM & 63 & $A-6$ \\
\hline 671 & 2.5 .2 & FUEL CYCLE FACILITIES FORUM & 63 & $A-6$ \\
\hline 672 & 2.3 .5 & FUEL CYCLE FACILITIES FORUM & 63 & $A-10$ \\
\hline 672 & 2.3 .6 & FUEL CYCLE FACILITIES FORUM & 63 & A-10 \\
\hline 672 & 2.5 .1 & FUEL CYCLE FACILITIES FORUM & 63 & $A-10$ \\
\hline 673 & 2.3 .5 & FUEL CYCLE FACILITIES FORUM & 63 & $A-11$ \\
\hline 673 & 2.5 .1 & FUEL CYCLE FACILITIES FORUM & 63 & $A-11$ \\
\hline 673 & 2.10 .1 & FUEL CYCLE FACILITIES FORUM & 63 & A-11 \\
\hline 673 & 2.10 .2 & FUEL CYCLE FACILITIES FORUM & 63 & $A-11$ \\
\hline 673 & 2.10 .4 & FUEL CYCLE FACILITIES FORUM & 63 & $A-11$ \\
\hline
\end{tabular}




\begin{tabular}{|c|c|c|c|c|c|c|}
\hline 674 & 2.3 .5 & FUEL CYCLE & FACILITIES & FORUM & 63 & $A-11$ \\
\hline 674 & 2.5 .1 & FUEL CYCLE & FACILITIES & EORUM & 63 & $A-11$ \\
\hline 675 & 2.3 .5 & FUEL CYCLE & FACILITIES & FORUM & 63 & $A-13$ \\
\hline 675 & 2.3 .9 & FUEL CYCLE & FACILITIES & FORUM & 63 & $A-13$ \\
\hline 675 & 2.5 .1 & FUEL CYCLE & FACILITIES & FORUM & 63 & $A-13$ \\
\hline 675 & 2.10 .5 .1 & FUEL CYCLE & FACILITIES & FORUM & 63 & $A-13$ \\
\hline 676 & 2.3 .9 & FUEL CYCLE & FACILITIES & FORUM & 63 & $A-14$ \\
\hline 677 & 2.3 .5 & FUEL CYCLE & FACILITIES & FORUM & 63 & $A-14$ \\
\hline 677 & 2.3 .6 & FUEL CYCLE & FACILITIES & FORUM & 63 & $A-14$ \\
\hline 677 & 2.3 .9 & FUEL CYCLE & FACILITIES & FORUM & 63 & $A-14$ \\
\hline 677 & 2.5 .1 & FUEL CYCLE & FACILITIES & FORUM & 63 & $A-14$ \\
\hline 677 & 2.10 .5 .1 & FUEL CYCLE & FACILITIES & FORUM & 63 & $A-14$ \\
\hline 678 & 2.4 .4 & FUEL CYCLE & FACILITIES & FORUM & 63 & A-17 \\
\hline 679 & 2.4 .4 & FUEL CYCLE & FACILITIES & FORUM & 63 & $A-17$ \\
\hline 679 & 2.10 .5 .1 & FUEL CYCLE & FACILITIES & FORUM & 63 & $A-17$ \\
\hline 680 & 2.3 .4 & FUEL CYCLE & FACILITIES & FORUM & 63 & A-19 \\
\hline 680 & 2.4 .5 & FUEL CYCLE & FACILITIES & FORUM & 63 & A-19 \\
\hline 680 & 2.6 .1 & FUEL, CYCLE & FACILITIES & FORUM & 63 & $A-19$ \\
\hline 681 & 2.6 .1 & FUEL CYCLE & FACILITIES & FORUM & 63 & $A-19$ \\
\hline 682 & 2.6 .4 & FUEL CYCLE & FACILITIES & FORUM & 63 & A-19 \\
\hline 682 & 2.10 .5 .3 & FUEL CYCLE & FACIUITIES & FORUM & 63 & $A-19$ \\
\hline 683 & 2.6 .2 & FUEL CYCLE & FACILITIES & FORUM & 63 & $A-20$ \\
\hline 684 & 2.6 .4 & FUEL CYCLE & FACILITIES & FORUM & 63 & $A-20$ \\
\hline 684 & 2.10 .1 & FUEL CYCLE & FACILITIES & FORUM & 63 & $A-20$ \\
\hline 685 & 2.2 .5 & FUEL CYCLE & FACILITIES & FORUM & 63 & $A-21$ \\
\hline 685 & 2.6 .1 & FUEE CYCLE & FACILITIES & FORUM & 63 & $A-21$ \\
\hline 685 & 2.6 .5 & FUEL CYCLE & FACILITIES & FORUM & 63 & $A-21$ \\
\hline 686 & 2.10 .5 .1 & FUEL CYCLE & FACILITIES & FORUM & 63 & $A-21$ \\
\hline 687 & 2.2 .5 & FUEL CYCLE & FACILITIES & FORUM & 63 & $A-22$ \\
\hline 687 & 2.6 .5 & FUEL CYCLE & FACILITIES & FORUM & 63 & $A-22$ \\
\hline 687 & 2.10 .4 & FUEL CYCLE & FACILITIES & FORUM & 63 & $A-22$ \\
\hline 688 & 2.2 .5 & FUEL CYCLE & FACILITIES & FORUM & 63 & $A-23$ \\
\hline 688 & 2.10 .4 & FUEL CYCLE & FACILITIES & FORUM & 63 & $A-23$ \\
\hline 689 & 2.2 .2 & FUEL CYCLE & FACILITIES & FORUM & 63 & $A-24$ \\
\hline 689 & 2.2 .3 & FUEL CYCLE & FACILITIES & FORUM & 63 & $A-24$ \\
\hline 690 & 2.2 .2 & FUEL CYCLE & FACILITIES & FORUM & 63 & $A-24$ \\
\hline 691 & 2.2 .5 & FUEL CYCLE & FACILITIES & FORUM & 63 & $A-25$ \\
\hline 692 & 2.2 .3 & FUEL CYCLE & FACILITIES & FORUM & 63 & $A-25$ \\
\hline 693 & 2.2 .3 & FUEL CYCLE & FACILITIES & FORUM & 63 & $A-25$ \\
\hline 694 & 2.2 .3 & FUEL CYCLE & FACILITIES & FORUM & 63 & $A-26$ \\
\hline 695 & 2.1 .3 & FUEL CYCLE & FACILITIES & FORUM & 63 & $A-26$ \\
\hline
\end{tabular}




\begin{tabular}{|c|c|c|c|c|}
\hline $\begin{array}{l}\text { Comment } \\
\text { Numbers }\end{array}$ & $\begin{array}{l}\text { Issue } \\
\text { Numbers }\end{array}$ & Commenter & $\begin{array}{l}\text { Docket } \\
\text { Letter }\end{array}$ & $\begin{array}{l}\text { Page } \\
\text { Number }\end{array}$ \\
\hline 696 & 2.8 .6 & FUEL CYCLE FACILITIES FORUM & 63 & $A-27$ \\
\hline 696 & 2.10 .5 .3 & FUEL CYCLE FACILITIES FORUM & 63 & $A-27$ \\
\hline 697 & 2.10 .5 .3 & FUEL CYCLE FACILITIES FORUM & 63 & $A-27$ \\
\hline 698 & 2.4 .5 & FUEL CYCLE FACILITIES FORUM & 63 & $A-28$ \\
\hline 698 & $2 \cdot 10.5 .3$ & FUEL CYCLE FACILITIES FORUM & 63 & $A-28$ \\
\hline 699 & 2.7 .2 & FUEL CYCLE FACILITIES FORUM & 63 & $A-29$ \\
\hline 700 & 2.7 .2 & FUEL CYCLE FACILITIES FORUM & 63 & $A-29$ \\
\hline 701 & 2.8 .1 & FUEL CYCLE FACILITIES FORUM & 63 & $A-29$ \\
\hline 702 & 2.8 .1 & FUEL CYCLE FACILITIES FORUM & 63 & $A-30$ \\
\hline 702 & 2.8 .2 & FUEL CYCLE FACILITIES FORUM & 63 & $A-30$ \\
\hline 703 & 2.8 .2 & FUEL CYCLE FACILITIES FORUM & 63 & $A-30$ \\
\hline 704 & 2.7 .2 & FUEL CYCLE FACILITIES FORUM & 63 & $A-30$ \\
\hline 704 & 2.10 .3 & FUEL CYCLE FACILITIES FORUM & 63 & $A-30$ \\
\hline 704 & 2.10 .5 .3 & FUEL CYCLE FACILITIES FORUM & 63 & $A-30$ \\
\hline 705 & 2.8 .3 & FUEL CYCLE FACILITIES FORUM & 63 & $A-30$ \\
\hline 706 & 2.3 .4 & FUEL CYCLE FACILITIES FORUM & 63 & $A-31$ \\
\hline 706 & 2.6 .3 & FUEL CYCLE FACILITIES FORUM & 63 & $A-31$ \\
\hline 706 & 2.10 .5 .1 & FUEL CYCLE FACILITIES FORUM & 63 & $A-31$ \\
\hline 707 & 2.3 .9 & FUEL CYCLE FACILITIES FORUM & 63 & $A-32$ \\
\hline 707 & 2.10 .2 & FUEL CYCLE FACILITIES FORUM & 63 & $A-32$ \\
\hline 708 & 2.3 .5 & FUEL CYCLE FACILITIES FORUM & 63 & $A-32$ \\
\hline 708 & 2.3 .9 & FUEL CYCLE FACILITIES FORUM & 63 & $A-32$ \\
\hline 708 & 2.10 .5 .1 & FUEL CYCLE FACILITIES FORUM & 63 & $A-32$ \\
\hline 709 & 2.10 .5 .2 & FUEL CYCLE FACILITIES FORUM & 63 & $A-35$ \\
\hline 710 & 2.2 .2 & FUEL CYCLE FACILITIES FORUM & 63 & $A-36$ \\
\hline 710 & 2.2 .3 & FUEL CYCLE FACILITIES FORUM & 63 & $A-36$ \\
\hline 710 & 2.2 .5 & FUEL CYCLE FACILITIES FORUM & 63 & $A-36$ \\
\hline 710 & 2.10 .1 & FUEL CYCLE FACILITIES FORUM & 63 & $A-36$ \\
\hline 710 & 2.10 .5 .3 & FUEL CYCLE FACILITIES FORUM & 63 & A -36 \\
\hline 711 & 2.12 .0 & AMERICAN MINING CONGRESS & 64 & A2 \\
\hline 712 & 2.2 .1 & AMERICAN MINING CONGRESS & 64 & A3 \\
\hline 713 & 2.3 .2 & AMERICAN MINING CONGRESS & 64 & A3 \\
\hline 713 & 2.3 .5 & AMERICAN MINING CONGRESS & 64 & A3 \\
\hline 713 & 2.5 .1 & AMERICAN MINING CONGRESS & 64 & A3 \\
\hline 714 & 2.3 .7 & AMERICAN MINING CONGRESS & 64 & A3 \\
\hline 715 & 2.3 .1 & AMERICAN MINING CONGRESS & 64 & A3 \\
\hline 716 & 2.12 .0 & AMERICAN MINING CONGRESS & 64 & A3 \\
\hline 717 & 2.3 .5 & AMERICAN MINING CONGRESS & 64 & A3 \\
\hline 717 & 2.3 .8 & AMERICAN MINING CONGRESS & 64 & A3 \\
\hline 718 & 2.2 .1 & AMERICAN MINING CONGRESS & 64 & A4 \\
\hline 718 & 2.10 .5 .3 & AMERICAN MINING CONGRESS & 64 & A4 \\
\hline
\end{tabular}




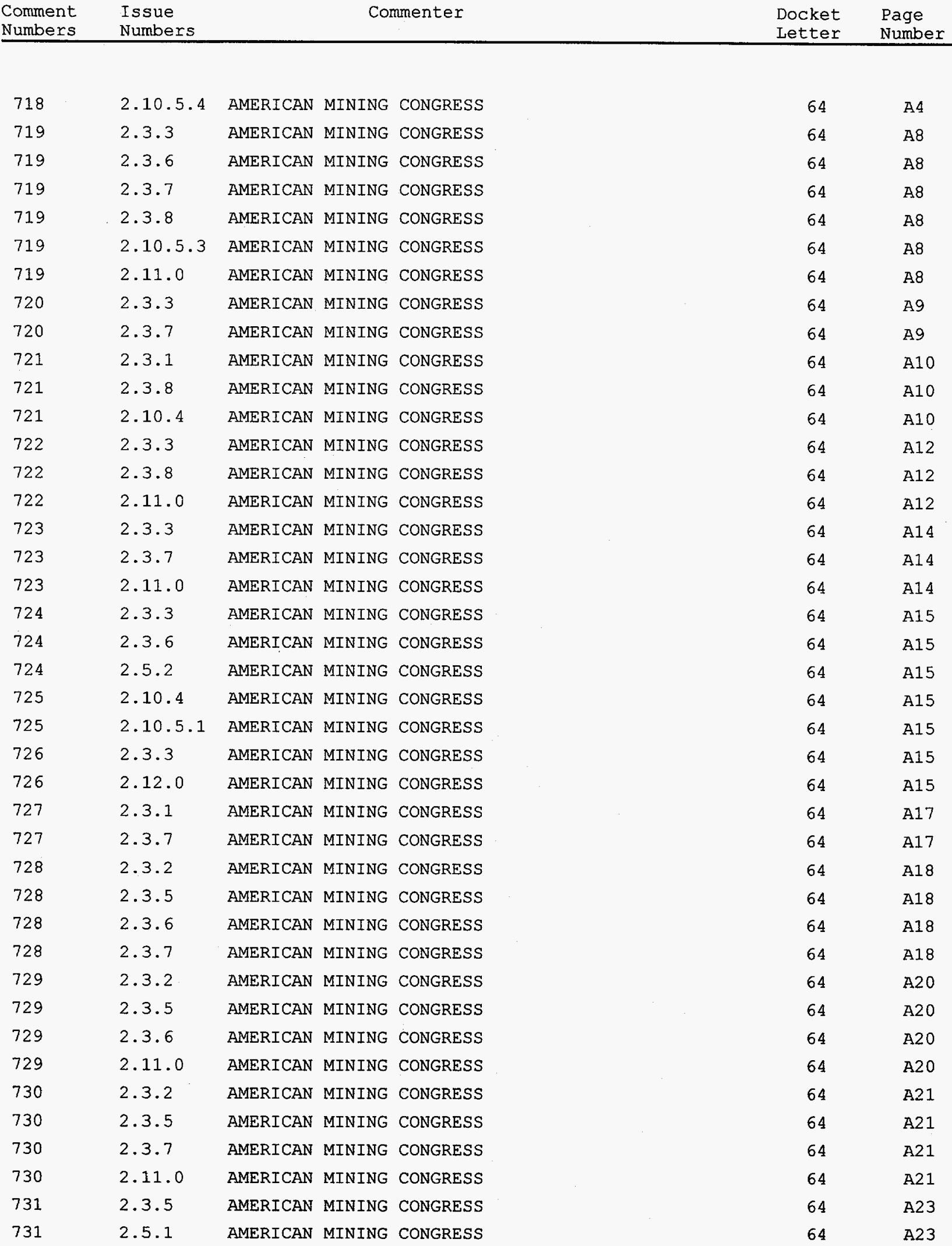




\begin{tabular}{|c|c|c|c|c|c|c|}
\hline 732 & 2.3 .5 & AMERICAN & MINING & CONGRESS & 64 & $\mathrm{~A} 24$ \\
\hline 732 & 2.3 .7 & AMERICAN & MINING & CONGRESS & 64 & A2 4 \\
\hline 732 & 2.5 .1 & AMERICAN & MINING & CONGRESS & 64 & A2 4 \\
\hline 733 & 2.3 .5 & AMERICAN & MINING & CONGRESS & 64 & A2 6 \\
\hline 733 & 2.3 .8 & AMERICAN & MINING & CONGRESS & 64 & A2 6 \\
\hline 733 & 2.10 .2 & AMERICAN & MINING & CONGRESS & 64 & A26 \\
\hline 734 & 2.10 .1 & AMERICAN & MINING & CONGRESS & 64 & A26 \\
\hline 734 & 2.10 .2 & AMERICAN & MINING & CONGRESS & 64 & A26 \\
\hline 735 & 2.3 .1 & AMERICAN & MINING & CONGRESS & 64 & A27 \\
\hline 736 & 2.3 .3 & AMERICAN & MINING & CONGRESS & 64 & A27 \\
\hline 737 & 2.2 .5 & AMERICAN & MINING & CONGRESS & 64 & A 29 \\
\hline 737 & 2.3 .4 & AMERICAN & MINING & CONGRESS & 64 & A29 \\
\hline 737 & 2.6 .1 & AMERICAN & MINING & CONGRESS & 64 & A29 \\
\hline 738 & 2.3 .4 & AMERICAN & MINING & CONGRESS & 64 & A32 \\
\hline 738 & 2.6 .4 & AMERICAN & MINING & CONGRESS & 64 & A32 \\
\hline 739 & 2.6 .2 & AMERICAN & MINING & CONGRESS & 64 & A35 \\
\hline 740 & 2.6 .2 & AMERICAN & MINING & CONGRESS & 64 & A39 \\
\hline 741 & 2.10 .4 & AMERICAN & MINING & CONGRESS & 64 & A4 3 \\
\hline 742 & 2.3 .1 & AMERICAN & MINING & CONGRESS & 64 & A4 4 \\
\hline 743 & 2.3 .1 & AMERICAN & MINING & CONGRESS & 64 & A 46 \\
\hline 743 & 2.3 .9 & AMERICAN & MINING & CONGRESS & 64 & A4 6 \\
\hline 743 & 2.10 .2 & AMERICAN & MINING & CONGRESS & 64 & A 46 \\
\hline 74.4 & 2.3 .1 & AMERICAN & MINING & CONGRESS & 64 & A47 \\
\hline 744 & 2.3 .4 & AMERICAN & MINING & CONGRESS & 64 & A4 7 \\
\hline 744 & 2.3 .9 & AMERICAN & MINING & CONGRESS & 64 & A47 \\
\hline 744 & 2.6 .4 & AMERICAN & MINING & CONGRESS & 64 & A 47 \\
\hline 744 & 2.10 .4 & AMERICAN & MINING & CONGRESS & 64 & A47 \\
\hline 745 & 2.3 .1 & AMERICAN & MINING & CONGRESS & 64 & A48 \\
\hline 745 & 2.3 .5 & AMERICAN & MINING & CONGRESS & 64 & A48 \\
\hline 745 & 2.5 .1 & AMERICAN & MINING & CONGRESS & 64 & A 48 \\
\hline 745 & 2.8 .6 & AMERICAN & MINING & CONGRESS & 64 & A 48 \\
\hline 746 & 2.3 .1 & AMERICAN & MINING & CONGRESS & 64 & A 49 \\
\hline 746 & 2.10 .1 & AMERICAN & MINING & CONGRESS & 64 & A49 \\
\hline 746 & 2.11 .0 & AMERICAN & MINING & CONGRESS & 64 & A49 \\
\hline 747 & 2.3 .5 & AMERICAN & MINING & CONGRESS & 64 & A50 \\
\hline 747 & 2.3 .8 & AMERICAN & MINING & CONGRESS & 64 & A50 \\
\hline 747 & 2.11 .0 & AMERICAN & MINING & CONGRESS & 64 & A 50 \\
\hline 748 & 2.8 .1 & AMERICAN & MINING & CONGRESS & 64 & A 51 \\
\hline 748 & 2.8 .6 & AMERICAN & MINING & CONGRESS & 64 & A51 \\
\hline 749 & 2.7 .2 & AMERICAN & MINING & CONGRESS & 64 & A52 \\
\hline 750 & 2.8 .2 & AMERICAN & MINING & CONGRESS & 64 & A 52 \\
\hline
\end{tabular}




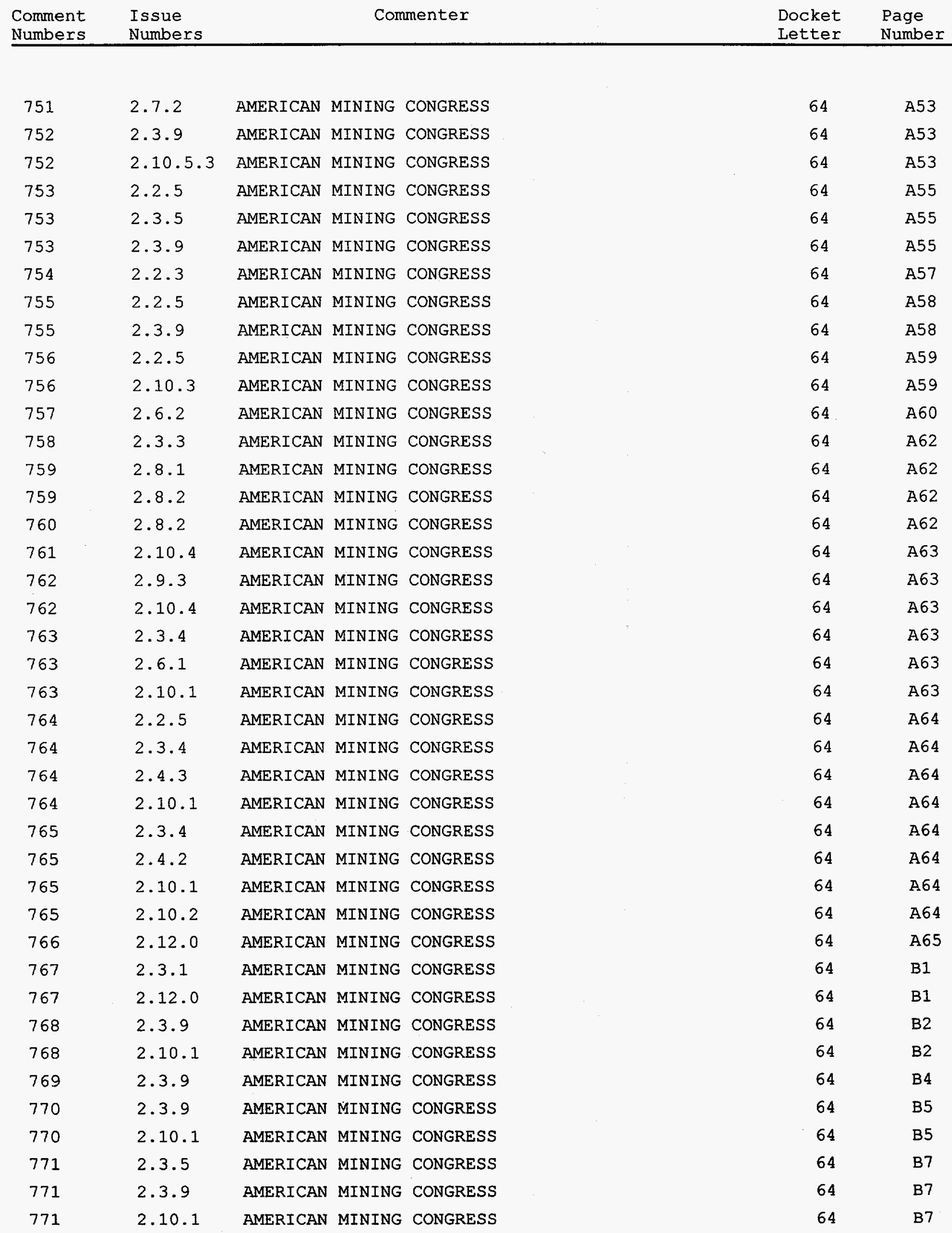




\begin{tabular}{|c|c|c|}
\hline 772 & 2.10 .1 & AMERICAN MINING CONGRESS \\
\hline 773 & 2.10 .1 & AMERICAN MINING CONGRESS \\
\hline 774 & 2.3 .3 & AMERICAN MINING CONGRES \\
\hline 774 & 2.11 .0 & AMERICAN MINING CONGRE \\
\hline 775 & 2.3 .9 & AMERICAN MINING CONGRE \\
\hline 775 & 2.10 .1 & AMERICAN MINING CONGRE \\
\hline 776 & 2.3 .9 & AMERICAN MINING CONGRI \\
\hline 777 & 2.3 .2 & AMERICAN MINING CONGRE \\
\hline 778 & 2.3 .9 & AMERICAN MINING CONGRE \\
\hline 778 & 2.10 .1 & AMERICAN MINING CONGR \\
\hline 779 & 2.2 .1 & KERR-MCGEE CORPORATION \\
\hline 779 & 2.3 .3 & KERR-MCGEE CORPORATION \\
\hline 779 & 2.3 .8 & KERR-MCGEE CORPORATION \\
\hline 779 & 2.12 .0 & KERR-MCGEE CORPORATION \\
\hline 780 & 2.3 .6 & KERR-MCGEE CORPORATION \\
\hline 780 & 2.3 .7 & KERR-MCGEE CORPORATION \\
\hline 780 & 2.10 .2 & KERR-MCGEE CORPORATION \\
\hline 781 & 2.3 .7 & KERR-MCGEE CORPORATION \\
\hline 781 & 2.10 .5 .1 & KERR-MCGEE CORPORATION \\
\hline 782 & 2.3 .7 & KERR-MCGEE CORPORATION \\
\hline 782 & 2.10 .2 & KERR-MCGEE CORPORATION \\
\hline 782 & 2.10 .5 .1 & KERR-MCGEE CORPORATION \\
\hline 783 & 2.3 .7 & KERR-MCGEE CORPORATION \\
\hline 783 & 2.10 .5 .1 & KERR-MCGEE CORPORATION \\
\hline 784 & 2.3 .1 & KERR-MCGEE CORPORATION \\
\hline 784 & 2.10 .2 & KERR-MCGEE CORPORATION \\
\hline 784 & 2.10 .5 .1 & KERR-MCGEE CORPORATION \\
\hline 785 & 2.3 .1 & KERR-MCGEE CORPORATION \\
\hline 785 & 2.3 .2 & KERR-MCGEE CORPORATION \\
\hline 785 & 2.3 .3 & KERR-MCGEE CORPORATION \\
\hline 785 & 2.3 .7 & KERR-MCGEE CORPORATION \\
\hline 786 & 2.3 .4 & KERR-MCGEE CORPORATION \\
\hline 786 & 2.6 .1 & KERR-MCGEE CORPORATION \\
\hline 787 & 2.4 .4 & KERR-MCGEE CORPORATION \\
\hline 788 & 2.3 .2 & KERR-MCGEE CORPORATION \\
\hline 788 & 2.3 .7 & KERR-MCGEE CORPORATION \\
\hline 788 & 2.10 .5 .3 & KERR-MCGEE CORPORATION \\
\hline 789 & 2.3 .5 & KERR-MCGEE CORPORATION \\
\hline 789 & 2.10 .2 & KERR-MCGEE CORPORATION \\
\hline 790 & 2.10 .2 & KERR-MCGEE CORPORATION \\
\hline 791 & 2.2 .1 & KERR-MCGEE CORPORATION \\
\hline
\end{tabular}

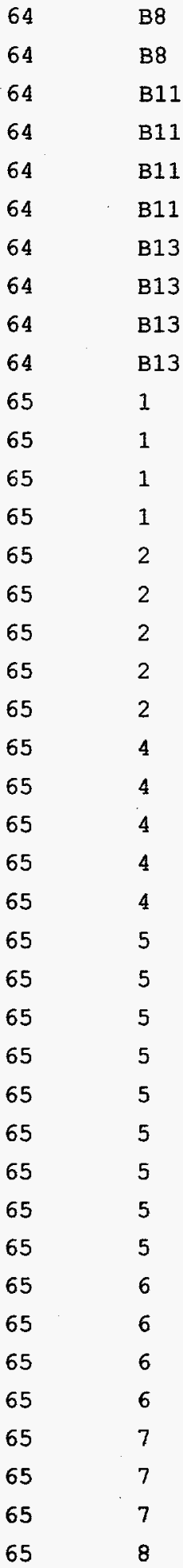




\begin{tabular}{|c|c|c|c|c|}
\hline $\begin{array}{l}\text { Comment } \\
\text { Numbers }\end{array}$ & $\begin{array}{l}\text { Issue } \\
\text { Numbers }\end{array}$ & Commenter & $\begin{array}{l}\text { Docket } \\
\text { Letter }\end{array}$ & $\begin{array}{l}\text { Page } \\
\text { Number }\end{array}$ \\
\hline 791 & 2.2 .5 & KERR-MCGEE CORPORATION & 65 & 8 \\
\hline 791 & 2.3 .5 & KERR-MCGEE CORPORATION & 65 & 8 \\
\hline 792 & 2.2 .1 & KERR-MCGEE CORPORATION & 65 & 9 \\
\hline 792 & 2.2 .5 & KERR-MCGEE CORPORATION & 65 & 9 \\
\hline 793 & 2.2 .1 & KERR-MCGEE CORPORATION & 65 & 9 \\
\hline 793 & 2.2 .5 & KERR-MCGEE CORPORATION & 65 & 9 \\
\hline 793 & 2.3 .2 & KERR-MCGEE CORPORATION & 65 & 9 \\
\hline 794 & 2.2 .1 & KERR-MCGEE CORPORATION & 65 & 10 \\
\hline 794 & $2.10 \cdot 5 \cdot 3$ & KERR-MCGEE CORPORATION & 65 & 10 \\
\hline 795 & 2.2 .2 & KERR-MCGEE CORPORATION & 65 & 10 \\
\hline 795 & 2.2 .5 & KERR-MCGEE CORPORATION & 65 & 10 \\
\hline 796 & 2.2 .3 & KERR-MCGEE CORPORATION & 65 & 11 \\
\hline 797 & 2.2 .5 & KERR-MCGEE CORPORATION & 65 & 12 \\
\hline 797 & 2.3 .9 & KERR-MCGEE CORPORATION & 65 & 12 \\
\hline 798 & 2.3 .4 & KERR-MCGEE CORPORATION & 65 & 13 \\
\hline 798 & 2.4 .4 & KERR-MCGEE CORPORATION & 65 & 13 \\
\hline 799 & 2.7 .1 & KERR-MCGEE CORPORATION & 65 & 13 \\
\hline 799 & 2.7 .2 & KERR-MCGEE CORPORATION & 65 & 13 \\
\hline 800 & 2.3 .7 & KERR-MCGEE CORPORATION & 65 & 14 \\
\hline 800 & 2.12 .0 & KERR-MCGEE CORPORATION & 65 & 14 \\
\hline 801 & 2.3 .1 & KERR-MCGEE CORPORATION & 65 & 14 \\
\hline 801 & 2.3 .2 & KERR-MCGEE CORPORATION & 65 & 14 \\
\hline 801 & 2.3 .7 & KERR-MCGEE CORPORATION & 65 & 14 \\
\hline 801 & 2.10 .1 & KERR-MCGEE CORPORATION & 65 & 14 \\
\hline 802 & 2.3 .6 & KERR-MCGEE CORPORATION & 65 & 16 \\
\hline 802 & 2.3 .7 & KERR-MCGEE CORPORATION & 65 & 16 \\
\hline 802 & 2.11 .0 & KERR-MCGEE CORPORATION & 65 & 16 \\
\hline 803 & 2.3 .1 & KERR-MCGEE CORPORATION & 65 & 16 \\
\hline 803 & 2.3 .7 & KERR-MCGEE CORPORATION & 65 & 16 \\
\hline 803 & 2.11 .0 & KERR-MCGEE CORPORATION & 65 & 16 \\
\hline 804 & 2.3 .5 & KERR-MCGEE CORPORATION & 65 & 17 \\
\hline 804 & 2.10 .2 & KERR-MCGEE CORPORATION & 65 & 17 \\
\hline 805 & 2.3 .3 & KERR-MCGEE CORPORATION & 65 & 18 \\
\hline 805 & 2.3 .7 & KERR-MCGEE CORPORATION & 65 & 18 \\
\hline 805 & 2.10 .1 & KERR-MCGEE CORPORATION & 65 & 18 \\
\hline 806 & 2.3 .2 & KERR-MCGEE CORPORATION & 65 & 19 \\
\hline 806 & 2.3 .5 & KERR-MCGEE CORPORATION & 65 & 19 \\
\hline 806 & 2.3 .6 & KERR-MCGEE CORPORATION & 65 & 19 \\
\hline 806 & 2.10 .5 .1 & KERR-MCGEE CORPORATION & 65 & 19 \\
\hline 806 & $2 \cdot 10 \cdot 5 \cdot 3$ & KERR-MCGEE CORPORATION & 65 & 19 \\
\hline 807 & 2.3 .5 & KERR-MCGEE CORPORATION & 65 & 20 \\
\hline
\end{tabular}




\begin{tabular}{|c|c|c|c|c|}
\hline $\begin{array}{l}\text { Comment } \\
\text { Numbers } \\
\end{array}$ & $\begin{array}{l}\text { Issue } \\
\text { Numbers } \\
\end{array}$ & Commenter & $\begin{array}{l}\text { Docket } \\
\text { Letter }\end{array}$ & $\begin{array}{l}\text { Page } \\
\text { Number }\end{array}$ \\
\hline 807 & 2.3 .7 & KERR-MCGEE CORPORATION & 65 & 20 \\
\hline 807 & 2.5 .1 & KERR-MCGEE CORPORATION & 65 & 20 \\
\hline 808 & 2.3 .5 & KERR-MCGEE CORPORATION & 65 & 21 \\
\hline 808 & 2.3 .7 & KERR-MCGEE CORPORATION & 65 & 21 \\
\hline 809 & 2.3 .2 & KERR-MCGEE CORPORATION & 65 & 22 \\
\hline 809 & 2.3 .3 & KERR-MCGEE CORPORATION & 65 & 22 \\
\hline 809 & 2.5 .2 & KERR-MCGEE CORPORATION & 65 & 22 \\
\hline 810 & 2.3 .2 & KERR-MCGEE CORPORATION & 65 & 24 \\
\hline 810 & 2.3 .3 & KERR-MCGEE CORPORATION & 65 & 24 \\
\hline 810 & 2.5 .2 & KERR-MCGEE CORPORATION & 65 & 24 \\
\hline 810 & 2.10 .1 & KERR-MCGEE CORPORATION & 65 & 24 \\
\hline 810 & 2.10 .5 .1 & KERR-MCGEE CORPORATION & 65 & 24 \\
\hline 811 & 2.3 .5 & KERR-MCGEE CORPORATION & 65 & 25 \\
\hline 811 & 2.3 .7 & KERR-MCGEE CORPORATION & 65 & 25 \\
\hline 811 & 2.10 .5 .1 & KERR-MCGEE CORPORATION & 65 & 25 \\
\hline 812 & 2.3 .5 & KERR-MCGEE CORPORATION & 65 & 26 \\
\hline 812 & 2.3 .7 & KERR-MCGEE CORPORATION & 65 & 26 \\
\hline 812 & 2.10 .2 & KERR-MCGEE CORPORATION & 65 & 26 \\
\hline 812 & 2.10 .5 .1 & KERR-MCGEE CORPORATION & 65 & 26 \\
\hline 813 & 2.3 .5 & KERR-MCGEE CORPORATION & 65 & 26 \\
\hline 813 & 2.3 .7 & KERR-MCGEE CORPORATION & 65 & 26 \\
\hline 814 & $2 \cdot 3 \cdot 3$ & KERR-MCGEE CORPORATION & 65 & 27 \\
\hline 814 & 2.3 .5 & KERR-MCGEE CORPORATION & 65 & 27 \\
\hline 814 & 2.3 .7 & KERR-MCGEE CORPORATION & 65 & 27 \\
\hline 814 & 2.10 .5 .3 & KERR-MCGEE CORPORATION & 65 & 27 \\
\hline 815 & 2.3 .2 & KERR-MCGEE CORPORATION & 65 & 27 \\
\hline 815 & 2.3 .7 & KERR-MCGEE CORPORATION & 65 & 27 \\
\hline 815 & 2.10 .5 .1 & KERR-MCGEE CORPORATION & 65 & 27 \\
\hline 816 & 2.3 .8 & KERR-MCGEE CORPORATION & 65 & 29 \\
\hline 817 & 2.3 .3 & KERR-MCGEE CORPORATION & 65 & 30 \\
\hline 817 & 2.3 .5 & KERR-MCGEE CORPORATION & 65 & 30 \\
\hline 817 & 2.3 .8 & KERR-MCGEE CORPORATION & 65 & 30 \\
\hline 818 & 2.10 .4 & KERR-MCGEE CORPORATION & 65 & 30 \\
\hline 819 & 2.10 .1 & KERR-MCGEE CORPORATION & 65 & 31 \\
\hline 819 & 2.10 .4 & KERR-MCGEE CORPORATION & 65 & 31 \\
\hline 819 & 2.11 .0 & KERR-MCGEE CORPORATION & 65 & 31 \\
\hline 820 & 2.3 .8 & KERR-MCGEE CORPORATION & 65 & 32 \\
\hline 821 & 2.3 .1 & KERR-MCGEE CORPORATION & 65 & 32 \\
\hline 822 & 2.2 .1 & KERR-MCGEE CORPORATION & 65 & 33 \\
\hline 822 & 2.2 .5 & KERR-MCGEE CORPORATION & 65 & 33 \\
\hline 823 & 2.2 .5 & KERR-MCGEE CORPORATION & 65 & 35 \\
\hline
\end{tabular}




\begin{tabular}{|c|c|c|c|c|}
\hline $\begin{array}{l}\text { Comment } \\
\text { Numbers } \\
\end{array}$ & $\begin{array}{l}\text { Issue } \\
\text { Numbers } \\
\end{array}$ & Commenter & $\begin{array}{l}\text { Docket } \\
\text { Letter }\end{array}$ & $\begin{array}{l}\text { Page } \\
\text { Number }\end{array}$ \\
\hline 823 & 2.10 .1 & KERR-MCGEE CORPORATION & 65 & 35 \\
\hline 824 & 2.2 .5 & KERR-MCGEE CORPORATION & 65 & 36 \\
\hline 824 & 2.10 .5 .2 & KERR-MCGEE CORPORATION & 65 & 36 \\
\hline 825 & 2.10 .1 & KERR-MCGEE CORPORATION & 65 & 37 \\
\hline 825 & 2.10 .2 & KERR-MCGEE CORPORATION & 65 & 37 \\
\hline 826 & 2.10 .1 & KERR-MCGEE CORPORATION & 65 & 38 \\
\hline 826 & 2.10 .2 & KERR-MCGEE CORPORATION & 65 & 38 \\
\hline 826 & 2.10 .5 .1 & KERR-MCGEE CORPORATION & 65 & 38 \\
\hline 827 & 2.10 .5 .2 & KERR-MCGEE CORPORATION & 65 & 39 \\
\hline 828 & 2.1 .5 & KERR-MCGEE CORPORATION & 65 & 43 \\
\hline 829 & 2.1 .6 & KERR-MCGEE CORPORATION & 65 & 43 \\
\hline 830 & 2.1 .6 & KERR-MCGEE CORPORATION & 65 & 45 \\
\hline 830 & 2.2 .5 & KERR-MCGEE CORPORATION & 65 & 45 \\
\hline 830 & 2.3 .3 & KERR-MCGEE CORPORATION & 65 & 45 \\
\hline 831 & 2.2 .1 & KERR-MCGEE CORPORATION & 65 & 45 \\
\hline 831 & 2.10 .5 .3 & KERR-MCGEE CORPORATION & 65 & 45 \\
\hline 832 & 2.2 .2 & KERR-MCGEE CORPORATION & 65 & 47 \\
\hline 832 & 2.2 .5 & KERR-MCGEE CORPORATION & 65 & 47 \\
\hline 833 & 2.2 .3 & KERR-MCGEE CORPORATION & 65 & 50 \\
\hline 834 & 2.4 .1 & KERR-MCGEE CORPORATION & 65 & 52 \\
\hline 834 & 2.10 .3 & KERR-MCGEE CORPORATION & 65 & 52 \\
\hline 834 & $2 \cdot 10 \cdot 5 \cdot 3$ & KERR-MCGEE CORPORATION & 65 & 52 \\
\hline 835 & 2.3 .3 & KERR-MCGEE CORPORATION & 65 & 53 \\
\hline 836 & 2.4 .4 & KERR-MCGEE CORPORATION & 65 & 55 \\
\hline 836 & 2.10 .5 .1 & KERR-MCGEE CORPORATION & 65 & 55 \\
\hline 837 & 2.1 .1 & KERR-MCGEE CORPORATION & 65 & 60 \\
\hline 837 & 2.1 .6 & KERR-MCGEE CORPORATION & 65 & 60 \\
\hline 837 & 2.3 .9 & KERR-MCGEE CORPORATION & 65 & 60 \\
\hline 838 & $2 \cdot 3 \cdot 3$ & KERR-MCGEE CORPORATION & 65 & 63 \\
\hline 838 & 2.6 .1 & KERR-MCGEE CORPORATION & 65 & 63 \\
\hline 839 & 2.6 .4 & KERR-MCGEE CORPORATION & 65 & 64 \\
\hline 840 & 2.6 .4 & KERR-MCGEE CORPORATION & 65 & 64 \\
\hline 841 & 2.6 .4 & KERR-MCGEE CORPORATION & 65 & 66 \\
\hline 841 & 2.10 .5 .1 & KERR-MCGEE CORPORATION & 65 & 66 \\
\hline 842 & 2.7 .1 & KERR-MCGEE CORPORATION & 65 & 67 \\
\hline 842 & 2.7 .2 & KERR-MCGEE CORPORATION & 65 & 67 \\
\hline 843 & 2.7 .2 & KERR-MCGEE CORPORATION & 65 & 67 \\
\hline 844 & 2.8 .1 & KERR-MCGEE CORPORATION & 65 & 68 \\
\hline 844 & 2.8 .6 & KERR-MCGEE CORPORATION & 65 & 68 \\
\hline 845 & 2.8 .1 & KERR-MCGEE CORPORATION & 65 & 68 \\
\hline 845 & 2.8 .5 & KERR-MCGEE CORPORATION & 65 & 68 \\
\hline
\end{tabular}




\begin{tabular}{|c|c|c|}
\hline $\begin{array}{l}\text { Comment } \\
\text { Numbers }\end{array}$ & $\begin{array}{l}\text { Issue } \\
\text { Numbers }\end{array}$ & Commenter \\
\hline 846 & 2.8 .2 & KERR-MCGEE CORPORATION \\
\hline 847 & 2.1 .2 & SIERRA CLUB-PENNSYLVANIA CHAPTER \\
\hline 847 & 2.3 .2 & SIERRA CLUB-PENNSYLVANIA CHAPTER \\
\hline 847 & 2.3 .5 & SIERRA CLUB-PENNSYLVANIA CHAPTER \\
\hline 848 & 2.12 .0 & SIERRA CLUB-PENNSYLVANIA CHAPTER \\
\hline 849 & 2.1 .1 & SIERRA CLUB-PENNSYLVANIA CHAPTER \\
\hline 849 & 2.3 .2 & SIERRA CLUB-PENNSYLVANIA CHAPTER \\
\hline 849 & 2.3 .5 & SIERRA CLUB-PENNSYLVANIA CHAPTER \\
\hline 850 & 2.3 .1 & SIERRA CLUB-PENNSYLVANIA CHAPTER \\
\hline 850 & 2.3 .2 & SIERRA CLUB-PENNSYLVANIA CHAPTER \\
\hline 850 & 2.3 .5 & SIERRA CLUB-PENNSYLVANIA CHAPTER \\
\hline 850 & 2.3 .6 & SIERRA CLUB-PENNSYLVANIA CHAPTER \\
\hline 851 & 2.1 .2 & SIERRA CLUB-PENNSYLVANIA CHAPTER \\
\hline 851 & 2.3 .2 & SIERRA CLUB-PENNSYLVANIA CHAPTER \\
\hline 851 & $2 \cdot 6.4$ & SIERRA CLUB-PENNSYLVANIA CHAPTER \\
\hline 852 & 2.2 .1 & SIERRA CLUB-PENNSYLVANIA CHAPTER \\
\hline 852 & 2.3 .1 & SIERRA CLUB-PENNSYLVANIA CHAPTER \\
\hline 852 & $2 \cdot 3 \cdot 4$ & SIERRA CLUB-PENNSYLVANIA CHAPTER \\
\hline 853 & 2.2 .1 & SIERRA CLUB-PENNSYLVANIA CHAPTER \\
\hline 853 & 2.3 .2 & SIERRA CLUB-PENNSYLVANIA CHAPTER \\
\hline 853 & $2 \cdot 3 \cdot 4$ & SIERRA CLUB-PENNSYLVANIA CHAPTER \\
\hline 853 & 2.3 .9 & SIERRA CLUB-PENNSYLVANIA CHAPTER \\
\hline 853 & 2.10 .2 & SIERRA CLUB-PENNSYLVANIA CHAPTER \\
\hline 854 & 2.3 .9 & SIERRA CLUB-PENNSYLVANIA CHAPTER \\
\hline 854 & 2.10 .6 & SIERRA CLUB-PENNSYLVANIA CHAPTER \\
\hline 855 & 2.10 .1 & SIERRA CLUB-PENNSYLVANIA CHAPTER \\
\hline 856 & 2.3 .9 & SIERRA CLUB-PENNSYLVANIA CHAPTER \\
\hline 856 & 2.12 .0 & SIERRA CLUB-PENNSYLVANIA CHAPTER \\
\hline 857 & 2.10 .1 & META \\
\hline 857 & 2.11 .0 & META \\
\hline 858 & 2.3 .7 & META \\
\hline 858 & 2.11 .0 & META \\
\hline 858 & 2.12 .0 & META \\
\hline 859 & 2.10 .1 & META \\
\hline 860 & 2.3 .7 & META \\
\hline 860 & 2.10 .1 & META \\
\hline 860 & 2.10 .6 & META \\
\hline 861 & 2.3 .2 & META \\
\hline 861 & 2.3 .7 & META \\
\hline 861 & 2.11 .0 & META \\
\hline 862 & 2.11 .0 & META \\
\hline
\end{tabular}

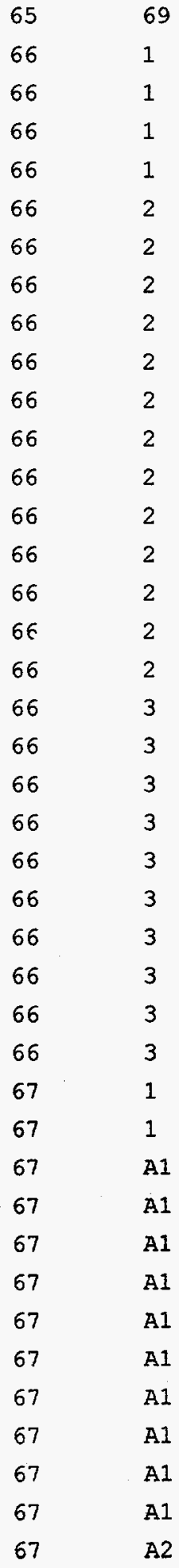




\begin{tabular}{|c|c|c|c|c|c|}
\hline $\begin{array}{l}\text { Comment } \\
\text { Numbers } \\
\end{array}$ & $\begin{array}{l}\text { Issue } \\
\text { Numbers } \\
\end{array}$ & & Commenter & $\begin{array}{l}\text { Docket } \\
\text { Letter }\end{array}$ & $\begin{array}{l}\text { Page } \\
\text { Number }\end{array}$ \\
\hline 863 & 2.3 .7 & META & & 67 & $\mathrm{~A} 2$ \\
\hline 864 & 2.3 .5 & META & & 67 & $\mathrm{~A} 2$ \\
\hline 864 & 2.3 .7 & META & & 67 & A2 \\
\hline 864 & 2.5 .1 & META & & 67 & $\mathrm{~A} 2$ \\
\hline 865 & $2 \cdot 3 \cdot 3$ & META & & 67 & $\mathrm{~A} 2$ \\
\hline 865 & 2.3 .7 & META & & 67 & $\mathrm{~A} 2$ \\
\hline 865 & 2.5 .2 & META & & 67 & $\mathrm{~A} 2$ \\
\hline 866 & $2 \cdot 3 \cdot 3$ & META & & 67 & A3 \\
\hline 867 & 2.3 .3 & META & & 67 & A3 \\
\hline 867 & 2.10 .1 & META & & 67 & A3 \\
\hline 867 & 2.10 .2 & META & & 67 & A3 \\
\hline 868 & 2.3 .2 & META & & 67 & A3 \\
\hline 868 & 2.3 .7 & META & & 67 & A3 \\
\hline 869 & 2.3 .1 & META & & 67 & A3 \\
\hline 869 & 2.3 .2 & META & & 67 & A3 \\
\hline 869 & 2.3 .3 & META & & 67 & A3 \\
\hline 869 & 2.5 .2 & META & & 67 & A3 \\
\hline 869 & 2.10 .1 & META & & 67 & A3 \\
\hline 870 & 2.3 .2 & META & & 67 & A4 \\
\hline 870 & $2 \cdot 3.3$ & META & & 67 & A4 \\
\hline 871 & $2 \cdot 3 \cdot 3$ & META & & 67 & A4 \\
\hline 871 & 2.3 .7 & META & & 67 & A4 \\
\hline 872 & 2.2 .3 & META & & 67 & A4 \\
\hline 872 & 2.3 .1 & META & & 67 & A4 \\
\hline 873 & 2.3 .7 & META & & 67 & A5 \\
\hline 873 & 2.11 .0 & META & & 67 & A5 \\
\hline 874 & 2.12 .0 & META & & 67 & A5 \\
\hline 875 & 2.10 .1 & META & & 67 & A5 \\
\hline 875 & 2.11 .0 & META & & 67 & A5 \\
\hline 876 & 2.11 .0 & META & & 67 & A5 \\
\hline 877 & 2.10 .1 & META & & 67 & A6 \\
\hline 877 & 2.11 .0 & META & & 67 & A6 \\
\hline 878 & $2 \cdot 3 \cdot 3$ & META & & 67 & A7 \\
\hline 878 & 2.10 .4 & META & & 67 & A7 \\
\hline 878 & 2.11 .0 & META & & 67 & A7 \\
\hline 879 & 2.11 .0 & META & & 67 & A7 \\
\hline 880 & 2.11 .0 & META & & 67 & A7 \\
\hline 881 & 2.11 .0 & META & & 67 & A7 \\
\hline 882 & 2.11 .0 & META & & 67 & A8 \\
\hline 883 & 2.11 .0 & META & & 67 & $\mathrm{~A} 8$ \\
\hline 884 & 2.11 .0 & META & & 67 & A8 \\
\hline
\end{tabular}




\begin{tabular}{|c|c|c|c|c|c|}
\hline $\begin{array}{l}\text { Comment } \\
\text { Numbers }\end{array}$ & $\begin{array}{l}\text { Issue } \\
\text { Numbers }\end{array}$ & & Commenter & $\begin{array}{l}\text { Docket } \\
\text { Letter }\end{array}$ & $\begin{array}{l}\text { Page } \\
\text { Number }\end{array}$ \\
\hline 885 & 2.11 .0 & META & & 67 & A8 \\
\hline 886 & 2.12 .0 & COMMONWEALTH & EDISON & 68 & 1 \\
\hline 887 & 2.1 .4 & COMMONWEALTH & EDISON & 68 & 1 \\
\hline 887 & 2.3 .1 & COMMONWEALTH & EDISON & 68 & 1 \\
\hline 888 & 2.3 .5 & COMMONWEALTH & EDISON & 68 & 1 \\
\hline 888 & 2.4 .4 & COMMONWEALTH & EDISON & 68 & 1 \\
\hline 888 & 2.5 .1 & COMMONWEALTH & EDISON & 68 & 1 \\
\hline 888 & 2.10 .5 .1 & COMMONWEALTH & EDISON & 68 & 1 \\
\hline 889 & 2.10 .1 & COMMONWEALTH & EDISON & 68 & 2 \\
\hline 889 & 2.10 .2 & COMMONWEALTH & EDISON & 68 & 2 \\
\hline 889 & 2.11 .0 & COMMONWEALTH & EDISON & 68 & 2 \\
\hline 890 & 2.7 .2 & COMMONWEALTH & EDISON & 68 & 2 \\
\hline 890 & 2.7 .3 & COMMONWEALTH & EDISON & 68 & 2 \\
\hline 890 & 2.10 .3 & COMMONWEALTH & EDISON & 68 & 2 \\
\hline 891 & 2.10 .5 .2 & COMMONWEALTH & EDISON & 68 & 2 \\
\hline 892 & 2.3 .3 & COMMONWEALTH & EDISON & 68 & $A-1$ \\
\hline 893 & 2.3 .1 & COMMONWEALTH & EDISON & 68 & $A-2$ \\
\hline 894 & 2.3 .1 & COMMONWEALTH & EDISON & 68 & $A-2$ \\
\hline 895 & 2.3 .1 & COMMONWEALTH & EDISON & 68 & $A-2$ \\
\hline 896 & 2.3 .1 & COMMONWEALTH & EDISON & 68 & $A-2$ \\
\hline 896 & 2.3 .3 & COMMONWEALTH & EDISON & 68 & $A-2$ \\
\hline 897 & 2.1 .4 & COMMONWEALTH & EDISON & 68 & $A-2$ \\
\hline 897 & 2.3 .1 & COMMONWEALTH & EDISON & 68 & $A-2$ \\
\hline 897 & 2.3 .8 & COMMONWEALTH & EDISON & 68 & $A-2$ \\
\hline 898 & 2.3 .5 & COMMONWEALTH & EDISON & 68 & $A-3$ \\
\hline 898 & 2.5 .1 & COMMONWEALTH & EDISON & 68 & $A-3$ \\
\hline 898 & 2.10 .5 .1 & COMMONWEALTH & EDISON & 68 & $A-3$ \\
\hline 899 & 2.4 .4 & COMMONWEALTH & EDISON & 68 & $A-3$ \\
\hline 899 & 2.10 .3 & COMMONWEALTH & EDISON & 68 & $A-3$ \\
\hline 900 & 2.5 .2 & COMMONWEALTH & EDISON & 68 & $A-4$ \\
\hline 900 & 2.10 .1 & COMMONWEALTH & EDISON & 68 & $A-4$ \\
\hline 900 & 2.11 .0 & COMMONWEALTH & EDISON & 68 & $A-4$ \\
\hline 901 & 2.10 .1 & COMMONWEALTH & EDISON & 68 & $A-4$ \\
\hline 902 & 2.5 .2 & COMMONWEALTH & EDISON & 68 & $A-4$ \\
\hline 902 & 2.10 .1 & COMMONWEAITH & EDISON & 68 & $A-4$ \\
\hline 903 & 2.10 .2 & COMMONWEALTH & EDISON & 68 & $A-5$ \\
\hline 904 & 2.5 .2 & COMMONWEALTH & EDISON & 68 & $A-6$ \\
\hline 904 & 2.10 .2 & COMMONWEALTH & EDISON & 68 & $A-6$ \\
\hline 905 & 2.3 .5 & COMMONWEALTH & EDISON & 68 & $A-6$ \\
\hline 905 & 2.3 .8 & COMMONWEALTH & EDISON & 68 & $A-6$ \\
\hline 906 & 2.10 .2 & COMMONWEALTH & EDISON & 68 & $A-7$ \\
\hline
\end{tabular}




\begin{tabular}{|c|c|c|c|c|c|}
\hline $\begin{array}{l}\text { Comment } \\
\text { Numbers } \\
\end{array}$ & $\begin{array}{l}\text { Issue } \\
\text { Numbers } \\
\end{array}$ & & Commenter & $\begin{array}{l}\text { Docket } \\
\text { Letter }\end{array}$ & $\begin{array}{l}\text { Page } \\
\text { Number }\end{array}$ \\
\hline 907 & 2.6 .1 & COMMONWEAITH & EDISON & 68 & $A-7$ \\
\hline 908 & 2.6 .5 & COMMONWEALTH & EDISON & 68 & $A-7$ \\
\hline 909 & 2.7 .2 & COMMONWEALTH & EDISON & 68 & $A-7$ \\
\hline 910 & 2.8 .2 & COMMONWEALTH & EDISON & 68 & $A-8$ \\
\hline 910 & 2.10 .3 & COMMONWEALTH & EDISON & 68 & $A-8$ \\
\hline 911 & 2.7 .3 & COMMONWEALTH & EDISON & 68 & $A-8$ \\
\hline 911 & 2.10 .3 & COMMONWEALTH & EDISON & 68 & $A-8$ \\
\hline 912 & 2.8 .2 & COMMONWEALTH & EDISON & 68 & $A-8$ \\
\hline 912 & 2.10 .3 & COMMONWEALTH & EDISON & 68 & $A-8$ \\
\hline 913 & 2.7 .3 & COMMONWEAITH & EDISON & 68 & $A-8$ \\
\hline 913 & 2.10 .3 & COMMONWEALTH & EDISON & 68 & $A-8$ \\
\hline 914 & 2.7 .2 & COMMONWEALTH & EDISON & 68 & $A-9$ \\
\hline 914 & 2.7 .3 & COMMONWEALTH & EDISON & 68 & $A-9$ \\
\hline 915 & 2.10 .5 .2 & COMMONWEALTH & EDISON & 68 & $A-10$ \\
\hline 916 & 2.10 .5 .1 & COMMONWEALTH & EDISON & 68 & $A-10$ \\
\hline 917 & 2.10 .1 & COMMONWEALTH & EDISON & 68 & $A-10$ \\
\hline 918 & 2.3 .1 & WESTINGHOUSE & ELECTRIC CORPORATION & 69 & $\mathrm{~A} 1$ \\
\hline 919 & 2.1 .8 & WEST INGHOUSE & ELECTRIC CORPORATION & 69 & A1 \\
\hline 919 & 2.2 .5 & WESTINGHOUSE & ELECTRIC CORPORATION & 69 & AI \\
\hline 919 & 2.10 .4 & WESTINGHOUSE & ELECTRIC CORPORATION & 69 & AI \\
\hline 919 & 2.10 .5 .1 & WESTINGHOUSE & ELECTRIC CORPORATION & 69 & A1 \\
\hline 920 & 2.1 .1 & WESTINGHOUSE & ELECTRIC CORPORATION & 69 & A1 \\
\hline 921 & 2.3 .3 & WESTINGHOUSE & ELECTRIC CORPORATION & 69 & A1 \\
\hline 921 & 2.3 .5 & WESTINGHOUSE & ELECTRIC CORPORATION & 69 & A1 \\
\hline 921 & 2.3 .6 & WESTINGHOUSE & ELECTRIC CORPORATION & 69 & A1 \\
\hline 922 & 2.3 .5 & WESTINGHOUSE & ELECTRIC CORPORATION & 69 & A2 \\
\hline 923 & 2.3 .2 & WESTINGHOUSE & ELECTRIC CORPORATION & 69 & A2 \\
\hline 924 & 2.3 .5 & WESTINGHOUSE & ELECTRIC CORPORATION & 69 & A2 \\
\hline 924 & 2.3 .8 & WESTINGHOUSE & ELECTRIC CORPORATION & 69 & A2 \\
\hline 924 & 2.10 .5 .3 & WESTINGHOUSE & ELECTRIC CORPORATION & 69 & A2 \\
\hline 925 & $2.3 \cdot 5$ & WESTINGHOUSE & ELECTRIC CORPORATION & 69 & $\mathrm{~A} 2$ \\
\hline 925 & $2 \cdot 10 \cdot 5 \cdot 3$ & WESTINGHOUSE & ELECTRIC CORPORATION & 69 & A2 \\
\hline 926 & 2.3 .3 & WESTINGHOUSE & ELECTRIC CORPORATION & 69 & $\mathrm{~A} 2$ \\
\hline 926 & 2.3 .5 & WEST INGHOUSE & ELECTRIC CORPORATION & 69 & A2 \\
\hline 926 & 2.5 .1 & WEST INGHOUSE & ELECTRIC CORPORATION & 69 & A2 \\
\hline 926 & 2.5 .2 & WESTINGHOUSE & ELECTRIC CORPORATION & 69 & A2 \\
\hline 927 & 2.3 .7 & WESTINGHOUSE & ELECTRIC CORPORATION & 69 & A2 \\
\hline 928 & 2.3 .5 & WESTINGHOUSE & ELECTRIC CORPORATION & 69 & A3 \\
\hline 929 & 2.3 .2 & WESTINGHOUSE & ELECTRIC CORPORATION & 69 & A3 \\
\hline 929 & 2.3 .3 & WESTINGHOUSE & ELECTRIC CORPORATION & 69 & A3 \\
\hline 929 & 2.6 .2 & WEST INGHOUSE & ELECTRIC CORPORATION & 69 & A3 \\
\hline
\end{tabular}




\begin{tabular}{|c|c|c|c|}
\hline 930 & 2.8 .2 & WESTINGHOUSE ELECTRIC CORPORATION & 69 \\
\hline 931 & 2.4 .3 & WESTINGHOUSE ELECTRIC CORPORATION & 69 \\
\hline 931 & 2.4 .4 & WESTINGHOUSE ELECTRIC CORPORATION & 69 \\
\hline 931 & 2.10 .1 & WESTINGHOUSE ELECTRIC CORPORATION & 69 \\
\hline 932 & 2.1 .8 & WESTINGHOUSE ELECTRIC CORPORATION & 69 \\
\hline 932 & 2.2 .3 & WESTINGHOUSE ELECTRIC CORPORATION & 69 \\
\hline 933 & 2.1 .8 & WESTINGHOUSE ELECTRIC CORPORATION & 69 \\
\hline 933 & 2.4 .2 & WESTINGHOUSE ELECTRIC CORPORATION & 69 \\
\hline 934 & 2.4 .5 & WESTINGHOUSE ELECTRIC CORPORATION & 69 \\
\hline 934 & 2.8 .5 & WESTINGHOUSE ELECTRIC CORPORATION & 69 \\
\hline 935 & 2.5 .3 & WESTINGHOUSE ELECTRIC CORPORATION & 69 \\
\hline 936 & 2.1 .8 & WESTINGHOUSE ELECTRIC CORPORATION & 69 \\
\hline 936 & 2.6 .1 & WESTINGHOUSE ELECTRIC CORPORATION & 69 \\
\hline 936 & 2.8 .1 & WESTINGHOUSE ELECTRIC CORPORATION & 69 \\
\hline 937 & 2.6 .3 & WESTINGHOUSE ELECTRIC CORPORATION & 69 \\
\hline 938 & 2.4 .5 & WESTINGHOUSE ELECTRIC CORPORATION & 69 \\
\hline 939 & 2.8 .1 & WESTINGHOUSE ELECTRIC CORPORATION & 69 \\
\hline 940 & 2.8 .1 & WESTINGHOUSE ELECTRIC CORPORATION & 69 \\
\hline 941 & 2.12 .0 & NUCLEAR INFORMATION AND RESOURCE SERVICE & 70 \\
\hline 942 & 2.12 .0 & NUCLEAR INEORMATION AND RESOURCE SERVICE & 70 \\
\hline 943 & 2.3 .2 & NUCLEAR INFORMATION AND RESOURCE SERVICE & 70 \\
\hline 943 & 2.10 .5 .1 & NUCLEAR INFORMATION AND RESOURCE SERVICE & 70 \\
\hline 944 & 2.9 .3 & NUCLEAR INFORMATION AND RESOURCE SERVICE & 70 \\
\hline 944 & 2.10 .4 & NUCLEAR INFORMATION AND RESOURCE SERVICE & 70 \\
\hline 945 & 2.7 .2 & NUCLEAR INFORMATION AND RESOURCE SERVICE & 70 \\
\hline 946 & 2.7 .2 & MEL SILBERBERG \& ASSOCIATES & 71 \\
\hline 947 & 2.8 .1 & MEL SILBERBERG \& ASSOCIATES & 71 \\
\hline 948 & 2.8 .2 & MEL SILBERBERG \& ASSOCIATES & 71 \\
\hline 949 & 2.12 .0 & WEIZENBAUM, RUTH & 76 \\
\hline 950 & 2.3 .5 & WEIZENBAUM, RUTH & 76 \\
\hline 951 & 2.3 .2 & WEIZENBAUM, RUTH & 76 \\
\hline 952 & 2.3 .7 & WEIZENBAUM, RUTH & 76 \\
\hline 953 & 2.4 .1 & WEIZENBAUM， RUTH & 76 \\
\hline 953 & 2.6 .2 & WEIZENBAUM， RUTH & 76 \\
\hline 953 & 2.6 .4 & WEIZENBAUM, RUTH & 76 \\
\hline 954 & 2.12 .0 & WEIZENBAUM， RUTH & 76 \\
\hline 955 & 2.12 .0 & WEIZENBAUM， RUTH & 76 \\
\hline 956 & 2.3 .2 & WEIZENBAUM, RUTH & 76 \\
\hline 956 & 2.6 .4 & WEIZENBAUM， RUTH & 76 \\
\hline 957 & 2.3 .1 & WEIZENBAUM, RUTH & 76 \\
\hline 957 & 2.12 .0 & WEIZENBAUM, RUTH & 76 \\
\hline
\end{tabular}




\begin{tabular}{|c|c|c|c|c|}
\hline 958 & 2.6 .3 & WEIZENBAUM, RUTH & 76 & 4 \\
\hline 959 & 2.12 .0 & WEIZENBAUM， RUTH & 76 & 4 \\
\hline 960 & 2.10 .4 & BEDFORD-FULTON-HUNTINGTON SOLID WASTE AUTHORITY & 77 & 1 \\
\hline 961 & 2.3 .2 & BEDFORD-FULTON-HUNTINGTON SOLID WASTE AUTHORITY & 77 & 1 \\
\hline 962 & 2.6 .2 & BEDFORD-FULTON-HUNTINGTON SOLID WASTE AUTHORITY & 77 & 1 \\
\hline 963 & 2.10 .5 .2 & BEDFORD-FULTON-HUNTINGTON SOLID WASTE AUTHORITY & 77 & 1 \\
\hline 964 & 2.9 .1 & BEDFORD-FULTON-HUNTINGTON SOLID WASTE AUTHORITY & 77 & 1 \\
\hline 965 & 2.12 .0 & BEDFORD-FULTON-HUNTINGTON SOLID WASTE AUTHORITY & 77 & 2 \\
\hline 966 & 2.12 .0 & BEDFORD COUNTY PLANNING COMMISSION & 78 & 1 \\
\hline 967 & 2.3 .2 & BEDFORD COUNTY PLANNING COMMTSSION & 78 & 1 \\
\hline 968 & 2.6 .2 & BEDFORD COUNTY PLANNING COMMISSION & 78 & 1 \\
\hline 969 & 2.10 .5 .2 & BEDFORD COUNTY PLANNING COMMISSION & 78 & 1 \\
\hline 970 & 2.7 .2 & BEDFORD COUNTY PLANNING COMMISSION & 78 & 1 \\
\hline 970 & 2.8 .3 & BEDFORD COUNTY PLANNING COMMISSION & 78 & 1 \\
\hline 971 & 2.7 .2 & BEDFORD COUNTY PLANNING COMMISSION & 78 & 1 \\
\hline 972 & 2.9 .1 & BEDFORD COUNTY PLANNING COMMISSION & 78 & 2 \\
\hline 973 & 2.12 .0 & BEDFORD COUNTY PLANNING COMMISSION & 78 & 2 \\
\hline 974 & 2.12 .0 & WINSTON \& STRAWN & 79 & 1 \\
\hline 975 & 2.10 .3 & WINSTON \& STRAWN & 79 & 2 \\
\hline 976 & 2.10 .5 .1 & WINSTON \& STRAWN & 79 & 2 \\
\hline 977 & 2.12 .0 & WINSTON \& STRAWN & 79 & 2 \\
\hline 978 & 2.2 .3 & WINSTON \& STRAWN & 79 & 2 \\
\hline 979 & 2.7 .2 & WINSTON \& STRAWN & 79 & 4 \\
\hline 980 & 2.7 .2 & WINSTON \& STRAWN & 79 & 4 \\
\hline 981 & 2.7 .2 & WINSTON \& STRAWN & 79 & 5 \\
\hline 982 & 2.7 .2 & WINSTON \& STRAWN & 79 & 7 \\
\hline 982 & 2.10 .5 .4 & WINSTON \& STRAWN & 79 & 7 \\
\hline 983 & 2.7 .2 & WINSTON \& STRAWN & 79 & 8 \\
\hline 983 & 2.8 .4 & WINSTON \& STRAWN & 79 & 8 \\
\hline 983 & 2.10 .5 .4 & WINSTON \& STRAWN & 79 & 8 \\
\hline 984 & 2.8 .1 & WINSTON \& STRAWN & 79 & 9 \\
\hline 984 & 2.8 .5 & WINSTON \& STRAWN & 79 & 9 \\
\hline 984 & 2.10 .5 .4 & WINSTON \& STRAWN & 79 & 9 \\
\hline 985 & 2.7 .2 & WINSTON \& STRAWN & 79 & 10 \\
\hline 986 & 2.8 .3 & WINSTON \& STRAWN & 79 & 11 \\
\hline 987 & 2.3 .2 & WINSTON \& STRAWN & 79 & 12 \\
\hline 987 & 2.4 .2 & WINSTON \& STRAWN & 79 & 12 \\
\hline 987. & 2.8 .5 & WINSTON \& STRAWN & 79 & 12 \\
\hline 987 & 2.10 .1 & WINSTON \& STRAWN & 79 & 12 \\
\hline 988 & 2.4 .4 & WINSTON \& STRAWN & 79 & 13 \\
\hline 9.88 & 2.10 .5 .1 & WINSTON \& STRAWN & 79 & 13 \\
\hline
\end{tabular}




\begin{tabular}{|c|c|c|c|c|}
\hline $\begin{array}{l}\text { Comment } \\
\text { Numbers }\end{array}$ & $\begin{array}{l}\text { Issue } \\
\text { Numbers }\end{array}$ & Commenter & $\begin{array}{l}\text { Docket } \\
\text { Letter }\end{array}$ & $\begin{array}{l}\text { Page } \\
\text { Number }\end{array}$ \\
\hline 989 & 2.2 .2 & WINSTON \& STRAWN & 79 & 14 \\
\hline 990 & 2.6 .2 & WINSTON \& STRAWN & 79 & 15 \\
\hline 990 & $2 \cdot 6.3$ & WINSTON \& STRAWN & 79 & 15 \\
\hline 991 & 2.9 .1 & WINSTON \& STRAWN & 79 & 16 \\
\hline 992 & 2.10 .5 .2 & WINSTON \& STRAWN & 79 & 17 \\
\hline 993 & 2.1 .3 & WINSTON \& STRAWN & 79 & 18 \\
\hline 993 & 2.10 .1 & WINSTON \& STRAWN & 79 & 18 \\
\hline 994 & 2.3 .9 & WINSTON \& STRAWN & 79 & 18 \\
\hline 994 & 2.10 .1 & WINSTON \& STRAWN & 79 & 18 \\
\hline 995 & 2.2 .5 & WINSTON \& STRAWN & 79 & 19 \\
\hline 996 & 2.12 .0 & SEQUOYAH FUELS & 80 & 1 \\
\hline 997 & 2.6 .4 & SEQUOYAH FUELS & 80 & 1 \\
\hline 997 & 2.10 .4 & SEQUOYAH FUELS & 80 & 1 \\
\hline 998 & 2.6 .4 & SEQUOYAH FUELS & 80 & 2 \\
\hline 999 & 2.3 .2 & YANKEE ATOMIC ELECTRIC COMPANY & 72 & 1 \\
\hline 999 & 2.3 .5 & YANKEE ATOMIC ELECTRIC COMPANY & 72 & 1 \\
\hline 999 & 2.5 .2 & YANKEE ATOMIC ELECTRIC COMPANY & 72 & 1 \\
\hline 1,000 & 2.5 .2 & YANKEE ATOMIC ELECTRIC COMPANY & 72 & 2 \\
\hline 1,001 & 2.4 .4 & YANKEE ATOMIC ELECTRIC COMPANY & 72 & 2 \\
\hline 1,001 & 2.10 .5 .1 & YANKEE ATOMIC ELECTRIC COMPANY & 72 & 2 \\
\hline 1,002 & 2.7 .2 & YANKEE ATOMIC ELECTRIC COMPANY & 72 & 3 \\
\hline 1,003 & 2.8 .6 & YANKEE ATOMIC ELECTRIC COMPANY & 72 & 4 \\
\hline 1,003 & 2.11 .0 & YANKEE ATOMIC ELECTRIC COMPANY & 72 & 4 \\
\hline 1,004 & 2.7 .2 & YANKEE ATOMIC ELECTRIC COMPANY & 72 & 4 \\
\hline 1,005 & 2.7 .2 & YANKEE ATOMIC ELECTRIC COMPANY & 72 & 4 \\
\hline 1,006 & 2.7 .2 & YANKEE ATOMIC ELECTRIC COMPANY & 72 & 5 \\
\hline 1,007 & 2.7 .2 & YANKEE ATOMIC ELECTRIC COMPANY & 72 & 5 \\
\hline 1,008 & 2.10 .5 .2 & YANKEE ATOMIC ELECTRIC COMPANY & 72 & 5 \\
\hline 1,009 & 2.11 .0 & YANKEE ATOMIC ELECTRIC COMPANY & 72 & 6 \\
\hline 1,010 & 2.12 .0 & NUCLEAR ENERGY INSTITUTE & 73 & 1 \\
\hline 1,011 & 2.3 .6 & NUCLEAR ENERGY INSTITUTE & 73 & 2 \\
\hline 1,011 & 2.4 .4 & NUCLEAR ENERGY INSTITUTE & 73 & 2 \\
\hline 1,011 & 2.6 .1 & NUCLEAR ENERGY INSTITUTE & 73 & 2 \\
\hline 1,011 & 2.7 .2 & NUCLEAR ENERGY INSTITUTE & 73 & 2 \\
\hline 1,012 & 2.3 .2 & NUCLEAR ENERGY INSTITUTE & 73 & 2 \\
\hline 1,012 & 2.3 .6 & NUCLEAR ENERGY INSTITUTE & 73 & 2 \\
\hline 1,012 & 2.11 .0 & NUCLEAR ENERGY INSTITUTE & 73 & 2 \\
\hline 1,013 & 2.3 .1 & NUCLEAR ENERGY INSTITUTE & 73 & 2 \\
\hline 1,013 & 2.3 .3 & NUCLEAR ENERGY INSTITUTE & 73 & 2 \\
\hline 1,014 & 2.8 .6 & NUCLEAR ENERGY INSTITUTE & 73 & 3 \\
\hline 1,014 & 2.10 .5 .4 & NUCLEAR ENERGY INSTITUTE & 73 & 3 \\
\hline
\end{tabular}




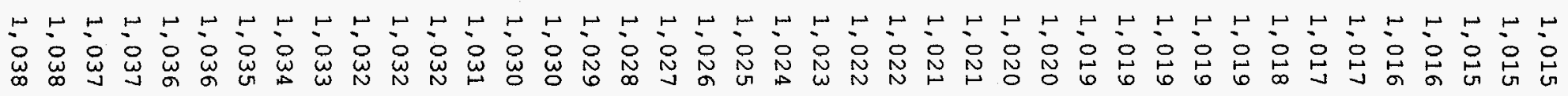

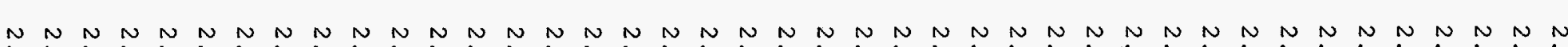

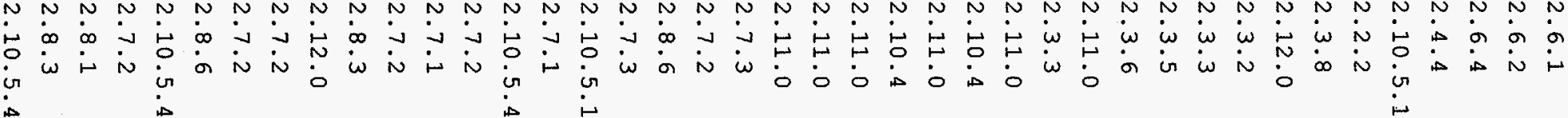

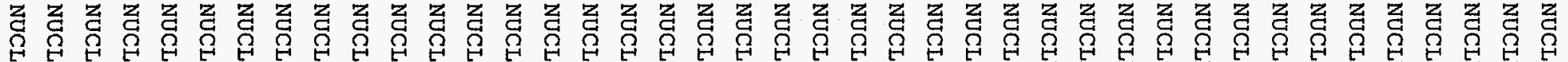

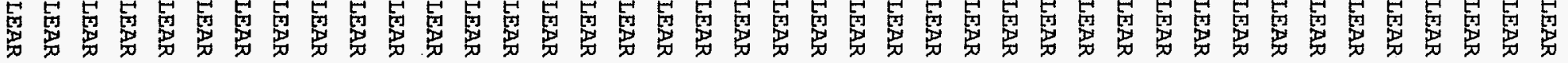

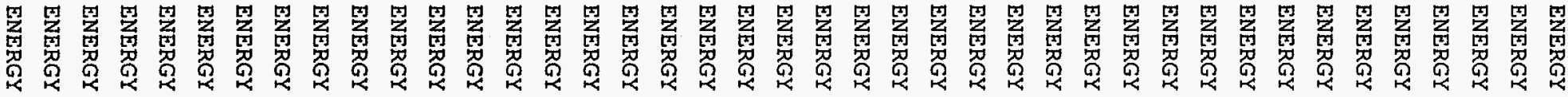

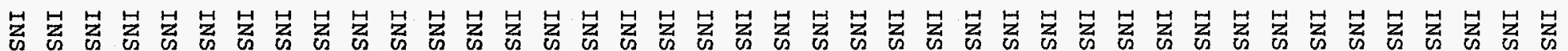

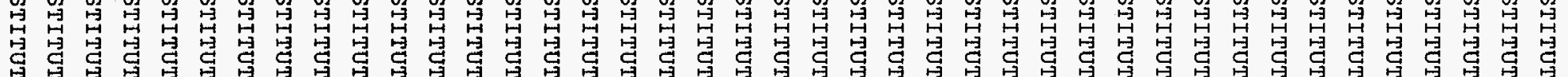

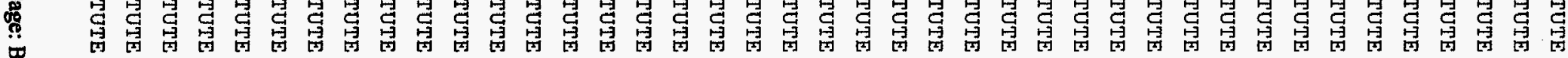

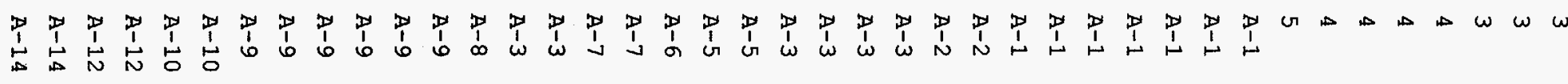




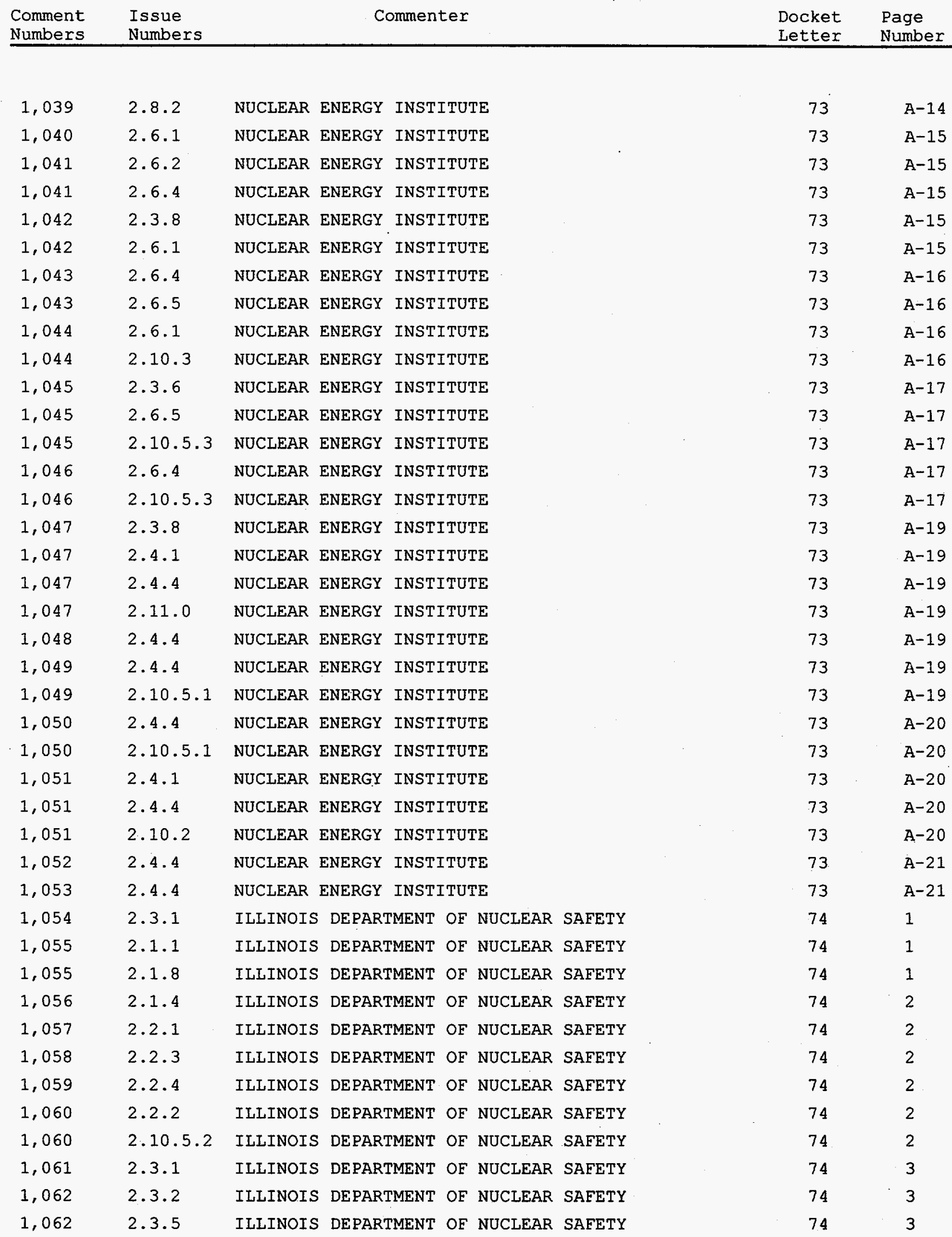




\begin{tabular}{|c|c|c|c|c|c|c|}
\hline 1,062 & 2.5 .1 & ILLINOIS & DEPARTMENT & OF & NUCLEAR & SAFETY \\
\hline 1,063 & 2.3 .7 & ILLINOIS & DEPARTMENT & OF & NUCLEAR & SAFETY \\
\hline 1,064 & 2.3 .2 & IILINOIS & DEPARTMENT & OF & NUCLEAR & SAFETY \\
\hline 1,064 & 2.3 .5 & ILLINOIS & DEPARTMENT & OF & NUCLEAR & SAEETY \\
\hline 1,065 & 2.3 .2 & ILLINOIS & DEPARTMENT & OF & NUCLEAR & SAFETY \\
\hline 1,065 & 2.3 .3 & ILIINOIS & DEPARTMENT & OF & NUCLEAR & SAFETY \\
\hline 1,065 & 2.3 .5 & ILLINOIS & DEPARTMENT & OF & NUCLEAR & SAFETY \\
\hline 1,066 & 2.3 .2 & ILLINOIS & DEPARTMENT & OF & NUCLEAR & SAFETY \\
\hline 1,066 & 2.3 .5 & ILLINOIS & DEPARTMENT & OF & NUCLEAR & SAFETY \\
\hline 1,066 & 2.5 .1 & ILLINOIS & DEPARTMENT & OF & NUCLEAR & SAFETY \\
\hline 1,067 & 2.3 .9 & ILLINOIS & DEPARTMENT & OF & NUCLEAR & SAFETY \\
\hline 1,068 & 2.3 .9 & ILLINOIS & DEPARTMENT & OF & NUCLEAR & SAFETY \\
\hline 1,069 & 2.4 .5 & ILLINOIS & DEPARTMENT & $O F$ & NUCLEAR & SAFETY \\
\hline 1,069 & 2.7 .2 & ILIINOIS & DEPARTMENT & OF & NUCLEAR & SAFETY \\
\hline 1,070 & 2.1 .8 & ILIINOIS & DEPARTMENT & $O F$ & NUCLEAR & SAEETY \\
\hline 1,070 & 2.6 .1 & ILLINOIS & DEPARTMENT & OF & NUCLEAR & SAEETY \\
\hline 1,071 & 2.1 .8 & ILLINOIS & DEPARTMENT & $\mathrm{OF}$ & NUCLEAR & SAFETY \\
\hline 1,071 & 2.6 .2 & ILIINOIS & DEPARTMENT & OF & NUCLEAR & SAEETY \\
\hline 1,072 & 2.10 .5 .2 & ILIINOIS & DEPARTMENT & OF & NUCLEAR & SAEETY \\
\hline 1,073 & 2.7 .2 & ILIINOIS & DEPARTMENT & OF & NUCLEAR & SAFETY \\
\hline 1,074 & 2.6 .4 & ILIINOIS & DEPARTMENT & $O F$ & NUCLEAR & SAEETY \\
\hline 1,075 & 2.10 .5 .2 & ILLINOIS & DEPARTMENT & OF & NUCLEAR & SAEETY \\
\hline 1,076 & 2.10 .1 & ILIINOIS & DEPARTMENT & OF & NUCLEAR & SAFETY \\
\hline 1,077 & 2.6 .4 & ILLINOIS & DEPARTMENT & OF & NUCLEAR & SAEETY \\
\hline 1,078 & 2.6 .4 & ILIINOIS & DEPARTMENT & OF & NUCLEAR & SAFETY \\
\hline 1,079 & 2.10 .1 & ILLINOIS & DEPARTMENT & OF & NUCLEAR & SAFETY \\
\hline 1,080 & 2.4 .4 & ILLINOIS & DEPARTMENT & OF & NUCLEAR & SAFETY \\
\hline 1,081 & 2.7 .2 & ILLINOIS & DEPARTMENT & OF & NUCLEAR & SAFETY \\
\hline 1,081 & 2.10 .5 .3 & ILLINOIS & DEPARTMENT & OF & NUCLEAR & SAEETY \\
\hline 1,082 & 2.3 .2 & ILLINOIS & DEPARTMENT & $O F$ & NUCLEAR & SAEETY \\
\hline 1,082 & 2.3 .5 & ILLINOIS & DEPARTMENT & OF & NUCLEAR & SAEETY \\
\hline 1,082 & 2.3 .6 & ILIINOIS & DEPARTMENT & OF & NUCLEAR & SAFETY \\
\hline 1,082 & 2.3 .7 & ILLINOIS & DEPARTMENT & $O F$ & NUCLEAR & SAEETY \\
\hline 1,083 & 2.2 .1 & \multicolumn{3}{|c|}{ DOW CHEMICAI COMPANY } & & \\
\hline 1,083 & 2.2 .5 & \multicolumn{3}{|c|}{ DOW CHEMICAI COMPANY } & & \\
\hline 1,084 & 2.6 .1 & \multicolumn{3}{|c|}{ DOW CHEMICAL COMPANY } & & \\
\hline 1,084 & 2.6 .4 & \multicolumn{3}{|c|}{ DOW CHEMICAL COMPANY } & & \\
\hline 1,085 & 2.6 .4 & \multicolumn{3}{|c|}{ DOW CHEMICAL COMPANY } & & \\
\hline 1,085 & 2.10 .1 & \multicolumn{3}{|c|}{ DOW CHEMICAL COMPANY } & & \\
\hline 1,085 & 2.10 .5 .1 & \multicolumn{3}{|c|}{ DOW CHEMICAL COMPANY } & & \\
\hline 085 & 2.10 .5 .3 & \multicolumn{5}{|c|}{ DOW CHEMICAL COMPANY } \\
\hline
\end{tabular}

\begin{tabular}{|c|c|}
\hline 74 & 3 \\
\hline 74 & 3 \\
\hline 74 & 3 \\
\hline 74 & 3 \\
\hline 74 & 3 \\
\hline 74 & 3 \\
\hline 74 & 3 \\
\hline 74 & 4 \\
\hline 74 & 4 \\
\hline 74 & 4 \\
\hline 74 & 4 \\
\hline 74 & 4 \\
\hline 74 & 4 \\
\hline 74 & 4 \\
\hline 74 & 4 \\
\hline 74 & 4 \\
\hline 74 & 5 \\
\hline 74 & 5 \\
\hline 74 & 5 \\
\hline 74 & 5 \\
\hline 74 & 5 \\
\hline 74 & 5 \\
\hline 74 & 5 \\
\hline 74 & 5 \\
\hline 74 & 6 \\
\hline 74 & 6 \\
\hline 74 & 6 \\
\hline 74 & 6 \\
\hline 74 & 6 \\
\hline 74 & 7 \\
\hline 74 & 7 \\
\hline 74 & 7 \\
\hline 74 & 7 \\
\hline 75 & $\mathrm{~A} 2$ \\
\hline 75 & A2 \\
\hline 75 & $A-4$ \\
\hline 75 & $A-4$ \\
\hline 75 & $A-4$ \\
\hline 75 & $A-4$ \\
\hline 75 & $A-4$ \\
\hline 75 & A-4 \\
\hline
\end{tabular}




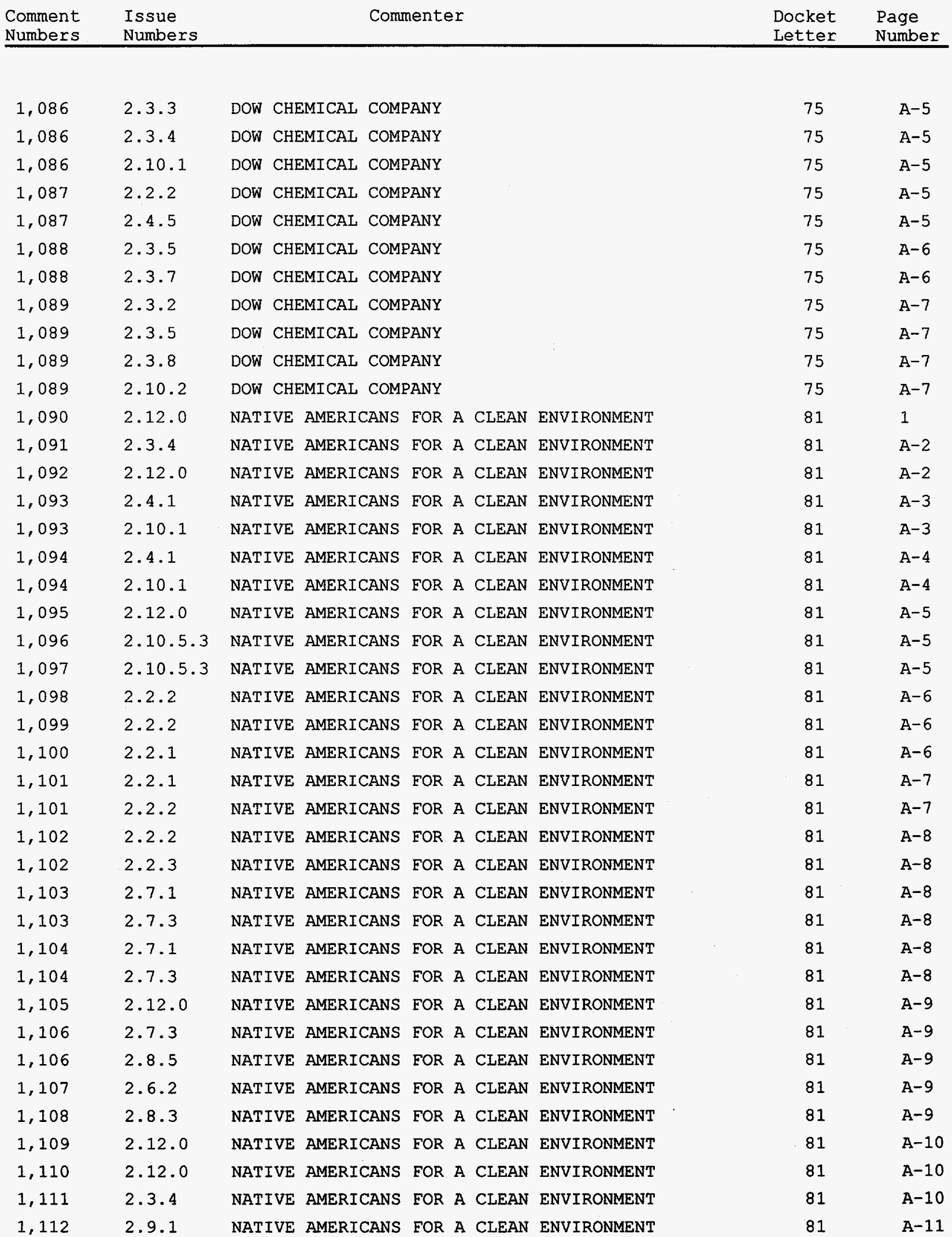




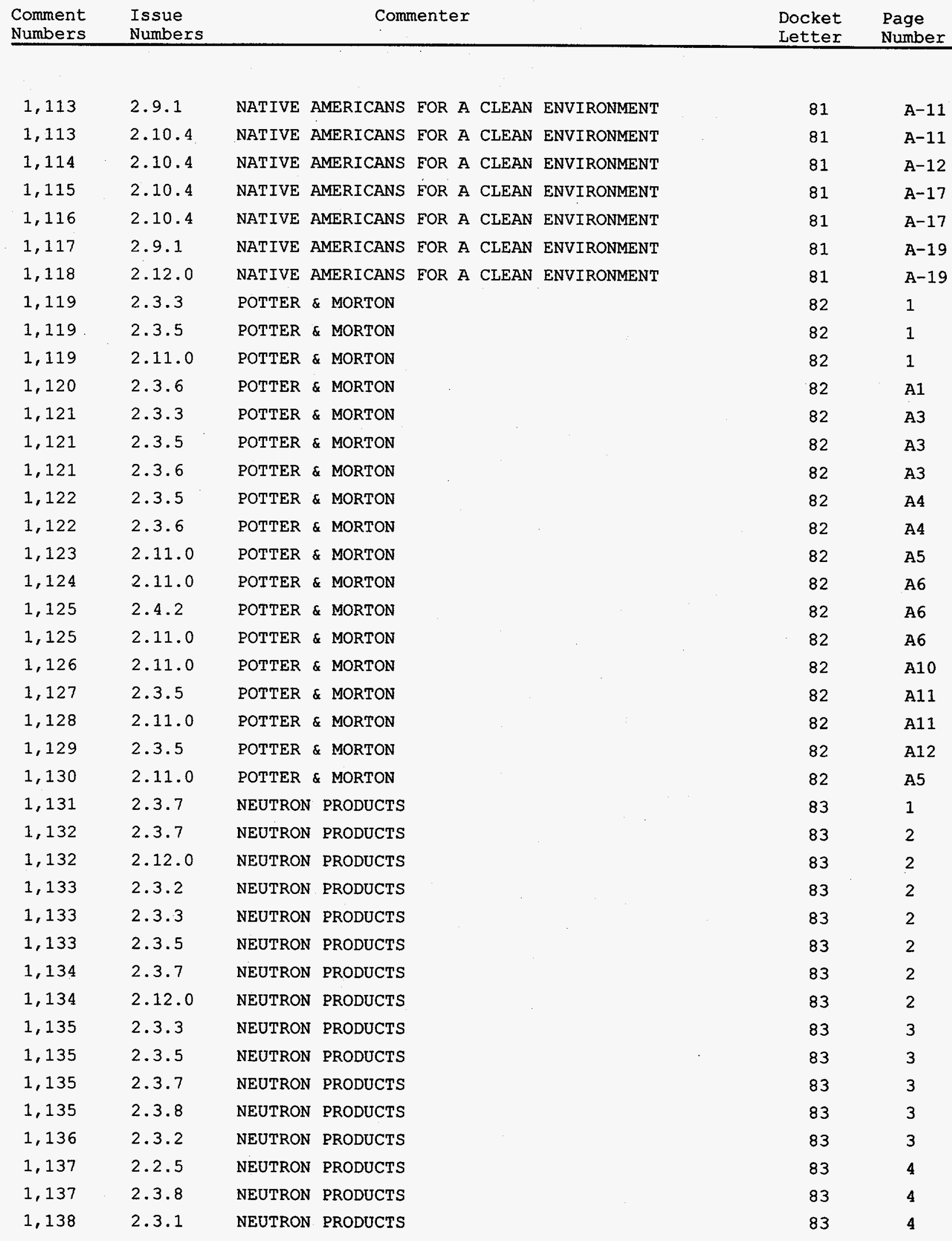




\begin{tabular}{|c|c|c|c|}
\hline 1,138 & 2.3 .8 & NEUTRON PRODUCTS & 83 \\
\hline 1,139 & 2.4 .2 & NEUTRON PRODUCTS & 83 \\
\hline 1,140 & 2.5 .3 & NEUTRON BRODUCTS & 83 \\
\hline 1,141 & 2.6 .3 & NEUTRON PRODUCTS & 83 \\
\hline 1,142 & 2.10 .5 .2 & NEUTRON PRODUCTS & 83 \\
\hline 1,143 & 2.10 .6 & NEUTRON PRODUCTS & 83 \\
\hline 1,144 & 2.3 .1 & U.S. ENVIRONMENTAL PROTECTION AGENCY & 84 \\
\hline 1,144 & 2.3 .2 & U.S. ENVIRONMENTAL PROTECTION AGENCY & 84 \\
\hline 1,144 & 2.3 .5 & U.S. ENVIRONMENTAL PROTECTION AGENCY & 84 \\
\hline 1,144 & 2.4 .4 & U.S. ENVIRONMENTAL PROTECTION AGENCY & 84 \\
\hline 1,144 & 2.5 .1 & U.S. ENVIRONMENTAL PROTECTION AGENCY & 84 \\
\hline 1,144 & 2.10 .5 .1 & U.S. ENVIRONMENTAL PROTECTION AGENCY & 84 \\
\hline 1,145 & 2.4 .4 & U.S. ENVIRONMENTAL PROTECTION AGENCY & 84 \\
\hline 1,145 & 2.6 .3 & U.S. ENVIRONMENTAL PROTECTION AGENCY & 84 \\
\hline 1,145 & 2.10 .5 .1 & U.S. ENVIRONMENTAL PROTECTION AGENCY & 84 \\
\hline 1,146 & 2.10 .5 .1 & U.S. ENVIRONMENTAL PROTECTION AGENCY & 84 \\
\hline 1,147 & 2.3 .2 & VIRGINIA POWER & 85 \\
\hline 1,147 & 2.3 .5 & VIRGINIA POWER & 85 \\
\hline 1,147 & 2.3 .8 & VIRGINIA POWER & 85 \\
\hline 1,147 & 2.10 .4 & VIRGINIA POWER & 85 \\
\hline 1,147 & $2 \cdot 10 \cdot 5 \cdot 3$ & VIRGINIA POWER & 85 \\
\hline 1,148 & 2.3 .5 & VIRGINIA POWER & 85 \\
\hline 1,149 & 2.7 .2 & VIRGINIA POWER & 85 \\
\hline 1,150 & 2.12 .0 & VIRGINIA POWER & 85 \\
\hline 1,151 & 2.12 .0 & E. I. DUPONT - MEDICAL DEPARTMENT & 86 \\
\hline 1,152 & 2.3 .1 & E. I. DUPONT - MEDICAL DERARTMENT & 86 \\
\hline 1,153 & 2.3 .2 & E. I. DUPONT - MEDICAL DEPARTMENT & 86 \\
\hline 1,153 & 2.3 .5 & E. I. DUPONT - MEDICAL DEPARTMENT & 86 \\
\hline 1,153 & 2.3 .6 & E. I. DUPONT - MEDICAL DEPARTMENT & 86 \\
\hline 1,154 & 2.3 .2 & E. I. DUPONT - MEDICAL DEPARTMENT & 86 \\
\hline 1,154 & 2.3 .3 & E. I. DUPONT - MEDICAL DEPARTMENT & 86 \\
\hline 1,154 & 2.3 .5 & E. I. DUPONT - MEDICAL DEPARTMENT & 86 \\
\hline 1,155 & 2.3 .3 & E. I. DUPONT - MEDICAL DEPARTMENT & 86 \\
\hline 1,155 & 2.3 .6 & E. I. DUPONT - MEDICAL DEPARTMENT & 86 \\
\hline 1,156 & 2.3 .2 & E. I. DUPONT - MEDICAL DEPARTMENT & 86 \\
\hline 1,157 & 2.3 .3 & E. I. DUPONT - MEDICAL DEPARTMENT & 86 \\
\hline 1,157 & 2.4 .2 & E. I. DUPONT - MEDICAL DEPARTMENT & 86 \\
\hline 1,157 & 2.10 .1 & E. I. DUPONT - MEDICAL DEPARTMENT & 86 \\
\hline 1,157 & 2.10 .2 & E. I. DUPONT - MEDICAL DEPARTMENT & 86 \\
\hline 1,158 & 2.4 .4 & E. I. DUPONT - MEDICAI DEPARTMENT & 86 \\
\hline 1,159 & 2.4 .5 & E. I. DUPONT - MEDICAL DEPARTMENT & 86 \\
\hline
\end{tabular}




\begin{tabular}{|c|c|c|}
\hline 1,160 & 2.3 .5 & E. I. DUPONT - MEDICAL DEPARTMENT \\
\hline 1,160 & 2.5 .1 & E. I. DUPONT - MEDICAL DEPARTMENT \\
\hline 1,160 & 2.6 .1 & E. I. DUPONT - MEDICAL DEPARTMENT \\
\hline 1,161 & 2.3 .6 & E. I. DUPONT - MEDICAL DEPARTMENT \\
\hline 1,161 & 2.6 .4 & E. I. DUPONT - MEDICAL DEPARTMENT \\
\hline 1,162 & 2.3 .6 & E. I. DUPONT - MEDICAL DEPARTMENT \\
\hline 1,162 & 2.10 .5 .1 & E. I. DUPONT - MEDICAI DEPARTMENT \\
\hline 1,163 & 2.2 .3 & E. I. DUPONT - MEDICAL DEPARTMENT \\
\hline 1,163 & 2.10 .5 .2 & E. I. DUPONT - MEDICAL DEPARTMENT \\
\hline 1,164 & 2.3 .7 & E. I. DUPONT - MEDICAL DEPARTMENT \\
\hline 1,165 & 2.3 .5 & E. I. DUPONT - MEDICAL DEPARTMENT \\
\hline 1,165 & 2.3 .6 & E. I. DUPONT - MEDICAL DEPARTMENT \\
\hline 1,165 & 2.3 .7 & E. I. DUPONT - MEDICAL DEPARTMENT \\
\hline 1,165 & 2.3 .8 & E. I. DUPONT - MEDICAL DEPARTMENT \\
\hline 1,166 & 2.12 .0 & FLORIDA POWER \& LIGHT COMPANY \\
\hline 1,167 & 2.4 .5 & FLORIDA POWER \& LIGHT COMPANY \\
\hline 1,167 & 2.10 .5 .3 & FLORIDA POWER \& LIGHT COMPANY \\
\hline 1,168 & 2.10 .6 & FLORIDA POWER \& LIGHT COMPANY \\
\hline 1,169 & 2.4 .5 & FLORIDA POWER \& LIGHT COMPANY \\
\hline 1,170 & 2.4 .4 & FLORIDA POWER \& LIGHT COMPANY \\
\hline 1,170 & 2.10 .5 .1 & FLORIDA POWER \& LIGHT COMPANY \\
\hline 1,171 & 2.4 .5 & FLORIDA POWER \& LIGHT COMPANY \\
\hline 1,171 & 2.7 .2 & FLORIDA POWER \& LIGHT COMPANY \\
\hline 1,172 & 2.6 .4 & FLORIDA POWER \& LIGHT COMPANY \\
\hline 1,173 & 2.10 .1 & FLORIDA POWER \& LIGHT COMPANY \\
\hline 1,173 & 2.10 .2 & FLORIDA POWER \& LIGHT COMPANY \\
\hline 1,174 & 2.3 .2 & SOUTHERN CALIFORNIA EDISON COMPANY \\
\hline 1,174 & 2.3 .5 & SOUTHERN CALIFORNIA EDISON COMPANY \\
\hline 1,174 & 2.3 .6 & SOUTHERN CALIFORNIA EDISON COMPANY \\
\hline 1,174 & 2.4 .4 & SOUTHERN CALIFORNIA EDISON COMPANY \\
\hline 1,174 & 2.10 .5 .1 & SOUTHERN CALIFORNIA EDISON COMPANY \\
\hline 1,174 & 2.10 .5 .3 & SOUTHERN CALIFORNIA EDISON COMPANY \\
\hline 1,175 & 2.12 .0 & ARIZONA PUBLIC SERVICE COMPANY \\
\hline 1,176 & 2.10 .1 & ARIZONA PUBLIC SERVICE COMPANY \\
\hline 1,177 & 2.3 .2 & ARIZONA PUBLIC SERVICE COMPANY \\
\hline 1,177 & 2.3 .5 & ARIZONA PUBLIC SERVICE COMPANY \\
\hline 1,177 & 2.3 .6 & ARIZONA PUBLIC SERVICE COMPANY \\
\hline 1,178 & 2.10 .2 & ARIZONA PUBLIC SERVICE COMPANY \\
\hline 1,179 & 2.3 .6 & ARIZONA PUBLIC SERVICE COMPANY \\
\hline 1,180 & 2.7 .2 & ARIZONA PUBLIC SERVICE COMPANY \\
\hline 180 & & ¿VICE CON \\
\hline
\end{tabular}

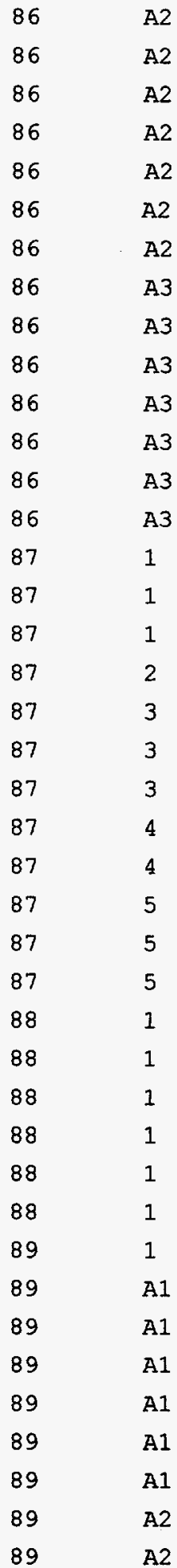




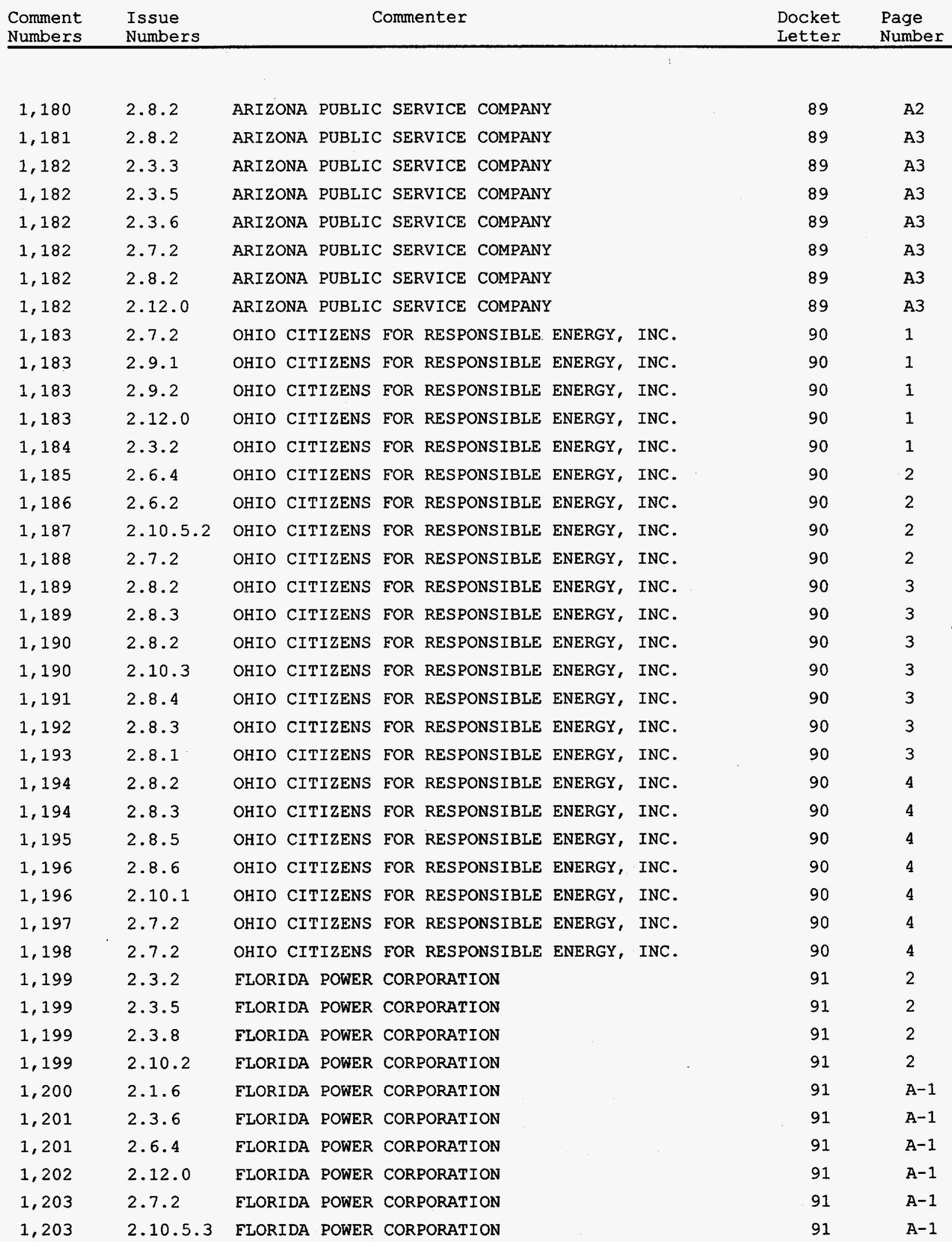


1,204

1,205

1,205

1,206

1,207

1,207

1,207

1,207

1,208

1,209

1,210

1,211

1,212

1,213

1,213

1,214

1,214

1,215

1,215

1,216

1,216

1,217

1,217

1,217

1,218

1,218

1,218

1,218

1,219

1,219

1,220

1,221

1,222

1,223

1,223

1,223

1,224

1,224

1,224

1,225

1,226
2.3 .9

2.2 .3

2.10 .5 .2

2.4 .4

2.7 .2

2.8 .5

2.8 .6

2.10 .5 .3

2.6.4

2.10 .1

2.11 .0

2.6.2

2.10 .1

2.1 .3

2.3. 4

2.1 .8

2.2 .3

2.3 .2

2.3.3

2.3 .4

2.6. 4

2.3 .2

2.3.5

2.5 .1

2.3 .5

2.3 .6

2.10.5.1

2.10 .5 .3

2.3 .3

2.11 .0

2.3.2

2.8 .3

2.8 .3

2.8 .3

2.8 .5

2.10 .2

2.8 .1

2.8 .3

2.10 .2

2.8 .3

2.8 .4
FLORIDA POWER CORPORATION

FLORIDA POWER CORPORATION

FLORIDA POWER CORPORATION

FLORIDA POWER CORPORATION

FLORIDA POWER CORPORATION

FLORIDA POWER CORPORATION

FLORIDA POWER CORPORATION

FLORIDA POWER CORPORATION

FLORIDA POWER CORPORATION

FLORIDA POWER CORPORATION

FLORIDA POWER CORPORATION

FLORIDA POWER CORPORATION

FLORIDA POWER CORPORATION

TEXAS DEPARTMENT OF HEALTH

TEXAS DEPARTMENT OF HEALTH

TEXAS DEPARTMENT OF HEALTH

TEXAS DEPARTMENT OF HEALTH

TEXAS DEPARTMENT OF HEALTH

TEXAS DEPARTMENT OF HEALTH

TEXAS DEPARTMENT OF HEALTH

TEXAS DEPARTMENT OF HEALTH

OHIO DEPARTMENT OF HEAITH

OHIO DEPARTMENT OF HEALTH

OHIO DEPARTMENT OF HEALTH

OHIO DEPARTMENT OF HEALTH

OHIO DEPARTMENT OF HEALTH

OHIO DEPARTMENT OF HEALTH

OHIO DEPARTMENT OF HEALTH

META

META

CITIZENS RESEARCH \& ENVIRONMENTAL WATCH (CREW)

CITIZENS RESEARCH \& ENVIRONMENTAL WATCH (CREW)

CITIZENS RESEARCH \& ENVIRONMENTAL WATCH (CREW)

CITIZENS RESEARCH \& ENVIRONMENTAL WATCH (CREW)

CITIZENS RESEARCH \& ENVIRONMENTAL WATCH (CREW)

CITIZENS RESEARCH \& ENVIRONMENTAL WATCH (CREW)

CITIZENS RESEARCH \& ENVIRONMENTAL WATCH (CREW)

CITIZENS RESEARCH \& ENVIRONMENTAL WATCH (CREW)

CITIZENS RESEARCH \& ENVIRONMENTAL WATCH (CREW)

CITIZENS RESEARCH \& ENVIRONMENTAL WATCH (CREW)

CITIZENS RESEARCH \& ENVIRONMENTAL WATCH (CREW)

\begin{tabular}{|c|c|}
\hline 91 & $A-1$ \\
\hline 91 & $A-2$ \\
\hline 91 & $A-2$ \\
\hline 91 & $A-2$ \\
\hline 91 & $A-2$ \\
\hline 91 & $A-2$ \\
\hline 91 & $A-2$ \\
\hline 91 & $A-2$ \\
\hline 91 & $A-2$ \\
\hline 91 & $A-2$ \\
\hline 91 & $A-3$ \\
\hline 91 & $A-4$ \\
\hline 91 & $A-5$ \\
\hline 92 & 1 \\
\hline 92 & 1 \\
\hline 92 & 1 \\
\hline 92 & 1 \\
\hline 92 & 1 \\
\hline 92 & 1 \\
\hline 92 & 2 \\
\hline 92 & 2 \\
\hline 93 & 1 \\
\hline 93 & 1 \\
\hline 93 & 1 \\
\hline 93 & 1 \\
\hline 93 & 1 \\
\hline 93 & 1 \\
\hline 93 & 1 \\
\hline 67 & A6 \\
\hline 67 & A6 6 \\
\hline 94 & 1 \\
\hline 94 & 1 \\
\hline 94 & $A-1$ \\
\hline 94 & $A-1$ \\
\hline 94 & $A-1$ \\
\hline 94 & $A-1$ \\
\hline 94 & $A-1$ \\
\hline 94 & $A-1$ \\
\hline 94 & $A-1$ \\
\hline 94 & $A-2$ \\
\hline 94 & $A-2$ \\
\hline
\end{tabular}




\begin{tabular}{|c|c|c|c|c|c|c|c|c|c|}
\hline 1,227 & 2.8 .1 & CITIZENS & RESEARCH & $\&$ & ENVIRONMENTAL & WATCH & (CREW) & 94 & $A-2$ \\
\hline 1,227 & 2.8 .3 & CITIZENS & RESEARCH & $\&$ & ENVIRONMENTAL & WATCH & (CREW) & 94 & $A-2$ \\
\hline 1,228 & 2.6 .4 & CITIZENS & RESEARCH & $\&$ & ENVIRONMENTAL & WATCH & (CREW) & 94 & $A-2$ \\
\hline 1,229 & 2.3 .1 & CITIZENS & RESEARCH & $\&$ & ENVIRONMENTAL & WATCH & (CREW) & 94 & $A-3$ \\
\hline 1,229 & 2.3 .2 & CITIZENS & RESEARCH & $\&$ & ENVIRONMENTAL & WATCH & (CREW) & 94 & $A-3$ \\
\hline 1,229 & 2.3 .5 & CITIZENS & RESEARCH & $\&$ & ENVIRONMENTAL & WATCH & (CREW) & 94 & $A-3$ \\
\hline 1,230 & 2.6 .4 & CITIZENS & S RESEARCH & $\&$ & ENVIRONMENTAL & WATCH & (CREW) & 94 & $A-3$ \\
\hline 1,231 & 2.3 .2 & CITIZENS & RESEARCH & $\&$ & ENVIRONMENTAL & WATCH & (CREW) & 94 & $A-4$ \\
\hline 1,231 & 2.10 .2 & CITIZENS & RESEARCH & $\&$ & ENVIRONMENTAL & WATCH & (CREW) & 94 & $A-4$ \\
\hline 1,232 & 2.10 .1 & CITIZENS & RESEARCH & $\&$ & ENVIRONMENTAI & WATCH & (CREW) & 94 & $A-4$ \\
\hline 1,232 & 2.10 .2 & CITIZENS & RESEARCH & $\varepsilon$ & ENVIRONMENTAL & WATCH & (CREW) & 94 & A-4 \\
\hline 1,233 & 2.10 .1 & CITIZENS & RESEARCH & $\&$ & ENVIRONMENTAL & WATCH & (CREW) & 94 & $A-4$ \\
\hline 1,233 & 2.10 .2 & CITIZENS & SESEARCH & $\&$ & ENVIRONMENTAL & WATCH & (CREW) & 94 & $A-4$ \\
\hline 1,234 & 2.12 .0 & CITIZENS & RESEARCH & 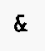 & ENVIRONMENTAL & WATCH & (CREW) & 94 & $A-4$ \\
\hline 1,235 & 2.4 .1 & CITIZENS & RESEARCH & $\&$ & ENVIRONMENTAL & WATCH & (CREW) & 94 & $A-5$ \\
\hline 1,236 & 2.7 .3 & CITIZENS & RESEARCH & $\&$ & ENVIRONMENTAL & WATCH & (CREW) & 94 & $A-5$ \\
\hline 1,236 & 2.8 .1 & CITIZENS & RESEARCH & $\&$ & ENVIRONMENTAL & WATCH & (CREW) & 94 & $A-5$ \\
\hline 1,236 & 2.8 .3 & CITIZENS & RESEARCH & $\&$ & ENVIRONMENTAL & WATCH & (CREW) & 94 & $A-5$ \\
\hline 1,237 & 2.3 .9 & CITIZENS & 5 RESEARCH & $\varepsilon$ & ENVIRONMENTAL & WATCH & (CREW) & 94 & $A-5$ \\
\hline 1,238 & 2.10 .2 & CITIZENS & 5 RESEARCH & $\&$ & ENVIRONMENTAL & WATCH & (CREW) & 94 & $A-6$ \\
\hline 1,239 & 2.3 .2 & CITIZENS & S RESEARCH & $\&$ & ENVIRONMENTAL & WATCH & (CREW) & 94 & $A-6$ \\
\hline 1,239 & 2.3 .4 & CITIZENS & RESEARCH & $\&$ & ENVIRONMENTAL & WATCH & (CREW) & 94 & $A-6$ \\
\hline 1,239 & 2.10 .2 & CITIZENS & S RESEARCH & $\&$ & ENVIRONMENTAL & WATCH & (CREW) & 94 & A- 6 \\
\hline 1,240 & 2.3 .9 & CITIZENS & S RESEARCH & $\&$ & ENVIRONMENTAL & WATCH & (CREW) & 94 & $A-6$ \\
\hline 1,241 & 2.1 .1 & CITIZENS & 5 RESEARCH & $\&$ & ENVIRONMENTAI & WATCH & (CREW) & 94 & $A-7$ \\
\hline 1,242 & 2.12 .0 & CITIZENS & S RESEARCH & $\&$ & ENVIRONMENTAL & WATCH & (CREW) & 94 & $A-7$ \\
\hline 1,243 & 2.3 .5 & BOSTON E & EDISON & & & & & 95 & 1 \\
\hline 1,244 & 2.6 .1 & BOSTON E & EDISON & & & & & 95 & 1 \\
\hline 1,244 & 2.7 .2 & BOSTON E & EDISON & & & & & 95 & 1 \\
\hline 1,245 & 2.12 .0 & BOSTON E & EDISON & & & & & 95 & 1 \\
\hline 1,246 & 2.3 .1 & BOSTON E & EDISON & & & & & 95 & $A-1$ \\
\hline 1,246 & 2.3 .5 & BOSTON E & EDISON & & & & & 95 & $A-1$ \\
\hline 1,246 & 2.3 .7 & BOSTON E & EDISON & & & & & 95 & $A-1$ \\
\hline 1,246 & 2.10 .5 .1 & BOSTON E & EDISON & & & & & 95 & $A-1$ \\
\hline 1,246 & 2.10 .5 .3 & BOSTON E & EDISON & & & & & 95 & $A-1$ \\
\hline 1,247 & 2.1 .8 & BOSTON EI & EDISON & & & & & 95 & $A-1$ \\
\hline 1,247 & 2.3 .3 & BOSTON E & EDISON & & & & & 95 & $A-1$ \\
\hline 1,247 & 2.3 .4 & BOSTON E & EDISON & & & & & 95 & $A-1$ \\
\hline 1,247 & 2.6 .1 & BOSTON E & EDISON & & & & & 95 & A-1 \\
\hline 1,248 & 2.3 .3 & BOSTON E & EDISON & & & & & 95 & $A-1$ \\
\hline 1,248 & 2.3 .8 & BOSTON E & EDISON & & & & & 95 & $A-I$ \\
\hline
\end{tabular}




\begin{tabular}{|c|c|c|c|c|}
\hline $\begin{array}{l}\text { Comment } \\
\text { Numbers } \\
\end{array}$ & $\begin{array}{l}\text { Issue } \\
\text { Numbers }\end{array}$ & Commenter & $\begin{array}{l}\text { Docket } \\
\text { Letter }\end{array}$ & $\begin{array}{l}\text { Page } \\
\text { Number }\end{array}$ \\
\hline 1,249 & 2.7 .2 & BOSTON EDISON & 95 & $A-2$ \\
\hline 1,250 & 2.3 .2 & CITY OF SYLVANIA & 96 & $A-1$ \\
\hline 1,250 & 2.3 .4 & CITY OF SYLVANIA & 96 & $A-1$ \\
\hline 1,250 & 2.6 .4 & CITY OF SYLVANIA & 96 & $A-1$ \\
\hline 1,251 & 2.8 .1 & CITY OF SYLVANIA & 96 & $A-1$ \\
\hline 1,252 & 2.3 .1 & COPE, TERRY & 97 & 1 \\
\hline 1,252 & 2.3 .2 & COPE, TERRY & 97 & 1 \\
\hline 1,252 & 2.3 .7 & COPE, TERRY & 97 & 1 \\
\hline 1,252 & 2.12 .0 & COPE, TERRY & 97 & 1 \\
\hline 1,253 & 2.9 .3 & COPE, TERRY & 97 & 1 \\
\hline 1,254 & 2.3 .4 & NATALE, ELIZABETH & 98 & 1 \\
\hline 1,254 & 2.12 .0 & NATALE, ELIZABETH & 98 & 1 \\
\hline 1,255 & 2.3 .2 & NATALE, ELIZABETH & 98 & 1 \\
\hline 1,256 & 2.10 .5 .1 & U.S. DEPARTMENT OF ENERGY & 99 & $A-1$ \\
\hline 1,257 & 2.2 .5 & U.S. DEPARTMENT OF ENERGY & 99 & $A-1$ \\
\hline 1,257 & 2.10 .5 .1 & U.S. DEPARTMENT OF ENERGY & 99 & $A-1$ \\
\hline 1,257 & 2.10 .5 .4 & U.S. DEPARTMENT OF ENERGY & 99 & $A-1$ \\
\hline 1,258 & 2.3 .2 & U.S. DEPARTMENT OF ENERGY & 99 & \\
\hline 1,258 & 2.4 .4 & U.S. DEPARTMENT OF ENERGY & 99 & \\
\hline 1,258 & 2.10 .2 & U.S. DEPARTMENT OF ENERGY & 99 & \\
\hline 1,258 & 2.10 .3 & U.S. DEPARTMENT OF ENERGY & 99 & \\
\hline 1,259 & 2.3 .4 & U.S. DEPARTMENT OF ENERGY & 99 & $A-2$ \\
\hline 1,260 & 2.3 .3 & U.S. DEPARTMENT OF ENERGY & 99 & $A-2$ \\
\hline 1,260 & 2.3 .9 & U.S. DEPARTMENT OF ENERGY & 99 & $A-2$ \\
\hline 1,261 & 2.10 .5 .1 & U.S. DEPARTMENT OF ENERGY & 99 & $A-2$ \\
\hline 1,262 & 2.3 .9 & U.S. DEPARTMENT OF ENERGY & 99 & $A-2$ \\
\hline 1,263 & 2.3 .2 & U.S. DEPARTMENT OF ENERGY & 99 & A-2 \\
\hline 1,263 & 2.3 .3 & U.S. DEPARTMENT OF ENERGY & 99 & $A-2$ \\
\hline 1,263 & 2.4 .2 & U.S. DEPARTMENT OF ENERGY & 99 & $A-2$ \\
\hline 1,263 & 2.5 .2 & U.S. DEPARTMENT OF ENERGY & 99 & $A-2$ \\
\hline 1,263 & 2.11 .0 & U.S. DEPARTMENT OF ENERGY & 99 & $A-2$ \\
\hline 1,263 & 2.12 .0 & U.S. DEPARTMENT OF ENERGY & 99 & $A-2$ \\
\hline 1,264 & 2.3 .4 & U.S. DEPARTMENT OF ENERGY & 99 & $A-2$ \\
\hline 1,265 & 2.6 .2 & U.S. DEPARTMENT OF ENERGY & 99 & $A-2$ \\
\hline 1,265 & 2.10 .1 & U.S. DEPARTMENT OF ENERGY & 99 & $A-2$ \\
\hline 1,266 & 2.3 .2 & U.S. DEPARTMENT OF ENERGY & 99 & \\
\hline 1,266 & 2.3 .3 & U.S. DEPARTMENT OF ENERGY & 99 & \\
\hline 1,266 & 2.5 .2 & U.S. DEPARTMENT OF ENERGY & 99 & \\
\hline 1,267 & 2.11 .0 & U.S. DEPARTMENT OF ENERGY & 99 & $A-3$ \\
\hline 1,268 & 2.4 .4 & U.S. DEPARTMENT OF ENERGY & 99 & $A-3$ \\
\hline 1,269 & $2 \cdot 3 \cdot 4$ & U.S. DEPARTMENT OF ENERGY & 99 & $A-3$ \\
\hline
\end{tabular}




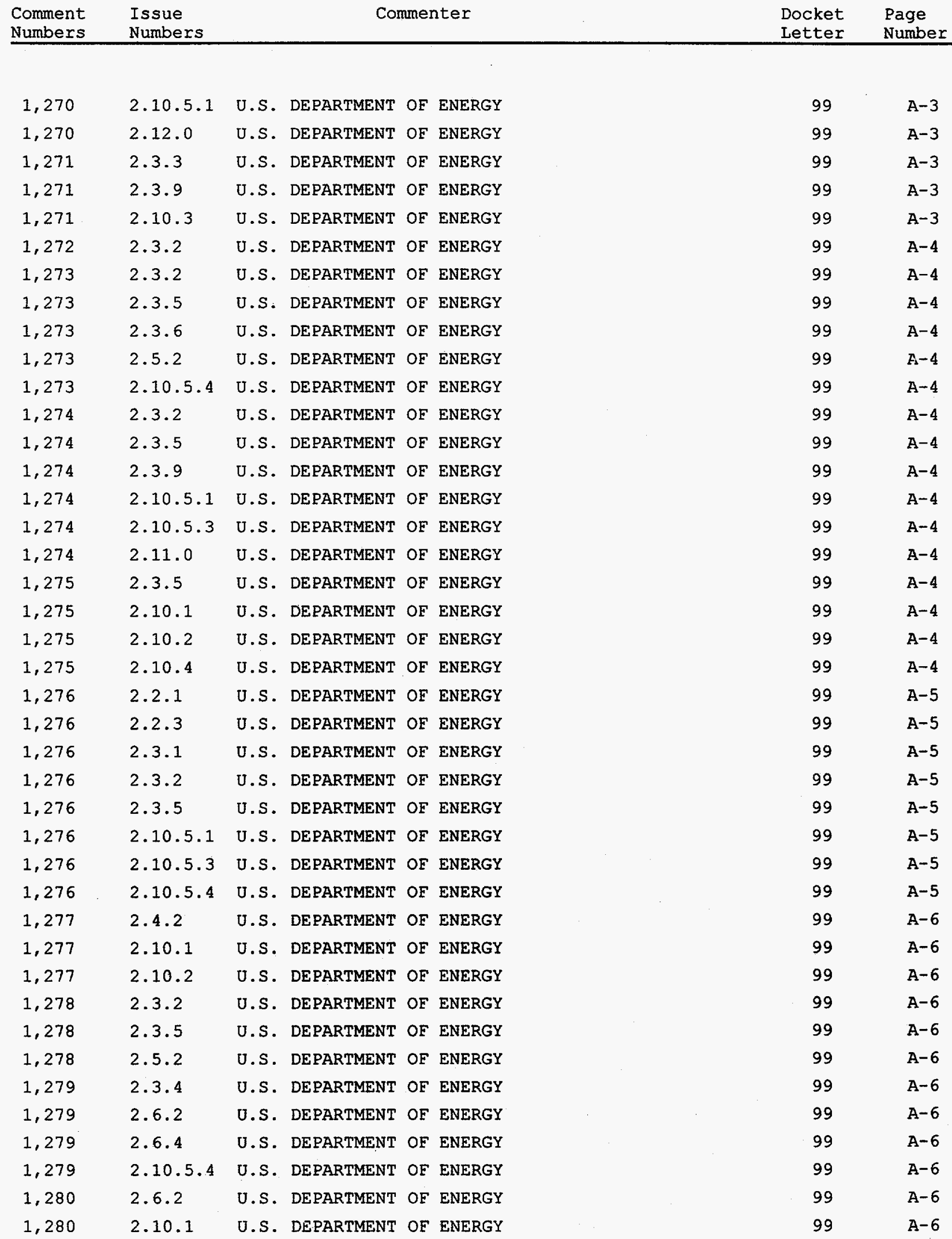




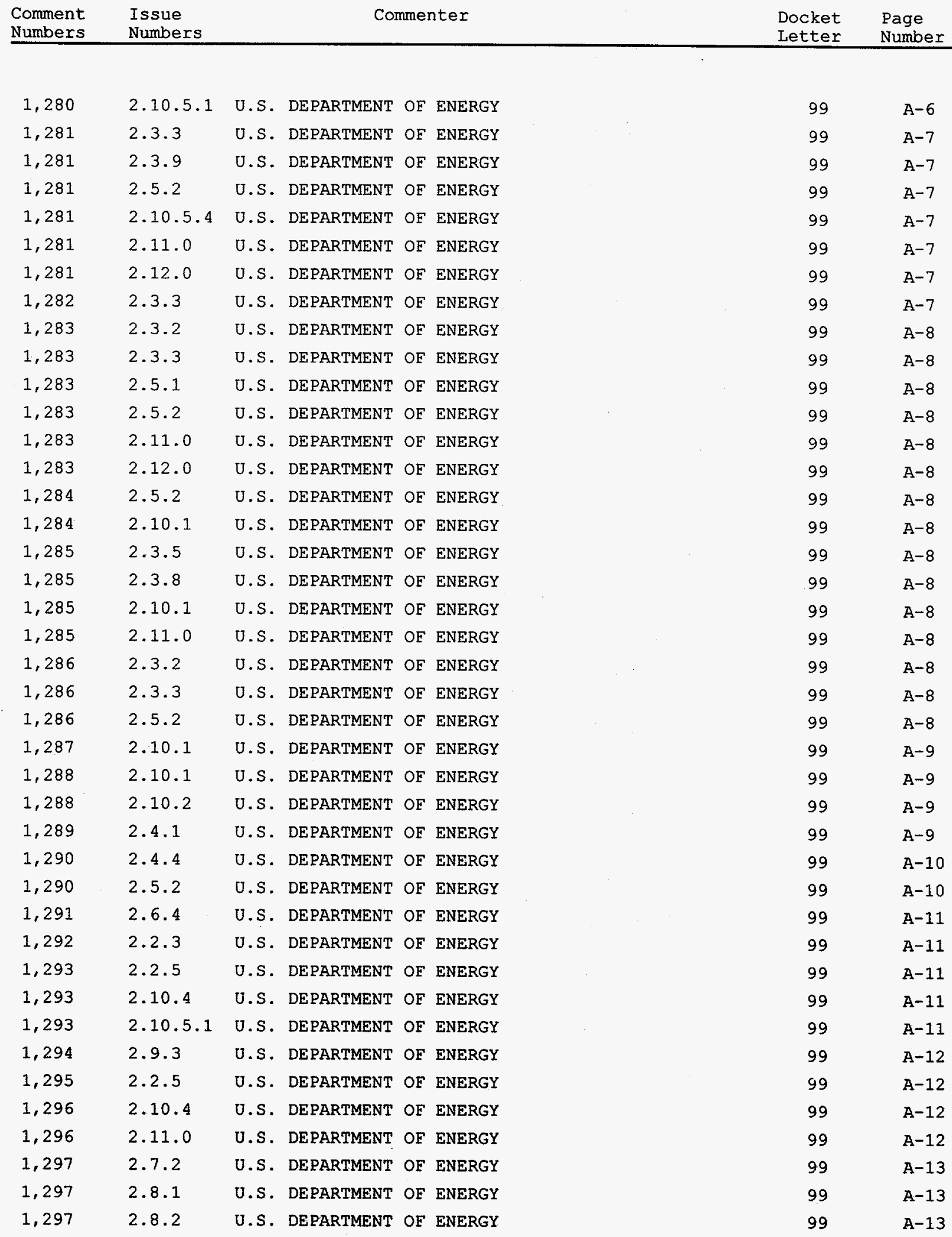




\begin{tabular}{|c|c|c|c|c|}
\hline $\begin{array}{l}\text { Comment } \\
\text { Numbers }\end{array}$ & $\begin{array}{l}\text { Issue } \\
\text { Numbers }\end{array}$ & Commenter & $\begin{array}{l}\text { Docket } \\
\text { Letter }\end{array}$ & $\begin{array}{l}\text { Page } \\
\text { Number }\end{array}$ \\
\hline 1,298 & 2.10 .1 & U.S. DEPARTMENT OF ENERGY & 99 & $A-14$ \\
\hline 1,299 & 2.1 .8 & NUCORE CONSULTING SERVICES, INC. & 100 & 1 \\
\hline 1,300 & 2.6 .4 & NUCORE CONSULTING SERVICES, INC. & 100 & 1 \\
\hline 1,300 & 2.10 .5 .1 & NUCORE CONSUETING SERVICES, INC. & 100 & 1 \\
\hline 1,301 & 2.10 .4 & KERR-MCGEE CORPORATION & 65 & $A-1$ \\
\hline 1,302 & 2.2 .1 & KERR-MCGEE CORPORATION & 65 & $A-2$ \\
\hline 1,302 & 2.10 .3 & KERR-MCGEE CORPORATION & 65 & $A-2$ \\
\hline 1,302 & 2.10 .4 & KERR-MCGEE CORPORATION & 65 & $A-2$ \\
\hline 1,303 & 2.4 .2 & KERR-MCGEE CORPORATION & 65 & $\mathrm{~B}-2$ \\
\hline 1,303 & 2.5 .2 & KERR-MCGEE CORPORATION & 65 & $B-2$ \\
\hline 1,303 & 2.10 .4 & KERR-MCGEE CORPORATION & 65 & $B-2$ \\
\hline 1,304 & 2.2 .1 & KERR-MCGEE CORPORATION & 65 & $c-1$ \\
\hline 1,304 & 2.5 .2 & KERR-MCGEE CORPORATION & 65 & $C-1$ \\
\hline 1,305 & 3.5 & FUEL CYCLE FACILITIES FORUM & 63 & $\mathrm{~B}-2$ \\
\hline 1,305 & 10.5 .3 & FUEL CYCLE FACILITIES FORUM & 63 & $\mathrm{~B}-2$ \\
\hline 1,306 & 3.2 & MAUNER, JEFERY R. & 101 & 1 \\
\hline 1,306 & 3.4 & MAUNER, JEFFRY R. & 101 & 1 \\
\hline 1,307 & 3.2 & MAUNER, JEFFRY $R$. & 101 & 1 \\
\hline 1,308 & 9.3 & MAUNER, JEFERY $R$. & 101 & 1 \\
\hline 1,309 & 10.4 & MAUNER, JEFFRY R. & 101 & 1 \\
\hline
\end{tabular}





\section{APPENDIX C}

COMMENT REFERENCES FOR THE GEIS 



\section{APPENDIX C - COMMENT REFERENCES FOR THE GEIS}

This appendix can be used to determine the origin of each comment and where each comment is used in the summary of conments on the GEIS. The listed information includes a comment number, the particular summary sections (issues) to which it contribules, the name or abbreviated name of the commenter, the docket number of the letter containing the comment, and the page of the letter on which the comment begins.

About half of the comments are used in more than one summary section, but the comment number is unique and remains with the comment in each summary section where it is used. The last name of the commenter is listed or, if an organization, the full or abbreviated name. For example:

\begin{tabular}{|c|c|c|c|}
\hline $\begin{array}{l}\text { Comment } \\
\text { Number }\end{array}$ & $\begin{array}{l}\text { Report } \\
\text { Section }\end{array}$ & Name & $\begin{array}{l}\text { Docket } \\
\text { Number }\end{array}$ \\
\hline 29 & $\begin{array}{l}3.3 .4 \\
3.5 .2\end{array}$ & E.I. DU PONT DE NEMOURS \& CO. & $6 \ldots \ldots$ \\
\hline
\end{tabular}

In this (fictitious) example, comment number 29 is used in sections 3.3 .4 and 3.5 .2 of this report. The name of the commenter is listed; the letter is docketed as number 6 , and the comment begins on page 2 of the first appendix to that letter. If no alphabet character is used, the number refers to the page of the basic letter; $A, B, C$, etc. refer to the successive appendices of a letter.

Thus, every comment is assigned a single number, retains that same number in each issue where it is summarized, and can be traced to a page in its docketed source letter.

The following pages contain a columun listing of these data per conment number. 


\begin{tabular}{|c|c|c|c|c|}
\hline $\begin{array}{l}\text { Comment } \\
\text { Numbers }\end{array}$ & $\begin{array}{l}\text { Issue } \\
\text { Numbers }\end{array}$ & Commenter & $\begin{array}{l}\text { Docket } \\
\text { Letter } \\
\end{array}$ & $\begin{array}{l}\text { Page } \\
\text { Number }\end{array}$ \\
\hline 1 & 3.3 .1 .4 & TECHNADYNE ENGINEERING CONSULTANTS, INC. & 10 & 1 \\
\hline 2 & 3.2 .5 .1 & TECHNADYNE ENGINEERING CONSULTANTS, INC. & 10 & 2 \\
\hline 2 & 3.2 .1 .2 & TECHNADYNE ENGINEERING CONSULTANTS, INC. & 10 & 2 \\
\hline 3 & 3.2 .1 .1 & TECHNADYNE ENGINEERING CONSULTANTS, INC. & 10 & 2 \\
\hline 4 & 3.3 .1 .3 & SANDIA NATIONAL LABORATORIES & 12 & 3 \\
\hline 5 & 3.1 .2 & MARVIN I. LEWIS & 13 & 1 \\
\hline 6 & 3.2 .5 .1 & MARVIN I. LEWIS & 13 & 1 \\
\hline 7 & 3.2 .2 .5 & ALLIED SIGNAL CHEMICAL & 14 & 2 \\
\hline 8 & 3.2 .3 & CENTER FOR BIOLOGICAL MONITORING & 26 & 2 \\
\hline 10 & 3.1 .1 & ORISE & 35 & $A-3$ \\
\hline 11 & 3.1 .2 & $\begin{array}{l}\text { NEW YORK STATE DEPARTMENT OF ENVIRONMENTAL } \\
\text { CONSERVATION }\end{array}$ & 36 & $A-2$ \\
\hline 13 & 3.2 .3 & NEW YORK STATE ENERGY OFFICE & 36 & $A-2$ \\
\hline 14 & 3.2 .4 .4 & CLEAN WATER FUND OF NORTH CAROLINA & 37 & 1 \\
\hline 15 & 3.3 .1 .1 & CLEAN WATER FUND OF NORTH CAROLINA & 37 & 1 \\
\hline 16 & 3.2 .5 .5 & CLEAN WATER FUND OF NORTH CAROLINA & 37 & 2 \\
\hline 17 & 3.3 .2 .1 & CLEAN WATER FUND OF NORTH CAROLINA & 37 & 2 \\
\hline 18 & 3.2 .2 .7 & CLEAN WATER FUND OF NORTH CAROLINA & 37 & 4 \\
\hline 19 & 3.2 .2 .7 & JOAN O. KING & 45 & 1 \\
\hline 20 & 3.3 .2 .2 & RIO-ALGOM MINING CORPORATION & 49 & 6 \\
\hline 21 & 3.2 .1 .4 & RIO-ALGOM MINING CORPORATION & 49 & 20 \\
\hline 22 & 3.2 .1 .4 & RIO-ALGOM MINING CORPORATION & 49 & 21 \\
\hline 23 & 3.2 .5 .1 & RIO-ALGOM MINING CORPORATION & 49 & 21 \\
\hline 24 & 3.2 .5 .4 & RIO-ALGOM MINING CORPORATION & 49 & 22 \\
\hline 24 & 3.2 .5 .3 & RIO-ALGOM MINING CORPORATION & 49 & 22 \\
\hline 25 & 3.1 .2 & AMERICAN NUCLEAR SOCIETY & 50 & 1 \\
\hline 26 & 3.1 .2 & AMERICAN NUCLEAR SOCIETY & 50 & 2 \\
\hline 27 & 3.1 .1 & AMERICAN NUCLEAR SOCIETY & 50 & $A-1$ \\
\hline 28 & 3.3 .2 .2 & AMERICAN NUCLEAR SOCIETY & 50 & $A-1$ \\
\hline 28 & 3.1 .2 & AMERICAN NUCLEAR SOCIETY & 50 & $A-1$ \\
\hline 29 & 3.2 .2 .1 & AMERICAN NUCLEAR SOCIETY & 50 & $A-1$ \\
\hline 30 & 3.2 .2 .2 & AMERICAN NUCLEAR SOCIETY & 50 & $A-3$ \\
\hline 31 & 3.2 .5 .2 & AMERICAN NUCLEAR SOCIETY & 50 & $A-3$ \\
\hline 32 & 3.2 .5 .2 & CORAR & 51 & $A-4$ \\
\hline 32 & 3.2 .5 .3 & CORAR & 51 & $A-4$ \\
\hline 34 & 3.2 .2 .2 & CORAR & 51 & 2 \\
\hline 34 & 3.3 .2 .2 & CORAR & 51 & 2 \\
\hline 35 & 3.2 .5 .4 & CORAR & 51 & 2 \\
\hline
\end{tabular}




\begin{tabular}{|c|c|c|c|c|}
\hline 36 & 3.2 .1 .6 & CORAR & 51 & 3 \\
\hline 36 & 3.3 .2 .2 & CORAR & 51 & 3 \\
\hline 36 & 3.2 .5 .3 & CORAR & 51 & 3 \\
\hline 37 & 3.2 .2 .2 & CORAR & 51 & 4 \\
\hline 38 & 3.1 .1 & CORAR & 51 & 5 \\
\hline 39 & 3.2 .4 .1 & CORAR & 51 & 5 \\
\hline 39 & 3.2 .2 .6 & CORAR & 51 & 5 \\
\hline 40 & 3.2 .5 .3 & CORAR & 51 & 5 \\
\hline 41 & 3.2 .2 .7 & IEER & 52 & 4 \\
\hline 41 & 3.3 .1 .4 & IEER & 52 & 4 \\
\hline 42 & 3.3 .1 .4 & IEER & 52 & 5 \\
\hline 43 & 3.2 .1 .3 & IEER & 52 & 5 \\
\hline 44 & 3.2 .3 & IEER & 52 & 6 \\
\hline 45 & 3.1 .2 & IEER & 52 & 6 \\
\hline 45 & 3.3 .1 .4 & IEER & 52 & 6 \\
\hline 46 & 3.2 .1 .1 & IEER & 52 & 6 \\
\hline 46 & 3.2 .2 .1 & IEER & 52 & 6 \\
\hline 47 & 3.3 .2 .2 & DAM & 53 & 1 \\
\hline 48 & 3.3 .1 .4 & DAM & 53 & 2 \\
\hline 48 & 3.1 .2 & DAM & 53 & 2 \\
\hline 49 & 3.2 .2 .6 & $\mathrm{DAM}$ & 53 & 2 \\
\hline 50 & 3.2 .5 .1 & DAM & 53 & 3 \\
\hline 51 & 3.2 .6 & DUPONT & 54 & 2 \\
\hline 51 & 3.3 .2 .2 & DUPONT & 54 & 2 \\
\hline 51 & 3.3 .1 .2 & DUPONT & 54 & 2 \\
\hline 52 & 3.2 .6 & DUPONT & 54 & 2 \\
\hline 52 & 3.2 .5 .6 & DUPONT & 54 & 2 \\
\hline 53 & 3.2 .4 .1 & DUPONT & 54 & 4 \\
\hline 54 & 3.2 .4 .3 & DUPONT & 54 & 6 \\
\hline 54 & 3.2 .6 & DUPONT & 54 & 6 \\
\hline 56 & 3.2 .4 .3 & DUPONT & 54 & 7 \\
\hline 56 & 3.2 .6 & DUPONT & 54 & 7 \\
\hline 57 & 3.2 .4 .3 & DUPONT & 54 & 8 \\
\hline 58 & 3.2 .4 .3 & DUPONT & 54 & 8 \\
\hline 58 & 3.2 .5 .1 & DUPONT & 54 & 8 \\
\hline 58 & 3.2 .6 & DUPONT & 54 & 8 \\
\hline 60 & 3.2 .5 .3 & DUPONT & 54 & 9 \\
\hline 62 & 3.2 .6 & DUPONT & 54 & 10 \\
\hline 63 & 3.2 .2 .5 & DUPONT & 54 & 10 \\
\hline 64 & 3.2 .5 .6 & DUPONT & 54 & $A-1$ \\
\hline 66 & 3.2 .2 .2 & PEARSON & 55 & 5 \\
\hline
\end{tabular}




\begin{tabular}{|c|c|c|c|c|}
\hline $\begin{array}{l}\text { Comment } \\
\text { Numbers }\end{array}$ & $\begin{array}{l}\text { Issue } \\
\text { Numbers }\end{array}$ & Commenter & $\begin{array}{l}\text { Docket } \\
\text { Letter }\end{array}$ & $\begin{array}{l}\text { Page } \\
\text { Number }\end{array}$ \\
\hline 67 & 3.1 .2 & ECNP & 56 & $A-1$ \\
\hline 68 & 3.2 .2 .3 & ECNP & 56 & $A-4$ \\
\hline 70 & 3.2 .2 .6 & ECNP & 56 & $A-9$ \\
\hline 73 & 3.2 .3 & ECNP & 56 & $A-11$ \\
\hline 74 & 3.1 .2 & ECNP & 56 & $A-11$ \\
\hline 75 & 3.2 .2 .3 & ECNP & 56 & A-13 \\
\hline 76 & 3.3 .1 .1 & ECNP & 56 & A-14 \\
\hline 77 & 3.2 .4 .1 & ECNP & 56 & $A-15$ \\
\hline 78 & 3.3 .2 .1 & ECNP & 56 & $A-16$ \\
\hline 79 & 3.3 .1 .1 & ECNP & 56 & $A-17$ \\
\hline 80 & 3.3 .1 .1 & ECNP & 56 & $A-20$ \\
\hline 81 & 3.2 .2 .1 & ECNP & 56 & $A-21$ \\
\hline 81 & 3.3 .2 .1 & ECNP & 56 & $A-21$ \\
\hline 82 & 3.2 .3 & ECNP & 56 & $A-21$ \\
\hline 82 & 3.1 .1 & ECNP & 56 & $A-21$ \\
\hline 82 & 3.3 .1 .2 & ECNP & 56 & $A-21$ \\
\hline 83 & 3.2 .2 .3 & ECNP & 56 & A-25 \\
\hline 84 & 3.2 .2 .6 & ECNP & 56 & $A-25$ \\
\hline 85 & 3.1 .1 & ECNP & 56 & $A-27$ \\
\hline 87 & 3.2 .1 .2 & CONSUMER POWER & 57 & 2 \\
\hline 88 & 3.2 .5 .1 & CONSUMER POWER & 57 & 3 \\
\hline 94 & 3.2 .5 .6 & WSLE & 59 & 2 \\
\hline 96 & 3.2 .2 .3 & WSLF & 59 & 3 \\
\hline 97 & 3.3 .1 .5 & WSLF & 59 & 4 \\
\hline 98 & 3.3 .1 .5 & WSLF & 59 & 4 \\
\hline 99 & 3.2 .1 .1 & WSLF & 59 & 11 \\
\hline 99 & 3.2 .5 .3 & WSLF & 59 & 11 \\
\hline 100 & 3.3 .1 .5 & WSLF & 59 & 12 \\
\hline 101 & 3.3 .1 .5 & WSLF & 59 & 12 \\
\hline 102 & 3.3 .1 .5 & WSLF & 59 & 12 \\
\hline 103 & 3.3 .1 .5 & WSLE & 59 & 13 \\
\hline 104 & 3.1 .2 & ARCO & 61 & $A-3$ \\
\hline 105 & 3.3 .1 .5 & ARCO & 61 & $A-7$ \\
\hline 106 & 3.3 .2 .2 & SHIELD ALLOY & 62 & $A-1$ \\
\hline 107 & 3.3 .1 .2 & SHIELD ALLOY & 62 & $A-3$ \\
\hline 108 & 3.2 .2 .6 & SHIELD ALLOY & 62 & $A-17$ \\
\hline 109 & 3.2 .2 .6 & SHIELD ALIOY & 62 & $A-20$ \\
\hline 110 & 3.2 .4 .1 & SHIELD ALLOY & 62 & $A-20$ \\
\hline 111 & 3.2 .1 .4 & AMC & 64 & $A-4$ \\
\hline 112 & 3.2 .6 & AMC & 64 & $A-8$ \\
\hline 113 & 3.2 .2 .2 & $\mathrm{AMC}$ & 64 & $A-9$ \\
\hline
\end{tabular}




\begin{tabular}{|c|c|c|c|c|}
\hline 114 & 3.2 .2 .6 & AMC & 64 & $A-12$ \\
\hline 115 & 3.2 .2 .6 & AMC & 64 & $A-14$ \\
\hline 116 & 3.2 .4 .2 & AMC & 64 & $A-15$ \\
\hline 117 & 3.1 .1 & AMC & 64 & A-15 \\
\hline 118 & 3.1 .1 & AMC & 64 & A-17 \\
\hline 119 & 3.2 .2 .2 & AMC & 64 & $A-21$ \\
\hline 120 & 3.3 .2 .2 & AMC & 64 & $A-27$ \\
\hline 121 & 3.3 .1 .5 & AMC & 64 & $A-39$ \\
\hline 122 & 3.2 .4 .1 & AMC & 64 & $A-43$ \\
\hline 122 & 3.3 .1 .4 & AMC & 64 & $A-43$ \\
\hline 123 & 3.1 .1 & AMC & 64 & A- -44 \\
\hline 124 & 3.2 .2 .8 & AMC & 64 & A -47 \\
\hline 125 & 3.2 .5 .2 & AMC & 64 & $A-50$ \\
\hline 125 & 3.2 .5 .3 & AMC & 64 & $A-50$ \\
\hline 125 & 3.2 .5 .4 & AMC & 64 & $A-50$ \\
\hline 126 & 3.2 .2 .7 & $\mathrm{AMC}$ & 64 & $A-58$ \\
\hline 127 & 3.2 .5 .6 & AMC & 64 & 64 \\
\hline 128 & 3.2 .1 .3 & AMC & 64 & B-11 \\
\hline 129 & 3.2 .2 .1 & AMC & 64 & B-11 \\
\hline 130 & 3.2 .2 .8 & KERR-MCGEE CORPORATION & 65 & 12 \\
\hline 131 & 3.2 .2 .1 & KERR-MCGEE CORPORATION & 65 & 16 \\
\hline 133 & 3.2 .2 .6 & KERR-MCGEE CORPORATION & 65 & 18 \\
\hline 134 & 3.3 .2 .2 & KERR-MCGEE CORPORATION & 65 & 30 \\
\hline 135 & 3.2 .1 .3 & KERR-MCGEE CORPORATION & 65 & 30 \\
\hline 136 & 3.2 .1 .3 & KERR-MCGEE CORPORATION & 65 & 31 \\
\hline 137 & 3.2 .5 .2 & KERR-MCGEE CORPORATION & 65 & 32 \\
\hline 138 & 3.2 .2 .3 & KERR-MCGEE CORPORATION & 65 & 38 \\
\hline 141 & 3.1 .1 & META & 67 & 1 \\
\hline 142 & 3.1 .1 & META & 67 & $A-1$ \\
\hline 143 & 3.2 .2 .1 & META & 67 & $A-1$ \\
\hline 144 & 3.1 .1 & META & 67 & $A-1$ \\
\hline 145 & 3.1 .1 & META & 67 & $A-1$ \\
\hline 146 & 3.1 .1 & META & 67 & $A-2$ \\
\hline 146 & 3.2 .2 .1 & META & 67 & $A-2$ \\
\hline 147 & 3.2 .2 .2 & META & 67 & $A-2$ \\
\hline 148 & 3.3 .1 .2 & META & 67 & $A-3$ \\
\hline 149 & 3.2 .2 .1 & META & 67 & $A-3$ \\
\hline 150 & 3.2 .2 .1 & META & 67 & $A-3$ \\
\hline 150 & 3.3 .2 .2 & META & 67 & $A-3$ \\
\hline 151 & 3.1 .1 & META & 67 & $A-4$ \\
\hline 152 & 3.2 .2 .6 & META & 67 & $A-4$ \\
\hline
\end{tabular}




\begin{tabular}{|c|c|c|c|c|}
\hline $\begin{array}{l}\text { Comment } \\
\text { Numbers }\end{array}$ & $\begin{array}{l}\text { Issue } \\
\text { Numbers }\end{array}$ & Commenter & $\begin{array}{l}\text { Docket } \\
\text { Letter } \\
\end{array}$ & $\begin{array}{l}\text { Page } \\
\text { Number }\end{array}$ \\
\hline 153 & 3.1 .1 & META & 67 & $A-5$ \\
\hline 154 & 3.1 .1 & META & 67 & $A-5$ \\
\hline 155 & 3.2 .1 .2 & META & 67 & $A-5$ \\
\hline 156 & 3.2 .1 .2 & META & 67 & $A-5$ \\
\hline 157 & 3.2 .1 .2 & META & 67 & $A-6$ \\
\hline 160 & 3.3 .1 .4 & META & 67 & $A-6$ \\
\hline 160 & 3.2 .2 .1 & META & 67 & $A-6$ \\
\hline 162 & 3.2 .2 .6 & META & 67 & $A-7$ \\
\hline 163 & 3.2 .2 .6 & META & 67 & $A-7$ \\
\hline 163 & 3.2 .2 .1 & META & 67 & $A-7$ \\
\hline 164 & 3.1 .1 & META & 67 & $A-7$ \\
\hline 165 & 3.2 .2 .1 & META & 67 & $A-7$ \\
\hline 165 & 3.2 .2 .4 & META & 67 & $A-7$ \\
\hline 166 & 3.2 .2 .6 & META & 67 & $A-8$ \\
\hline 167 & 3.1 .1 & META & 67 & $A-8$ \\
\hline 169 & 3.2 .2 .1 & META & 67 & $A-8$ \\
\hline 169 & 3.2 .2 .6 & META & 67 & $A-8$ \\
\hline 170 & 3.2 .2 .1 & META & 67 & $A-8$ \\
\hline 171 & 3.2 .1 .3 & FUEL CYCLE FACILITIES & 63 & $A-5$ \\
\hline 172 & 3.2 .1 .3 & FUEL CYCIE FACILITLES & 63 & $A-5$ \\
\hline 173 & 3.2 .1 .3 & EUEL CYCLE FACILITIES & 63 & $A-6$ \\
\hline 173 & 3.3 .1 .2 & FUEL CYCLE FACILITIES & 63 & $A-6$ \\
\hline 174 & 3.2 .6 & FUEL CYCLE FACILITIES & 63 & $A-11$ \\
\hline 175 & 3.2 .1 .2 & COMMONWEALTH EDISON & 68 & 2 \\
\hline 175 & 3.3 .2 .2 & COMMONWEALTH EDISON & 68 & 2 \\
\hline 176 & 3.1 .1 & COMMONWEALTH EDISON & 68 & $A-1$ \\
\hline 177 & 3.1 .1 & COMMONWEALTH EDISON & 68 & $A-2$ \\
\hline 178 & 3.1 .1 & COMMONWEALTH EDISON & 68 & $A-4$ \\
\hline 179 & 3.3 .2 .2 & COMMONWEALTH EDISON & 68 & $A-4$ \\
\hline 180 & 3.2 .5 .2 & COMMONWEALTH EDISON & 68 & $A-5$ \\
\hline 181 & 3.2 .1 .2 & COMMONWEALTH EDISON & 68 & $A-6$ \\
\hline 182 & 3.2 .1 .2 & COMMONWEALTH EDISON & 68 & $A-6$ \\
\hline 183 & 3.2 .1 .2 & COMMONWEALTH EDISON & 68 & $A-6$ \\
\hline 184 & 3.2 .5 .2 & COMMONWEALTH EDISON & 68 & $A-7$ \\
\hline 185 & 3.1 .2 & COMMONWEALTH EDISON & 68 & $A-6$ \\
\hline 186 & 3.3 .2 .2 & NUCLEAR ENERGY INSTITUTE & 73 & 2 \\
\hline 187 & 3.3 .1 .3 & NUCLEAR ENERGY INSTITUTE & 73 & 4 \\
\hline 188 & 3.3 .1 .2 & NUCLEAR ENERGY INSTITUTE & 73 & $A-1$ \\
\hline 189 & 3.2 .1 .2 & NUCLEAR ENERGY INSTITUTE & 73 & $A-2$ \\
\hline 189 & 3.2 .5 .2 & NUCLEAR ENERGY INSTITUTE & 73 & $A-2$ \\
\hline 189 & 3.2 .5 .1 & NUCLEAR ENERGY INSTITUTE & 73 & $A-2$ \\
\hline
\end{tabular}




\begin{tabular}{|c|c|c|c|c|}
\hline $\begin{array}{l}\text { Comment } \\
\text { Numbers } \\
\end{array}$ & $\begin{array}{l}\text { Issue } \\
\text { Numbers }\end{array}$ & Commenter & $\begin{array}{l}\text { Docket } \\
\text { Letter }\end{array}$ & $\begin{array}{l}\text { Page } \\
\text { Number }\end{array}$ \\
\hline 189 & 3.3 .2 .2 & NUCLEAR ENERGY INSTITUTE & 73 & $A-2$ \\
\hline 190 & 3.2 .1 .2 & NUCLEAR ENERGY INSTITUTE & 73 & $A-2$ \\
\hline 190 & 3.2 .1 .3 & NUCLEAR ENERGY INSTITUTE & 73 & $A-2$ \\
\hline 191 & 3.2 .1 .2 & NUCLEAR ENERGY INSTITUTE & 73 & $A-3$ \\
\hline 192 & 3.2 .5 .2 & NUCLEAR ENERGY INSTITUTE & 73 & $A-3$ \\
\hline 193 & 3.3 .2 .2 & NUCLEAR ENERGY INSTITUTE & 73 & $A-3$ \\
\hline 194 & 3.3 .1 .3 & NUCLEAR ENERGY INSTITUTE & 73 & $A-19$ \\
\hline 195 & 3.3 .1 .3 & NUCLEAR ENERGY INSTITUTE & 73 & A-19 \\
\hline 196 & 3.3 .1 .3 & NUCLEAR ENERGY INSTITUTE & 73 & $A-20$ \\
\hline 197 & 3.3 .1 .3 & NUCLEAR ENERGY INSTITUTE & 73 & $A-21$ \\
\hline 198 & 3.1 .1 & NATIVE AMERICANS FOR A CLEAN ENVIRONMENT & 81 & $A-1$ \\
\hline 199 & 3.2 .1 .4 & NATIVE AMERICANS FOR A CLEAN ENVIRONMENT & 81 & $A-2$ \\
\hline 200 & 3.2 .2 .3 & NATIVE AMERICANS FOR A CLEAN ENVIRONMENT & 81 & $A-3$ \\
\hline 201 & 3.2 .2 .3 & NATIVE AMERICANS FOR A CLEAN ENVIRONMENT & 81 & $A-3$ \\
\hline 201 & 3.2 .2 .5 & NATIVE AMERICANS FOR A CLEAN ENVIRONMENT & 81 & $A-3$ \\
\hline 202 & 3.2 .1 .3 & NATIVE AMERICANS FOR A CLEAN ENVIRONMENT & 81 & $A-5$ \\
\hline 203 & 3.2 .5 .6 & NATIVE AMERICANS FOR A CLEAN ENVIRONMENT & 81 & A-11 \\
\hline 204 & 3.3 .1 .2 & POTTER & 82 & 1 \\
\hline 205 & 3.3 .1 .2 & POTTER & 82 & $A-5$ \\
\hline 206 & 3.3 .1 .2 & POTTER & 82 & $A-5$ \\
\hline 207 & 3.3 .1 .2 & POTTER & 82 & $A-6$ \\
\hline 208 & 3.3 .1 .2 & POTTER & 82 & $A-6$ \\
\hline 209 & 3.3 .1 .2 & POTTER & 82 & $A-10$ \\
\hline 210 & 3.3 .1 .2 & POTTER & 82 & $A-11$ \\
\hline 211 & 3.3 .1 .2 & POTTER & 82 & $A-11$ \\
\hline 212 & 3.3 .1 .2 & POTTER & 82 & $A-12$ \\
\hline 213 & 3.2 .1 .1 & POTTER & 82 & $A-17$ \\
\hline 214 & 3.2 .1 .2 & POTTER & 82 & $A-17$ \\
\hline 214 & 3.2 .1 .3 & POTTER & 82 & $A-17$ \\
\hline 215 & 3.1 .1 & US ENVIRONMENTAL PROTECTION AGENCY & 84 & 2 \\
\hline 216 & 3.2 .5 .1 & VIRGINIA POWER & 85 & 2 \\
\hline 216 & 3.2 .5 .2 & VIRGINIA POWER & 85 & 2 \\
\hline 216 & 3.2 .1 .2 & VIRGINIA POWER & 85 & 2 \\
\hline 217 & 3.2 .5 .3 & E.I. DUPONT-MEDICAL DEPARTMENT & 86 & $A-4$ \\
\hline 218 & 3.1 .1 & FLORIDA POWER CORPORATION & 91 & $A-1$ \\
\hline 219 & 3.2 .5 .2 & FLORIDA POWER CORPORATION & 91 & $A-5$ \\
\hline 220 & 3.2 .5 .2 & FLORIDA POWER CORPORATION & 91 & $A-5$ \\
\hline 221 & 3.2 .5 .2 & FLORIDA POWER CORPORATION & 91 & $A-5$ \\
\hline 222 & 3.2 .5 .2 & FLORIDA POWER CORPORATION & 91 & $A-5$ \\
\hline 223 & 3.2 .1 .7 & FLORIDA POWER CORPORATION & 91 & $A-5$ \\
\hline 224 & 3.2 .5 .2 & FLORIDA POWER CORPORATION & 91 & $A-5$ \\
\hline
\end{tabular}




\begin{tabular}{|c|c|c|c|c|}
\hline $\begin{array}{l}\text { Comment } \\
\text { Numbers }\end{array}$ & $\begin{array}{l}\text { Issue } \\
\text { Numbers }\end{array}$ & Commenter & $\begin{array}{l}\text { Docket } \\
\text { Letter }\end{array}$ & $\begin{array}{l}\text { Page } \\
\text { Number }\end{array}$ \\
\hline 225 & 3.2 .2 .1 & U.S. DEPARTMENT OF ENERGY & 99 & $A-2$ \\
\hline 225 & 3.2 .2 .6 & U.S. DEPARTMENT OF ENERGY & 99 & $A-2$ \\
\hline 225 & 3.3 .2 .2 & U.S. DEPARTMENT OF ENERGY & 99 & $A-2$ \\
\hline 226 & 3.3 .1 .2 & U.S. DEPARTMENT OF ENERGY & 99 & $A-2$ \\
\hline 226 & 3.2 .2 .6 & U.S. DEPARTMENT OF ENERGY & 99 & $A-2$ \\
\hline 227 & 3.2 .5 .2 & U.S. DEPARTMENT OF ENERGY & 99 & $A-3$ \\
\hline 228 & 3.2 .2 .1 & U.S. DEPARTMENT OF ENERGY & 99 & $A-3$ \\
\hline 229 & 3.2 .2 .6 & U.S. DEPARTMENT OF ENERGY & 99 & $A-3$ \\
\hline 230 & 3.3 .1 .2 & U.S. DEPARTMENT OF ENERGY & 99 & $A-4$ \\
\hline 231 & 3.2 .2 .6 & U.S. DEPARTMENT OF ENERGY & 99 & $A-7$ \\
\hline 231 & 3.2 .2 .7 & U.S. DEPARTMENT OF ENERGY & 99 & $A-7$ \\
\hline 232 & 3.2 .5 .2 & U.S. DEPARTMENT OF ENERGY & 99 & $A-8$ \\
\hline 232 & 3.2 .5 .6 & U.S. DEPARTMENT OF ENERGY & 99 & $A-8$ \\
\hline 233 & 3.2 .2 .6 & U.S. DEPARTMENT OF ENERGY & 99 & $A-8$ \\
\hline 234 & 3.2 .2 .3 & U.S. DEPARTMENT OE ENERGY & 99 & $A-9$ \\
\hline 235 & 3.2 .6 & U.S. DEPARTMENT OF ENERGY & 99 & $A-12$ \\
\hline 236 & 3.2 .4 .1 & U.S. DEPARTMENT OF ENERGY & 99 & $A-12$ \\
\hline 237 & $3.2 \cdot 1.3$ & KERR-MCGEE CORPORATION & 65 & $A-1$ \\
\hline 238 & 3.2 .1 .3 & KERR-MCGEE CORPORATION & 65 & $A-2$ \\
\hline 239 & 3.2 .1 .3 & KERR-MCGEE CORPORATION & 65 & $\mathrm{~B}-2$ \\
\hline 240 & 3.2 .1 .3 & KERR-MCGEE CORPORATION & 65 & $\mathrm{C}-1$ \\
\hline 241 & 3.1 .1 & $\begin{array}{l}\text { NEW YORK STATE DEPARTMENT OF ENVIRONMENTAL } \\
\text { CONSERVATION }\end{array}$ & 28 & 2 \\
\hline 242 & 3.2 .4 .1 & WSLE & 59 & 1 \\
\hline 243 & 3.2 .2 .2 & WSLF & 59 & 11 \\
\hline 244 & 3.2 .5 .2 & CONSUMER POWER & 57 & 2 \\
\hline 245 & 3.2 .5 .2 & CONSUMER POWER & 57 & 2 \\
\hline 246 & 3.2 .2 .1 & META & 67 & $A-6$ \\
\hline 247 & 3.2 .5 .2 & NUCLEAR ENERGY INSTITUTE & 73 & $A-2$ \\
\hline 248 & 3.2 .5 .2 & VIRGINIA POWER & 85 & 2 \\
\hline 249 & $3.3 \cdot 1.2$ & FUEL CYCLE FACILITIES FORUM & 63 & $A-6$ \\
\hline 250 & 3.2 .2 .8 & AMC & 64 & $B-11$ \\
\hline 251 & 3.2 .1 .2 & TECHNADYNE ENGINEERING CONSULTANTS, INC. & 10 & 2 \\
\hline 252 & 3.1 .1 & NATIVE AMERICANS FOR A CLEAN ENVIRONMENT & 81 & $A-2$ \\
\hline 253 & 3.1 .1 & NATIVE AMERICANS FOR A CLEAN ENVIRONMENT & 81 & $A-1$ \\
\hline 254 & 3.1 .1 & KERR-MCGEE CORPORATION & 10 & 16 \\
\hline 256 & 3.1 .2 & KERR-MCGEE CORPORATION & 65 & 14 \\
\hline 257 & 3.2 .2 .1 & AMC & 64 & $B-6$ \\
\hline 258 & 3.2 .2 .5 & $\mathrm{AMC}$ & 64 & $B-6$ \\
\hline 259 & 3.2 .2 .8 & AMC & 64 & $\mathrm{~B}-5$ \\
\hline 260 & 3.2 .2 .4 & AMC & 64 & 39 \\
\hline
\end{tabular}




\begin{tabular}{|c|c|c|c|c|}
\hline $\begin{array}{l}\text { Comment } \\
\text { Numbers }\end{array}$ & $\begin{array}{l}\text { Issue } \\
\text { Numbers }\end{array}$ & Commenter & $\begin{array}{l}\text { Docket } \\
\text { Letter }\end{array}$ & $\begin{array}{l}\text { Page } \\
\text { Number }\end{array}$ \\
\hline 261 & 3.2 .2 .2 & CAREY, CORINNE & 42 & 4 \\
\hline 262 & 3.2 .2 .2 & $\begin{array}{l}\text { NEW YORK STATE DEPARTMENT OF ENVIRONMENTAL } \\
\text { CONSERVATION }\end{array}$ & 28 & $A-1$ \\
\hline 263 & 3.2 .2 .1 & KERR-MCGEE CORPORATION & 65 & 39 \\
\hline 264 & 3.2 .2 .1 & U.S. DEPARTMENT OF ENERGY & 99 & $A-9$ \\
\hline 265 & 3.2 .2 .1 & ALLIED SIGNAL CHEMICAL & 14 & 1 \\
\hline 266 & 3.3 .1 .5 & ALLIED SIGNAI CHEMICAL & 14 & 1 \\
\hline 267 & 3.2 .2 .4 & ALLIED SIGNAI CHEMICAI & 14 & 1 \\
\hline 268 & 3.2 .2 .1 & AMC & 64 & $\mathrm{~B}-8$ \\
\hline 269 & 3.2 .2 .1 & FLORIDA POWER CORPORATION & 91 & $A-6$ \\
\hline 270 & 3.2 .2 .2 & FLORIDA POWER CORPORATION & 91 & $A-3$ \\
\hline 271 & 3.2 .2 .2 & SHIELDALLOY METALLURGICAL CORP. & 62 & $A-2$ \\
\hline 272 & 3.2 .2 .2 & SHIELDALLOY METALLURGICAL CORP. & 62 & $A-8$ \\
\hline 273 & 3.2 .2 .2 & PEARSON, CHARLES E. & 55 & 4 \\
\hline 274 & 3.2 .2 .2 & NEUTRON PRODUCTS, INC. & 83 & 1 \\
\hline 275 & 3.2 .2 .2 & ENVIRONMENTAL COALITION ON NUCLEAR POWER & 56 & $A-25$ \\
\hline 275 & 3.2 .2 .1 & ENVIRONMENTAL COALITION ON NUCLEAR POWER & 56 & $A-25$ \\
\hline 276 & 3.2 .2 .1 & KERR-MCGEE CORPORATION & 65 & 38 \\
\hline 277 & 3.2 .2 .3 & CLEAN WATER FUND OF NORTH CAROLINA & 37 & 2 \\
\hline 278 & 3.2 .2 .3 & SIERRA CLUB-PENNSYLVANIA CHAPTER & 66 & 3 \\
\hline 278 & 3.1 .2 & SIERRA CLUB-PENNSYLVANIA CHAPTER & 66 & 3 \\
\hline 279 & 3.2 .2 .3 & WEIZENBAUM， RUTH & 76 & 2 \\
\hline 280 & 3.2 .2 .5 & CITIZENS RESEARCH \& ENVIRONMENTAL WATCH & 94 & $A-5$ \\
\hline 280 & 3.2 .2 .3 & CITIZENS RESEARCH \& ENVIRONMENTAL WATCH & 94 & $A-5$ \\
\hline 281 & 3.2 .2 .3 & BARKLEY， RICHARD S. & 5 & 1 \\
\hline 282 & 3.2 .2 .6 & KENNECOTT ENERGY & 31 & 3 \\
\hline 283 & 3.2 .1 .5 & DUPONT WHITE PIGMENT \& MINERAL PRODUCTS & 54 & 10 \\
\hline 284 & 3.2 .2 .6 & WYOMING MINING ASSOCIATION & 33 & 3 \\
\hline 285 & 3.2 .2 .6 & DUPONT WHITE PIGMENT \& MINERAL PRODUCTS & 54 & $A-8$ \\
\hline 286 & 3.2 .2 .1 & DUPONT WHITE PIGMENT \& MINERAL PRODUCTS & 54 & $C-1$ \\
\hline 287 & 3.2 .2 .6 & DUPONT WHITE PIGMENT \& MINERAL PRODUCTS & 54 & $\mathrm{C}-3$ \\
\hline 288 & 3.2 .2 .1 & DUPONT WHITE PIGMENT \& MINERAL PRODUCTS & 54 & 8 \\
\hline 289 & 3.2 .2 .8 & DUPONT WHITE PIGMENT \& MINERAL PRODUCTS & 54 & 9 \\
\hline 290 & 3.2 .2 .8 & GEHRKE，ROBERT，J. & 24 & 1 \\
\hline 291 & 3.2 .2 .8 & KENNECOTT ENERGY & 31 & 1 \\
\hline 292 & 3.2 .2 .8 & KENNECOTT ENERGY & 31 & 2 \\
\hline 293 & 3.2 .5 .1 & DUPONT WHITE PIGMENT \& MINERAL PRODUCTS & 54 & $A-6$ \\
\hline 294 & 3.2 .5 .1 & DUPONT WHITE PIGMENT \& MINERAL PRODUCTS & 54 & $A-5$ \\
\hline 294 & 3.2 .4 .1 & DUPONT WHITE PIGMENT \& MINERAI PRODUCTS & 54 & $A-5$ \\
\hline 294 & 3.2 .5 .4 & DUPONT WHITE PIGMENT \& MINERAL PRODUCTS & 54 & $A-5$ \\
\hline 294 & 3.2 .5 .3 & DUPONT WHITE PIGMENT \& MINERAL PRODUCTS & 54 & $A-5$ \\
\hline
\end{tabular}




\begin{tabular}{|c|c|c|c|c|}
\hline $\begin{array}{l}\text { Comment } \\
\text { Numbers } \\
\end{array}$ & $\begin{array}{l}\text { Issue } \\
\text { Numbers }\end{array}$ & Commenter & $\begin{array}{l}\text { Docket } \\
\text { Letter }\end{array}$ & $\begin{array}{l}\text { Page } \\
\text { Number }\end{array}$ \\
\hline 295 & 3.2 .1 .1 & DUPONT WHITE PIGMENT \& MINERAI PRODUCTS & 54 & $A-12$ \\
\hline 295 & 3.2 .5 .4 & DUPONT WHITE PIGMENT \& MINERAI PRODUCTS & 54 & $A-12$ \\
\hline 295 & 3.2 .5 .3 & DUPONT WHITE PIGMENT \& MINERAI PRODUCTS & 54 & A -12 \\
\hline 296 & 3.2 .5 .4 & DAM, SCOTT A. & 53 & 2 \\
\hline 297 & 3.2 .5 .5 & ENVIRONMENTAL COALITION ON NUCLEAR POWER & 56 & $A-20$ \\
\hline 298 & 3.2 .5 .5 & LEWIS, MARVIN I. & 13 & 1 \\
\hline 299 & 3.2 .5 .1 & LEWIS, MARVIN I. & 13 & 1 \\
\hline 300 & 3.2 .5 .4 & AMC & 64 & $A-50$ \\
\hline 301 & 3.2 .2 .8 & AMC & 64 & $A-47$ \\
\hline 302 & 3.2 .2 .8 & AMC & 64 & $A-47$ \\
\hline 303 & 3.2 .2 .8 & AMC & 64 & $A-47$ \\
\hline 304 & 3.2 .5 .1 & FLORIDA POWER CORPORATION & 91 & $A-4$ \\
\hline 305 & 3.2 .5 .6 & FLORIDA POWER CORPORATION & 91 & $A-3$ \\
\hline 306 & 3.1 .1 & FLORIDA POWER CORPORATION & 91 & $A-4$ \\
\hline 306 & 3.3 .2 .2 & FLORIDA POWER CORPORATION & 91 & $A-4$ \\
\hline 307 & 3.2 .5 .1 & FLORIDA POWER CORPORATION & 91 & $A-4$ \\
\hline 307 & 3.2 .5 .6 & FLORIDA POWER CORPORATION & 91 & $A-4$ \\
\hline 308 & 3.1 .2 & SIERRA CLUB-PENNSYLVANIA CHAPTER & 66 & 2 \\
\hline 308 & 3.3 .1 .1 & SIERRA CLUB-PENNSYLVANIA CHAPTER & 66 & 2 \\
\hline 309 & 3.3 .1 .1 & SIERRA CLUB-PENNSYLVANIA CHAPTER & 66 & 2 \\
\hline 310 & 3.2 .2 .8 & KERR-MCGEE CORPORATION & 65 & 60 \\
\hline 311 & 3.1 .1 & KERR-MCGEE CORPORATION & 65 & 23 \\
\hline 311 & 3.2 .1 .1 & KERR-MCGEE CORPORATION & 65 & 23 \\
\hline 311 & 3.3 .1 .2 & KERR-MCGEE CORPORATION & 65 & 23 \\
\hline 312 & 3.3 .2 .2 & AMERICAN NUCLEAR SOCIETY & 50 & $A-1$ \\
\hline 313 & 3.2 .1 .4 & RIO-ALGOM MINING CORPORATION & 49 & 22 \\
\hline 314 & 3.3 .2 .2 & POTTER, THOMAS \& MORTON, HENRY & 82 & $A-3$ \\
\hline 315 & 3.3 .2 .2 & AMC & 64 & $A-10$ \\
\hline 316 & 3.2 .4 .1 & VIRGINIA POWER & 85 & 1 \\
\hline 316 & 3.2 .5 .3 & VIRGINIA POWER & 85 & 1 \\
\hline 316 & 3.3 .2 .2 & VIRGINIA POWER & 85 & 1 \\
\hline 317 & 3.3 .2 .1 & MARIOTTE, MICHAEL (N.I.R.S) & 70 & 2 \\
\hline 317 & 3.2 .5 .5 & MARIOTTE, MICHAEL (N.I.R.S) & 70 & 2 \\
\hline 318 & 3.3 .2 .1 & WESTERN STATES LEGAL FOUNDATION & 59 & 3 \\
\hline 319 & 3.2 .5 .5 & STEWART, JAMES A. & 21 & 1 \\
\hline 320 & 3.3 .1 .1 & CAREY, CORINNE & 42 & 2 \\
\hline 321 & 3.2 .2 .8 & CHEM-NUCLEAR SYSTEMS, INC. & 43 & 2 \\
\hline 322 & 3.2 .2 .8 & FUEL CYCLE FACILITIES FORUM & 63 & $A-32$ \\
\hline 322 & 3.2 .2 .1 & FUEL CYCLE FACIIITIES FORUM & 63 & $A-32$ \\
\hline 323 & 3.2 .4 .1 & KENNECOTT ENERGY & 31 & 4 \\
\hline 324 & 3.2 .4 .1 & U.S. DEPARTMENT OF ENERGY & 99 & $A-13$ \\
\hline
\end{tabular}




\begin{tabular}{|c|c|c|c|c|}
\hline $\begin{array}{l}\text { Comment } \\
\text { Numbers } \\
\end{array}$ & $\begin{array}{l}\text { Issue } \\
\text { Numbers }\end{array}$ & Commenter & $\begin{array}{l}\text { Docket } \\
\text { Letter }\end{array}$ & $\begin{array}{l}\text { Page } \\
\text { Number }\end{array}$ \\
\hline 325 & 3.3 .2 .2 & POTTER, THOMAS \& MORTON, HENRY & 82 & $A-17$ \\
\hline 326 & 3.2 .5 .4 & POWER RESOURCES & 15 & 3 \\
\hline 326 & 3.2 .5 .6 & POWER RESOURCES & 15 & 3 \\
\hline 327 & 3.3 .1 .1 & MEDDICK, SHERRY LEE \& REMINGTON, STUART A. & 27 & 2 \\
\hline 328 & 3.2 .5 .4 & KENNECOTT ENERGY & 31 & 5 \\
\hline 328 & 3.2 .5 .6 & KENNECOTT ENERGY & 31 & 5 \\
\hline 329 & 3.3 .2 .2 & WHITTAKER CORPORATION & 44 & 6 \\
\hline 330 & 3.2 .5 .4 & WHITTAKER CORPORATION & 44 & 3 \\
\hline 330 & 3.2 .5 .6 & WHITTAKER CORPORATION & 44 & 3 \\
\hline 332 & 3.2 .2 .1 & DUPONT WHITE PIGMENT \& MINERAL PRODUCTS & 54 & 1 \\
\hline 332 & 3.1 .1 & DUPONT WHITE PIGMENT \& MINERAL PRODUCTS & 54 & 1 \\
\hline 333 & 3.3 .1 .5 & WOODWARD CLYDE & 58 & 4 \\
\hline 334 & $3.3 \cdot 1 \cdot 5$ & SIERRA CLUB-PENNSYLVANIA CHAPTER & 66 & 2 \\
\hline 335 & 3.2 .5 .6 & YANKEE ATOMIC ELECTRIC COMPANY & 72 & 4 \\
\hline 336 & 3.2 .2 .1 & WEIZENBAUM, RUTH & 76 & 2 \\
\hline 337 & 3.2 .2 .2 & NEUTRON PRODUCTS, INC. & 83 & 2 \\
\hline
\end{tabular}




\section{APPENDIX D}

TEXT OF THE PROPOSED RULE 


\section{CFR Part 70}

Criminal penalties, Hazardous materials transportation, Material control and accounting, Nuclear materials, Packaging and containers, Radiation protection, Reporting and recordkeeping requirements, Scientific equipment, Security measures, Special nuclear material.

\section{CFR Part 72}

Manpower training programs, Nuclear materials, Occupational safety and health, Reporting and recordkeeping requirements, Security measures, Spent fuel.

For the reasons set out in the preamble and under the authority of the Atomic Energy Act of 1954, as amended: the Energy Reorganization Act of 1974, as amended; and 5 U.S.C. 553; the NRC is proposing to adopt the following amendments to 10 CFR Parts 20, 30, 40, $50,51,70$ and 72 .

\section{PAAT 20-STANDARDS FOR PROTECTION AGAINST RADIATION}

1. The authority citation for Part 20 continues to read as follows:

Authority: Secs. 53, 63, 65, 81, 103, 104, $161,182,186,68$ stat. $930,933,935,936$, $937,948,953,955$, as amended (2 U.S.C. 2073, 2093, 2095, 2111, 2133, 2134, 2201. 2232,2236 ), secs. 201, as amended, 202, 206 , 88 stat. 1242, as amended, 1244, 1246, ( 42 U.S.C. 5841, 5842, 5846).

2. In 10 CFR 20.1003, "Definitions," the definition of background radiation is revised and new definitions Critical Group, Decommissioning, Indistinguishable from background, Readily removable, Residual Radioactivity, and Site-Specific Advisory Board are added in alphabetical order to read as follows:

\section{$\$ 20.1003$ Definitions.}

Background radiation means radiation from cosmic sources; naturally occurring radioactive material, including radon (except as a decay product of source or special nuclear material); and global fallout as it exists in the environment from the testing of nuclear explosive devices or from past nuclear accidents like Chernobyl which contribute to background radiation and are not under the control of the licensee. "Background radiation" does not include radiation from source. byproduct, or special nuclear materials regulated by the Commission.

Critical Group means the group of individuals reasonably expected to receive the greatest exposure to residual radioactivity for any applicable set of circumstances.

* $\stackrel{*}{*} * * *$
facility or site safely from service and reduce residual radioactivity to a level that permits (1) release of the property for unrestricted use and termination of the license, or (2) release of the property under restricted conditions and termination of the license.

Indistinguishable from background means that the detectable concentration of a radionuclide is not statistically different from the background concentration of that radionuclide in the vicinity of the site or, in the case of structures, in similar materials using adequate measurement technology, survey, and statistical techniques.

Readily removable means removable using non-destructive, common, housekeeping techniqués (e.g., washing with moderate amounts of detergent and water) that do not generate large volumes of radioactive waste requiring subsequent disposal or produce chemical wastes that are expected to adversely affect public health or the environment.

\section{Residual radioactivity means} radioactivity in structures, materials, soils, groundwater, and other media at a site resulting from activities under the licensee's control. This includes radioactivity from all licensed and unlicensed sources used hy the licensee. but excludes background radiation. It also includes radioactive materials remaining at the site as a result of routine or accidental releases of radioactive material at the site and previous burials at the site, even if those burials were made in accordance with the provisions of 10 CFR Part 20.

Site-Specific Advisory Board (SSAB) means a committee constituted by the licensee to provide advice to the licensee on decommissioning.

3. In $\$ 20.1009$, paragraph (b) is revised to read as follows:

\section{$\$ 20.1009$ Information collection requirements: OMB approval.}

(b) The approved information collection requirements contained in this part appear in $\$ \S 20.1101,20.1202$, 20.1204, 20.1206, 20.1301, 20.1302, $20.1403,20.1405,20.1407,20.1408$, 20.1501, 20.1601, 20.1703, 20.1901, 20.1902, 20.1904, 20.1905, 20.1906, $20.2002,20.2004,20.2006,20.2102$,
$20.2103,20.2104,20.2105,20.2106$, 20.2107, 20.2108, 20.2110, 20.2201, 20.2202, 20.2203, 20.2204, 20.2206, and Appendix F.

4. A new Subpart $E$ entitled

"Radiological Criteria for Decommissioning," is added to 10 CFR Part 20 to read as follows:

\section{Suspart E-Radiological Criteria for Decommissioning}

Sec.

20.1401 Scope.

20.1402 Concepts.

20.1403 General provisions.

20.1404 Radiological criteria for unrestricted reléase.

20.1405 Criteria for license termination under restricted conditions.

20.1406 Notification and public participation.

20.1407 Site-Specific Advisory Board. 20.1408 Minimization of contamination.

\section{\$20.1401 Scope.}

(a) The criteria in this subpart apply to the decommissioning of facilities licensed under Parts 30, 40, 50, 60, 61, 70 , and 72 of this chapter, as well as other facilities subject to the Commission's jurisdiction under the Atomic Energy Act of 1954, as amended, and the Energy Reorganization Act of 1974, as amended. For high-level and low-level waste disposal facilities (10 CFR Parts 60 and 61), the criteria apply only to ancillary surface facilities that support radioactive waste disposal activities. For uranium mills, the criteria apply to decommissioning of the facility but not to the disposal of uranium mill tailings or to soil cleanup. (See Appendix A of 10 CFR Part 40).

(b) The criteria in this subpart do not apply to sites already covered by a decommissioning plan approved by the Commission before linsert effective date of rulel and in accordance with the criteria identified in the Site Decommissioning Management Plan Action Plan of April 16, 1992 (57 FR 13389).

(c) After a site has been decommissioned and the license terminated in accordance with the criteria in this proposed rule, the Commission will require additional cleanup only if, based on new information, it determined that residual radioactivity remaining at the site could result in significant public risk.

(d) This subpart also requires that, after the effective date of rule, applicants for licenses, other than renewals, describe in the application how facility design and procedures for operation will minimize contamination of the facility and the environment, facilitate eventual decommissioning. 
and minimize the generation of radioactive waste.

\section{$\$ 20.1402$ Concepts.}

(a) The objective of decommissioning is to reduce the residual radioactivity in structures, materials, soils, groundwater, and other media at the site so that the concentration of each radionuclide that could contribute to residual radioactivity is indistinguishable from the background radiation concentration for that radionuclide. The Commission realizes that, as a practical matter, it would be extremely difficult to demonstrate that such an objective has been met. Therefore, the Commission has established a site release limit and is requiring that licensees demonstrate that the residual radioactivity at a site is as far below this limit as reasonably achievable.

(b) The limit for release of a site is $\mathbf{1 5}$ mrem/y (0.15 mSv/y) Total Effective Dose Equivalent (TEDE) to an average member of the Critical Group for residual radioactivity distinguishable from background. If doses from residual radioactivity are less than $15 \mathrm{mrem} / \mathrm{y}$ TEDE, the Commission will terminate the license and authorize release of the site for unrestricted use following the licensee's demonstration that the residual radioactivity at the site has been reduced to As Low As Reasonably Achievable (ALARA).

(c) ALARA considerations must include all significant risks to humans and the environment resulting from the decommissioning process. Licensees shall demonstrate why further reductions below the limit are not reasonably achievable. Depending on the site-sperific ALARA analysis, any dose level less than or equal to 15 mrem/y may be considered AlARA. However, in many situations, licensees may have little or no site contamination and should be able to readily achieve the overall objective for decommissioning (e.g. licensees that use only sealed sources or short-lived radicisutupes).

(d) The Commission expects the lic:ensee to make every reasonable effort to reduce residual radioactivity to Jevels that will allow unrestricted release of the site. However, the Commission will consider terminating a license in cases where restrictions must be imposed on the use of the site to ensure that public: doses are maintained below the -15 $\mathrm{mrem} / \mathrm{y}(0.15 \mathrm{mSv} / \mathrm{y}) \mathrm{TEDE}$ limit, provided the licensee:

(1) Can demonstrate by analysis of the benefits and risks of further reduction that residual radioactivity at the site is ALARA and that further reductions in residual radioactivity neressary to comply with the $15 \mathrm{mrem} / \mathrm{y}$ TEDE limit for unrestricted use are nof technically achievable, would be prohibitively expensive, or would result in net public or environmental harm;

(2) Has made adequate provisions for institutional controls to reduce annual TEDE from residual radioactivity distinguishable from background to the average member of the appropriate critical group to 15 mrem (0.15 mSv) TEDE;

(3) Has provided sufficient financial assurance to enable an independent third party to assume and carry out responsibilities for any necessary control and maintenance of the site; and

(4) Has reduced the residual radioactivity at the site so that the TEDE from residual radioactivity would not exceed 100 mrem (1 mSv) per year even if the restrictinns applied in the termination were no longer effective in limiting the possible scenarios or pathways of exposure.

\section{\$20.1403 General provisions.}

(a) When calculating TEDE, the licensee shall base estimates on the greatest annual TEDE dose expected within the first 1000 years after decommissioning. Estimates must be substantiated using actual measurements to the maximum extent practical.

(b) When determining Al.ARA, the licensee shall consider all significant risks to humans and the environment resulting from the decommissioning process (including transportation and disposal of radioactive wastes generated in the process) and from residual radioactivity remaining at the site following termination of the license.

(c) During decommissioning, the licensee shall take reasonable steps to remove all readily removable residual radioactivity from the site.

(d) The licensee shall demonstrate a reasonable expectation that residual radioactivity from the site will not cause the level of radioactivity in any groundwater that is a current or potential source of drinking water to exceed the limits specified in 40 CFR Part 141 as they exist on linsert effective date of this regulation].

(e) Licensee notification to the Commission of intent to decommission in accordance with $\$ \$ 30.36(\mathrm{~b}), 40.42(\mathrm{~b})$, $50.82(a), 70.38(b)$ or 72.54 of this chapter shall specify whether the licensee intends to decommission in accordance with $\$ 20.1405$. Licensees pronosing to decommission in accordance with $\$ 20.1405$ shall submit a plan for establishing and supporting a Site Specific Advisory Board (SSAB). (f) Licensees proposing to decommission in accordance with $\$ 20.1405$, shall submit a decommissioning plan to the Commission. This plan shall include the recommendations of the SSAB and the licensee's proposed analysis and disposition of this advice.

\section{$\$ 20.1404$ Radiological criteria 1or} unrestricted release.

A site will be considered acceptable for unrestricted use if:

(a) The residual radioactivity that is distinguishable from background radiation results in a TEDE to the average member of the critical group that does not exceed 15 mrem (0.15 $\mathrm{mSv}$ ) per year; and

(b) The residual radioactivity has been reduced to levels that are as low as reasonably achievable (ALARA).

\$20.1405 Criteria for license termination under restricted conditions.

A site will be considered acceptable for license termination under restricted conditions if:

(a) The licensee can demonstrate that further reductions in residual radioactivity necessary to comply with the provisions of $\$ 20.1404$ are not technically achievable, would be prohibitively expensive, or would result in net public or environmental harm; and

(b) The licensee has made provisions for institutional controls that provide reasonable assurance that the TEDE from residual radioactivity distinguishable from background to the aversge member of the critical group will not exceed 15 mrem (0.15 mSv) TEDE per year. Institutional controls must be enforceable by a responsible government entity or in a court of law in response to suits by affected parties; and

(c) The licensee has provided sufficient financial assurance to enable an independent third party to assume and carry out responsibilities for any necessary control and maintenance of the site. Acceptable financial assurance mechanisms are:

(1) Funds placed into an account segregated from the licensee's assets and outside the licensee's administrative control as described in $\$ 30.35(f)(1)$ of this chapter;

(2) Surety method, insurance, or other guarantee method as described in $\$ 30.35(f)(2)$ of this chapter; or

(3) A statement of intent in the case of Federal, State, or local government licensees, as described in $\$ 30.35(f)(4)$ of this chapter.

(d) Residual radioactivity at the site has been reduced so that if the 
institutional controls were no longer in effect, there is reasonable assurance that the TEDE from residual radioactivity distinguishable from background to the average member of the critical group would not exceed 100 mrem ( $1 \mathrm{mSv}$ ) per year, and is as low as reasonably achievable. Calculations used to show compliance with this provision may not assume any benefits from earthen cover or other earthen barriers unless specifically authorized by the Commission.

\section{$\$ 20.1406$ Public notification and public participation.}

(a) Upon the receipt of a decommissioning plan from the licensee, or a proposal by the licensee for restricted release of a site pursuant to $\$ 20.1405$, or whenever the Commission deems such notice to be in the public interest, the Commission shall:

(1) Notify and solicit comments from local and State governments in the vicinity of the site and any Indian Nation or other indigenous people that have treaty or statutory rights that could be affected by the decommissioning; and

(2) Yublish a notice in the Federal Register and in a forum, such as local newspapers, which is readily accessible to individuals in the vicinity of the site and solicit comments from affected parties.

(b) For decommissioning where the licensee does not propose to meet the conditions for unrestricted release pursuant to $\S 20.1404$ of this part, the licensee shall convene a Site Specific Advisory Board (SSAB) as described in $\$ 20.1407$ for the purpose of obtaining advice from affected parties regarding the proposed decommissioning.

\section{\$20.1407 Site Specific Advisory Board.}

(a) The SSAB should provide advice to the licensee, as appropriate, on:

(1) Whether there are ways to reduce residual radioactivity to a level necessary to comply with the provisions of $\$ 20.1404$ which are technically achievable, would not be prohibitively ovnonsive and would not result in net public or erivironmental harm;

(2) Whet'1er provisions for institutional controls proposed by the licensee:

(i) Will provide reasonable assurance that the TEDE from resid:al radioactivity distinguishable fiom hackground to the average member of the critical group will not exceed 15 mrem (0.15 mSv) TEDE per year;

(ii) Will be entorceable; and

(iii) Will impose undue burdens on the local community or other affected parties.
(3) Whether the licensee has provided sufficient financial assurance to enable an independent third party to assume and carry out responsibilities for any necessary control and maintenance of the site.

(b) Membership of the SSAB shall to the extent that representatives are willing to participate:

(1) Reflect the full range of interests in the affected community and region, and be composed of individuals who could be directly affected by residual radioactivity at the decommissioned site;

(2) Be selected from individuals nominated by organizations which renresent these interests; and

(3) Include representatives from the licensee; local and state governments; persons residing in the vicinity of the site; citizen, environmental, environmental justice, and other public interest groups; and Indian Nation or other indigenous people that have treaty or statutory rights that could be affected.

(c) The SSAB shall consist of approximately 10 members plus an ex officio representative selected by the Commission.

(d) The licensee shall be responsible for establishing the SSAB and the developing of appropriate SSAB operating procedures with the advice of the SSAB.

(e) The licensee shall provide adequate administrative support for SSAB activities and shall provide the SSAB access to studies and andlyses that are readily available to the licensee and are pertinent to the proposed decommissioning.

(f) Meetings of the SSAB are open to the public. The licensee shall provide adequate public notice of the location, time, date, and agenda for the meetings at least 2 weeks in advance of each meeting. All records generated or reviewed by the SSAB become part of the docket, must be retained by the licensee until the license is terminated. and must be available for public inspection.

\section{$\$ 20.1408$ Minimization of contamination.}

Applicants for licenses, other than renewals, after linsert effective date of rule], shall describe in the application how facility design and procedures for operation will minimize, to the extent practicable, contamination of the facility and the ervirnmment. facilitate eventual decommissioning, and minum. se to the extent practicable, the generation of radioactive waste.

\section{PART 30-RULES Of GENERAL APPLICABILITY TO DOMESTIC LICENSING OF BYPRODUCT MATERIAL}

5. The authority citation for Part $\mathbf{3 0}$ continues to read as follows:

Authority: Secs. 81, 82, 161, 182, 183, 186. 68 Stat. $935,948,953,954,955$, as amended. sec. 234,83 Stat 444 , as amended (42 U.S.C. $2111,2112,2201,2232,2233,2236,2282)$; secs. 201, as amended, 202, 206, 88 Stat. 1242 , as amended, 1244, 1246, (42 U.S.C. $5841,5842,5846$ ).

Section 30.7 also issued under Pub. L. 95-601, sec. 10, 92 Stat. 2951 as amended by Pub, $L, 102-486$, sec. 2902 , 106 Stat 3123, (42 U.S.C. 5851). Section $30.34(\mathrm{~b})$ also issued under sec. 184, 68 Stat. 954, as amended (42 U.S.C. 2234). Section 30.61 also issued under sec. 187, 68 Stat. 955 (42 U.S.C. 2237).

6. In $\S 30.4$, "Definitions," the definition of decommission is revised to read as follows:

\$30.4 Definitions.

Decommission means to remove a facility or site safely from service and reduce residual radioactivity to a level that permits (1) release of the property for unrestricted use and termination of the license, or (2) release of the property under restricted conditions and termination of the license.

7. In $\$ 30.35$, paragraph (g)(3)(iv) is revised to read as follows:

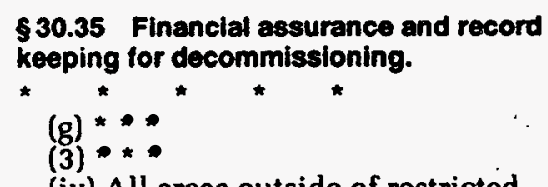

(iv) All areas outside of restricted areas that contain material such that, if the license expired, the licensee would be required to either decontaminate the area to meet the criteria for

decommissioning in 10 CFR 20, subpart $\mathrm{E}$, or apply for approval for disposal under 10 CFR 20.2002.

8. In § 30.36, paragraphs (c)(1)(v),(d), and $(f)(3)$ are revised to read as follows:

$\$ 30.36$ Expiration and termination of licenses.

(c) $(1) * *$

(v) Conduct a radiation survey of the premises where the licensed activities were carried out and submit a report of the results of this survey, unless the licensee denionstrates that the premises are suitable for release in accordance with NRC requirements in some other manner. 
(d) If the information submitted under paragraphs (c)(1)(v) or (c)(3) of this section does not adequately demonstrate that the premises are suitable for release in accordance with NRC requirements, the Commission will inform the licensee of the appropriate further actions required for termination of license.

(f) ***

(3).(i) A radiation survey has been performed which demonstrates that the premises are suitable for release in accordance with NRC requirements; or

(ii) Other information submitted by. the licensee is sufficient to demonstrate that the premises are suitable for release in accordance with NRC requirements.

\section{PART 40-DOMESTIC LICENSING OF SOURCE MATERIAL}

9. The authorily citation for Part 40 continues to read as follow's:

Aulhority: Secs. 62, 63.64, 65, 81, 161, $182,183,186,68$ Stat. 932, 933, 935, 948 . $953,954,955$, as amended, secs. $11 \mathrm{e}(2), 83$. 84, Pub. L. 95-604, 92 Stat. 3033, as amended, 3039 , sec. 234,83 Stat. 444 , as amended (42 U.S.C. 2014(e)(2), 2092, 2093. 2094, 2095, 2111, 2113, 2114, 2201, 2232, 2233, 2236, 2282); sec. 274 , Pub. L. 86-373. 73 Stat. 688 (42 U.S.C. 2021 ); secs. 201, as amended, 202, 206, 88 Stat. 1242, as amended, 1244, 1246 (42 U.S.C. 5841,5842 , 5846); sec. 275, 92 Stat. 3021, as amended by Pub. L. 97-415, 96 Stal. 2067 (42 U.S.C. 2022).

Section 40.7 also issued under Pub. $\mathbf{L}$. 95-601, sec. 10, 92 Sta1. 2951 as amended by Pub. L. 102-486, sec. 2902 , 106 Stat. 3123, (42 U.S.C. 5851). Section $40.31(\mathrm{~g})$ also issued under sec. 122,68 Stat. 939 ( 42 U.S.C. 21.52). Section 40.46 also issued under sec. 184, 68 Stat. 954, as amended (42 U.S.C. 2234). Section 40.71 also issued under sec. 187,68 Stat. 955 ( 42 U.S.C. 2237).

10. In $\$ 40.4$, "Definitions," the definition of decommission is revised to read:

\section{$\$ 40.4$ Definitions.}

* * * *

Decommission means to remove a facility or site safely from service and reduce residual radionctivity to a level that permits (1) release of the property for unrestricted use and termination of the license, or (2) release of the property under restricted conditions and terminition of the license.

11. In $\$ 40.3 n$, paragraph (t)(3)(iv) is revised to read as follows:

$\$ 40.36$ Financial assurance and record keeping for decommissioning.

in $* *$
(3) ** *

(iv) All areas outside of restricted areas that contain material such that, if the license expired, the licensee would be required to either decontaminate the area to meet the criteria for decommissioning in 10 CFR 20, subpart $E$, or apply for approval for disposal under 10 CFR 20.2002.

12. In $\S 40.42$, paragraphs (c)(1)(v),(d), and $(n)(3)$ are revised to read as follows:

$\$ 40.42$ Expiration and termination of licenses.$$
\text { (c) }(1) \cdots
$$

(v) Conduct a radiation survey of the premises where the licensed activities were carried out and submit a report of the results of this survey, unless the licensee demonstrates that the premises are suitable for release in accordance with NRC requirements in some other manner. The licensee shall, as appropriate-

(d) If the information submitied under paragraphs (c)(1)(v) or (c)(3) of this section does not adequately demonstrate that the premises are suitable for release in accordance with NRC requirements, the Commission will inform the licensee of the appropriate further actions required for termination of license.

\section{(f)***}

(3) (i) A radiation survey has been performed which demonstrates that the premises are suitable for release in accordance with NRC requirements; or

(ii) Other information submitted by the licensee is sufficient to demonstrate that the premises are suitable for release in accordance with NRC requirements.

\section{PART 50-DOMESTIC LICENSING OF PRODUCTION AND UTILIZATION FACILITIES}

13. The authority citation for Part 50 continues to read as follows:

Authority: Secs. 102, 103. 104. 105. 161 182, 183, 186, 189, 68 Stat. 936, 937. 938 $94 \mathrm{~d}, 953,954,955,956$, as amended, sin 234,83 Stat. 1244 , as amended 142 II.S.C $2132,2133,2134,2135,2201,2232,2233$ $2236,2239,2282$ ); secs. 201 , as amented, 202, 206, 88 Stat. 1242, as amended. 1244, 1246 (42 U.S.C. $5841,5842,5846$ ).

Section 50.7 is also issund under Pub. L. 95-601, sec. 10, 92 Stat. 2951 as amended by Pub. L. 102-486, ser. 29012. 1166 Stat. 3123. (42 U.S.C. 5851 ). Section 50.10 also issued under secs. 101. 185. fir Stat 936,955 , as amended 142 II.S.C. 21:31, 2235); sec. 102, Pub. L. 91-190, 82 Stat. 853 (42 U.S.C. 4332). Sextions 5.1.13.50.54(dd), and 50.103 also issured under sec. 108, 68 Stat. 939, as amended (42 U.S.C. 2138). Sections 50.23, 50.35. 50.55 , and 50.56 also issued under sec. 185, 68 Stat. 955 (42 U.S.C. 2235). Sections 50.33a, 50.55a and Appendix $Q$ also issued under sec. 102, Pub. L. 91190, 83 Stat. 853 (42 U.S.C. 4332). Sections 50.34 and 50.54 also issued under sec. 204, 88 Stat. 1245 (42 U.S.C. 5844). Sections 50.58, 50.91, and 50.92 also issued under Pub. L. 97-415, 96 Stat. 2073 (42 U.S.C. 2239). Section 50.78 also issued under sec. 122,68 Stat. 939 (42 U.S.C. 2152). Sections $50.80-50-81$ also issued under sec. 184 , 68 Stat. 954, as amended 142 U.S.C. 2234). Appendix $F$ also issued under sec. 187, 68 Stat. 955 (42 U.S.C. 2237).

14. In $\S 50.2$, "Definitions,", the definition of decommission is revised to read:

\section{$\$ 50.2$ Definitions.}

Decommission means to remove a facility or site safely from service and reduce residual radioactivity to a level that permits (1) release of the property for unrestricted use and termination of the license, or (2) release of the property under restricted conditions and termination of the license.

15. In $\S 50.82$, paragraph $(\eta(2)$ is revised to read as follows:

\section{\$50.82 Application for termination of license. \\ (f) ***}

(2) The terminal radiation survey and associated documentation demonstrates that the facility and site are suitable for release in accordance with NRC requirements.

\section{PART 51-ENVIRONMENTAL PAOTECTION REGULATIONS FOA DOMESTIC LICENSING AND RELATED RELULATORY FUNCTIONS}

16. The authority citation for Parl 51 continues to read as follows:

Authority: Sec. 161, 68 Stat. 948, as anmended (42 l!.S.C 2201); sucs. 201, as amomiled. 202. 88 Stat. 1242, as amenited 1244 ( 42 1 i.S.(. 5841,5842 ).

Subpart A also issued under Notional Environmental Policy Act of 1969. ser.s. 102, 104. 105, 83 Stat. 853-854, as amended (42 U.S.C. $4332,4334.4335)$ ): and Pub. L. 95-604, Title 11, 92 Stat. 303.2-3041: and sec. 193, Pub. 1. 101$575.16+$ Slat. 2835 (42 (U.S.C. 2243). Sections 51.20,51.30, 51.60. 51.61. 51.80 , and 51.97 also issued under swes. 135, 141. Pub. L. 97-425, 96 Stat. 223\% 2241, and sec: 148 , Pub. I. $10(1-20)$. : 111

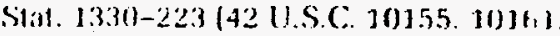


10168). Section 51.22 also issued under sec. 274, 73 Stat. 688 , as amended by 92 Stat. $3036-3038$ (42 U.S.C. 2021) and under Nuclear Waste Policy Act of 1982, sec. 121, 96 Stat. 2228 (42 U.S.C. 10141. Soctions 51.43, 51.67, and 51.109 also issued under Nuclear Waste Policy Act of 1982, sec. 114(f), 96 Stat. 2216, as amended (42 U.S.C. 10134(f)).

17. In $\$ 51.22$, paragraph $(c)(19)$ is added to read as follows:

\subsection{Criterion for categorical exclusion: identficalion of licensing and regulatory actions eligible for categorical exclusion or othenwise not requiting environmental reviow.

$$
(\mathrm{c}) * *
$$

(19) Decommissioning of sites where licensed operations have been limiter to the use of:

(i) Small quantities of short-lived radioactive materials, or

(ii) Radioactive materials in sealed sources, provided there is no evidence of leakage of radioactive material from these sealed sources.

\section{PART 70-DOMESTIC LICENSING OF SPECIAL NUCLEAR MATERIAL}

18. The authority citation for Part 70 continues to read as follows:

Authority: Secs. 51, 53, 161, 182, 183, 68 Stat. 929, 930, 948, 953, 954, as amended, sec. 234,83 Stat. 444 , as amended ( 42 U.S.C. 2071, 2073, 2201, 2232, 2233, 2282); secs. 201, as amended, 202, 204, 206, 88 Stat. 1242. as amended, 1244, 1245, 1246 (42 U.S.C. 5841, 5842, 5845, 5846).

Sections 70.1(c) and 70.20a(b) also issued under secs. 135, 141, Pub. L. 97425, 96 Stat. 2232, 2241 (42 U.S.C. $10155,10161)$. Section 70.7 also issued under Pub. L. 95-601, sec. 10, 92 Stat. 2951 as amended by Pub. L. 102-486 sec. 2902, 106 Stat. 3123 (42 U.S.C. $5851)$. Section $70.21(\mathrm{~g})$ also issued under sec. 122, 68 Stat, 939 (42 U.S.C. 2152). Section 70.31 also issued under sec. 57d, Pub. L. 93-377, 88 Stat. 475 (42 U.S.C. 2077). Sections 70.36 and 70.44 also issued under sec. 184,68 Stat. 954, as amended (42 U.S.C. 2234) Section 70.61 also issued under secs. 186, 187,68 Stat. 955 (42 U.S.C. 2236. 2237). Section 70.62 also issued under sec. 108, 68 Stat. 939, as amended ( 42 U.S.C. 2138).

19. In $\$ 70.4$, "Definitions," the definition of decommission is revised to read as follows:

\section{$\$ 70.4$ Definitions.}

Decommission means to remove a facility or site safely from service and reduce residual radioactivity to a level that permits (1) release of the property for unrestricted use and termination of the license, or (2) release of the property under restricted conditions and termination of the license.

20. In $\S 70.25$, paragraph (g)(3)(iv) is revised to read as follows:

$\$ 70.25$ Financial assurance and record keeping for decommissioning.

$$
\begin{aligned}
& \text { (g) *** } * * \\
& \text { (3) ** } \\
& \text { (iv) All areas outside of restricted }
\end{aligned}
$$
areas that contain material such that, if the license expired, the licensee would be required to either decontaminate the area to meet the criteria for

decommissioning in 10 CFR 20, subpart $E$, or apply for approval for disposal under 10 CFR 20.2002.

21. In $\$ 70.38$, paragraphs (c)(1)(v),(d). and $(f)(3)$ are revised to read as follows:

$\$ 70.38$ Expiration and termination of licenses.

$$
\begin{aligned}
& \text { (c) }(1)^{*} * * \\
& \text { (v) Conduct a radiation survey of the }
\end{aligned}
$$
premises where the licensed activities were carried out and submit a report of the results of this survey, unless the licensee demonstrates that the premises are suitable for release in accordance with NRC requirements in some other manner.

(d) If the information submitted under paragraphs $(c)(1)(v)$ or $(c)(3)$ of this section does not adequately demonstrate that the premises are suitable for release in accordance with NRC requirements, the Commission will inform the licensee of the appropriate further actions required for termination of license.

$$
\text { (f) *** }
$$

(3) (i) A radiation survey has been performed which demonstrates that the premises are suitable for release in accordance with NRC requirements; or

(ii) Other information submitted by the licensee is sufficient to demonstrate that the premises are suitable for release in accordance with NRC requirements.

\section{PART 72-LICENSING}

REQUIREMENTS FOR THE INDEPENDENT STORAGE OF SPENT NUCLEAR FUEL AND HIGH-LEVEL

\section{RADIOACTIVE WASTE}

22. The authority citation for Part 72 continues to read as follows:

Authority: Secs. $51,53,57,62,63,65,69$, $81,161,182,183,184,186,187,189,68$ Stat $929,930,932,933,934,935,948,953,954$. 955, as amended, sec. 234,83 Stat. 444, as amended (42 U.S.C. 2071, 2073, 2077, 2092 2093, 2095, 2099, 2111, 2201, 2232, 22.33. 2234, 2236, 2237, 2238, 2282); sec. 274, Pub. L. 86-373, 73 Stat. 688, as amended ( 42 U.S.C. 2021); sec. 201, as amended, 202. 206. 88 Stat. 1242, es amended. 1244, 1246 (42 U.S.C. 5841, 5342, 5846); Pub. L. 95-6n1, sec. 10, 92 Stat. 2951 as amended by Pub. L. 102486, sec. 2902, 106 Stat. 3123 (42 U.S.C. 5851); sec. 102 Pub. L. 91-190, 83 Stat. 853 (42 U.S.C. 4332). Secs. 131, 132, 133, 135. 137, 141, Pub. L. 97-425, 96 Stat. 2229, 2230 2232, 2241, sec. 148. Pub. L. 100-203, $1 \mathrm{nl}$ Stat. 1330-235 (42 U.S.C. 10151, 10152. $10153,10155,10157,10161,10168$ ).

Section $72.44(\mathrm{~g})$ also issued under secs. 142(b) and 148(c), (d), Pub. L. 100203, 101 Stat. 1330-232, 1330-236 (42 U.S.C. 10162(b), 10168(c), (d)). Section 72.46 also issued under sec. 189,68 Stat. 955 (42 U.S.C. 2239); sec. 134. Pub. L. $97-425,96$ Stat. 2230 (42 U.S.C. 10154). Section 72.96(d) also issued under sec. 145 (g), Pub. L. 100-203, 101 Stat. 1330-235 (42 U.S.C. $10165(\mathrm{~g})$ ). Subpart J also issued under secs. 2(2), 2(15), 2(19), 117(a), 141(h), Pub. L. 97425,96 Stat. 2202. 2203, 2204, 2222. 2244, (42 U.S.C. 10101, 10137(a), $10161(\mathrm{~h}))$. Subparts $K$ and $L$ are also issued under sec. 133. 98 Stat. 2230 (42 U.S.C. 10153) and Sec. 218(a) 96 Stat. 2252 (42 U.S.C. 10198).

23. In $§ 72.3$, "Definitions," the definition of decommission is revised to read as follows:

\section{$\$ 72.3$ Definitions.}

Decommission means to remove a facility or site safely from service and reduce residual radioactivity to a level that permits (1) release of the property for unrestricted use and termination of the license, or (2) release of the property under restricted conditions and termination of the license.

24. In $\S 72.54$, paragraph $(e)(2)$ is revised to read as follows:

\$72.54 Application for termination of license.

(e) * *

(2) The terminal radiaition survey and associated documentation demonstrates that the ISFSI or MRS and site are suitable for release in accordance with NRC requirements.

Dated at Rockville, Maryland, this 15th day of August 1994.

For the Nuclear Regulatory Commission. John C. Hoyle, Acting Secretary of the Commission. [FR Doc. 94-20427 Filed 8-19-94; 8:45 am] BLLLHG CODE 7590-01-P 

(See instructions on the reverse)

NUREG/CR-6353

\section{TITLE AND SUBTITLE}

Comments Received on Proposed Rule on Radiological Criteria

for Decommissioning and Related Documents

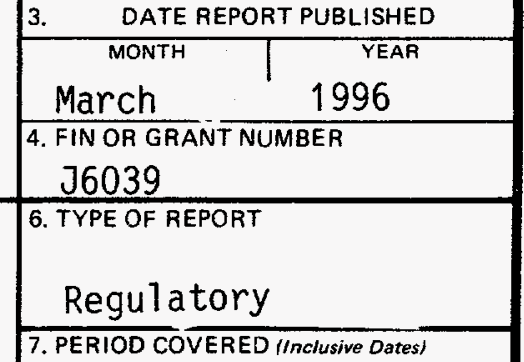

G. Page, J. Caplin, D. Smith, C. Wibl in

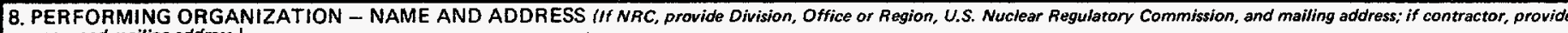
name and mailing addiress.)

Advanced Systems Technology, Inc.

847-F Quince Orchard Boulevard

Gaithersburg, MD 20878

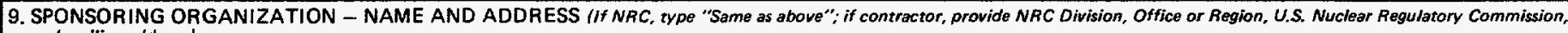
and mailing address.)

Division of Regulatory Applications

Office of Nuclear Regulatory Research

U.S. Nuclear Regulatory Commission

Washington, DC 20555-0001

10. SUPPLEMENTARY NOTES

S. Jones, NRC Project Manager

11. ABSTRACT (200 words or less)

The Nuclear Regulatory Commission (NRC) is conducting an enhanced participatory rulemaking to establish radiological criteria for the decommissioning of NRClicensed facilities. As a part of this action, the Commission published in the Federal Register (59 FR 43200), on August 22, 1994, a proposed rule on radiological criteria for decommissioning, soliciting comments both on the rule as proposed and on certain specific items as identified in its supplementary statement of considerations. A draft Generic Environmental Impact Statement (GEIS) in support of the rule, also published in August 1994 as NUREG-1496, along with its Appendix A (NUREG-1501), were also made available for comment. A staff working draft on regulatory guidance (NUREG-1500) was also made available. This report summarized the 1,309 comments on the proposed rule and supplementary items and the 311 comments on the GEIS as excerpted from 101 docketed letters received as solicited in the Federal Register notice. Comments from two NRC/Agreement-States meetings are also summarized.

Decommissioning

Radiological Criteria

Comment Summary

Enhanced Participatory Rulemaking

Generic Environmental Impact Statement

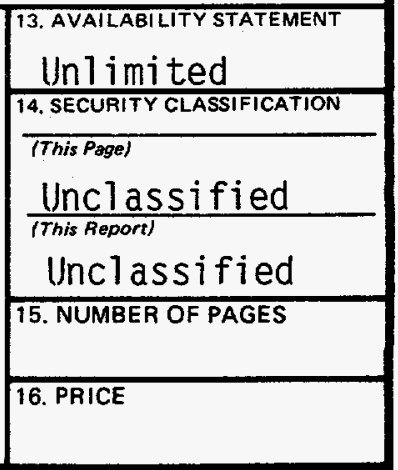

